Florida International University FIU Digital Commons

$11-13-2015$

\title{
Effect of Pavement-Vehicle Interaction on Highway Fuel Consumption and Emission
}

Xin Jiao

Florida International University, xjiao002@fiu.edu

DOI: $10.25148 /$ etd.FIDC000142

Follow this and additional works at: https://digitalcommons.fiu.edu/etd

Part of the Civil Engineering Commons

\section{Recommended Citation}

Jiao, Xin, "Effect of Pavement-Vehicle Interaction on Highway Fuel Consumption and Emission" (2015). FIU Electronic Theses and Dissertations. 2251.

https://digitalcommons.fiu.edu/etd/2251

This work is brought to you for free and open access by the University Graduate School at FIU Digital Commons. It has been accepted for inclusion in FIU Electronic Theses and Dissertations by an authorized administrator of FIU Digital Commons. For more information, please contact dcc@fiu.edu. 


\section{FLORIDA INTERNATIONAL UNIVERSITY}

Miami, Florida

\section{EFFECT OF PAVEMENT-VEHICLE INTERACTION ON HIGHWAY FUEL CONSUMPTION AND EMISSION}

A dissertation submitted in partial fulfillment of

the requirements for the degree of

DOCTOR OF PHILOSOPHY

in

CIVIL ENGINEERING

by

Xin Jiao

2015 
To: Interim Dean Ranu Jung

College of Engineering and Computing

This dissertation, written by Xin Jiao, and entitled Effect of Pavement-Vehicle Interaction on Highway Fuel Consumption and Emission, having been approved in respect to style and intellectual content, is referred to you for judgment.

We have read this dissertation and recommend that it be approved.

Cesar Constantino

Wallied Orabi

Walter Tang

Amir Mirmiran

Michael Bienvenu, Major Professor

Date of Defense: November 13, 2015

The dissertation of Xin Jiao is approved.

$\begin{array}{r}\text { Interim Dean Ranu Jung } \\ \text { College of Engineering and Computing } \\ \hline \begin{array}{r}\text { Dean Lakshmi N. Reddi } \\ \text { University Graduate School }\end{array}\end{array}$

Florida International University, 2015 
(C) Copyright 2015 by Xin Jiao

All rights reserved. 


\section{DEDICATION}

To my wonderful parents and lovely girlfriend for their selfless support and endless encouragement. 


\section{ACKNOWLEDGMENTS}

The first and most person I would like to express my appreciation is Dr. Michael Bienvenu. Dr. Bienvenu was in the role of my major advisor for more than three years. Dr. Bienvenu has the characters and substances of a great mentor. He convincingly bringing constructive guidance and selfless encouragement throughout my doctoral years. The dissertation would not have been possible without his instruction and persistent support. I have thoroughly enjoyed working with him.

I also would like to thank Dr. Amir Mirmiran for serving as the chair of my dissertation committee. Dr. Mirmiran has granted a lot of selfless help and support in many aspects and I sincerely appreciate that. In addition, I am also grateful to my dissertation committee members: Professor Walter Tang, Professor Wallied Orabi, and Dr. Cesar Constantino, for their encouragement and valuable suggestions during my doctoral studies.

Finally, I would like to acknowledge the Ready Mix Concrete (RMC) Research and Education Foundation and Florida Concrete \& Product Association (FCPA) for the funding supported to complete the research. I also want to thank the Florida Department of Transportation (DOT) State Material Office (SMO) for the necessary information provided and CCC Transportation Inc. for the experiment equipment donated. This research would not be possible without their contributions. 
ABSTRACT OF THE DISSERTATION

EFFECT OF PAVEMENT-VEHICLE INTERACTION ON HIGHWAY FUEL

CONSUMPTION AND EMISSION

by

Xin Jiao

Florida International University, 2015

Miami, Florida

Professor Michael Bienvenu, Major Professor

Vehicle fuel consumption and emission are two important effectiveness measurements of sustainable transportation development. Pavement plays an essential role in goals of fuel economy improvement and greenhouse gas (GHG) emission reduction. The main objective of this dissertation study is to experimentally investigate the effect of pavement-vehicle interaction (PVI) on vehicle fuel consumption under highway driving conditions. The goal is to provide a better understanding on the role of pavement in the green transportation initiates.

Four study phases are carried out. The first phase involves a preliminary field investigation to detect the fuel consumption differences between paired flexible-rigid pavement sections with repeat measurements. The second phase continues the field investigation by a more detailed and comprehensive experimental design and independently investigates the effect of pavement type on vehicle fuel consumption. The third study phase calibrates the HDM-IV fuel consumption model with data collected in the second field phase. The purpose is to understand how pavement deflection affects vehicle fuel consumption from a mechanistic approach. The last phase applies the 
calibrated HDM-IV model to Florida’s interstate network and estimates the total annual fuel consumption and $\mathrm{CO}_{2}$ emissions on different scenarios. The potential annual fuel savings and emission reductions are derived based on the estimation results.

Statistical results from the two field studies both show fuel savings on rigid pavement compared to flexible pavement with the test conditions specified. The savings derived from the first phase are $2.50 \%$ for the passenger car at $112 \mathrm{~km} / \mathrm{h}$, and $4.04 \%$ for 18 -wheel tractor-trailer at $93 \mathrm{~km} / \mathrm{h}$. The savings resulted from the second phase are $2.25 \%$ and $2.22 \%$ for passenger car at $93 \mathrm{~km} / \mathrm{h}$ and $112 \mathrm{~km} / \mathrm{h}$, and $3.57 \%$ and $3.15 \%$ for the 6wheel medium-duty truck at $89 \mathrm{~km} / \mathrm{h}$ and $105 \mathrm{~km} / \mathrm{h}$. All savings are statistically significant at 95\% Confidence Level (C.L.).

From the calibrated HDM-IV model, one unit of pavement deflection (1mm) on flexible pavement can cause an excess fuel consumption by $0.234-0.311 \mathrm{~L} / 100 \mathrm{~km}$ for the passenger car and by $1.123-1.277 \mathrm{~L} / 100 \mathrm{~km}$ for the truck. The effect is more evident at lower highway speed than at higher highway speed. From the network level estimation, approximately 40 million gallons of fuel (combined gasoline and diesel) and 0.39 million tons of $\mathrm{CO}_{2}$ emission can be saved/reduced annually if all Florida's interstate flexible pavement are converted to rigid pavement with the same roughness levels. Moreover, each 1-mile of flexible-rigid conversion can result in a reduction of 29 thousand gallons of fuel and 258 tons of $\mathrm{CO}_{2}$ emission yearly. 


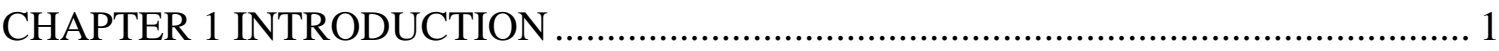

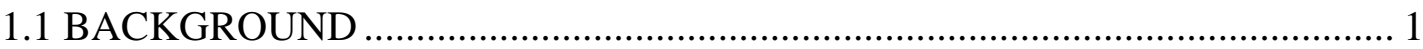

1.2 OBJECTIVES AND SIGNIFICANCE ……………........................................ 4

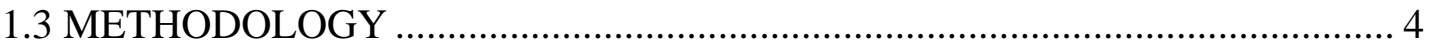

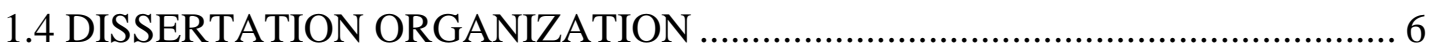

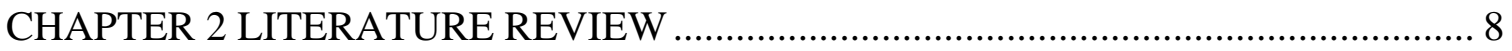

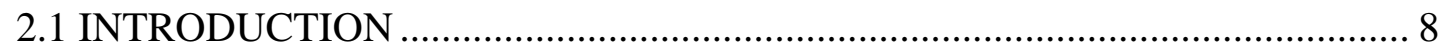

2.2 PAVEMENT-VEHICLE INTERACTION (PVI) …………………………........ 8

2.3 PREVIOUS STUDIES .......................................................................... 9

2.3.1 Effect of Pavement Roughness.............................................................. 9

2.3.2 Effect of Pavement Texture ........................................................................ 13

2.3.3 Effect of Pavement Type (Deflection) ...................................................... 17

2.4 FUEL CONSUMPTION MODELS …………………................................. 23

2.4.1 Empirical Models .............................................................................. 23

2.4.2 Mechanistic Models.......................................................................... 24

2.4.2.1 HDM-III Model............................................................................. 25

2.4.2.2 South Africa Model ...................................................................... 26

2.4.2.3 ARRB Model................................................................................ 27

2.4.2.4 ARFCOM Model............................................................................ 28

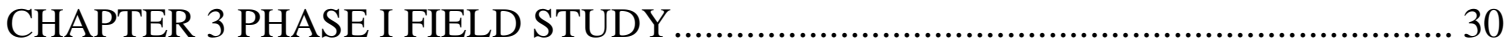

3.1 INTRODUCTION .................................................................................... 30

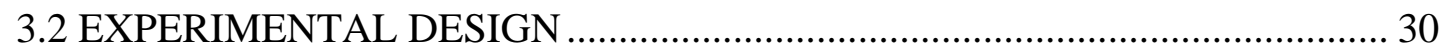

3.2.1 Roadway Sections ……………………………................................. 30

3.2.2 Testing Vehicles ................................................................................... 36

3.2.3 Data Collection Devices ....................................................................... 38

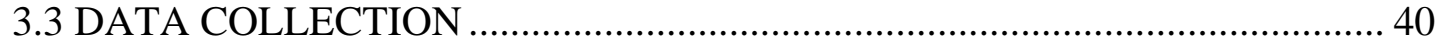

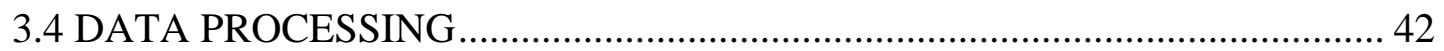

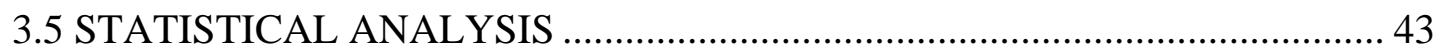

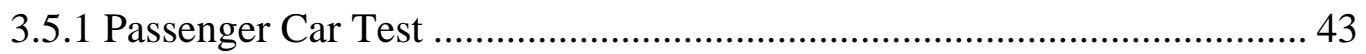

3.5.1.1 Average Fuel Consumption Differences ......................................... 43

3.5.1.2 Paired T-test .................................................................................. 44

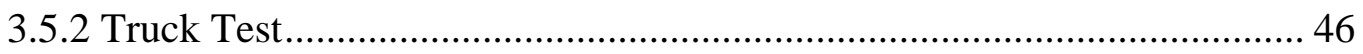

3.5.2.1 Average Fuel Consumption Differences .......................................... 46

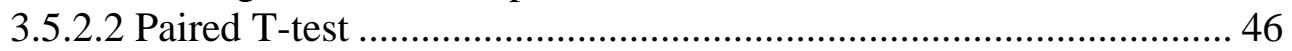

3.6 CONCLUSION AND DISCUSSION ........................................................... 47

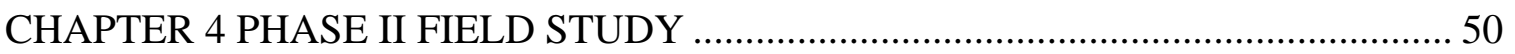

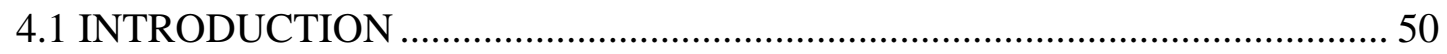

4.2 FIELD EXPERIMENT............................................................................... 50

4.2.1 Roadway Sections ………………………………….............................. 50 
4.2.2 Testing Vehicles ....................................................................................... 55

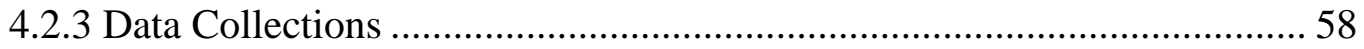

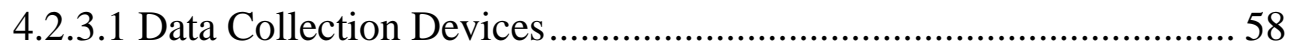

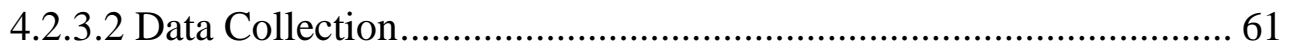

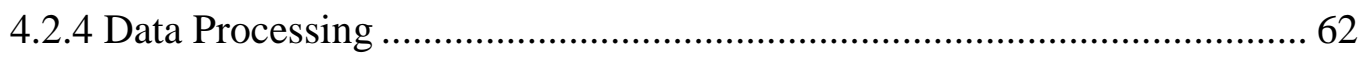

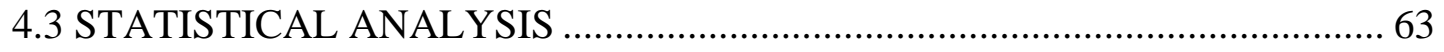

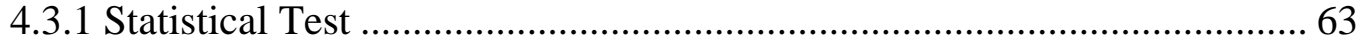

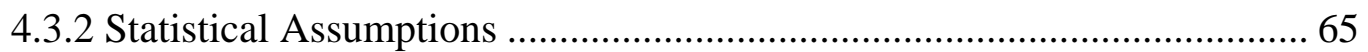

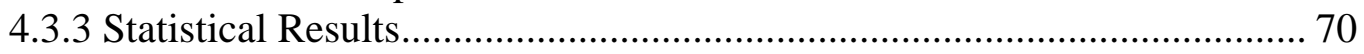

4.3.3.1 Descriptive Statistics ...................................................................... 70

4.3.3.2 Tests of Between-Subjects Effect ................................................... 70

4.3.3.3 Pairwise Comparisons .................................................................. 72

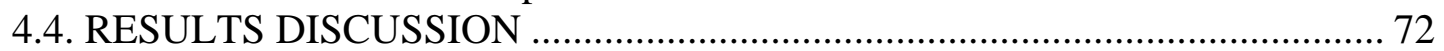

4.4.1 Comparison with Phase I Study ……………………………………....... 72

4.4.2 Comparison with Other Studies................................................................ 74

4.5. KEY FINDINGS ……………………………………………………. 75

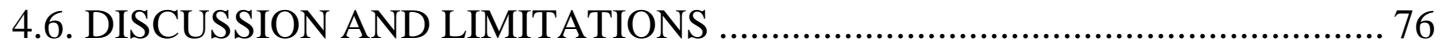

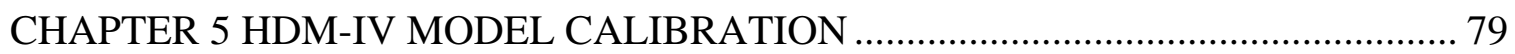

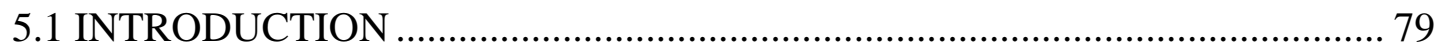

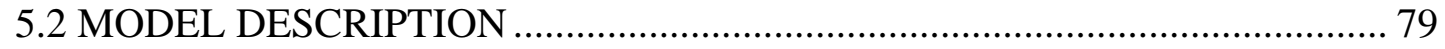

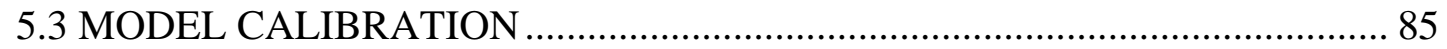

5.3.1 Calibration Methodology....................................................................... 88

5.3.1.1 Assumptions and Limitations .......................................................... 88

5.3.1.2 Identification of Calibration Factors …………….............................. 89

5.3.1.3 Model Calibration .......................................................................... 90

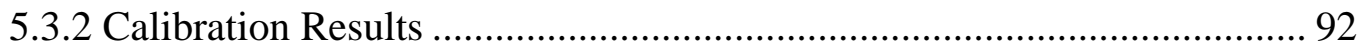

5.4 MODEL EVALUATION ………………………......................................... 93

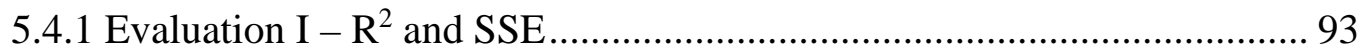

5.4.2 Evaluation I - Bias ............................................................................ 93

5.4.3 Model Validation ..................................................................................... 97

5.5 EFFECT OF PAVEMENT DEFLECTION ON FUEL CONSUMPTION......... 98

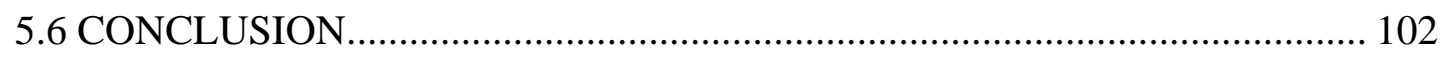

CHAPTER 6 NETWORK LEVEL ESTIMATION ………......................................... 103

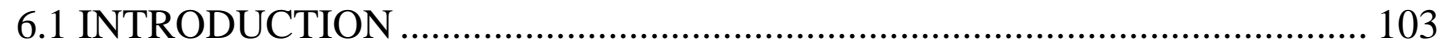

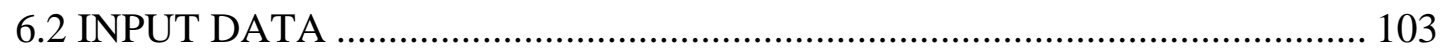

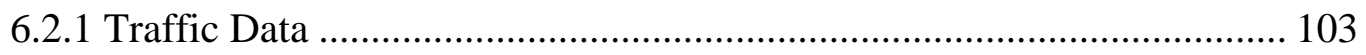

6.2.2 Pavement Type ..................................................................................... 104

6.2.3 International Roughness Index (IRI) ..................................................... 104

6.2.4 Falling Weight Deflectometer (FWD) Centre Deflection (D0) ............... 106

6.2.5 Texture (mean profile depth)................................................................... 108

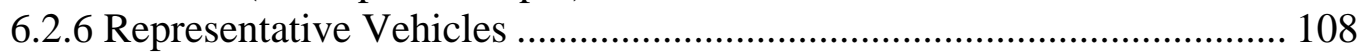

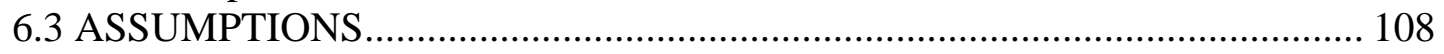

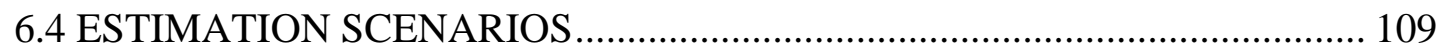




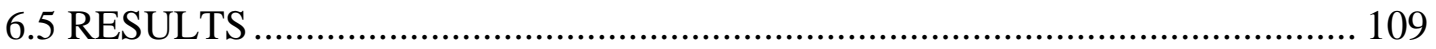

6.5.1 Annual Fuel Consumption...................................................................... 110

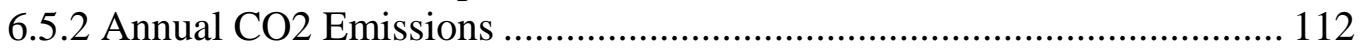

6.5.3 Potential Fuel Savings and Emission Reductions ..................................... 114

6.6 CONCLUSION AND DISCUSSION ........................................................... 117

CHAPTER 7 SUMMARY, CONCLUSIONS AND FUTURE WORK ……………...... 120

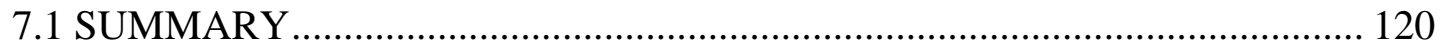

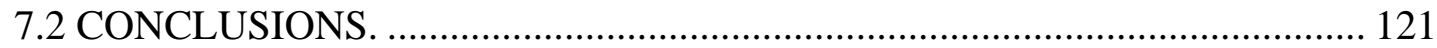

7.2.1 Phase I Field Study ............................................................................. 122

7.2.2 Phase II Field Study............................................................................. 122

7.2.3 HDM-IV Model Calibration................................................................ 123

7.2.4 Network Level Estimation.................................................................... 124

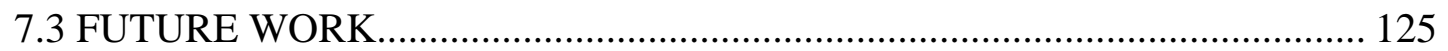

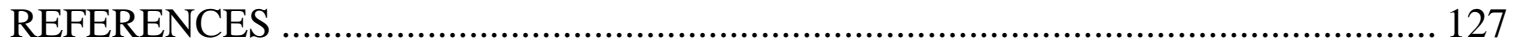

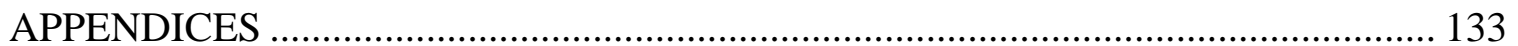




\section{LIST OF TABLES}

TABLE

PAGE

Table 2.1 Average Fuel Savings for Trucks in Taylor’s Study (Taylor \& Petten, 2006). 20

Table 2.2 Average Fuel Savings for Car in Taylor's Study (Taylor \& Petten, 2006) ...... 20

Table 3.1 Roadway Information of Site I ............................................................ 31

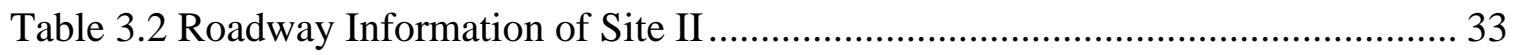

Table 3.3 Gross Weight of Tractor-trailer of All Tests .............................................. 38

Table 3.4 Environmental Condition of All Tests ..................................................... 41

Table 3.5 Passenger Car Test Results (in GPHM) ...................................................... 43

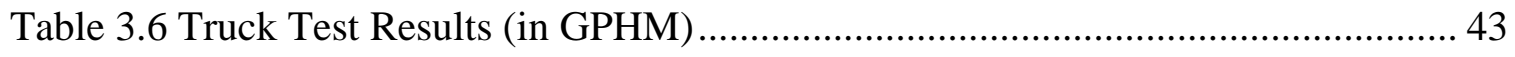

Table 3.7 Passenger Car FC Percentage Difference .................................................... 44

Table 3.8 Passenger Car Paired T-test Results .......................................................... 46

Table 3.9 Truck FC Percentage Difference ............................................................ 46

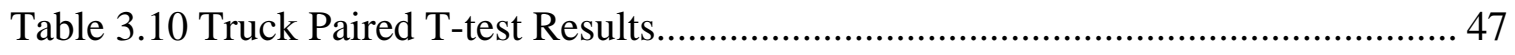

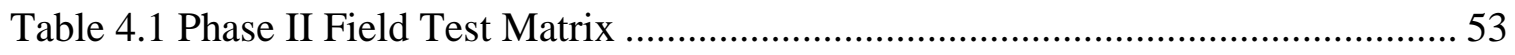

Table 4.2 Passenger Car Test Phase II Environmental Condition .................................. 63

Table 4.3 Truck Test Phase II Environmental Condition ............................................. 63

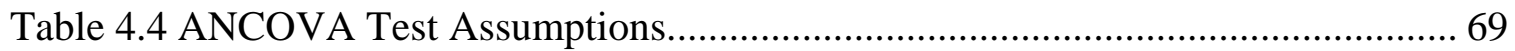

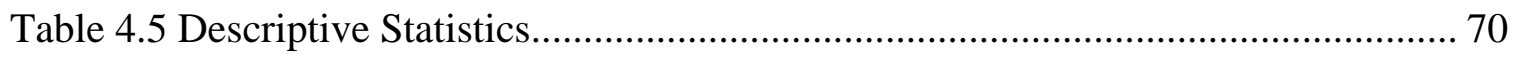

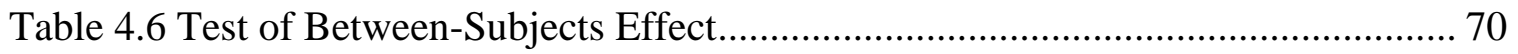

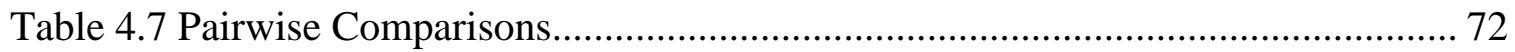

Table 4.8 Comparisons with Phase I Results......................................................... 74

Table 5.1 HDM-IV Fuel Consumption Model Components ........................................ 81 
Table 5.2 Parameters Adoption for Engine Speed Model 85

Table 5.3 Default Parameters of CR2 Model in Fr for Flexible and Rigid Pavement...... 85

Table 5.4. Parameters Adopted in HDM-IV ..................................................................... 91

Table 5.5 Calibration Results................................................................................ 92

Table 5.6 Changes of $\mathrm{R}^{2}$ and SSE Before and After Calibration..................................... 94

Table 5.7 Paired T-Test Results................................................................................ 97

Table 6.1 Mean and Standard Deviation of Pavement IRI in in/mile............................. 106

Table 6.2 Mean and Standard Deviation of D0 (mils) and Pavement Temperature $\left({ }^{\circ} \mathrm{F}\right) 107$

Table 6.3 Equations for CR2 in Calibrated HDM-IV Model ........................................ 110

Table 6.4 Base Fuel Consumption ............................................................................... 111

Table 6.5 Annual Fuel Savings and Emission Reductions ........................................... 114

Table 6.6 Fuel Savings and Emission Reductions on 1-mile Scale................................. 116

Table A1 Passenger Car Test at 93km/h on Flexible Pavement (L/100km).................. 133

Table A2 Passenger Car Test at 93km/h on Rigid Pavement (L/100km)...................... 134

Table A3 Passenger Car Test at 112km/h on Flexible Pavement (L/100km)................. 135

Table A4 Passenger Car Test at 112km/h on Rigid Pavement (L/100km).................... 136

Table A5 Truck Test at 89km/h on Flexible Pavement (L/100km)............................. 137

Table A6 Truck Test at 89km/h on Rigid Pavement (L/100km) .................................. 138

Table A7 Truck Test at 105km/h on Flexible Pavement (L/100km)............................. 139

Table A8 Truck Test at 105km/h on Rigid Pavement (L/100km) ................................. 140

Table B1 IRI of Flexible Pavement of Passenger Car Test $(\mathrm{m} / \mathrm{km})$............................... 141

Table B2 IRI of Rigid Pavement of Passenger Car Test $(\mathrm{m} / \mathrm{km})$................................... 142

Table B3 IRI of Flexible Pavement of Truck Test (m/km) ........................................... 143 
Table B4 IRI of Rigid Pavement of Truck Test (m/km) .............................................. 144

Table C1 Passenger Car Test Adjusted FWD Centre Deflection D0 (mm) ................... 145

Table C2 Truck Test Adjusted FWD Centre Deflection D0 (mm)................................. 146

Table D1 Passenger Car FC at Each Speed (zero Deflection and 1mm Deflection)...... 147

Table D2 Truck FC at Each Speed (zero Deflection and 1mm Deflection) .................... 148 


\section{LIST OF FIGURES}

FIGURE

PAGE

Figure 1.1 U.S. GHG Emission Composition by Different Sectors in 2013 (EPA, 2015). 1

Figure 2.1 Illustration of Pavement-Vehicle Interaction (Arbarian \& Ulm, 2012) ........... 9

Figure 2.2 Pavement Textures (Rasmussen, 2013).................................................... 14

Figure 2.3 Texture Influence on Surface Characteristics (ISO 13473-2, 2002) .............. 14

Figure 2.4 Typical Load Distribution under Rigid and Flexible Pavement (Lenz, 2011) 18

Figure 2.5 Hysteresis Curves of FWD Tests from (Lengrenn \& Faldner, 2010) ............. 22

Figure 2.6 Approach to Estimate Fuel Consumption in HDM-IV .................................. 28

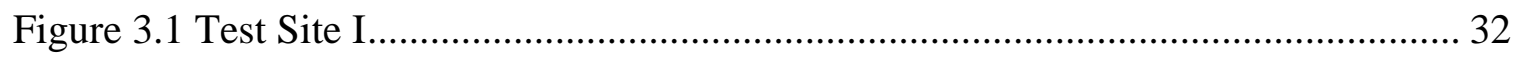

Figure 3.2 Location of Site I Sections ................................................................... 32

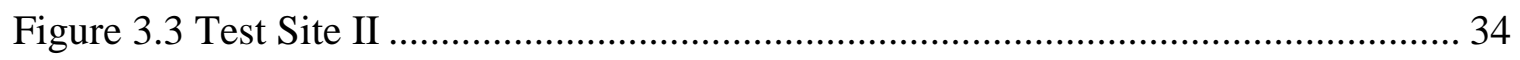

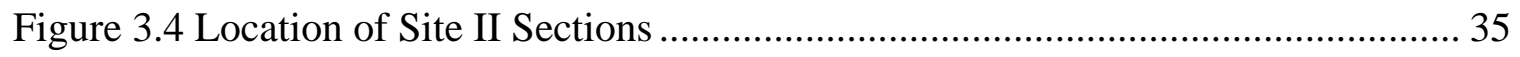

Figure 3.5 Surface Texture of Highway Pavements in Florida ................................... 36

Figure 3.6 Passenger Car Used in Phase I Field Study ............................................ 37

Figure 3.7 Commercial Tractor-trailer Used in Phase I Field Study .............................. 38

Figure 3.8 Phase I Car Test Real-time Data Collection............................................. 39

Figure 3.9 Phase I Truck Test Real-time Data Collection......................................... 40

Figure 3.10 Sample Fuel Curves of Phase I Passenger Car Test .................................. 41

Figure 4.1 Phase II Passenger Car Test Locations.................................................... 52

Figure 4.2 Phase II Truck Test Locations ............................................................. 52

Figure 4.3 Typical Layers in Florida’s Interstate Pavement ........................................ 54

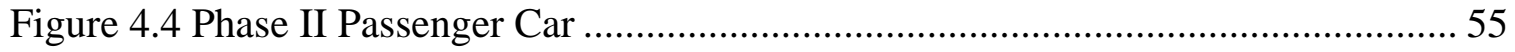


Figure 4.5 Phase II Truck.......................................................................................... 56

Figure 4.6 Truck Load ............................................................................................ 57

Figure 4.7 Concrete Horizontal Constraints .................................................................... 57

Figure 4.8 Phase II Passenger Car OBD Device............................................................. 58

Figure 4.9 Phase II Passenger Car Test Data Recording ................................................... 59

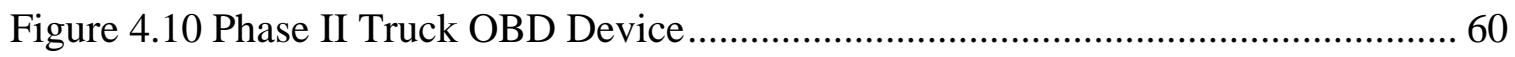

Figure 4.11 Phase II Truck Test Data Recording ........................................................... 60

Figure 4.12 Sample Repeatability Curve .................................................................. 62

Figure 4.13 Linearity Plot of Truck Test at $89 \mathrm{~km} / \mathrm{h}$.................................................... 66

Figure 4.14 Linearity Plot of Truck Test at 105km/h .................................................... 66

Figure 4.15 Homogeneity of Regression Plot for Car Test at 112km/h ......................... 66

Figure 4.16 Homogeneity of Regression Plot for Truck Test at 89km/h........................ 69

Figure 4.17 Truck Test Results Compared with Other Studies ......................................... 76

Figure 4.18 Passenger Car Test Results Compared with Other Studies ............................ 76

Figure 5.1 Energy Distribution in Passenger Car at Steady Speed (Michelin, 2003)....... 81

Figure 5.2 FWD System and Deflection Basin............................................................ 86

Figure 5.3 Model Residuals Plots ................................................................................ 97

Figure 5.4 Change of Passenger Car FC by 1-unit of Pavement Deflection .................... 99

Figure 5.5 Change of Truck FC by 1-unit of Pavement Deflection................................ 100

Figure 5.6 Percentage Change of Passenger Car FC by 1-unit of Pavement Deflection 100 Figure 5.7 Percentage Change of Truck FC by 1-unit of Pavement Deflection ............... 101

Figure 6.1 2014 Florida Interstate Passenger Car Annual Average Daily Traffic........... 105

Figure 6.2 2014 Florida Interstate Truck Annual Average Daily Traffic......................... 105 
Figure 6.3 Pavement Type on Florida’s Interstate Roadways .................................... 106

Figure 6.4 Annual Fuel Consumption Estimated in Scenario 1.................................. 106

Figure 6.5 Annual Fuel Consumption Estimated in Scenario 2................................. 112

Figure 6.6 Annual $\mathrm{CO}_{2}$ Emission Estimated in Scenario 1 ...................................... 113

Figure 6.7 Total Annual $\mathrm{CO}_{2}$ Emission Estimated in Scenario 2................................ 113

Figure 6.8 Total Annual Fuel Savings (Combined Car and Truck)............................. 115

Figure 6.9 Total Annual Emission Reductions (Combined Car and Truck).................. 115

Figure 6.10 Potential Fuel Savings and Emission Reductions ................................... 116 


\section{ABBREAVATIONS AND ACRONYMS}

$\begin{array}{ll}\text { GHG } & \text { Greenhouse gas } \\ \text { EPA } & \text { Environmental Protection Agency } \\ \text { HDM-IV } & \text { Highway development and management model 4th generation } \\ \text { PVI } & \text { Pavement-vehicle interaction } \\ \text { PCC } & \text { Portland Cement Concrete } \\ \text { IRI } & \text { International roughness index } \\ \text { NCAT } & \text { National center for asphalt technology } \\ \text { FWD } & \text { Falling weight deflectometer } \\ \text { HDM-III } & \text { Highway development and management model 3rd generation } \\ \text { ARRB } & \text { Australian road research board } \\ \text { ARFCOM } & \text { Australian road research board road fuel consumption model } \\ \text { MM } & \text { Mile marker } \\ \text { MP } & \text { Mile post } \\ \text { AADT } & \text { Annual average daily traffic } \\ \text { JPCP } & \text { Jointed plain concrete pavement } \\ \text { HMA } & \text { Superpave Hot-Mixed Asphalt } \\ \text { FDOT } & \text { Florida department of transportation } \\ \text { MPD } & \text { Mean profile depth } \\ \text { OGFC } & \text { Open graded friction course } \\ \text { LDG } & \text { Fongitudinal grinding } \\ \text { OBD } & \end{array}$




$\begin{array}{ll}\text { GPHM } & \text { Gallons per hundred miles } \\ \text { C.I. } & \text { Confidence Interval } \\ \text { C.L. } & \text { Confidence level } \\ \text { GVW } & \text { Gross vehicle weight } \\ \text { ANCOVA } & \text { Analysis of covariates test } \\ \text { ANOVA } & \text { Analysis of variances test } \\ \text { PT } & \text { Pavement surface temperature } \\ \text { Tdsp } & \text { Sand patch texture depth } \\ \text { D0 } & \text { FWD test centre deflection } \\ \text { SSE } & \text { Sum square of differences/errors } \\ \text { SMO } & \text { State material office } \\ \text { LCCA } & \text { Life-cycle cost analysis } \\ \text { LCA } & \text { life-cycle assessment }\end{array}$




\section{CHAPTER 1 \\ INTRODUCTION}

\subsection{BACKGROUND}

Greenhouse gas (GHG) emissions from transportation activities account for about 27\% of the total U.S. GHG emission in 2013 (EPA, 2015). It is the second largest contributor of U.S. GHG emission following electricity sector (Figure 1.1). Within the transportation sector, light-duty vehicles (including passenger cars and light duty trucks) comprise $62 \%$ of total transportation GHG emission. Medium- and heavy-duty trucks contribute to the second largest sector, about $22 \%$ of the total transportation emission. Virtually, all GHG emissions generated from these end-use sectors come from petroleum products.

\section{U.S. GHG Emissions by Sectors}

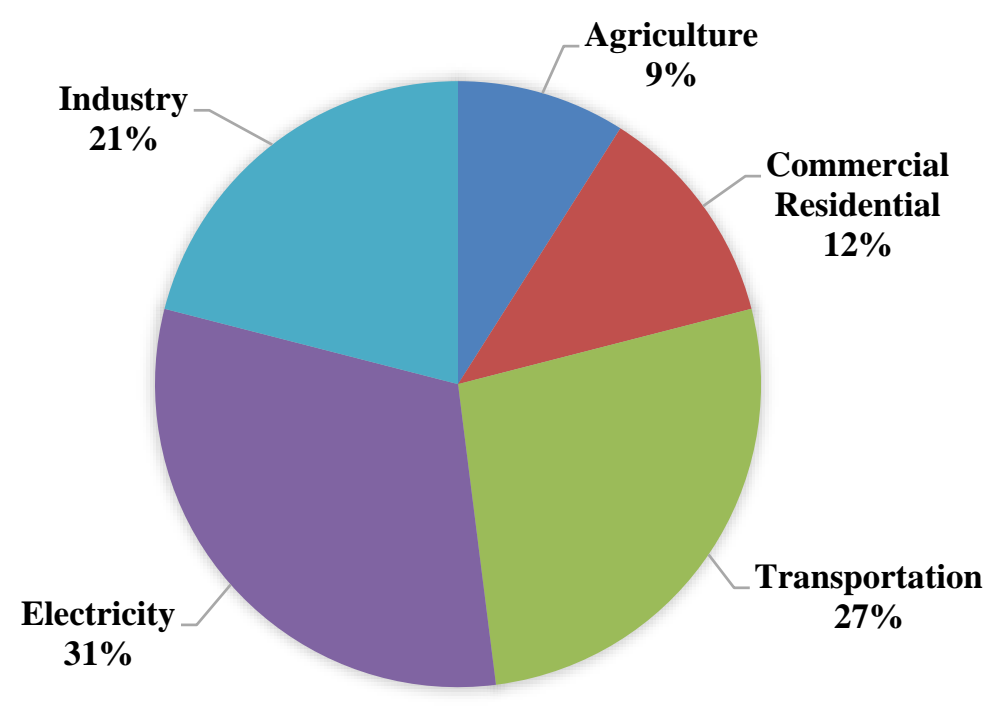

Figure 1.1 U.S. GHG Emission Composition by Different Sectors in 2013 (EPA, 2015) 
On the other end, the toughest fuel economy and GHG emission standard for light duty vehicles has been carried out by the Obama's administration in 2012. It requires an average vehicle performance of 54.5 miles per gallon by the model year of 2025. The standard is aiming at saving consumers $\$ 1.7$ trillion gas expenses and reducing 6 billion metric tons of GHG emission over the lifetime of the vehicle sold during this period (The White House, 2011). In 2014, The President continued the stealth initials on heavy-duty trucks and targeted at saving vehicle owners and operators an estimate of \$50 billion in fuel costs and reducing a projected 270 million metric tons of GHG emissions by 2018 (The White House, 2014).

The successful implements of these green initials shall not only rely on the advancement of vehicle and engine technology. Pavement, where the rubbers move on, can also play an essential role in vehicle fuel economy improvement and GHG emission reduction.

Pavement affects vehicle fuel consumption by the pavement-vehicle interaction (PVI) mechanism. Pavement-vehicle interaction (PVI) describes the dynamic interplay between the roadway surface and the moving wheels. Pavement roughness, texture, and deflection are three key aspects of the PVI behavior. Pavement roughness and texture are indicators of roadway surface characteristics. The mechanic work dissipated within vehicle's suspension system when traveling on an uneven roadway surface lead to excess energy consumption which may affect vehicle rolling resistance and fuel consumption consequently. Pavement deflection relates primarily to pavement stiffness or pavement deformations under wheel loads. Stiffer pavement structure can lead to less pavement surface deflection and thus less vehicle rolling resistance and fuel consumption. In 
addition, pavement temperature also has an impact on the vehicle rolling resistance by affecting the stiffness of the pavement layers. This is most predominant in asphaltic materials.

Flexible pavement and rigid pavement are two different pavement types that differ considerably in their structural components and layer materials. Due to the high modulus of elasticity of the concrete material (opposed to asphalt), the rigid pavement has substantially higher rigidity or stiffness than flexible pavement reference to same levels of pavement serviceability design. Pavement surface texture (macrotexture) is another material dependent parameter that differentiate significantly between flexible pavement and rigid pavement. The texture on the rigid pavement is normally supplement treatment and varies significantly with the measuring direction by the laser profiler (Gee, 2005). This is most evident on Portland Cement Concrete (PCC) pavements that have distinct surface striations and/or grooves in the direction of tinning, dragging, or grinding. But for flexible pavement surfaced with asphalt materials, the texture is dominated by the mix design and has little change with measuring directions. An example can be found that the open graded asphalt surface layer used in Florida's highway flexible pavement has a higher averaged texture level than the rigid pavement surface made of plain concrete. This is primarily due to the predominant use of coarse aggregates in the friction course of flexible pavement (Kane, 1990).

Studies has been carried out by Louhgalam and Chatti (Louhghalam, et al., 2014) (Chatti \& Zaabar, 2012) and demonstrated that the mechanic work dissipated within vehicle's suspension system when traveling on uneven roadway surface lead to excess energy consumption and thus excess fuel consumption. Pavement deflection/stiffness has 
also demonstrated measurable effect on fuel efficiency regardless of vehicle type. As early in 1970s, Walter (Walter \& Conant, 1974) has suggested that for a unit-ton wheel load, 30-pounds force is required for moving the wheel with every one inch of tire sinking (into the ground). Tao Lu from England (Lukanen \& Stubstad, 2010) concluded with finite element analysis that an increase of 24 microns in pavement vertical deflection would yield a $0.02 \mathrm{~L} / 100 \mathrm{~km}$ increases in fuel consuming to overcome pavement resistance for a 5-axle tractor trailer. The results from all of these studies indicate the crucial impact of pavement on vehicle rolling resistance and fuel economy.

\subsection{OBJECTIVES AND SIGNIFICANCE}

The objective of this dissertation study is to investigate the effect of pavementvehicle interaction (PVI) on vehicle highway fuel consumption and GHG emission. This research mainly focuses on the impact induced by the differences in two pavement types: flexible pavement and rigid pavement. The effect was investigated with four phases by field experiments and mechanistic fuel consumption models. It is intended to provide a better understanding on how PVI affects the road user fuel expenses and GHG emissions on Florida's highway network. The goal is to help engineers and researchers better recognize the role of pavement in goals of fuel economy improvement and GHG emission reduction. It is desired that the findings of this study can be good references for policymakers and stakeholders in future's comparative evaluation of roadway construction and maintenance alternatives.

\subsection{METHODOLOGY}

The work to be performed in this research was accomplished in four phases, as outlined below: 


\section{A) Phase-I Field Study}

The Phase-I field study is the preliminary field investigation. It aims at performing direct fuel comparison on paired flexible-rigid roadway sections with repeated measurements. The flexible pavement and rigid pavement in each pair have either identical or similar surface, traffic, geographical and environmental condition. The fuel consumption differences detected in each comparison are expected purely caused by the differences in pavement type. Two vehicle classes at constant highway speed are studied: passenger car $(112 \mathrm{~km} / \mathrm{h})$ and loaded 18-wheel tractor-trailer $(93 \mathrm{~km} / \mathrm{h})$.

B) Phase-II Field Study

The Phase-II field study involves a more detailed and robust experimental design. It independently investigates the pavement-induced fuel effect between flexible pavement and rigid pavement. Highway sections with varied structure and surface condition are selected for the field test. Pavement roughness and temperature are taken into consideration in this phase. The goal is to investigate the impact of pavement type on vehicle fuel consumption with control of confounding variables pavement smoothness and surface temperature. Two levels of highway speeds are studied for passenger car and medium-duty box truck respectively.

C) HDM-IV Fuel Consumption Model Calibration

The highway development and management (HDM-IV) fuel consumption model is calibrated with fuel data collected in the Phase II field study. The objective is to estimate the pavement-induced fuel effect from a mechanistic approach: by a locally calibrated fuel consumption model. It is also intended to provide a tool to estimate the annual fuel consumption and $\mathrm{CO}_{2}$ emission on a network level. Calibrated HDM-IV model was 
evaluated with different methodologies in order to ensure its reliability. The effect of pavement deflection on vehicle fuel consumption is also quantified with the wellcalibrated fuel consumption model.

D) Network Level Estimation

At last, the calibrated HDM-IV model is applied to estimate the total annual fuel consumption and $\mathrm{CO}_{2}$ emission on Florida's interstate network. Two scenarios are estimated with differences in the percentages of flexible pavement and rigid pavement that comprise Florida's interstate roadways. The first scenario represents the current Florida's interstate pavement distribution: 91.3\% flexible pavement and $8.7 \%$ rigid pavement. The second scenario simulates one extreme circumstance: rigid pavement consists of all Florida's interstate pavement. The outcomes between scenario 1 and scenario 2 are compared and the potential fuel savings and emission reductions are estimated.

\subsection{DISSERTATION ORGANIZATION}

The dissertation is divided into seven chapters including introduction. Chapter 2 summarizes previous empirical/mechanistic studies on the influence of pavement roughness, texture and type on vehicle fuel consumption or rolling resistance. Chapter 3 and Chapter 4 describe the experimental work and statistical results from Phase-I field study and Phase-II field study. Chapter 5 presents the calibration work of HDM-IV fuel consumption model. Effect of pavement deflection on fuel consumption are also presented in this chapter. Chapter 6 demonstrates the application of the calibrated HDMIV model to Florida's interstate network. The last chapter (Chapter 7) summarizes the findings and conclusions as well as recommendations for future studies. 


\section{CHAPTER 2}

\section{LITERATURE REVIEW}

\subsection{INTRODUCTION}

This chapter summarizes the findings from past research works. Firstly, the PVI phenomenon and its theory are explained. Then the findings on how pavement have influence on vehicle fuel consumption or rolling resistance are summarized from three perspectives: roughness, texture and pavement type. Finally, different empirical and mechanistic fuel consumption models are identified and described.

\subsection{PAVEMENT-VEHICLE INTERACTION (PVI)}

Pavement-vehicle interaction (PVI), or tire-pavement interaction, describes the dynamic response of pavement structure subject to moving tire load. Its effect on vehicle rolling resistance and fuel consumption has gained increased attention by researchers and engineers in recent years (Arbarian \& Ulm, 2012; Louhghalam, et al., 2014). Vehicle and tire properties are the main factors that affect vehicle fuel consumption. But pavement properties also play an essential role and its effect shall not be neglected.

Pavement surface characteristic (roughness and texture) and deflection are the two key aspects of the pavement-induced fuel effect. The interactions between vehicle suspension system and pavement surface generate dynamic loads that affect vehicle rolling resistance. Any increase of vehicle rolling resistance can lead to extra vehicle energy dissipation and fuel consumption consequently. Pavement deflection relates primarily to pavement stiffness or surface deformation under wheel loads. It affects vehicle rolling resistance and fuel consumption in two ways: 1) the viscoelastic characteristics of the pavement materials cause energy dissipation when surface 
deflection is created by moving wheels. 2) The larger surface deflection in front of the tire relative to the deflection behind the tire causes the wheels traveling "uphill" constantly while vehicle moves. The steeper the "hill", the more energy the vehicle required to maintain the speed. Figure 2.1 illustrates the roughness (left) and deflection (right) induced PVI phenomenon.

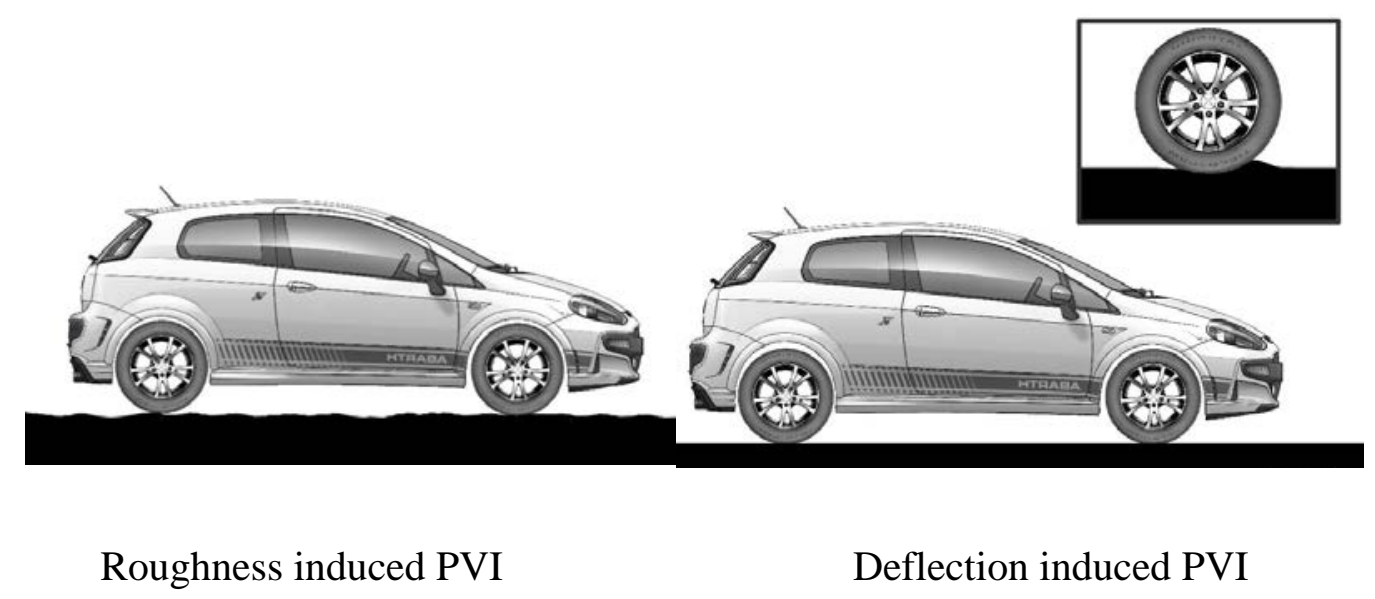

Figure 2.1 Illustration of Pavement-Vehicle Interaction (Arbarian \& Ulm, 2012)

\subsection{PREVIOUS STUDIES}

This section summarizes the studies that have been carried out by researchers and engineers on how pavement roughness, texture and pavement type (or deflection) have impact on vehicle rolling resistance and fuel consumption.

\subsubsection{Effect of Pavement Roughness}

Pavement roughness, also referred as "smoothness", describes the irregularities in pavement surface that adversely affect vehicle's ride quality and user costs. Roughness is normally quantified with the international roughness index (IRI) in most state agencies. It is defined as the filtered ratio of a standard vehicle's accumulated suspension motion (in 
mm, inches, etc.) divided by the distance traveled by the wheel-track that performs the measurement ( $\mathrm{km}$, mile, etc.). Roughness has a recognized effect on vehicle rolling resistance and fuel consumption. The following paragraphs chronologically summarize the findings of previous studies.

\section{(Velinsky \& White, 1979)}

Velinsky and White investigated the effect of road roughness on vehicle dissipated energy with vehicle axle acceleration in the field. A mechanistic pavement roughness model was developed based on field data. The model was able to predict the vehicle energy losses from both the tire and suspension system. Sensitive analysis through the roughness model revealed that vehicle rolling losses increased with the increase of pavement roughness because of the energy dissipation in tire and vehicle suspension system.

\section{(Bester, 1984)}

Bester conducted field experiment on eight different pavement surfaces, including 2 asphalt, 1 concrete, 4 surface treatment and 1 unsurfaced. Coast-down tests were performed with passenger car and truck and vehicle rolling resistances were measured. Experiments revealed that smoother roads had lower rolling resistance: both asphalt and concrete pavement exhibited lower rolling resistance compared to surface treatment and unsurfaced pavement.

\section{(Lu, 1985)}

Lu simulated the rolling resistance responses of a quarter car model with spectral density functions and investigate the influence of pavement roughness on the car rolling resistance. Results showed that the rolling resistance increased significantly with the 
increase of pavement roughness: pavement with bad surface condition may increase the vehicle rolling resistance by about $40 \%$.

\section{(Laganier \& Lucas, 1990)}

Laganier and Lucas evaluated the roughness effect on fuel consumption with three studies: laboratory studies, test track studies and open road studies. Pavement roughness was simulated with a vibration bench in the laboratory study. Results showed that roughness is an important factor for vehicle fuel consumption. The correlations between rolling resistance and smoothness were also generated from the field tests.

\section{(Sandberg, 1990)}

Sandberg measured the fuel consumption on 20 different pavement surfaces including asphalt mixture, chip seals and unsurfaced pavement. Three speeds were studied: $50 \mathrm{~km} / \mathrm{h}, 60 \mathrm{~km} / \mathrm{h}$ and $70 \mathrm{~km} / \mathrm{h}$. Results showed that pavement roughness can affect vehicle fuel consumption as much as $12 \%$ for the surface condition tested.

\section{(Du Plessis, et al., 1990)}

Plessis, et al. investigated the effect of pavement surface condition on vehicle fuel consumption in South African with three vehicle classes: passenger car, medium duty truck and bus. Coastdown tests were performed to measure the rolling resistance over varied roadway sections. Results found that the decrease of pavement roughness can lead to the decrease in vehicle rolling resistance. The impact was up to $7 \%$ for a passenger car at $100 \mathrm{~km} / \mathrm{h}$.

\section{(Delanne, 1994)}

Delanne investigated the effect of pavement roughness on light vehicle fuel consumption with field experiments. Ten different roadway sections were tested in 
France and vehicle rolling resistances were measured with hydraulic bench test. Test results showed that the increase of pavement smoothness can increase the vehicle fuel consumption significantly: by up to $6 \%$.

\section{(Cenek, 1994)}

Cenek measured vehicle rolling resistance when traveling on selected roadway sections at $20 \mathrm{~km} / \mathrm{h}$ and $75 \mathrm{~km} / \mathrm{h}$. Results found that an increase of roughness level from 1.4 to $2.3 \mathrm{~m} / \mathrm{km}$ can lead to an increase of vehicle rolling resistance by $55 \%$.

\section{(Amos, 2006)}

Amos collected fuel data on a 22-mile interstate loop with a dump truck at 60mph. Data was collected before and after the pavement resurfacing. The IRI before and after resurfacing are $130 \mathrm{in} / \mathrm{mile}$ and $60 \mathrm{in} / \mathrm{mile}$. Results from fuel data showed that a $2.46 \%$ fuel saving was found for the dump truck before and after the roadway was resurfaced.

(Soliman, 2006)

Soliman simulated vehicle motion on two roadway sections with a quarter car model. The goal was to find the effect of pavement roughness on vehicle's rolling resistance. By comparing the roughest and smoothest pavements, a $38.7 \%$ rolling resistance difference was found. Results also showed that the effect of roughness increased with the increase of simulated vehicle speed.

\section{(Heffernan, 2006)}

Heffernan measured the fuel consumption of a truck on NCAT pavement testing track cycle over a two-year study period. The pavement thickness of the test track is over 20in. The roughness range is from 65in/mile to $75 \mathrm{in} / \mathrm{mile}$. Results found a $10 \mathrm{in} / \mathrm{mile}$ 
increase in roughness level can increase the vehicle fuel efficiency by 0.5 miles per gallon.

\section{(Chatti \& Zaabar, 2012)}

Chatti and Zaabar conducted field investigation on five different roadways sections with five vehicle classes: passenger car, SUV, passenger van, light truck and articulated heavy truck. Tests were performed in both winter and summer environmental condition. Three vehicle speeds were involved: $35 \mathrm{mph}, 45 \mathrm{mph}$, and 55mph. The IRI range of the roadway sections was from $0.8 \mathrm{~m} / \mathrm{km}$ to $6 \mathrm{~m} / \mathrm{km}$ for all pavement type. Firstly, the roughness effect was found statistically significant from the analysis of covariance test. Then the fuel data was used to calibrate the HDM-4 fuel consumption model. From the (claimed) well-calibrated model, sensitivity analysis was performed. Results showed that the effect of roughness can increase fuel consumption by 1.60 for passenger car, 1.35 for SUV, 1.75 for van, 1.15 for light truck, and 1.70 for heavy truck.

\subsubsection{Effect of Pavement Texture}

Pavement texture can be divided into three categories based on the surface profile wavelength: megatexture $(50-500 \mathrm{~mm})$, macrotexture $(0.5-50 \mathrm{~mm})$, and microtexture (less than $0.5 \mathrm{~mm}$ ). Figure 2.2 displays the relative scale of each texture.

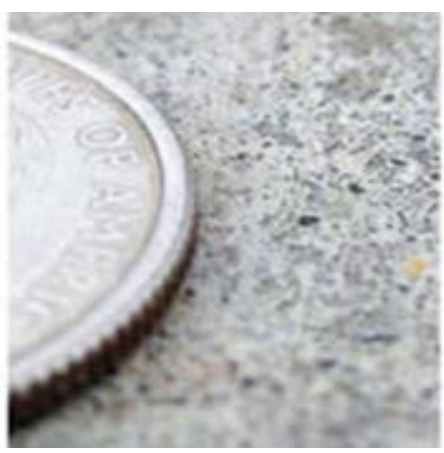

Microtexture

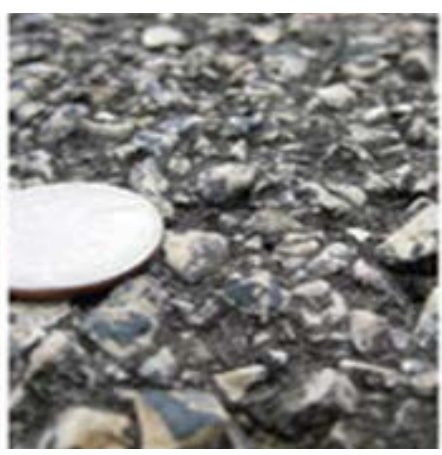

Macrotexture

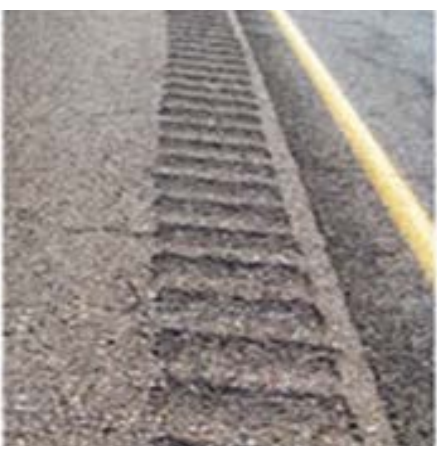

Megatexture 
Figure 2.2 Pavement Textures (Rasmussen, 2013)

Pavement texture affects vehicle rolling resistance and fuel consumption in the same way of pavement roughness. The vibrations of vehicle suspension induced by surface texture lead to energy consumption and excess fuel consumption. The longer the texture wavelength, the larger the influence. This is most significant for pavement megatexture. In addition. Pavement textures are also much correlated to vehicle tire wear, roadway friction, and noise. Figure 2.3 shows the anticipated effects of each texture components including roughness (unevenness). Roughness can be treated as texture with wavelength larger than $500 \mathrm{~mm}$. The following sections summarize the findings of the texture effect from previous studies.

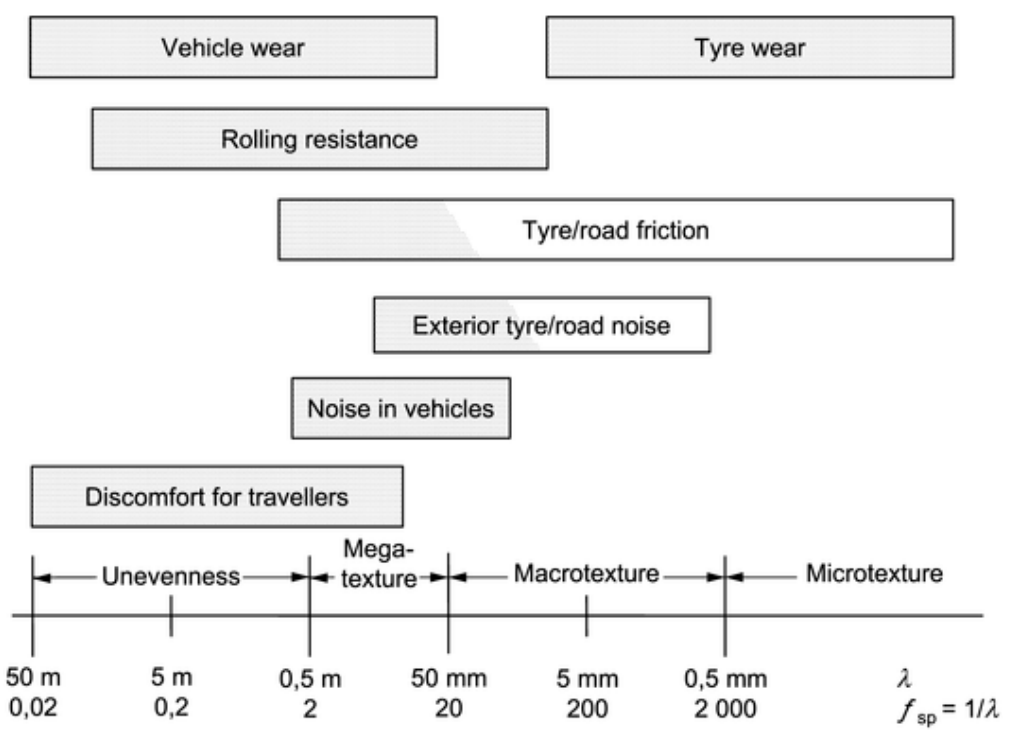

Figure 2.3 Texture Influence on Surface Characteristics (ISO 13473-2, 2002) 


\section{(Deraad, 1978)}

Deraad conducted a two-phase investigation on the effect of pavement texture on vehicle rolling resistance. The first phase involved indoor laboratory testing. Ten different radial tires were tested at $50 \mathrm{mph}$ on a smooth steel surface and a safety-walk surface respectively. Results showed an average of 5.3\% higher rolling resistance was found on the safety-walk surface (textured surface) compared to the non-textured steel surface. The difference range is from $2.5 \%$ to $11 \%$.

The second phase is field investigation. Ten different tires (including both radial tire and bias tires) were tested on six pavement surfaces: 1) polished concrete, 2) textured concrete, 3) regular asphalt, 4) asphalt with small amount of rounded exposed aggregates, 4) asphalt with large amount of rounded exposed aggregates, and 5) sealcoat covered asphalt. The testing speed is $30 \mathrm{mph}$. Results showed that vehicle rolling resistance increased with the increase of surface texture 2). Rolling resistance of each surface was compared to the textured concrete surface. A maximum of $30 \%$ difference was found on surface 5) compared to the textured concrete surface. The minimum difference was shown on surface 3), with one unit of rolling resistance.

\section{(Sandberg, 1990)}

Sandberg conducted fuel consumption measurements on 20 different pavement surfaces including asphalt mixture, chip seals, and unsurfaced pavement. Three speeds were tested: $50 \mathrm{~km} / \mathrm{h}, 60 \mathrm{~km} / \mathrm{h}$ and $70 \mathrm{~km} / \mathrm{h}$. The texture was measured by a laser profiler mounted to a passenger car. Results found that texture could lead to a change of fuel consumption by $7 \%$. But it was only significant with testing speeds more than $60 \mathrm{~km} / \mathrm{h}$. 
Also, conclusions were made that the effect of macrotexture was not as significant as megatexture and unevenness (roughness).

\section{(Descornet, 1990)}

Descornet measured the rolling resistance of a 14in patternless Michelin tire on 37 roadway sections. Results found that the tire rolling resistance coefficient increased by 0.0021 with each mm's increase of texture. Megatexture has the most significant effect on rolling resistance followed by transversely grooved macrotexture. Conclusion was made that the combination of megatexture and macrotexture can contribute to a total of $47 \%$ influence on vehicle rolling resistance and $9 \%$ fuel consumption.

\section{(Delanne, 1994)}

Delanne investigated the effect of pavement macrotexture on light vehicle fuel consumption with field experiments. Ten different roadway sections were tested in France and vehicle rolling resistances were measured with hydraulic bench test. A relationship between pavement properties and fuel consumption was developed. Results revealed an increase of $1.5 \mathrm{~mm}$ texture can cause a $50 \%$ increase in rolling resistance. This also equaled to a $5 \%$ increase in fuel consumption.

\section{(Cenek, 1994)}

Cenek measured vehicle rolling resistance when traveling on selected roadway sections at $20 \mathrm{~km} / \mathrm{h}$ and $75 \mathrm{~km} / \mathrm{h}$. Results found that an increase of $1 \mathrm{~mm}$ of texture can increase rolling resistance by $44 \%$ given a fixed roughness level of $1 \mathrm{~m} / \mathrm{km}$.

\section{(Chatti \& Zaabar, 2012)}

Chatti and Zaabar performed field investigation on five roadways locations with five vehicle classes: passenger car, SUV, passenger van, light truck and articulated heavy 
truck. Tests were conducted in both winter and summer environmental condition. Three vehicle speeds were tested: $35 \mathrm{mph}, 45 \mathrm{mph}$, and $55 \mathrm{mph}$. The texture ranges of the roadway sections were from $0.23 \mathrm{~mm}$ to $1.96 \mathrm{~mm}$ for asphalt pavement and $0.23 \mathrm{~mm}$ to 2.7mm for concrete pavement. Results showed that surface texture had no effect on fuel consumption for all vehicle classes except for heavy truck. An increase in texture of $1 \mathrm{~mm}$ increased the truck fuel consumption by $1.5 \%$ at $55 \mathrm{mph}$ and $2 \%$ at $35 \mathrm{mph}$.

\section{(Sandberg, 2011)}

Sandberg measured the rolling resistance on 100 car tires on two types of surfaces: smooth surface and surface dressed with $11 \mathrm{~mm}$ chips. The texture values of this two surfaces were $0.12 \mathrm{~mm}$ and $2.4 \mathrm{~mm}$. Three speeds were tested: $80 \mathrm{~km} / \mathrm{h}, 100 \mathrm{~km} / \mathrm{h}$, and $120 \mathrm{~km} / \mathrm{h}$. Results found that pavement texture in mean profile depth (MPD) clearly affected vehicle rolling resistance.

\subsubsection{Effect of Pavement Type (Deflection)}

Flexible pavement and rigid pavement are two different pavements structures differentiated considerably in their layer components and materials. One of the primary difference between flexible pavement and the rigid pavement is the way the pavement distribute traffic loads to subgrade. Rigid pavement distributes loads over a larger area compared to flexible pavement given its higher stiffness. Consequently, flexible pavement exhibits larger surface deflection than rigid pavement with the same level of traffic load. The more the tires "sink" into the pavement surface, the more energy required to maintain vehicle movement. Figure 2.4 displays the typical load distribution under rigid pavement (left) and flexible pavement (right) respectively (Lenz, 2011). Following studies has been carried out from the past to investigate the impact of 
pavement type on vehicle rolling resistance and fuel consumption. Not only traditional asphalt pavement and concrete pavement were covered in these studies, but also the composite pavement.

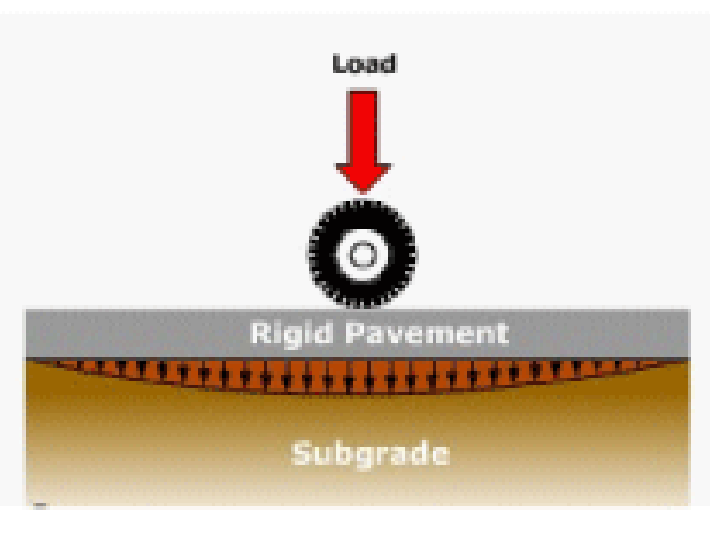

Rigid Pavement

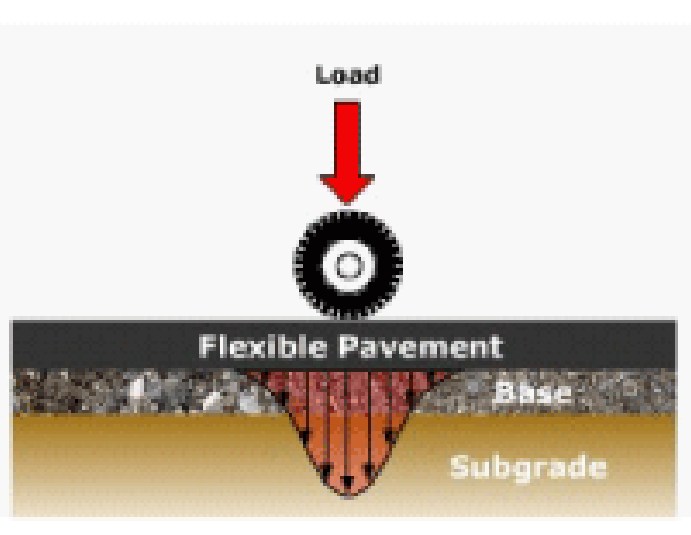

Flexible Pavement

Figure 2.4 Typical Load Distribution under Rigid and Flexible Pavement (Lenz, 2011)

\section{(Zaniewski, et al., 1982)}

Zaniewski et al. investigated the impact of pavement type on vehicle fuel consumption. Eight vehicle classes, four automobiles and four trucks of different classes/sizes, were tested. Twelve pavement sections were selected for the test, with similar roughness range (SI 3.4 to 4.4) and grade scales. The test speed was from 10mph to $70 \mathrm{mph}$ with an increment of $10 \mathrm{mph}$. Results showed a difference in fuel consumption between asphalt and concrete pavement by $20 \%$ (with savings on concrete pavement) while the difference is no statistically significant at 95\% confidence level.

\section{(Taylor, 2002)}

Taylor et al. in 2002 analyzed the data from a preliminary experimental study between 1999 and 2000 and performed multivariate linear regression analysis to 
investigate the impact of pavement type on fuel consumption of semi-trailer tank truck. The variables of this study included vehicle load, pavement temperature, International Roughness Index (IRI), road grade and vehicle speed. Results showed that compared to the concrete pavement, asphalt pavement and composite pavement exhibited higher fuel consumption by $4.1-4.9 \%$ and $2.7-3.2 \%$ respectively. Also the fuel consumption on asphalt and composite pavement increased with the increasing of pavement temperature.

\section{(Taylor \& Petten, 2006)}

Taylor et al., again, investigated the fuel consumption differences among concrete, asphalt and composite pavements with a semi-trailer truck and a passenger car. Five climatic conditions, which including spring, winter, summer cool, summer hot, and fall, and two vehicle speeds (60 km/h and $100 \mathrm{~km} / \mathrm{h}$ ) were studied. The experimental variables included international roughness index (IRI), grade, applied load, pavement temperature, vehicle speed, and air speed. Results suggested that for the $100 \mathrm{~km} / \mathrm{h}$ test on truck, an increase of fuel consumption by $0.8-1.8 \%$ was found on asphalt pavement compared to concrete pavement. The same trend was discovered on composite pavement to concrete pavement with an increase of $0.8-3.1 \%$. However the difference between asphalt pavement and composite pavement is small. The author also suggested that in winter condition, the fuel consumption of passenger car is $2.9 \%$ lower on concrete pavement compared to asphalt pavement, and 2.3\% higher on concrete pavement with respect to composite pavement. Besides, it was found that the accuracy of fuel measurement systems decreased significantly on the pavement with IRI values greater than $2.2 \mathrm{~m} / \mathrm{km}$ due to the impact of roughness on vehicle dynamics. Table 2.1 and 2.2 shows the average fuel savings between each pavement types. 
Table 2.1 Average Fuel Savings for Trucks in Taylor’s Study (Taylor \& Petten, 2006)

\begin{tabular}{|c|c|c|c|c|}
\hline $\begin{array}{l}\text { Pavements Being } \\
\text { Compared }\end{array}$ & $\begin{array}{l}\text { Speed } \\
(\mathbf{k m} / \mathbf{h})\end{array}$ & Load & $\begin{array}{c}\text { Fuel Savings } \\
\text { (L/100km) }\end{array}$ & $\begin{array}{c}\text { Fuel Savings } \\
\text { (\%) }\end{array}$ \\
\hline Concrete-Asphalt & 100 & Empty and Full & $0.4-0.7$ & $0.8-1.8$ \\
\hline Concrete-Composite & 100 & Empty & $0.2-1.5$ & $0.8-3.1$ \\
\hline $\begin{array}{l}\text { Composite-Concrete } \\
\text { (Summer Days) }\end{array}$ & 100 & Empty & 0.5 & 1.5 \\
\hline Concrete-Composite & 100 & Full & $0.4-1.2$ & $0.8-2.6$ \\
\hline $\begin{array}{l}\text { Composite-Concrete } \\
\text { (Summer Days) }\end{array}$ & 100 & Full & 0.5 & 1.3 \\
\hline Concrete-Asphalt & 60 & Empty & $0.4-0.5$ & $1.7-3.9$ \\
\hline Concrete-Asphalt & 60 & Full & $0.2-0.4$ & $1.3-3$ \\
\hline Concrete-Composite & 60 & Empty & $1.1-1.9$ & $2-6$ \\
\hline $\begin{array}{l}\text { Composite-Concrete } \\
\text { (Summer Days) }\end{array}$ & 60 & Empty & 0.2 & 3 \\
\hline Concrete-Composite & 60 & Full & $0.6-1.4$ & $1.9-4.1$ \\
\hline $\begin{array}{l}\text { Composite-Concrete } \\
\text { (Summer Days) }\end{array}$ & 60 & Full & 0.2 & 2.4 \\
\hline
\end{tabular}

*The type of pavement in bold-print showed fuel savings over the other type of pavement listed

Table 2.2 Average Fuel Savings for Car in Taylor’s Study (Taylor \& Petten, 2006)

\begin{tabular}{|c|c|c|c|}
\hline Pavement Being Compared & Season & Fuel Savings (L/100km) & Fuel Savings (\%) \\
\hline Concrete-Asphalt & Winter & 0.3 & 2.9 \\
\hline Composite-Concrete & Winter & 0.2 & 2.3 \\
\hline Concrete-Composite & Summer & 0.1 & 1.5 \\
\hline Concrete-Asphalt & Summer & 0.05 & 0.3 \\
\hline
\end{tabular}

*The type of pavement in boldprint showed fuel savings over the other type of pavement listed

(Benbow, et al., 2007)

Benbow et al. investigated the influence of the rigidity of asphalt and concrete pavement on vehicle fuel consumption. Results showed that the reduced deflection of 
concrete pavement can lead to a 5.7\% reduction in rolling resistance, corresponding to a fuel saving of $1.14 \%$. However, the difference was not approved statistically insignificant. Possible reasons may be related to the fact that the pavements were built in laboratory conditions.

\section{(Sumitsawan, et al., 2009)}

Ardekani et al. performed two field studies on asphalt and concrete pavement to investigate the impact of pavement type on fuel consumption at city speeds. Two driving conditions were tested: constant speed of $48 \mathrm{~km} / \mathrm{h}$ and acceleration from a stand still. The measurements also controlled humidity, ambient temperature, fuel type, tire pressure, vehicle mass and wind speed, and direction. The result showed that the fuel consumption of tested vehicle was 7-20\% lower on concrete pavement compared to asphalt pavements, for both constant speed and acceleration scenarios. The results found in this study were much larger than what is suggested by other studies.

\section{(Lengrenn \& Faldner, 2010)}

Lenngren and Faldner investigated the energy attenuation losses in pavement using falling weight deflectometer (FWD) in North Uppsala in Sweden. By evaluating the falling weight deflectometer time history, it was shown that the energy losses in asphalt pavement is four times higher than the energy losses in concrete pavement. Figure 2.5 displays the hysteresis loop of the FWD test for asphalt and concrete pavement respectively. The amount of energy loss was represented by the size of the area within the

loop. It was shown that part of the energy was dissipated in the structure due to the viscoelastic behavior of pavement structure. 


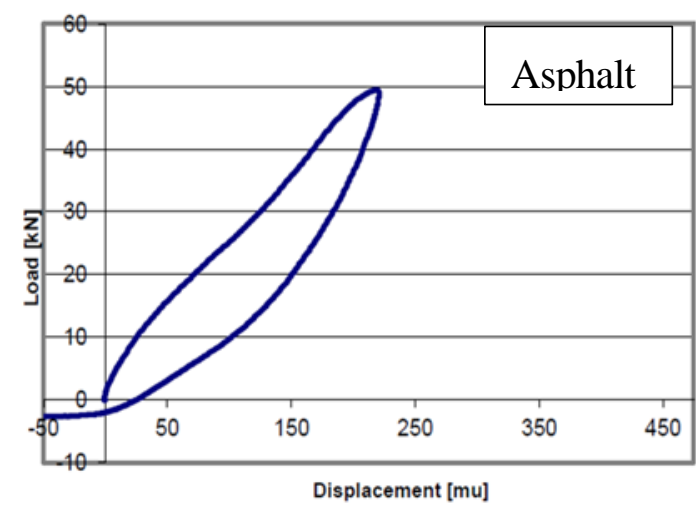

Asphalt Pavement

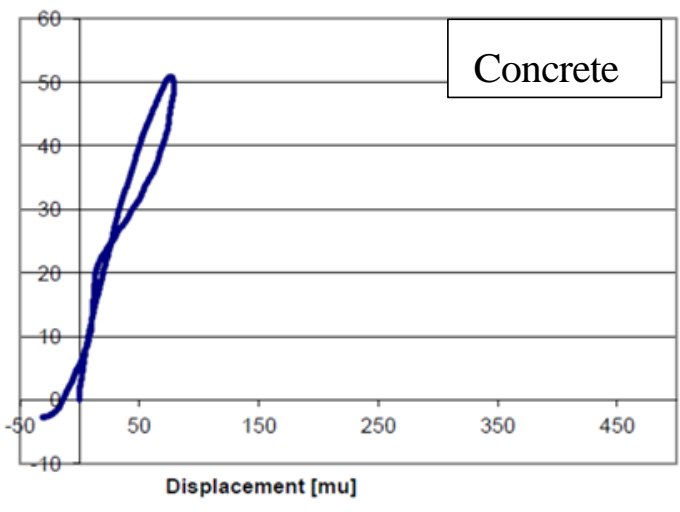

Rigid Pavement

Figure 2.5 Hysteresis Curves of FWD Tests from (Lengrenn \& Faldner, 2010)

\section{(Hultqvist, 2010)}

Hultqvist investigated the influence of pavement type (asphalt and concrete) on fuel consumption experimentally. The surface materials of these two pavements were stone mastic asphalt and brushed concrete. Results showed that a statistically significant fuel consumption difference of $1.1 \%$ was derived in favor of concrete pavement for passenger car. For the 3-axle trailer (60-ton), the average fuel consumption difference was $6.7 \%$ in favor of concrete pavement.

\section{(Yoshimoto, et al., 2010)}

Yoshimoto et al. performed coast-down tests on a heavy truck and measured the vehicle running resistance (the sum of aerodynamic drag and rolling resistance) on asphalt and concrete pavement. The vehicle was accelerated to a certain speed, shifted into neutral gear and then allowed to freely decelerate to a speed of $5 \mathrm{~km} / \mathrm{h}(3.1 \mathrm{mph})$. The rolling resistances were then derived from the speed-time relationship. The 
differences in fuel consumption were calculated from the rolling resistances. Results showed that for city driving tests, the fuel consumption of asphalt pavement was $0.8 \%$ to 3.4\% higher than concrete pavement. For highway driving tests, the excess fuel consumption on asphalt pavement varied from $1.4 \%$ to $4.8 \%$.

(Chatti \& Zaabar, 2012)

Zaabar conducted field tests to investigate the impact of pavement type on fuel consumption. Five vehicles including passenger car, van, SUV, light truck, articulated truck were used at three speed levels: $56 \mathrm{~km} / \mathrm{h}, 72 \mathrm{~km} / \mathrm{h}$ and $88 \mathrm{~km} / \mathrm{h}$. Results showed that a $5 \%$ fuel consumption difference was found between asphalt pavement and concrete pavement in summer conditions at lower testing speed for light and articulated truck only.

\subsection{FUEL CONSUMPTION MODELS}

This section describes the major fuel consumption models from the literature. A number of fuel consumption models have been generated since 1996 (De Weille, 1966). At the beginning, the models were developed purely based on empirical data. Then experimental studies were incorporated into the models with specific operating conditions, but still in an empirical way. In recent decades, vehicle fuel consumption has been modeled with mechanistic approaches in which the fuel consumption was related to

different forces opposing to motion. The sections below give a brief review on some of the major empirical and mechanistic fuel consumption models.

\subsubsection{Empirical Models}

In early empirical fuel consumption models, the vehicle speed was the only variable related to fuel consumption. A U-shape relationship was found between vehicle 
speed and fuel consumption from early studies. The optimum vehicle traveling speed for the best fuel economy was between $40 \mathrm{~km} / \mathrm{h}$ and $60 \mathrm{~km} / \mathrm{h}$ (Greenwood \& Bennett , 2003). Later studies included pavement roughness and roadway grade into the models and the following empirical equation (Equation 2.1) can be a general representative.

$$
F C=a 0+\frac{a 1}{S}+a 2 S^{2}+a 3 R I S E+a 4 F A L L+a 5 I R I
$$

\begin{tabular}{|c|c|c|}
\hline \multirow[t]{5}{*}{ Where } & FC & is the fuel consumption in $\mathrm{L} / 1000 \mathrm{~km}$ \\
\hline & $S$ & is the vehicle speed in $\mathrm{km} / \mathrm{h}$ \\
\hline & IRI & is the pavement roughness in $\mathrm{m} / \mathrm{km}$ \\
\hline & RISE & is the rise of roadway grade in $\mathrm{m} / \mathrm{km}$ \\
\hline & FALL & is the fall of roadway grade in $\mathrm{m} / \mathrm{km}$ \\
\hline
\end{tabular}

The development of the empirical fuel consumption models requires extensive data collection and model calibration. They are more applicable to the situations that data access is considerably limited. As a result the empirical approach has been gradually replaced by the mechanistic approaches.

\subsubsection{Mechanistic Models}

The models that were developed based on the mechanical relationship between the vehicle and the forces opposing to the motion were considered as mechanistic fuel consumption models. Mechanistic models have significant improvements over empirical models given their transferability to different vehicle and roadway conditions.

Three major mechanistic models have been developed as the HDM-III (Highway Development and Management Model III) Model, South Africa Model, and Australian Road Research Board Model (ARRB). The Australian Road Research Board Model was then built upon by Biggs (Biggs, 1988) to develop the most comprehensive mechanistic 
fuel consumption model: ARFCOM (ARRB Road Fuel Consumption Model). The ARFCOM model was then applied as the basis of the currently most adopted fuel consumption model, HDM-IV (Highway Development and Management Model IV), with modifications of engine speed, engine drag, and the accessories power. This study selected the HDM-IV fuel consumption model for the analysis. But before going into the HDM-IV Models (which will be detailed in Chapter 5), the HDM-III, South Africa Model, Australian Road Research Board Model, and ARFCOM were first described in the following sections.

\subsubsection{HDM-III Model}

The HDM-III fuel consumption model predicts vehicle fuel consumption as functions of the power required to overcome the tractive force and the engine speed. Equation 2.2 to 2.4 demonstrate the calculations of fuel consumption in HDM-III model.

$$
\begin{aligned}
& \text { IFC }=\quad U F C 0+(a 3+a 4 \text { RMP }) \text { Ptr }+a 5 \text { Ptr }^{2} \quad \text { if Ptr } \geq 0 \quad 2.2 \\
& \text { UFCO }+ \text { a6 Ptr }+a 7 \text { Ptr }^{2} \quad \text { if } N H 0 \leq P t r \leq 0 \quad 2.3 \\
& \text { UFCO }+a 6 \mathrm{NHO}+a 7 \mathrm{NHO}^{2} \quad \text { if Ptr }<\mathrm{NHO} \quad 2.4
\end{aligned}
$$

Where IFC is the instantaneous fuel consumption in $\mathrm{mL} / \mathrm{s}$

$\operatorname{Ptr} \quad$ is the tractive power

RPM is the engine speed in revolution per minute

NH0 are model parameters

a3 to a7 are model parameters

The term UFC0 represents the fuel required to operate the vehicle engine. It is calculated as Equation 2.5.

$$
U F C 0=a 0+a 1 R P M+a 2 R P M^{2}
$$

Where a0 to a2 are the model coefficients 
The HDM-III fuel consumption equation predicted two power regimes: positive power regime, and negative power regime. Propulsive power was generated from the engine in the positive power regime. When the gravitation acceleration exceeds the combined aerodynamic and rolling resistance, negative power regime was generated.

\subsubsection{South Africa Model}

Bester (Bester, 1981) developed the South African mechanistic fuel consumption model in 1981. He proposed that the vehicle fuel consumption was proportional to the total energy required to vehicle motion. The general form of the model is displayed as equation 2.6.

$$
F C=1000 \beta \frac{\text { Ptot }}{v}
$$
Where $\mathrm{FC} \quad$ is the fuel consumption in $\mathrm{mL} / \mathrm{km}$
$\beta \quad$ is the fuel efficiency factor in $\mathrm{mL} / \mathrm{kW} / \mathrm{s}$ or $\mathrm{mL} / \mathrm{kJ}$
Ptot is the total power requirement in $\mathrm{kW}$
$\mathrm{v}$ is the vehicle velocity in $\mathrm{m} / \mathrm{s}$

Equation 2.7 presents the detailed fuel consumption calculation in South Africa

Model.

$$
F C=a 0+\frac{a 1}{S}+a 2 S^{2}+a 3 G R+a 4 a
$$

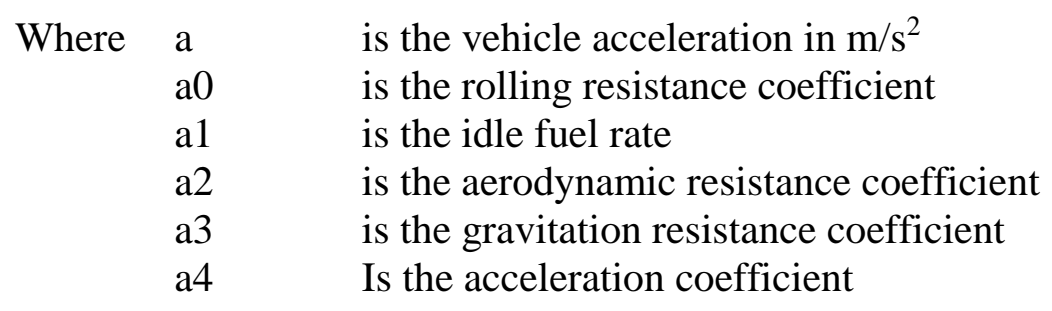


The disadvantage of the South African Model is that the engine speed was not taken into consideration in the fuel modeling. Continuous experimental studies were also carried out in South Africa with the similar approach as Bester's studies. A variety of fuel consumption models were then developed afterward.

\subsubsection{ARRB Model}

Studies have been conducted since the early 1980s in Australia to model the passenger car fuel consumption. Bowyer (Bowyer, et al., 1985) developed the Australian Road Research Board Model (ARRB) based on the early experimental works. s mechanistic fuel consumption model developed was shown as equation 2.8 .

$$
I F C=\alpha+\beta P t r+\frac{\beta_{2} M a^{2} v}{1000}
$$

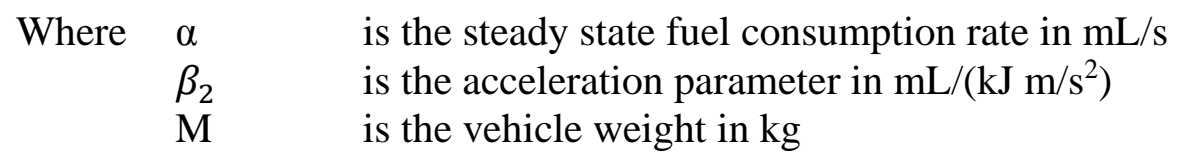

The formation of fuel consumption model is very similar to what proposed by Bester (Bester, 1981). The only difference is the efficiency parameters $\beta$. Bowyer also discussed the importance of modeling vehicle fuel consumption in different modes. Four modes were simulated: steady state speed, acceleration, deceleration, and idle. Four submodels were developed based on the general AARB formation: instantaneous, elemental, running speed, and average travel speed. However only the instantaneous model is a pure mechanistic fuel consumption model. 


\subsubsection{ARFCOM Model}

The ARRB model was extended into the comprehensive ARFCOM (ARRB Road Fuel Consumption Model) by Biggs (1998). The ARFCOM was a mechanistic fuel consumption model that was transferable between vehicle classes. The model was generated based on engine-map data and only required limited input data for the application. The approach ARFCOM estimated vehicle fuel consumption is displayed in Figure 2.6.

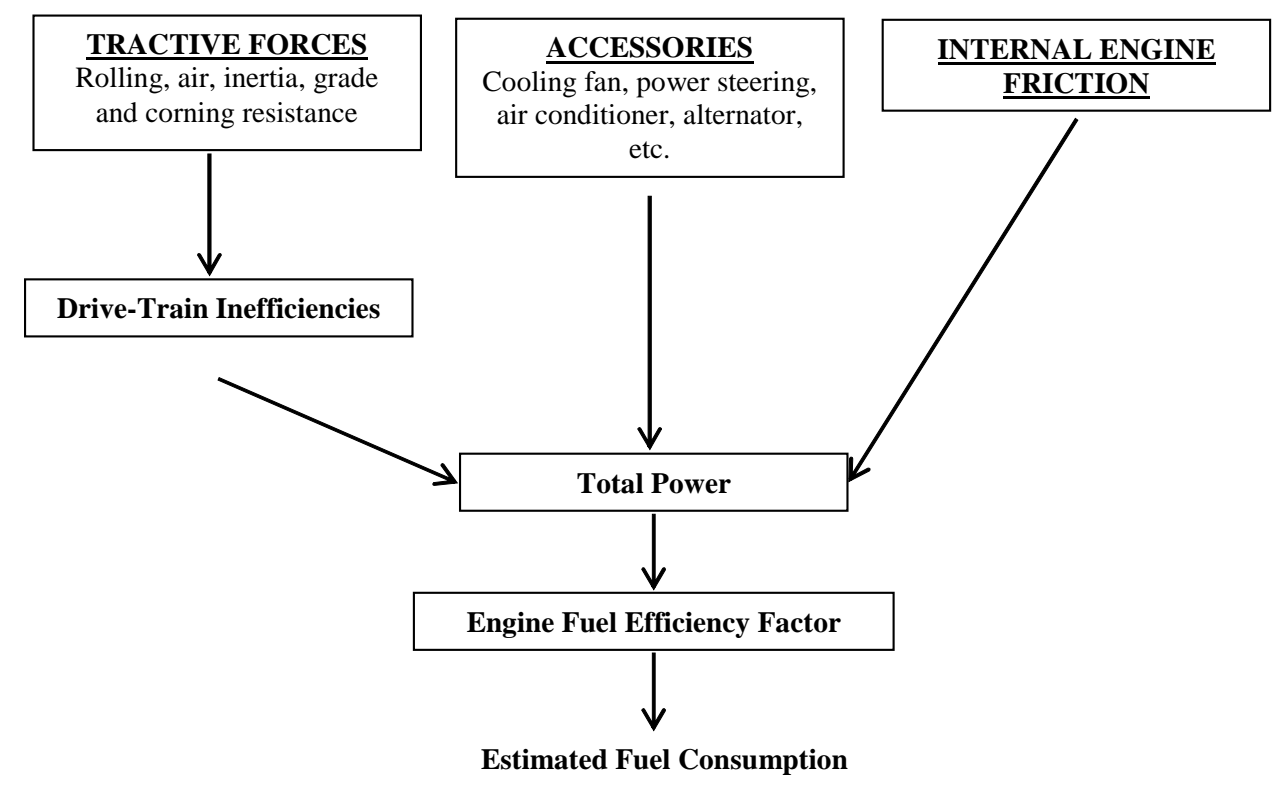

Figure 2.6 Approach to Estimate Fuel Consumption in HDM-IV (Bennett \& Greenwood, 2003a)

The ARFCOM models fuel consumption with the following Equation 2.9.

$$
I F C=\max (\alpha, \beta(\text { Pout }+ \text { Peng })
$$

Where Pout is the power required to overcome external forces in $\mathrm{kW}$ Peng is the power required to overcome internal engine drag in $\mathrm{kW}$ 
The ARFCOM model is similar to the South African model in estimating fuel consumption as proportional to vehicle power. But the ARFCOM also considered the power required to overcome the internal engine forces, Peng. The ARFCOM was close to the basic engine-vehicle mapping models which give the most detailed fuel consumption representation. Thus, the ARFCOM was the model that HDM-IV selected as the basin model. The detailed model components of HDM-IV fuel consumption model will be discussed in Chapter 5. 


\section{CHAPTER 3}

\section{PHASE I FIELD STUDY}

\subsection{INTRODUCTION}

This chapter presents the field experiment and statistical result of the Phase I field study. The Phase I field study is a preliminary experimental investigation on how the differences in pavement type would result in the difference in vehicle fuel consumption. The study involves direct fuel comparison tests on two pairs of flexible pavement-rigid pavement sections with repeated measurement. The sections are selected from the two major interstate roadways I-95 and I-75 in Florida. At least six measurements were performed on each paired section. Two vehicle classes were studied: passenger car and a loaded 18-wheel tractor trailer. The following sections explain the detailed experimental design, data collection, data processing, and statistical analysis and results.

\subsection{EXPERIMENTAL DESIGN}

\subsubsection{Roadway Sections}

The goal is to select test sites from Florida's interstate roadways that have adjacent (paired) flexible pavement and rigid pavement sections. The paired flexible-rigid pavement sections shall have either identical or similar roadway geometries, traffic volume, and environmental condition. Each candidate location was screened from its geography, operation feasibility, and loop distance. Two of the following sites on Interstate 95 (I-95) and Interstate 75 (I-75) were finalized.

\section{Site I: Interstate 95 from Mile-marker 189 to Mile-marker 204}

The first site is located on Interstate highway 95 (I-95) in Brevard County in Florida. It is composed of $11 \mathrm{~km}$ (7mile) of flexible pavement section, $11 \mathrm{~km}$ (7mile) of 
rigid pavement section and $1.6 \mathrm{~km}$ (1mile) of transition section (partially flexible pavement and partially rigid pavement) between the flexible section and rigid section. The flexible pavement section was located between mile-marker (MM) 189 and milemarker (MM) 196 in both direction. The rigid pavement was located between milemarker (MM) 197 and mile-marker (MM) 204 in both direction. The tests were designed to be conducted on double traveling direction (northbound and southbound). A total of four roadway sections were generated, which was summarized in Table 3.1.

Table 3.1 Roadway Information of Site I

\begin{tabular}{|c|c|c|c|c|c|c|}
\hline Section & RW-ID & Begin MM & End MM & Direction & Distance (km) & Pavement Type \\
\hline $\mathbf{1}$ & I-95 & 189 & 196 & Northbound & 11 & HMA \\
\hline $\mathbf{2}$ & I-95 & 196 & 189 & Southbound & 11 & HMA \\
\hline $\mathbf{3}$ & I-95 & 197 & 204 & Northbound & 11 & JPCP \\
\hline $\mathbf{4}$ & I-95 & 204 & 197 & Southbound & 11 & JPCP \\
\hline
\end{tabular}

Figure 3.1 shows the similarity of the geometries of the roadways sections. Figure 3.2 displays the section location. The flexible section and rigid section are both nearly straight sections run north-northwesterly on the northbound side and south-southeasterly on the southbound side. There is a slight curve on the north end of the flexible section, but the curvature effect is not taken into consideration given its small magnitude.

In this test site, section 1 and 2 were composed of 19mm (0.75in) of FC-5 friction course, 216mm (8.5in) of Superpave Hot-Mixed Asphalt (HMA) structure layer and 305mm (12in) of Type-B stabilized base course. Section 3 and 4 were jointed plain concrete pavement (JPCP) composed of 330mm (13in) of Portland Cement Concrete 
(PCC) slab with 102mm (4inch) of asphalt-treated permeable base. The typical subgrade treatment of all sections were Type B stabilization (LBR-40).

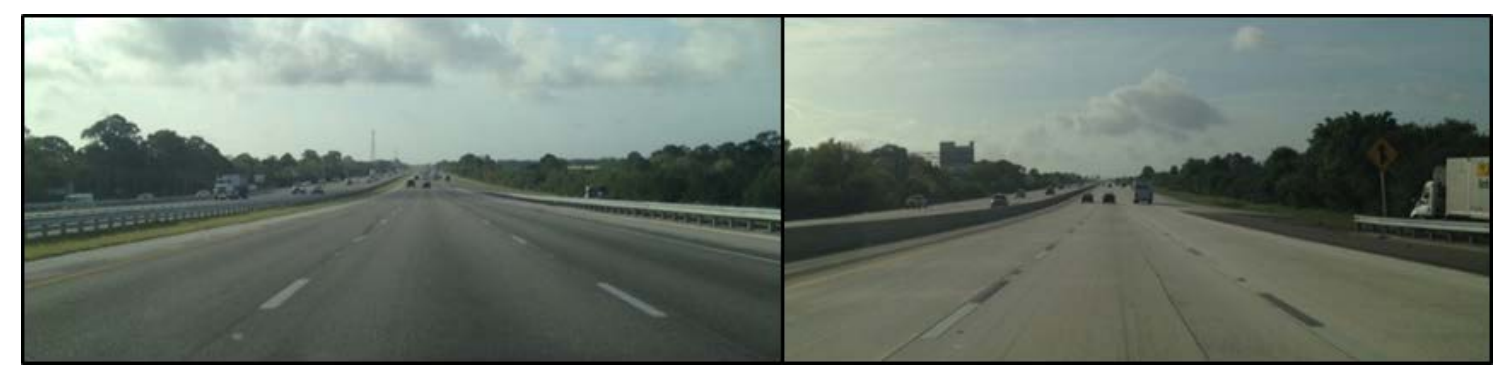

Flexible Pavement

Rigid Pavement

Figure 3.1 Test Site I

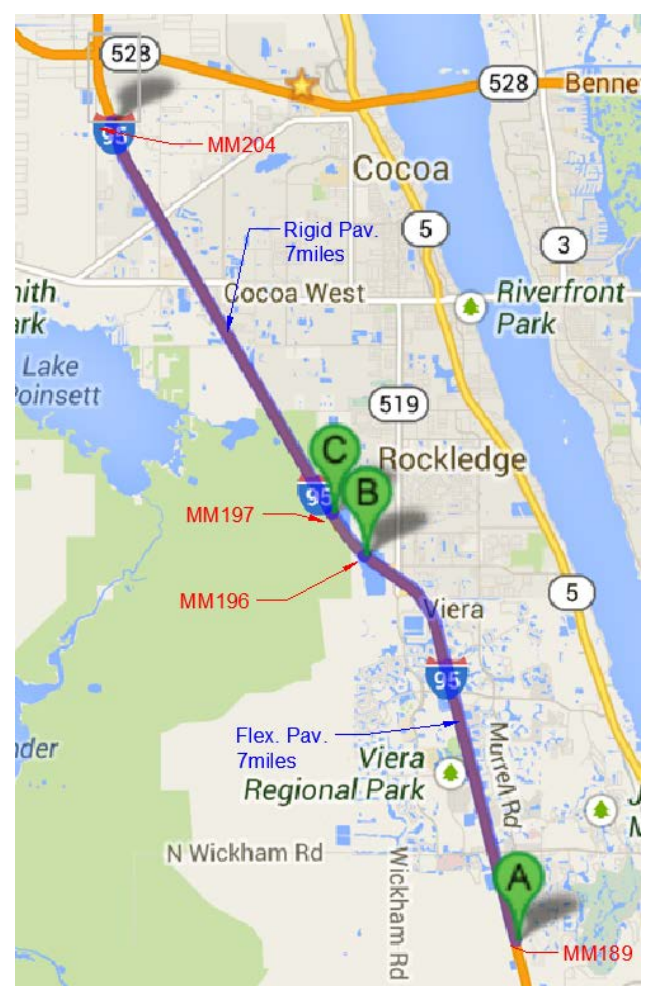

Figure 3.2 Location of Site I Sections 
The average International Roughness Index (IRI) obtained from State Department of Transportation (DOT) right before the test was $0.75 \mathrm{~m} / \mathrm{km}$ (48in/mile) for flexible pavement and $0.73 \mathrm{~m} / \mathrm{km}$ (46in/mile) for rigid pavement. Although the IRI of flexible pavement was slightly higher than rigid pavement, there was no statistically significant difference between them. The texture information of the pavement surface was not available. The annual average daily traffic (AADT) of the four sections was 78,000 vehicles with a 5.1\% truck volume (in 2013).

\section{Site II: Interstate 75 from Mile-marker 247.5 to Mile-marker 253.5}

The second test site was located on Interstate highway 75 (I-75) in Hillsborough County in Florida. This test site contained 8km (5mile) of flexible pavement section, $8 \mathrm{~km}$ (5mile) of rigid pavement section and 1.6km (1mile) of the transition section between the flexible section and rigid section. The flexible section was located between MM 247.5 and MM 252.5. The rigid section was located between MM 253.5 and MM 258.5. Similarly to the first test site, four sections were generated in this site. Table 3.2 shows the detail section information of this four sections.

Table 3.2 Roadway Information of Site II

\begin{tabular}{|c|c|c|c|c|c|c|}
\hline Section & RW-ID & Begin MM & End MM & Direction & Distance (km) & Pavement Type \\
\hline $\mathbf{5}$ & I-75 & 247.5 & 252.5 & Northbound & 8 & HMA \\
\hline $\mathbf{6}$ & I-75 & 252.5 & 247.5 & Southbound & 8 & HMA \\
\hline $\mathbf{7}$ & I-75 & 253.5 & 258.5 & Northbound & 8 & JPCP \\
\hline $\mathbf{8}$ & I-75 & 258.5 & 253.5 & Southbound & 8 & JPCP \\
\hline
\end{tabular}

In this test site, section 5 and 6 were flexible pavement sections composed of 19mm (0.75in) of FC-5 friction layer and 229mm (9in) of HMA structure course. Section 
7 and 8 were rigid pavement sections composed of 330mm (13in) of PCC slab and 102mm (4in) of asphalt-treated permeable base. Similar to site 1, the typical subgrade treatment was also Type B stabilization (LBR-40). The average IRIs of the flexible pavement and rigid pavement were both $0.85 \mathrm{~m} / \mathrm{km}$ (54in/mile). The subgrade resilient modulus of section 5 is $145 \mathrm{Mpa}(21 \mathrm{ksi})$ and $165 \mathrm{Mpa}(24 \mathrm{ksi})$ for section 6 . The texture information was not available. The annual average daily truck (AADT) of the section was 95,958 and the truck volume was 9.5\%.

Figure 3.3 displays roadways sections and Figure 3.4 shows the section location. The flexible and rigid section both ran nearly straight along north-south direction.

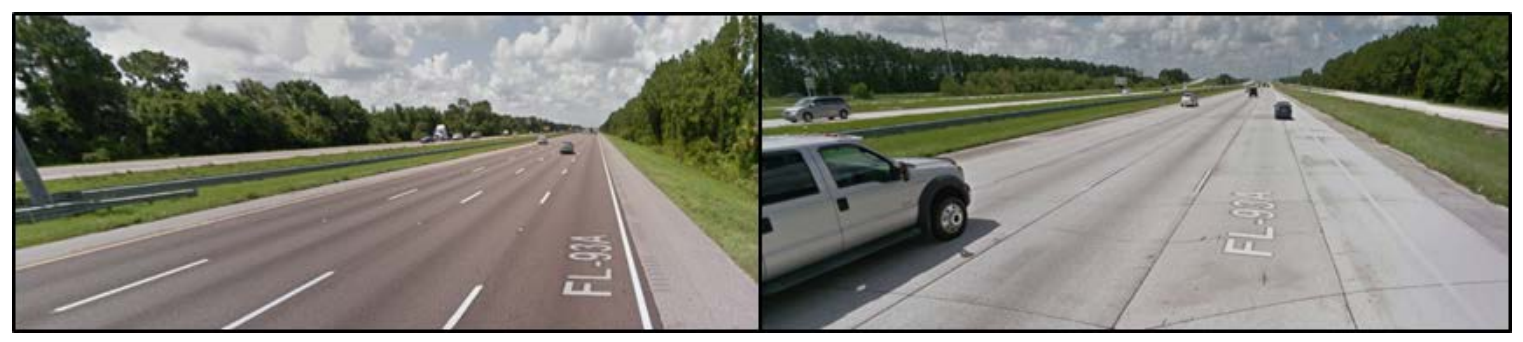

Flexible Pavement

Rigid Pavement

Figure 3.3 Test Site II

It is worth to give some explanations about the pavement texture since the data was not available. For Florida's highway construction, the typical texture level in mean profile depth (MPD) for open graded friction course (OGFC) FC-5 is normally between $0.76 \mathrm{~mm}$ (0.03in) and 2mm (0.08in). It varies from the asphalt mix design and the amount of course aggregates used. For rigid pavement in Florida's highway construction, the MPD of the surface concrete is typically between $0.25 \mathrm{~mm}(0.01 \mathrm{in})$ and $0.76 \mathrm{~mm}(0.03 \mathrm{in})$. Flexible 


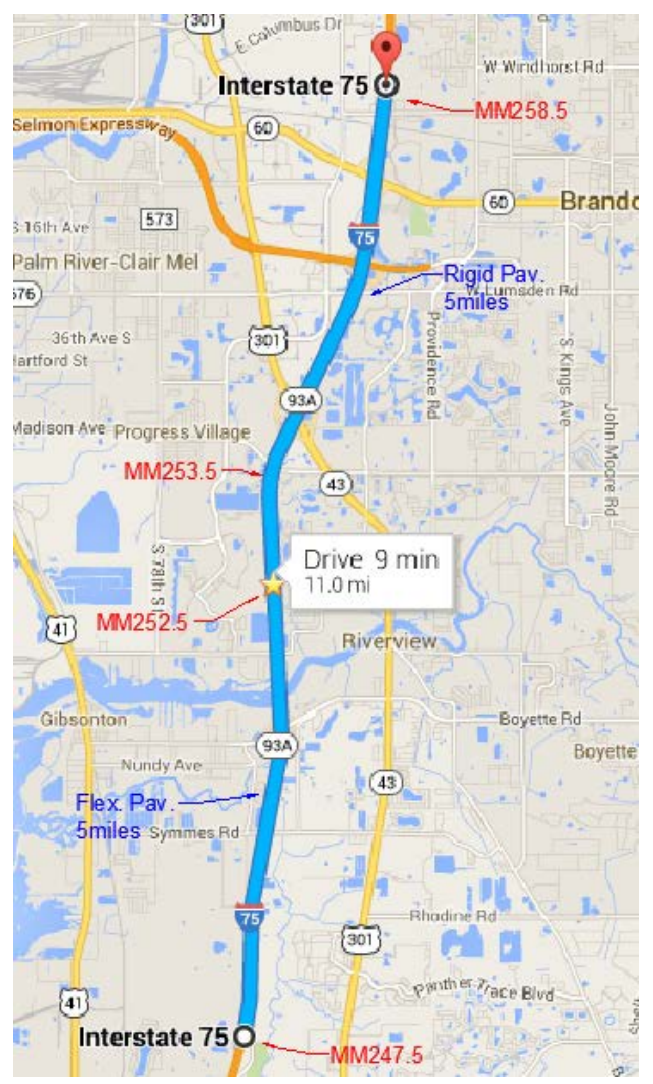

Figure 3.4 Location of Site II Sections

pavement normally exhibits a higher texture level than rigid pavement surface. This is partially due to the fact that the direction the laser profiler measures the concrete surface is the same as the longitudinal grinding (LGD) operation. On the other hand, the major contributors of the high MPD level on the flexible pavement is the exposed course aggregates in OGFC. The large amount of coarse aggregates ensure a safe traveling surface with sufficient friction but increase the surface texture depth at the same time. Given the facts above, the texture differences between flexible pavement and rigid pavement in this study are treated as a material (or pavement type) dependent characteristic. Figure 3.5 displays a close look of the typical OGFC surface and concrete surface used in Florida’s highway pavement. 


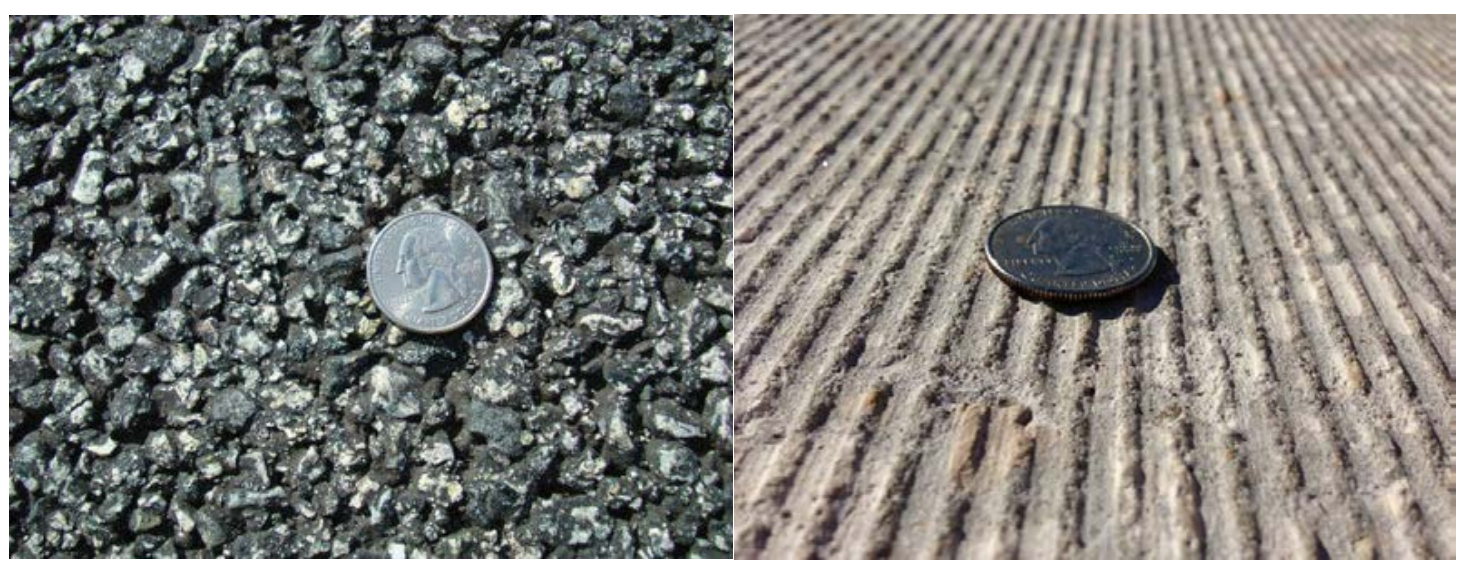

OGFC Surface

Concrete Surface

Figure 3.5 Surface Texture of Highway Pavements in Florida

\subsubsection{Testing Vehicles}

Two types of vehicles were used in the field tests: a passenger car and a commercial tractor-trailer. The passenger car is a 2011 Hyundai Genesis sedan (3.8L/V6) equipped with a 3.8-Liter 6-cylider V-shape gas engine. The engine is capable of producing 290 horsepower at 6,200 rmp and $264 \mathrm{ft}-\mathrm{lbs}$ torque at 4,500rmp. The car features a 6-speed automatic transmission and rear wheel drive. The fuel tank capacity is 73L (19.3gal). The tire model is Goodyear 225/55HR17. Tires pressure were adjusted to 35psi before each run. The curb weight of the passenger car is approximately $1,700 \mathrm{~kg}$ (3,750lbs). It represents the large-size of passenger vehicle group. The weight of the passenger car was treated as constant throughout the test. Figure 3.6 shows the passenger car used in this study.

The commercial tractor trucks used is an 18-wheel tractor-trailer rig with goods loaded before each test. The truck was provided by CCC Transportation Inc. from central Florida. The tractor of the 18-wheeler was a 6x4 2011 Mack Day Cab model CXU613. 
The tractor engine was Mack MP8-415C Diesel with a peak horsepower of 415hp and maximum torque of $1660 \mathrm{lb} / \mathrm{ft}$. The transmission was FRO-16210B with 10-speed. The standard axle capacity was $40,000 \mathrm{lbs}$ in the rear and $12,000 \mathrm{lbs}$ in the front. Bridgestone 295/75R22.5 low profile tires were equipped with the tractor. Figure 3.7 displays the 18wheeler.

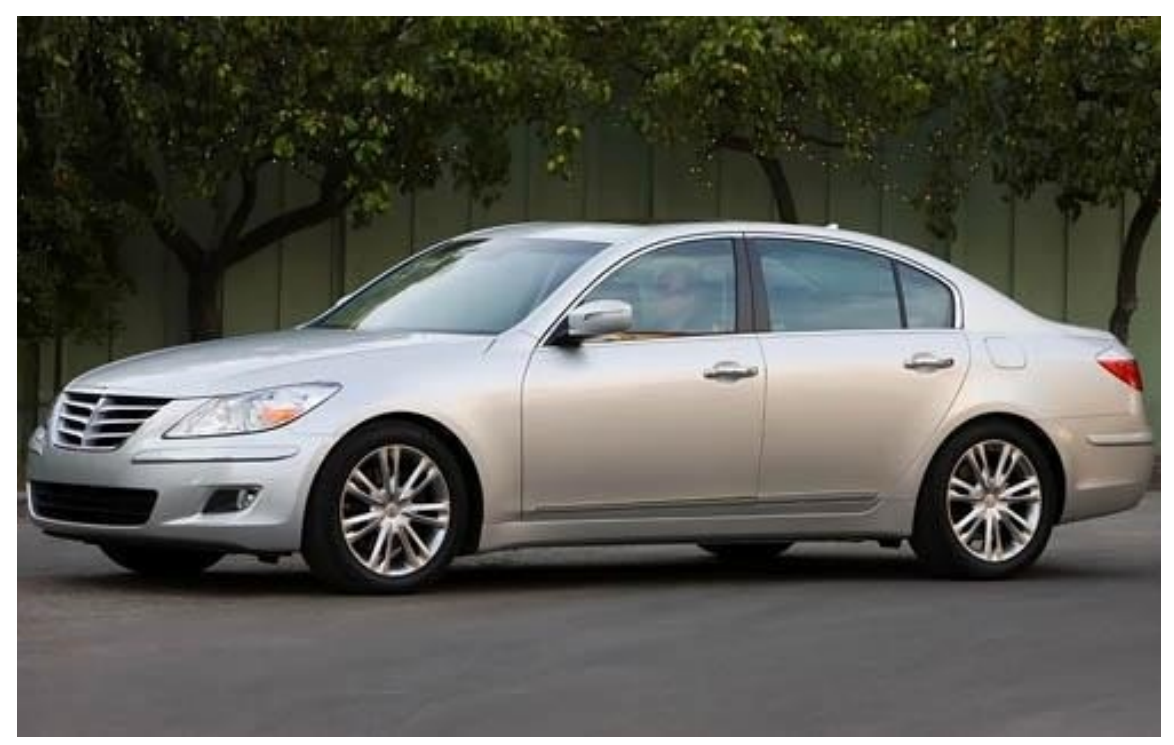

Figure 3.6 Passenger Car Used in Phase I Field Study

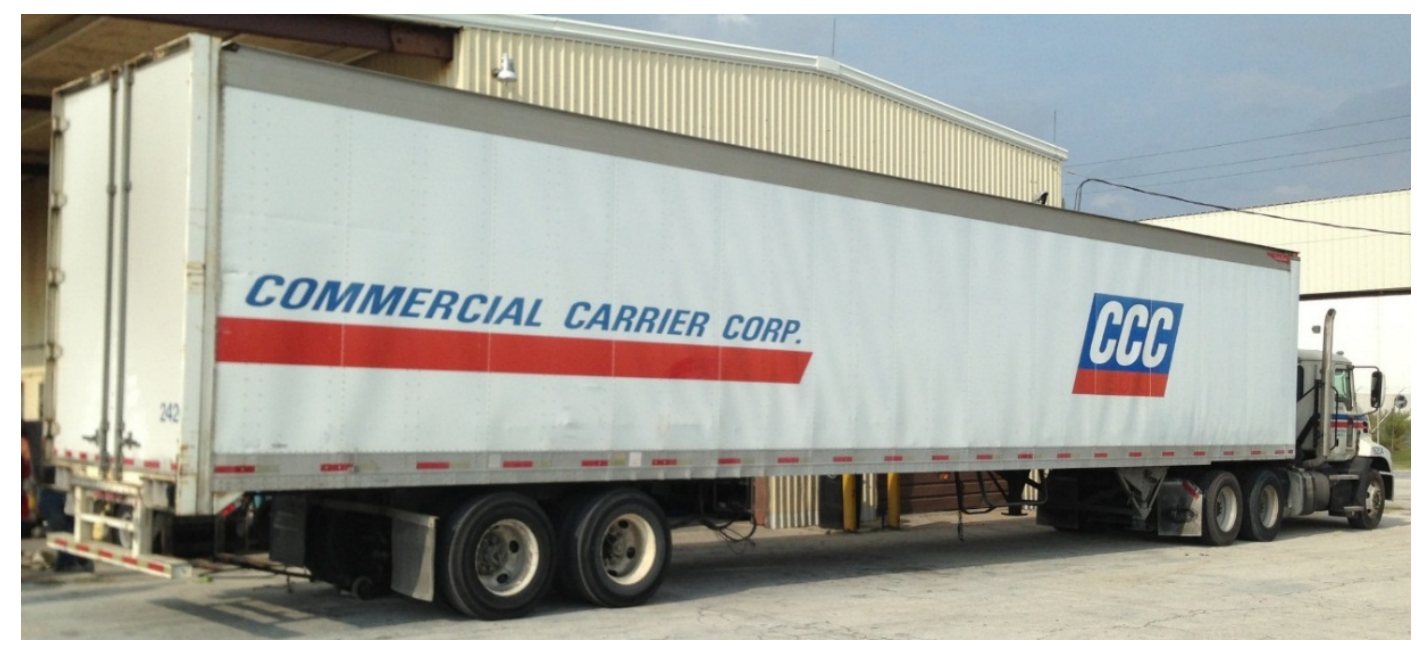


Figure 3.7 Commercial Tractor-trailer Used in Phase I Field Study

Goods were loaded to the truck box before every test. The gross weights of the 18-wheeler were measured and recorded after each test session. Table 3.3 summarizes the gross vehicle weight in each test. The average gross truck weight of all tests was $34,709 \mathrm{~kg}(76,520 \mathrm{lbs})$, with a minimum weight of 33,067kg (72,900lbs) and maximum weight of $36,505 \mathrm{~kg}(80,480 \mathrm{lbs})$. Because of the truck availability, the truck test was only performed on the test site I. The passenger car test was completed on both site I and site II.

Table 3.3 Gross Weight of Tractor-trailer of All Tests

\begin{tabular}{|c|c|c|c|c|c|c|}
\hline Test & $\mathbf{1}^{\text {st }}$ & $\mathbf{2}^{\text {nd }}$ & $\mathbf{3}^{\text {rd }}$ & $\mathbf{4}^{\text {th }}$ & $\mathbf{5}^{\text {th }}$ & $\mathbf{6}^{\text {th }}$ \\
\hline Weight (kg) & 34,700 & 33,566 & 36,052 & 36,505 & 34,364 & 33,067 \\
\hline Weight (lbs) & 76,500 & 74,000 & 79,480 & 80,480 & 75,760 & 72,900 \\
\hline
\end{tabular}

\subsubsection{Data Collection Devices}

For the passenger car test, an On-Board Diagnostic (OBD) device made by OBDCOM was used to collect the required data. One end of the device was connected to the vehicle OBD port and another end to a laptop for test operation and data displaying. The OBD port of the 2011 Hyundai Genesis was located under the driver-side dashboard. Desired data was uploaded into the laptop in real time during the test. The real-time data recorded were gas consumption and vehicle speed. The data collection speed was 5 readings per second. The data were then entered into Excel Spreadsheet database format for further analysis. Figure 3.8 shows the passenger car data collection in real time from the laptop screen. 
The truck data collection system was similar to the passenger vehicle which utilized the On-Board Diagnostics port on the tractor along with a laptop and compatible software. Figure 3.9 displays the truck real-time data recording.

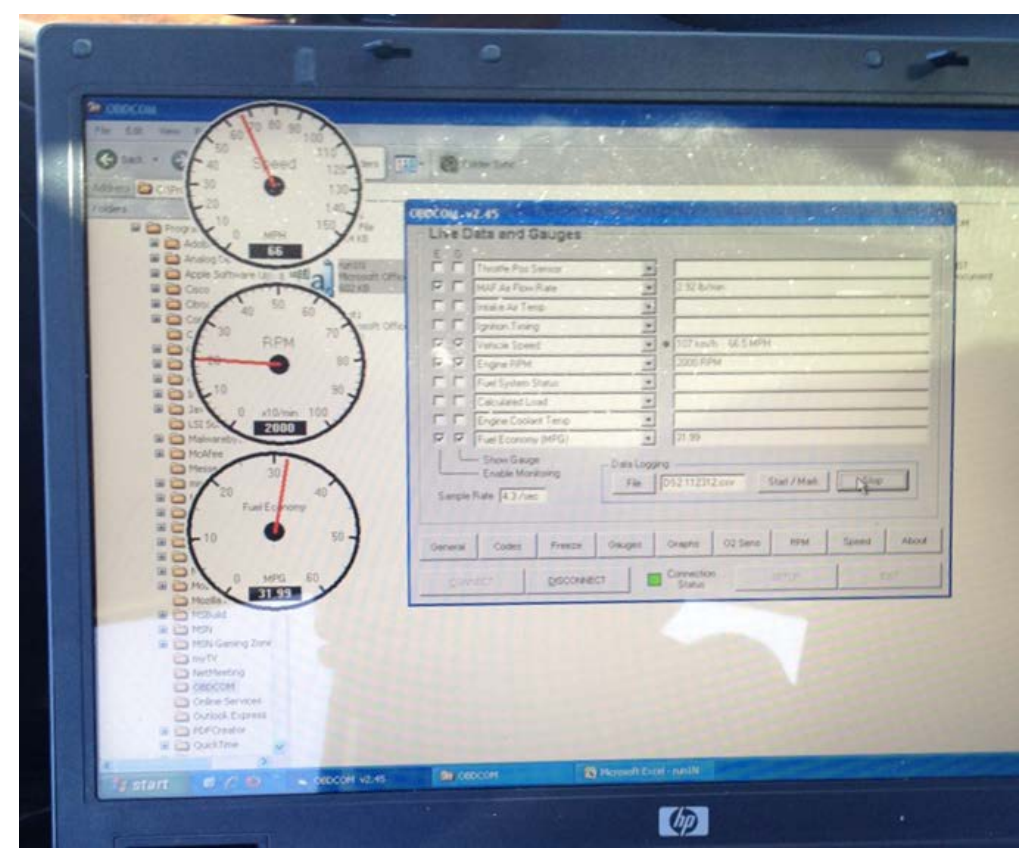

Figure 3.8 Phase I Car Test Real-time Data Collection

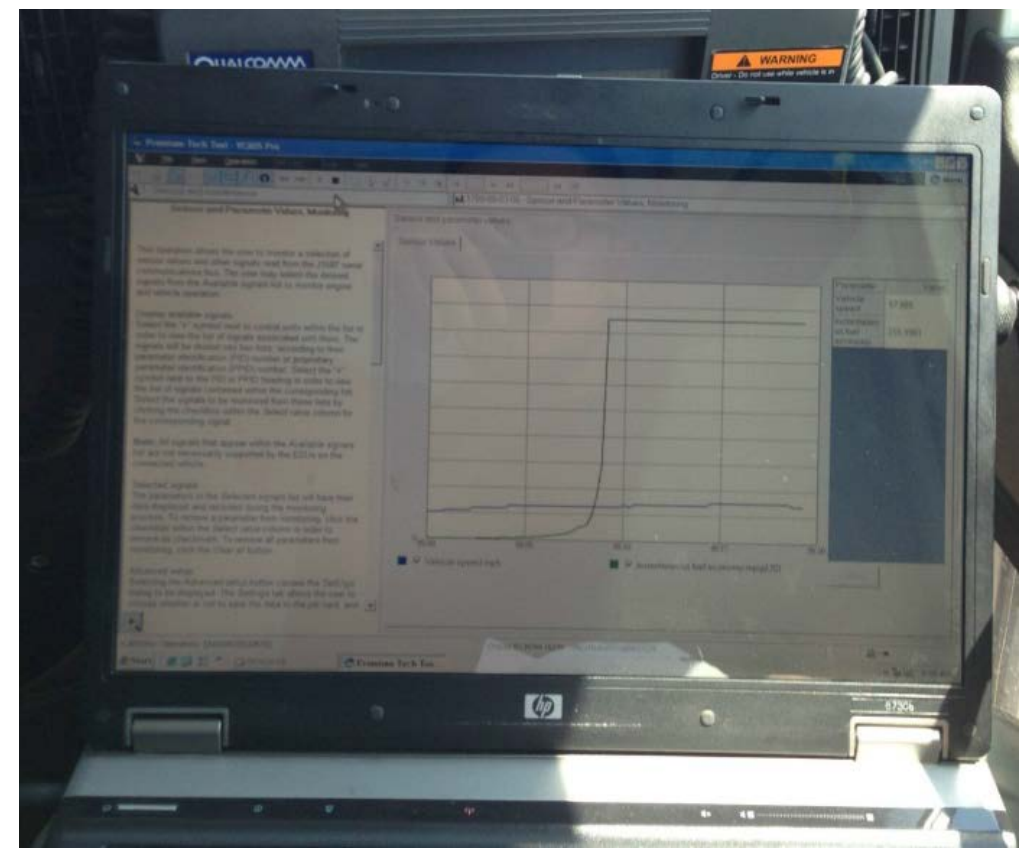


Figure 3.9 Phase I Truck Test Real-time Data Collection

\subsection{DATA COLLECTION}

Instantaneous gas consumption was prime data collected through vehicle OnBoard Data (OBD) collection device. Each section was driven three consecutive runs at constant speed of $112 \mathrm{~km} / \mathrm{h}(70 \mathrm{mph})$ for passenger car and $93 \mathrm{~km} / \mathrm{h}(58 \mathrm{mph})$ for the tractor-trailer. Vehicle speed during the test is kept constant through vehicle cruise control function. A total of 14 measurements (8 on site I and 6 on site II) were conducted for passenger car and 6 measurements (on site I) for tractor-trailer at a monthly frequency.

The instantaneous fuel rates recorded during the test was manually operated by the same personnel according to the mile-marker signs along the roadways. Data recording started when passing the begin $\mathrm{MM}$ and stopped at the point of end MM (MM shown in Table 3.1 and 3.2). The fuel rates were recorded in miles per gallon (MPG) for both vehicle classes. Experiments were not affected by traffic flow: no brakes and accelerations were engaged during the tests. Other information such as ambient temperature $\left({ }^{\circ} \mathrm{F}\right)$, wind speed and direction (mph) were also recorded. The ambient temperature measured and recorded during the test varied from the lowest of $9^{\circ} \mathrm{C}\left(49^{\circ} \mathrm{F}\right)$ to the highest of $31^{\circ} \mathrm{C}\left(88^{\circ} \mathrm{F}\right)$, with an average of $24^{\circ} \mathrm{C}\left(75^{\circ} \mathrm{F}\right)$. Tests were only conducted under dry roadway surface condition. This was intended to exclude the influence of wet surface on the experimental outcome. Vehicles were driven at the right-most roadway lane in each direction. Table 3.4 summarizes the environmental condition during the tests. 
Figure 3.10 shows sample fuel curves of a passenger car test on section 3 of test site I (May 10 ${ }^{\text {th }}$ 2013). The plot indicates high measuring repeatability. The two sets of troughs and spikes in the plot correspond to the fuel consumption when passing through roadway overpasses.

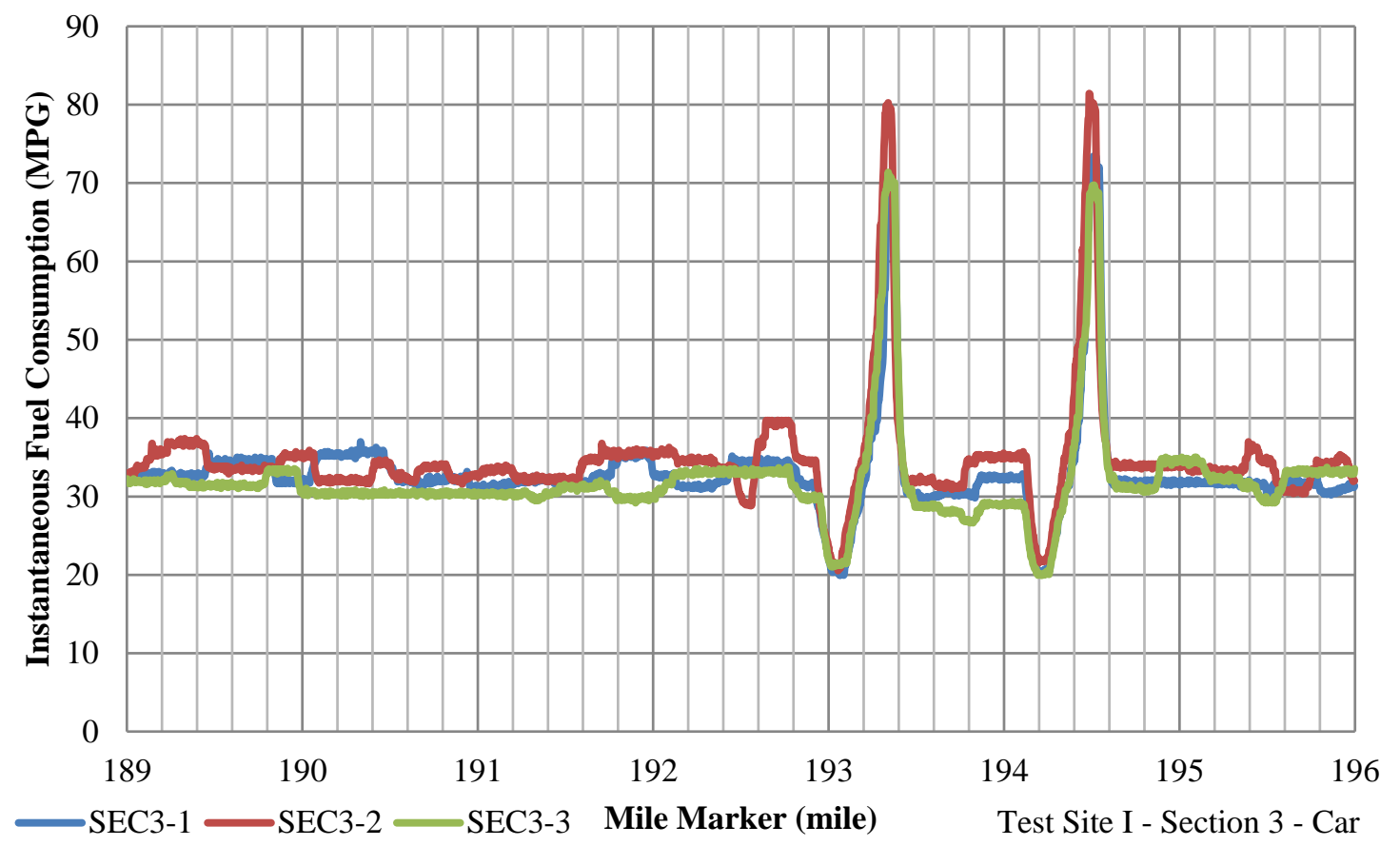

Figure 3.10 Sample Fuel Curves of Phase I Passenger Car Test

Table 3.4 Environmental Condition of All Tests

\begin{tabular}{|c|c|c|c|c|c|c|c|c|c|}
\hline \multicolumn{10}{|c|}{ Ambient Temperatures $\left.\mathbf{(}^{\mathbf{}} \mathbf{F}\right)$} \\
\hline Vehicle & Test & $\mathbf{1}^{\text {st }}$ & $\mathbf{2}^{\text {nd }}$ & $\mathbf{3}^{\text {rd }}$ & $\mathbf{4}^{\text {th }}$ & $\mathbf{5}^{\text {th }}$ & $\mathbf{6}^{\text {th }}$ & $\mathbf{7}^{\text {th }}$ & $\mathbf{8}^{\text {th }}$ \\
\hline $\begin{array}{c}\text { Passenger } \\
\text { Car }\end{array}$ & Site I & 62 & 76 & 72 & 68 & 49 & 79 & 80 & 84 \\
\cline { 2 - 11 } & Site II & 73 & 80 & 51 & 85 & 74 & 88 & N/A & N/A \\
\hline Truck & Site II & 81 & 84 & 82 & 83 & 76 & 69 & N/A & N/A \\
\hline \multicolumn{10}{|c|}{ Wind Speed and Direction (mph) } \\
\hline Vehicle & Test & $\mathbf{1}^{\text {st }}$ & $\mathbf{2}^{\text {nd }}$ & $\mathbf{3}^{\text {rd }}$ & $\mathbf{4}^{\text {th }}$ & $\mathbf{5}^{\text {th }}$ & $\mathbf{6}^{\text {th }}$ & $7^{\text {th }}$ & $\mathbf{8}^{\text {th }}$ \\
\hline Passenger & Site I & NW11 & S6 & SE11 & W4 & NNW4 & WSW10 & SW10 & E4 \\
\hline
\end{tabular}




\begin{tabular}{|c|c|c|c|c|c|c|c|c|c|}
\hline Car & Site II & E5 & SSW13 & NNE14 & S9 & NE6 & SSW7 & N/A & N/A \\
\hline Truck & Site II & SE9 & E13 & E6 & N1 & E8 & SSE14 & N/A & N/A \\
\hline
\end{tabular}

\subsection{DATA PROCESSING}

Each section generates three repeated time-based data series in miles per gallon (MPG). The average fuel consumption on each section was calculated based on each three data sets. Then the units were converted to gallons per hundred miles (GPHM) by Equation 3.1.

$$
G P H M=\frac{100}{M P G}
$$

There were a few overpasses (less than 2) in each section. In order to exclude the impact of roadway gradient on fuel consumption, data filtering was employed to the data sets. The fuel outliers in each data set were identified and eliminated statistically. This was based on the assumption that the fuel rates when passing through overpasses were either extremely low (uphill) or high (downhill) compared to flat terrains. Figure 3.10 can be a fair proof of this assumption. As a result, the fuel data corresponding to roadway overpasses were discarded. Constant roadway grade can be assumed for each section. Finally, fuel rates of each section were averaged in each bound for future statistical analysis. Table 3.5 and 3.6 summarizes the fuel data from passenger car test and truck test respectively. 


\subsection{STATISTICAL ANALYSIS}

\subsubsection{Passenger Car Test}

\subsubsection{Average Fuel Consumption Differences}

As noted in "Data Processing" section, fuel consumption in gallons per hundred miles (GPHM) was calculated separately for southbound sections and the northbound section.

As shown in Table 3.5 and 3.6, there are considerable fuel consumption differences

Table 3.5 Passenger Car Test Results (GPHM)

\begin{tabular}{|c|c|c|c|c|c|c|c|}
\hline Site & Test & NB_Flex. & SB_Flex. & Ave._Flex. & NB_Rigid & SB_Rigid & Ave.RRigid \\
\hline \multirow{5}{*}{ Site I } & Ist & 3.24 & 2.94 & 3.09 & 3.16 & 2.81 & 2.99 \\
\cline { 2 - 8 } & 2nd & 2.71 & 3.00 & 2.85 & 2.70 & 2.87 & 2.78 \\
\cline { 2 - 8 } & 3rd & 3.08 & 3.49 & 3.28 & 3.08 & 3.27 & 3.18 \\
\cline { 2 - 8 } & 4th & 3.50 & 3.27 & 3.39 & 3.59 & 3.16 & 3.38 \\
\cline { 2 - 8 } & 5th & 3.60 & 3.52 & 3.56 & 3.58 & 3.50 & 3.54 \\
\cline { 2 - 8 } & 6th & 3.20 & 3.61 & 3.41 & 3.13 & 3.50 & 3.32 \\
\cline { 2 - 8 } & 7th & 3.25 & 3.76 & 3.51 & 3.16 & 3.64 & 3.40 \\
\cline { 2 - 8 } & 8th & 3.33 & 3.23 & 3.28 & 3.23 & 3.21 & 3.22 \\
\hline \multirow{5}{*}{ Site II II } & 1st & 3.11 & 3.19 & 3.15 & 3.03 & 2.91 & 2.97 \\
\cline { 2 - 8 } & 2nd & 3.29 & 3.27 & 3.28 & 3.02 & 3.22 & 3.12 \\
\cline { 2 - 8 } & 3rd & 3.18 & 3.11 & 3.14 & 3.32 & 2.83 & 3.08 \\
\cline { 2 - 8 } & 4th & 3.12 & 3.58 & 3.35 & 3.12 & 3.56 & 3.34 \\
\cline { 2 - 8 } & 5th & 3.27 & 3.40 & 3.34 & 3.20 & 3.34 & 3.27 \\
\cline { 2 - 8 } & 6th & 3.24 & 3.45 & 3.35 & 3.22 & 3.42 & 3.32 \\
\hline
\end{tabular}

Table 3.6 Truck Test Results (GPHM)

\begin{tabular}{|c|c|c|c|c|c|c|c|}
\hline Site & Test & NB_Flex. & SB_Flex. & Ave._Flex. & NB_Rigid & SB_Rigid & Ave._Rigid \\
\hline \multirow{4}{*}{ Site I I } & 1st & 11.90 & 13.81 & 12.85 & 11.66 & 12.99 & 12.33 \\
\cline { 2 - 8 } & 2nd & 13.64 & 15.15 & 14.39 & 13.54 & 13.97 & 13.75 \\
\cline { 2 - 8 } & 3rd & 12.86 & 15.09 & 13.98 & 12.75 & 14.10 & 13.42 \\
\cline { 2 - 8 } & 4th & 13.96 & 14.98 & 14.47 & 14.02 & 13.98 & 14.00 \\
\hline
\end{tabular}




\begin{tabular}{|l|l|l|l|l|l|l|l|}
\hline & 5th & 13.39 & 15.07 & 14.23 & 13.20 & 14.17 & 13.68 \\
\cline { 2 - 7 } & 6th & 11.92 & 16.27 & 14.10 & 11.38 & 15.77 & 13.57 \\
\hline
\end{tabular}

between northbound and southbound. The main cause of these difference is the wind effect. In order to exclude the wind effect and exam the fuel difference purely resulted from the pavement type, the average fuel consumptions between northbound FC and southbound FC were calculated. Based on the average fuel consumptions, the percentage differences in each test session can be determined by dividing the absolute difference over rigid pavement FC. Table 3.7 summarizes the differences for the passenger car test and the truck test. Results show that there were $2.24 \%$ fuel saving on rigid pavement compared to flexible pavement for passenger car on test site I. Same saving was found as 2.76\% on test site II. Combine the two sites results, we can conclude that the passenger car consumes an average of $2.50 \%$ more fuel on flexible pavement compared to the rigid pavement.

Table 3.7 Passenger Car FC Percentage Difference

\begin{tabular}{|c|c|c|c|c|c|c|c|c|c|}
\hline \multirow{2}{*}{ Car Test } & \multicolumn{8}{|c|}{ FC Differences Divided by Rigid Pavement FC } \\
\cline { 2 - 10 } & $\mathbf{1}^{\text {st }}$ & $\mathbf{2}^{\text {nd }}$ & $\mathbf{3}^{\text {rd }}$ & $\mathbf{4}^{\text {th }}$ & $\mathbf{5}^{\text {th }}$ & $\mathbf{6}^{\text {th }}$ & $\mathbf{7}^{\text {th }}$ & $\mathbf{8}^{\text {th }}$ & Average \\
\hline Site I & $3.47 \%$ & $2.45 \%$ & $3.40 \%$ & $0.32 \%$ & $0.63 \%$ & $2.73 \%$ & $3.01 \%$ & $1.92 \%$ & $2.24 \%$ \\
\hline Site II & $6.02 \%$ & $5.17 \%$ & $2.10 \%$ & $0.32 \%$ & $2.20 \%$ & $0.74 \%$ & N/A & N/A & $2.76 \%$ \\
\hline \multicolumn{10}{|c|}{ Average \% Difference } \\
\hline
\end{tabular}

\subsubsection{Paired T-test}

Statistical test was carried out to detect if the fuel consumption differences are statistically significant. Paired t-test was applied to compare the mean of flexible pavement fuel consumption and rigid pavement fuel consumption for all tests. Paired t- 
test is a pairwise test used when comparing two sets of measurements to assess whether the means are statistically different. It was used herein as a statistical tool for hypothesis testing purposes in comparing fuel consumption differences between the two pavement types. The data were tested at a 95\% confidence level (C.L.) in order to obtain statistically meaningful conclusions. The hypothesis of the paired t-test is:

$$
\begin{aligned}
& \mathrm{H}_{0}: \mathrm{u} 1=\mathrm{u} 2 \\
& \mathrm{H}_{\mathrm{a}}: \mathrm{u} 1>\mathrm{u} 2 \\
& \text { Where: } \mathrm{u} 1 \text { = the mean car fuel consumption on flexible pavement (GPHM) } \\
& \qquad \mathrm{u} 2 \text { = the mean car fuel consumption on rigid pavement (GPHM) }
\end{aligned}
$$

Before performing the paired t-test, the normality of the fuel differences (flexible minus rigid) was checked by Shapiro Test and visualized through histogram. Resulted pvalue from Shapiro Test equals to 0.346 (greater than 0.05 ), which indicate sound data normality assumption. The histogram also showed the same conclusion. Paired t-test was then carried out through statistical program "R". The resulted low p-value $(9.254 \mathrm{e}-$ $05<<0.05$ ) indicated that the fuel consumption difference was statistically significant at a 95\% C.L.

The 95\% confidence interval (C.I.) of the percentage differences were also calculated. The lower and upper percentage differences were calculated by dividing the lower and upper C.I. limits over the mean rigid fuel consumption. Conclusion can be drawn that under the test condition for passenger car, there was a 95\% possibility that the interval of $1.47 \%$ to $3.34 \%$ contained the true fuel consumption difference between flexible pavement and rigid pavement, with a less fuel consumption on the rigid pavement. Table 3.8 summarizes the results of the paired t-test. 


\subsubsection{Truck Test}

\subsubsection{Average Fuel Consumption Differences}

Similarly, the fuel consumption differences of the truck test were also calculated.

Table 3.9 summarizes the results. From the table, we can conclude that tractor-trailer consumed an average of $4.04 \%$ more fuel on flexible pavement compared to rigid pavement.

Table 3.8 Passenger Car Paired T-test Results

\begin{tabular}{|c|c|c|c|c|c|c|}
\hline \multirow{4}{*}{$\begin{array}{l}\text { Flexible } \\
\text { minus } \\
\text { Rigid }\end{array}$} & \multicolumn{3}{|c|}{ Paired Differences } & \multirow{3}{*}{$\mathbf{t}$} & \multirow{3}{*}{ df } & \multirow{3}{*}{$\begin{array}{c}\text { p-value } \\
\text { (two way) }\end{array}$} \\
\hline & \multirow[b]{2}{*}{ Mean } & \multicolumn{2}{|c|}{ 95\% C.I. of FC Diff. } & & & \\
\hline & & $\begin{array}{l}\text { Lower } \\
\text { Diff. }\end{array}$ & $\begin{array}{c}\text { Upper } \\
\text { Diff. }\end{array}$ & & & \\
\hline & 0.077 & 0.047 & 0.107 & 5.558 & 13 & $9.254 \mathrm{e}-05$ \\
\hline \multicolumn{7}{|c|}{ Percentage Differences } \\
\hline $\begin{array}{l}\text { Mean of } \\
\text { Flexible }\end{array}$ & 3.284 & Lower \% & Upper \% & \multirow{2}{*}{\multicolumn{3}{|c|}{$\begin{array}{l}* \text { Calculation based on } 95 \% \text { C.I. of FC } \\
\text { differences over the mean fuel consumption of } \\
\text { rigid pavement }\end{array}$}} \\
\hline $\begin{array}{c}\text { Mean of } \\
\text { Rigid }\end{array}$ & 3.207 & $1.47 \% *$ & $3.34 \% *$ & & & \\
\hline
\end{tabular}

Table 3.9 Truck FC Percentage Difference

\begin{tabular}{|c|c|c|c|c|c|c|c|}
\hline \multirow{2}{*}{ Truck Test } & \multicolumn{7}{|c|}{ FC Differences Divided by Rigid Pavement FC } \\
\cline { 2 - 8 } & $\mathbf{1}^{\text {st }}$ & $\mathbf{2}^{\text {nd }}$ & $\mathbf{3}^{\text {rd }}$ & $\mathbf{4}^{\text {th }}$ & $\mathbf{5}^{\text {th }}$ & $\mathbf{6}^{\text {th }}$ & Average \\
\hline Site I & $4.28 \%$ & $4.65 \%$ & $4.13 \%$ & $3.36 \%$ & $3.99 \%$ & $3.85 \%$ & $4.04 \%$ \\
\hline
\end{tabular}

\subsubsection{Paired T-test}

Same as the passenger car test, normality of the FC difference (flexible minus

rigid) was first evaluated through Shapiro test and histogram. The p-value from Shapiro Test was 0.521 (greater than 0.05), which validated the distribution normality 
assumption. Histogram plot also showed the same conclusion. The hypothesis of the truck paired t-test is:

$\mathrm{H}_{0}: \mathrm{u} 1=\mathrm{u} 2$

$\mathrm{H}_{\mathrm{a}}: \mathrm{u} 1>\mathrm{u} 2$

Where: $\mathrm{u} 1$ = the mean truck fuel consumption on flexible pavement (GPHM)

$$
\mathrm{u} 2=\text { the mean truck fuel consumption on rigid pavement (GPHM) }
$$

Paired t-test was then performed to the truck fuel data and the yielded small pvalue $(2.321 \mathrm{e}-06<<0.05)$ indicated that the truck fuel consumption difference was also statistically significant at a 95\% C.L. Table 3.10 summarizes the results. It can be concluded that there is a $95 \%$ possibility that the interval of $3.61 \%$ to $4.47 \%$ contains the true truck FC difference between flexible pavement and rigid pavement, with a less fuel consumption on rigid pavement.

Table 3.10 Truck Paired T-test Results

\begin{tabular}{|c|c|c|c|c|c|c|}
\hline \multirow{4}{*}{$\begin{array}{c}\text { Flexible } \\
\text { minus } \\
\text { Rigid }\end{array}$} & \multicolumn{3}{|c|}{ Paired Differences } & \multirow{3}{*}{$\mathbf{t}$} & \multirow{3}{*}{ df } & \multirow{3}{*}{$\begin{array}{c}\text { p-value } \\
\text { (two-way) }\end{array}$} \\
\hline & \multirow{2}{*}{ Mean } & \multicolumn{2}{|c|}{ 95\% C.I. of FC Diff. } & & & \\
\hline & & Lower Diff. & Upper Diff. & & & \\
\hline & 0.544 & 0.486 & 0.602 & 24.038 & 5 & 2.321e-06 \\
\hline \multicolumn{7}{|c|}{ Percentage Differences } \\
\hline $\begin{array}{l}\text { Mean of } \\
\text { Flexible }\end{array}$ & 14.003 & Lower \% & Upper \% & \multirow{2}{*}{\multicolumn{3}{|c|}{$\begin{array}{l}\text { * Calculation based on 95\% C.I. of } \\
\text { FC differences over the mean fuel } \\
\text { consumption of rigid pavement }\end{array}$}} \\
\hline $\begin{array}{c}\text { Mean of } \\
\text { Rigid }\end{array}$ & 13.459 & $3.61 \% *$ & $4.47 \% *$ & & & \\
\hline
\end{tabular}

\subsection{CONCLUSION AND DISCUSSION}

The Phase I field study implemented repeated fuel measurements by operating passenger car and tractor-trailer on two pairs of flexible-rigid highway sections in 
Florida. Measurements were conducted on double traveling direction and average fuel consumptions were calculated on each test. Statistical comparisons were applied to the results between flexible pavement and rigid pavement. It was found that the average fuel consumption differences between flexible pavement and rigid pavement are $4.04 \%$ for tractor-trailer and $2.50 \%$ for passenger car, both with a less fuel consumption on rigid pavement. Fuel savings on rigid pavement were tested statistically significant at $95 \%$ confidence level (C.L.) for all comparisons. The 95\% confidence bounds of the percentage differences were also computed for each vehicle type, with $1.47 \%$ to $3.34 \%$ for passenger car and $3.61 \%$ to $4.47 \%$ for the tractor-trailer.

There are two potential causes of the fuel differences: pavement stiffness (deflection) and surface texture. Both of two factors are the major differences between the flexible pavement and rigid pavement tested in the study. The higher layer stiffness (modulus) of the rigid pavement compared to the flexible pavement lead to a larger pavement deflection on flexible pavement surface than on rigid pavement surface with the same amount of traffic load. The larger surface deflection on flexible pavement surface causes vehicle tires constantly traveling on steeper "hill" compared to tires on the rigid pavement surface. This results a higher fuel consumption for vehicle traveling on flexible pavement than flexible pavement with other variables remain the same. Meanwhile, the heavier the vehicle weight, the more significant the effect. This was approved by the higher fuel differences detected on tractor-trailer than the passenger car.

The second cause of the fuel difference is the different texture levels between these two pavement surfaces. Higher texture depth can result in a more significant interaction between pavement surface and vehicle suspension system, which lead to extra 
energy consumption and fuel consumption consequently. Although the texture data on the test sections was not available, due to the material characteristics of the pavement surface layer, the texture depth on flexible pavement section is normally more than twice of the texture on rigid pavement sections. Thus, the higher texture depth on flexible pavement surface is the second potential cause of the fuel consumption difference.

Pavement surface texture (macrotexture) has been a partially desired and partially undesired pavement property. Short macrotexture waves, around $5 \mathrm{~mm}$, can act as acoustical pores in pavement surface and reduce type noise significantly. It also provides wet road friction especially in high speeds roadways. However, excessive texture may increase vehicle rolling resistance and thus fuel consumption and $\mathrm{CO}_{2}$ emission which contributing to global warming. Thus, it is essential to balance the disadvantage and advantages of pavement texture among different aspects to ensure a sustainable roadway system. 


\section{CHAPTER 4}

\section{PHASE II FIELD STUDY}

\subsection{INTRODUCTION}

The Phase I Filed study is basically a preliminary study on direct fuel comparison between paired flexible-rigid pavement sections. The initiation and objective of the Phase II field study is to independently investigate the effect of pavement type on fuel consumption with a more comprehensive and detailed experimental design. The variables that are targeted in this study are pavement type (flexible pavement group and rigid pavement group), pavement surface roughness (International Roughness Index (IRI)), and pavement temperature. The flexible pavement and rigid pavement is differentiated primarily in pavement material, structural component, and surface macrotexture. Again two vehicle classes are aimed at studying: passenger car and truck. Two highway speed levels are designed for each vehicle experiment.

\subsection{FIELD EXPERIMENT}

\subsubsection{Roadway Sections}

Two series of tests were designed and performed separately for passenger car and truck respectively. A total of 13 roadway sections (6 flexible and 7 rigid) were selected for the passenger car test and 10 sections ( 5 flexible and 5 rigid) were selected for the truck test. All sections are interstate highway sections (one exception in car test) located in Florida. Since the passenger car test was designed and performed ahead of the truck test, the truck test sections were the refined/expanded selections of the car test sections. All sections have a minimal of 1-mile center lane length. 
One of the essential criteria for the section selection was that each section must locate in a flat terrain with no bridges or overpasses inside. This was intended to exclude the potential influence of roadway gradient on the experiment results. Another effort that was made to eliminate the gradient effect was to perform a double direction test and average the fuel data on both traveling direction, instead of utilizing data from a single traveling direction. Such experimental design also excluded the disturbance of wind effect since each section was tested in a short period (wind velocity and direction were barely changed). Figure 4.1 and Figure 4.2 shows the locations for passenger car test and truck test respectively.

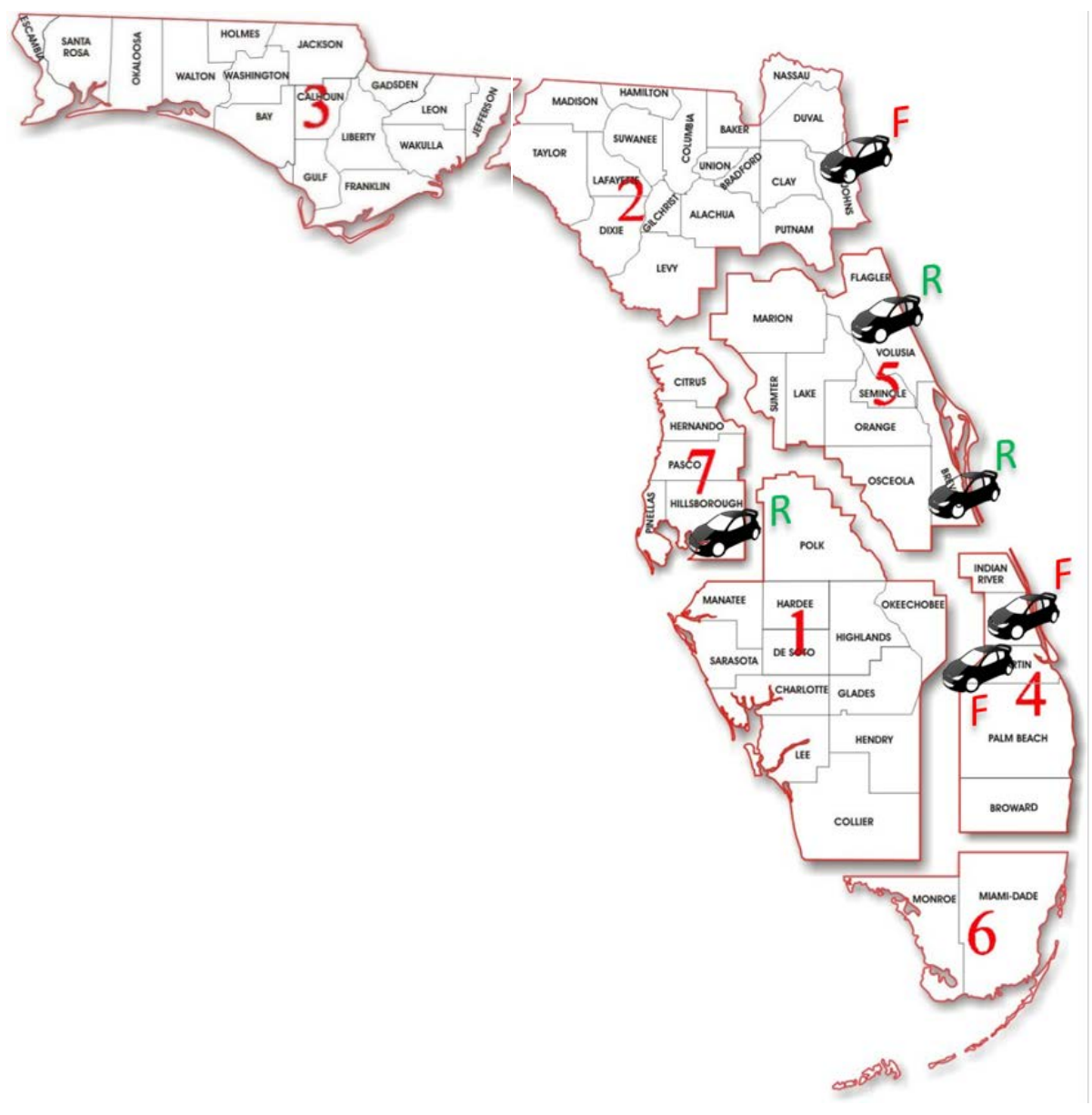

Figure 4.1 Phase II Passenger Car Test Locations 


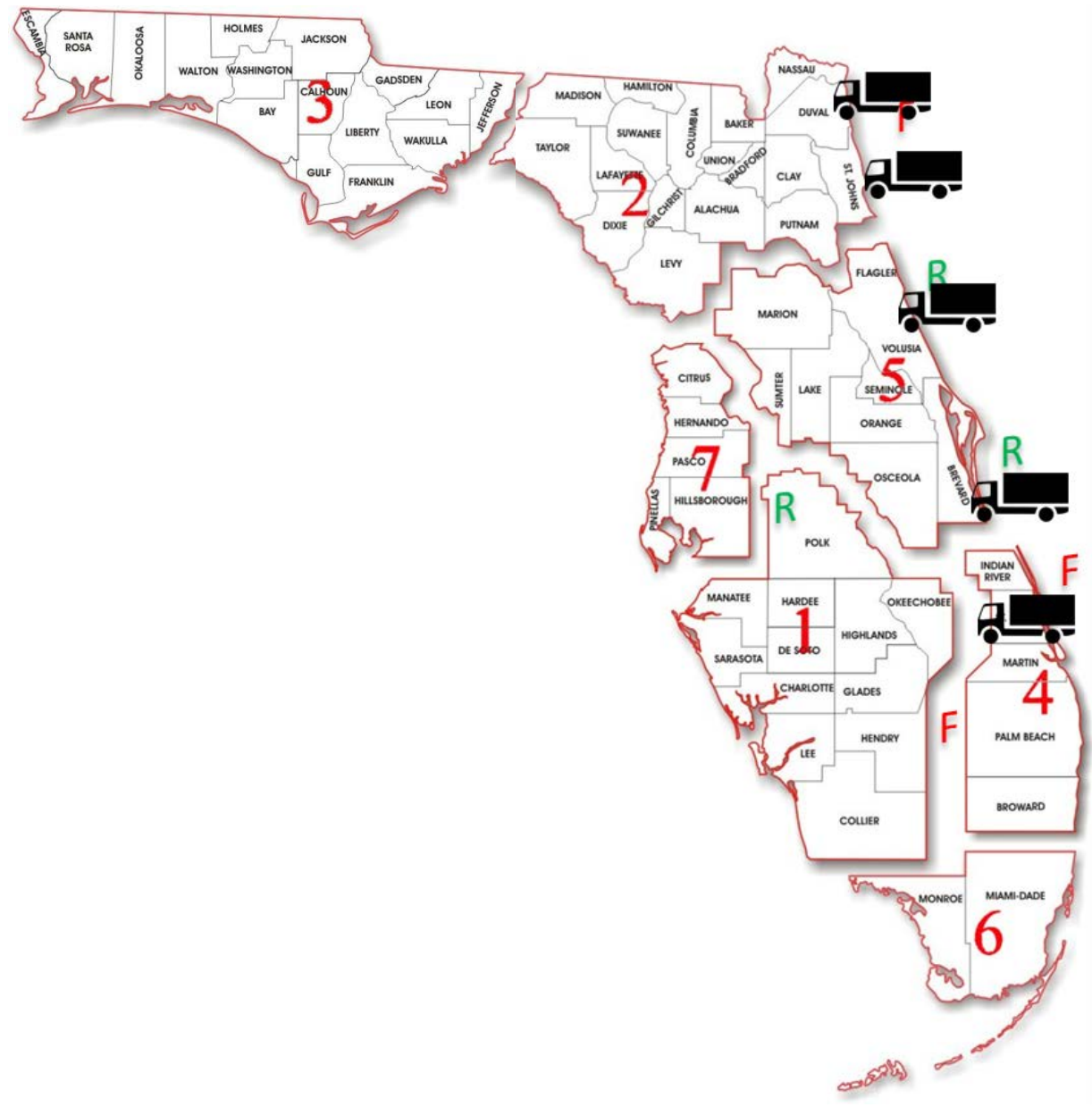

Figure 4.2 Phase II Truck Test Locations

Information of each section such as county, roadway ID, section mile-marker, pavement surface layer thickness, roughness (IRI ranges), texture (in mean profile depth) were gathered before the test. Not all sections have the texture data since the Florida Department of Transportation (FDOT) collects the texture only upon request and thus has a limited texture inventory. Table 4.1 shows the test matrix. 


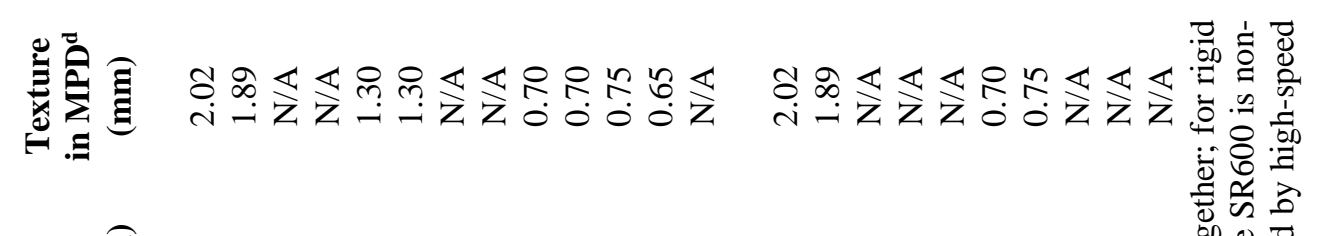
폴

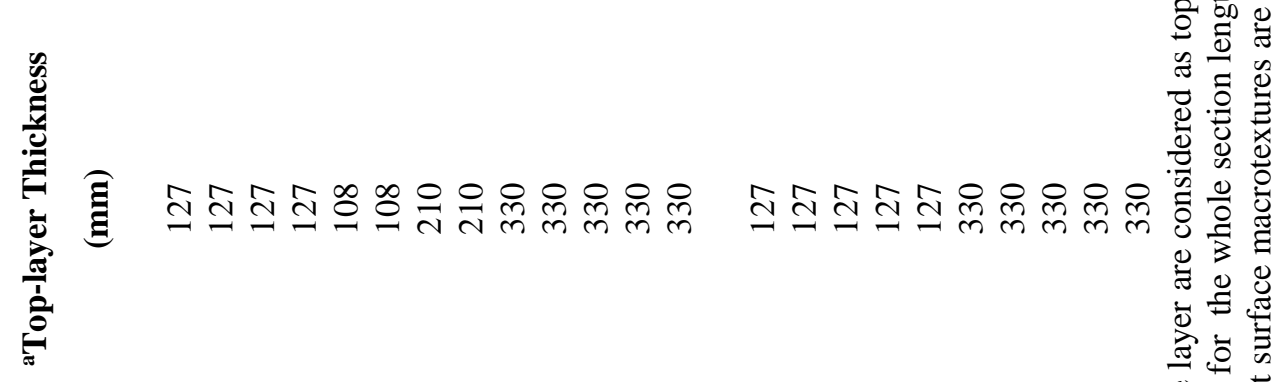

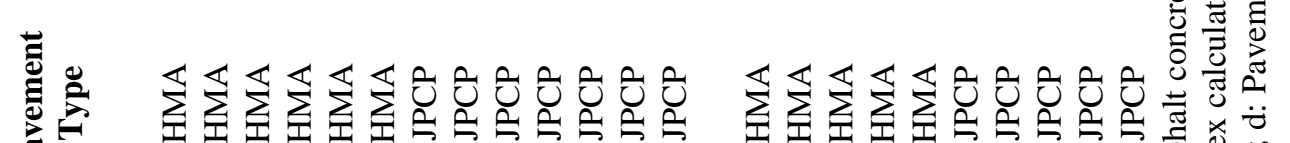

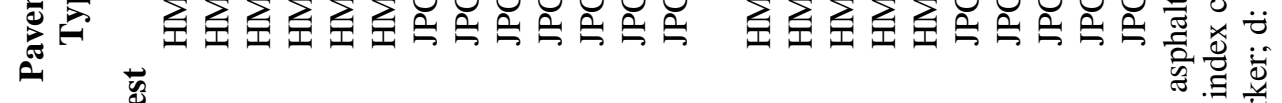

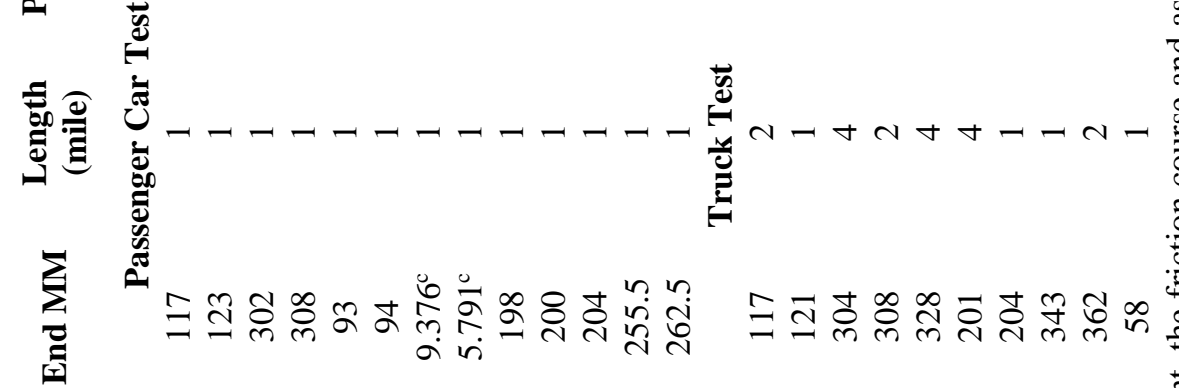

差 䒕包 丽

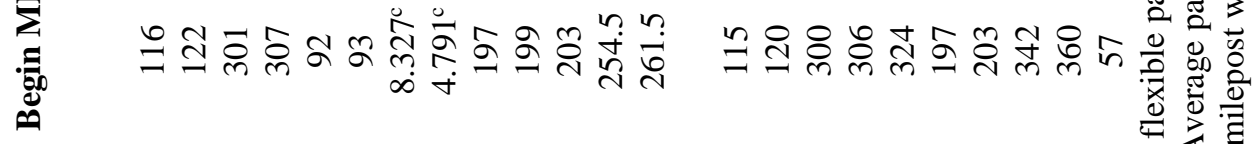

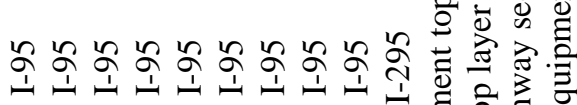


Figure 4.3 shows the structural components and their corresponding thicknesses for the typical pavements constructed in Florida's interstate highway system (left-half for flexible pavement and right-half for rigid pavement).

\section{Flexible Pavement Rigid Pavement}

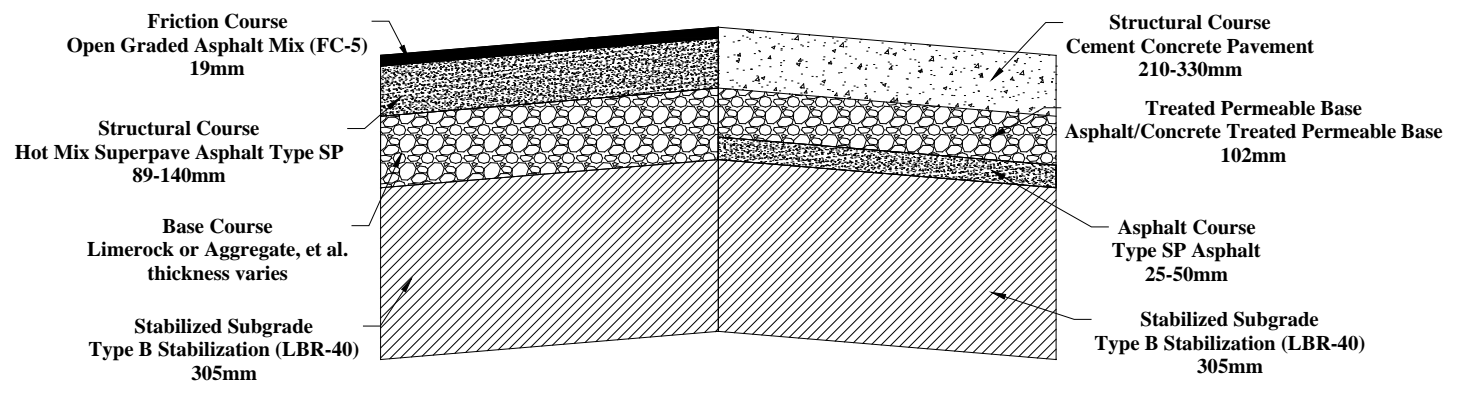

Figure 4.3 Typical Layers in Florida’s Interstate Pavement

The flexible pavement and rigid pavement are differentiated mainly in three aspects: pavement material, structural component, and surface macrotexture. The structural course of flexible pavement is made of hot mix Superpave asphalt with a typical depth between 89 and 140mm. The primary load bearing layer of rigid pavement is composed of concrete slab with a minimum thickness of $210 \mathrm{~mm}$. The differentiations in load bearing material and thickness between this two pavements lead to the differences in pavement overall stiffness and surface deflection under the wheels. On the other hand, the open graded asphalt surface course in flexible pavement predominately uses coarse aggregate within the mix design and only small amount of fine materials. The large voids asphalt layer provides rapid water removal capability and high skid resistance for the flexible pavement. But it causes a higher surface macrotexture level compared to a concrete surface. Proofs can be found in Table 4.1 that the average texture in mean 
profile depth (MPD) for the flexible sections (that are available) is $1.74 \mathrm{~mm}$, but the average for rigid pavement sections is much lower at $0.71 \mathrm{~mm}$. Thus, the distinctions in pavement stiffness (or deflection under loads) and surface macrotexture make up the differences between flexible pavement and rigid pavement tested in this study.

\subsubsection{Testing Vehicles}

A 2014 Chevrolet Cruze was used for the passenger car test. The car is equipped with a 1.4 liters I-4 Turbo (138hp) Engine and had a curb weight of 1414kg (3118pound). The tire model was Continental ContiProContact P225/50R with 0.43m (17in) rim diameter and in radial construction. Tire pressure was examined and adjusted to $0.24 \mathrm{MPa}$ (35psi) before each test. The gas tank was also fully filled in order to maintain a constant vehicle weight (wheel loads). Regular gasoline (U.S. \#87) was used for the car engine. Figure 4.4 displays the passenger car used in the study.

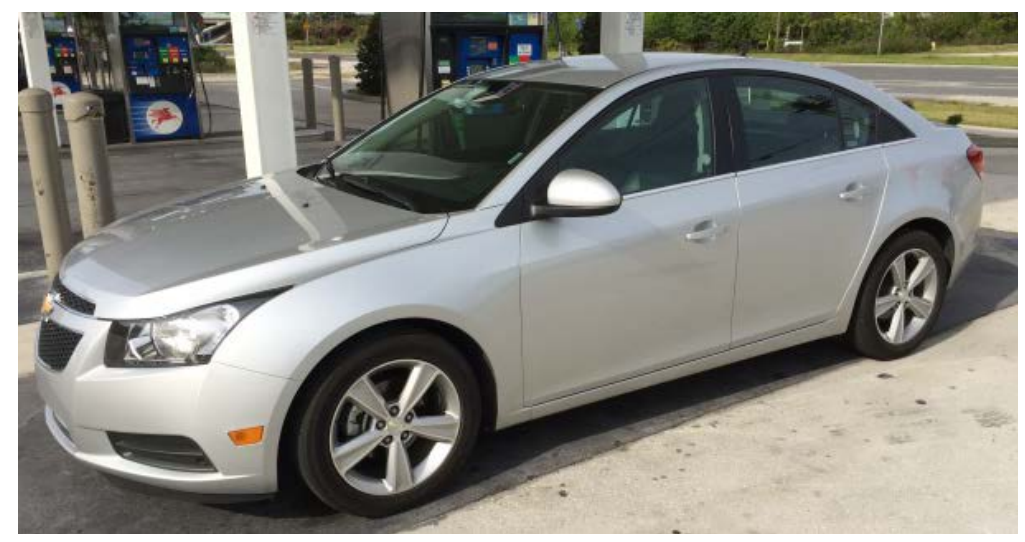

Figure 4.4 Phase II Passenger Car 
The truck used in this study was a 2-axle 2011 International 4300 diesel truck with a $26 \mathrm{ft}$ long cargo box. Figure 4.5 shows the truck used in the study.

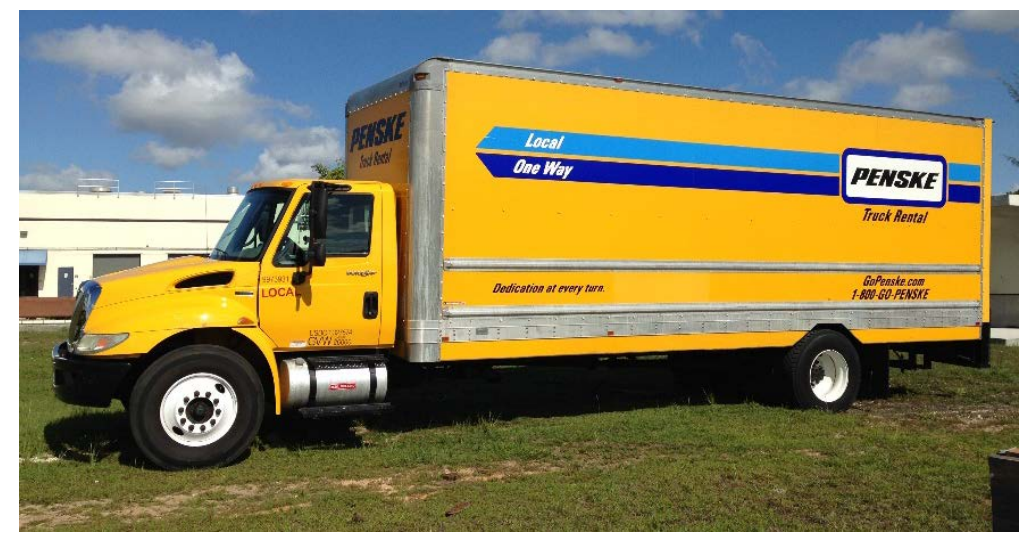

Figure 4.5 Phase II Truck

The truck was equipped with a 7.6L inline-6 International Durastar MaxxForce DT diesel engine with rated power between $157 \mathrm{~kW}$ and $190 \mathrm{~kW}$. The two tires of the front axle were Bridgestone Ecopia R268 with 1.05m (41.5in) wheel diameter and in radial construction. The four rear tires were Continental 11R22.5 with the same wheel diameters and construction as the front tires. Tire pressures were set to 0.72Mpa (105psi) as the manufactory recommended and remained unadjusted throughout the tests. Regular diesel fuel was used for the truck engine. The gross vehicle weight (GVW) of the truck is $11,792 \mathrm{~kg}(25,999 \mathrm{lbs})$ and the curb vehicle weight is $6,994 \mathrm{~kg}(15,420 \mathrm{lbs})$. A concrete block (4ft x 4ft x 3ft) was loaded into the cargo box approximately above the rear axle before the test (Figure 4.6). Small wood blocks were used to stabilize the concrete in the horizontal direction (Figure 4.7). There is no constraint in the longitudinal direction. After the test, the concrete was found moved approximately $0.15 \mathrm{~m}$ (6in) in the 
longitudinal direction. The total weight of the truck with full fuel tank was measured at highway weight station as $10,614 \mathrm{~kg}(23,400 \mathrm{lbs})$.

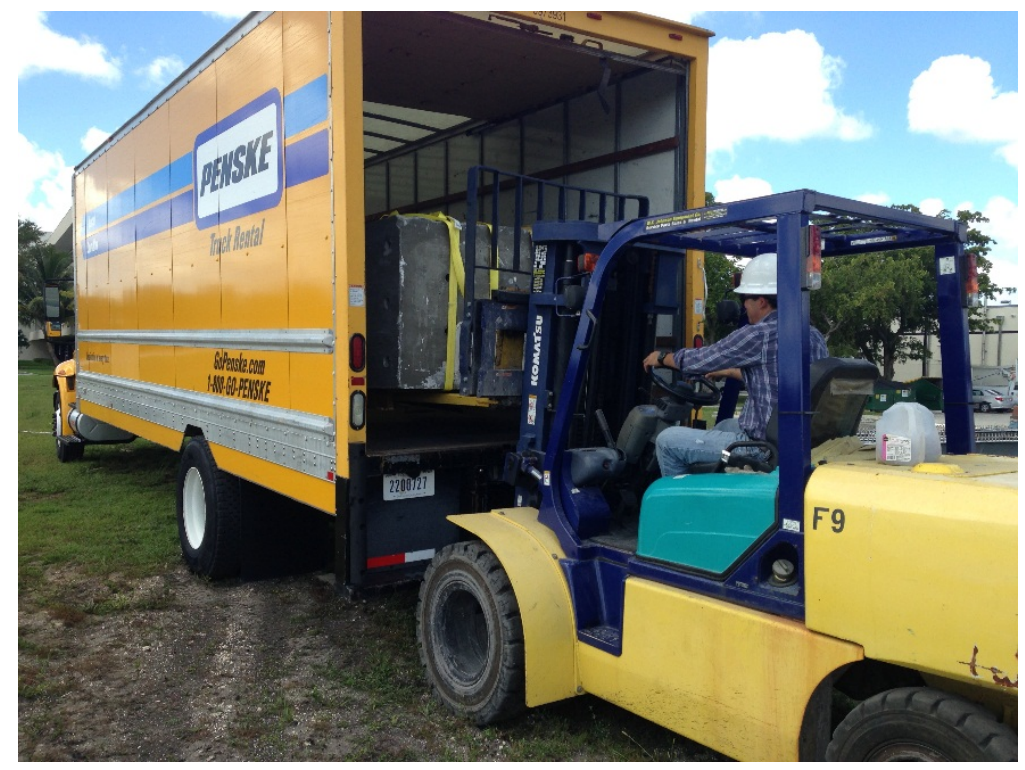

Figure 4.6 Truck Load

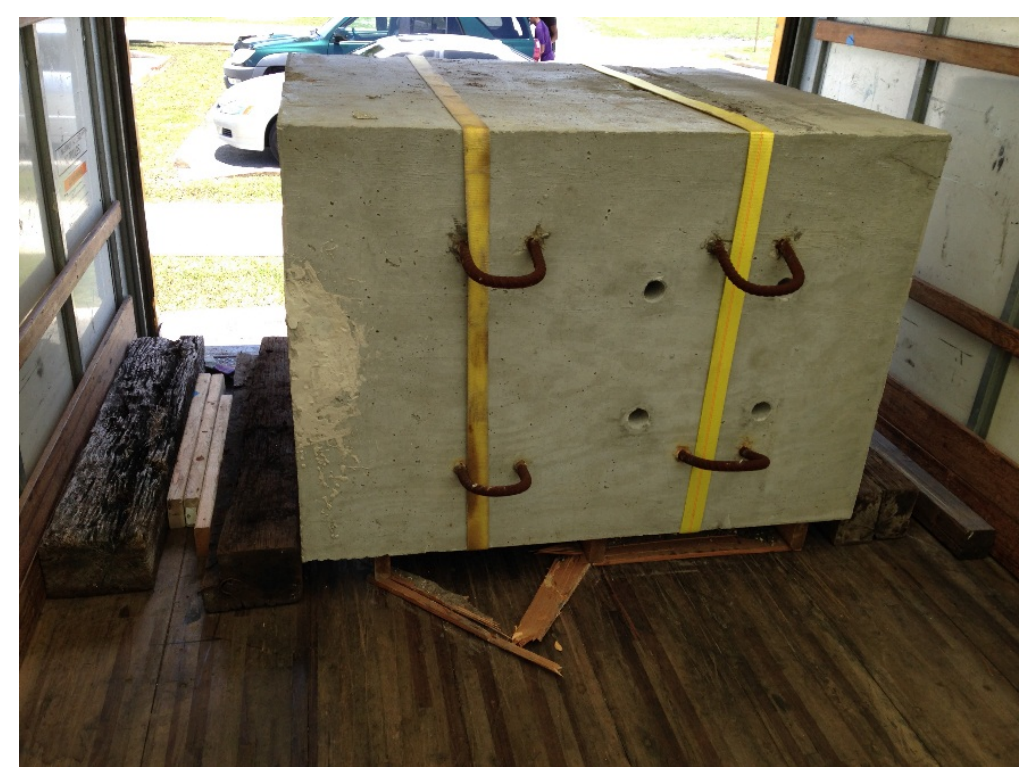

Figure 4.7 Concrete Horizontal Constraints 
All tests were conducted with the same driver and data collection personnel. Air condition, rain-wipers, and radio were turned off during the tests and lights were set to "Auto".

\subsubsection{Data Collections}

\subsubsection{Data Collection Devices}

For passenger car test, an On-Board Diagnostic (OBD) device made by AUTOENGINUITY®, L.L.C. was used to collect the data at a speed of 5 readings per second. One end of the OBD device was connected to the vehicle OBD port located under the driver steering wheel and another end to a laptop for test operation and data displaying. Figure 4.8 displays the passenger car OBD device. Figure 4.9 shows the passenger car test data recording.

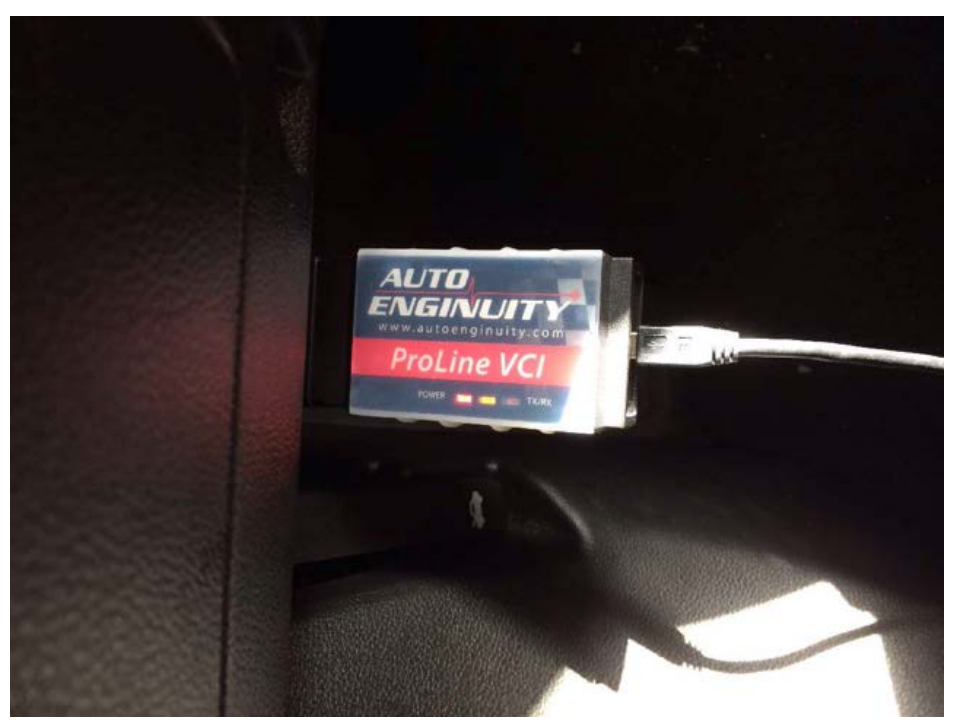

Figure 4.8 Phase II Passenger Car OBD Device 


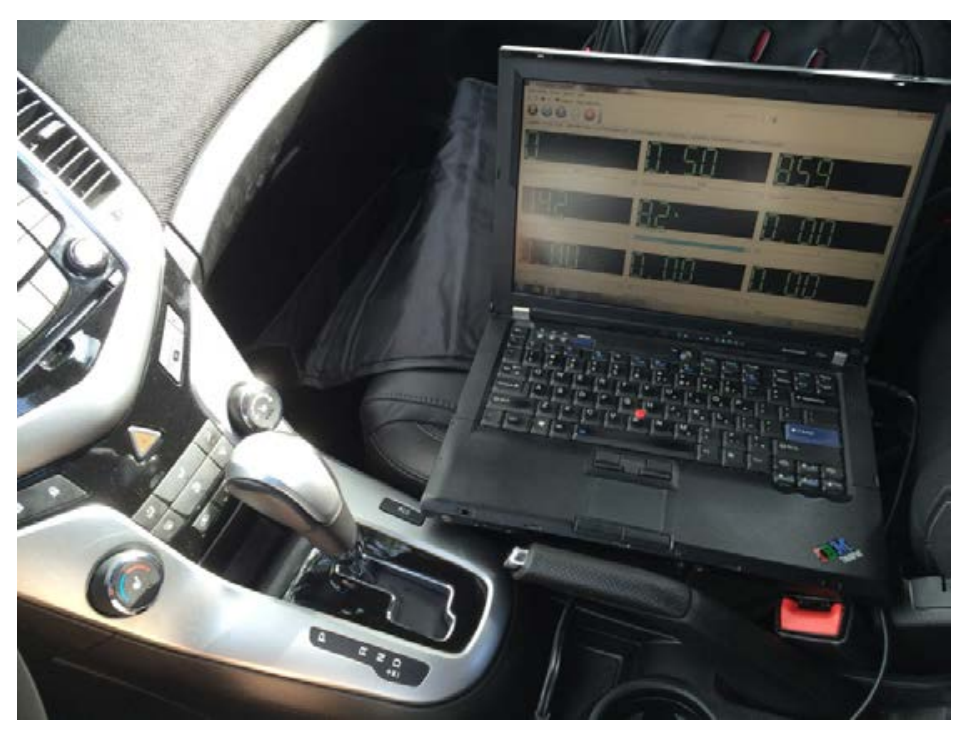

Figure 4.9 Phase II Passenger Car Test Data Recording

The instantaneous data collected during the tests were mass air flow rate (MAF) (lb/min), speed and engine speed. The instantaneous fuel rates were then calculated from Equation 4.1 with the input of mass air flow rate and vehicle speed. The formula works very well in modern automobiles owe to the fact that the engine computer spends almost 100 percent of its time managing the fuel-air-ratio to 14.7 owe to the "close loop" feedback from $\mathrm{O}_{2}$ sensor(s) (Lightner, 2004). This methodology has also been applied by other engineers and researchers for fuel measurements (Chatti \& Zaabar, 2012).

$$
\mathrm{MPG}=(14.7 \times 6.17 \times \mathrm{VSS}) /(60 \times \mathrm{MAF})=1.5 \times \mathrm{VSS} / \mathrm{MAF}
$$

Where MPG is the vehicle fuel consumption in miles per gallon Peng is the vehicle speed in miles per hour MAF is the vehicle mass air flow rate in pounds per minute

The data collection device used for the truck test was a NEXIQ USB Link Model 125032 and the compatible software was International Navistar ServiceMaxx Fleet Pro. 
The truck device was able to measure and record the instantaneous fuel rate directly in gallons per second. The data recording rate was 5 readings per second. Instantaneous vehicle speed in mph and engine speed in RPM were also collected during the test. Figure 4.10 displays the truck OBD device. Figure 4.11 shows truck test data recording.

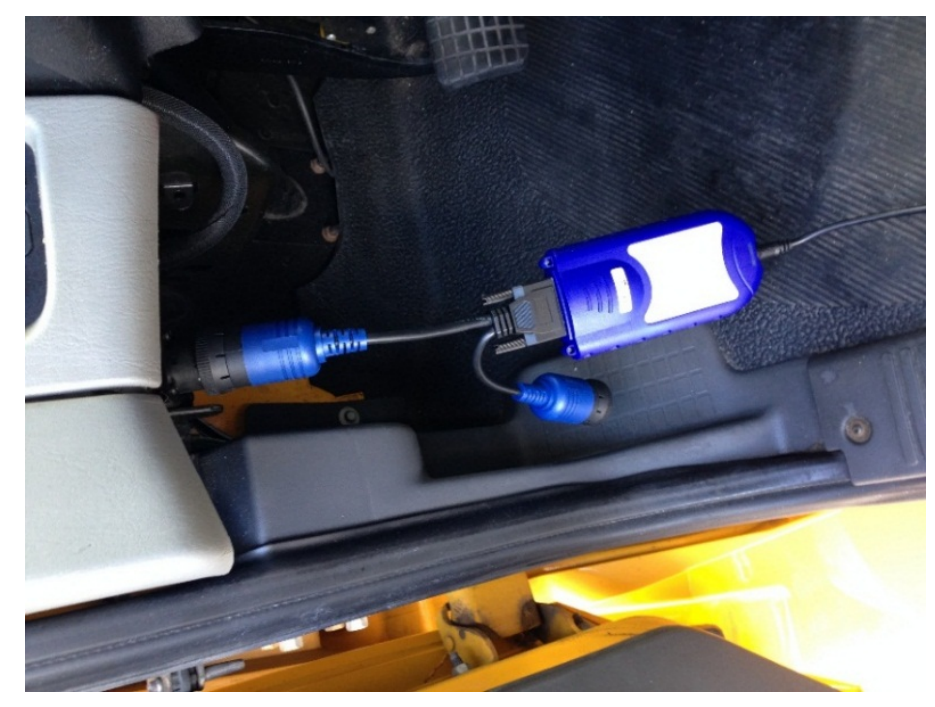

Figure 4.10 Phase II Truck OBD Device

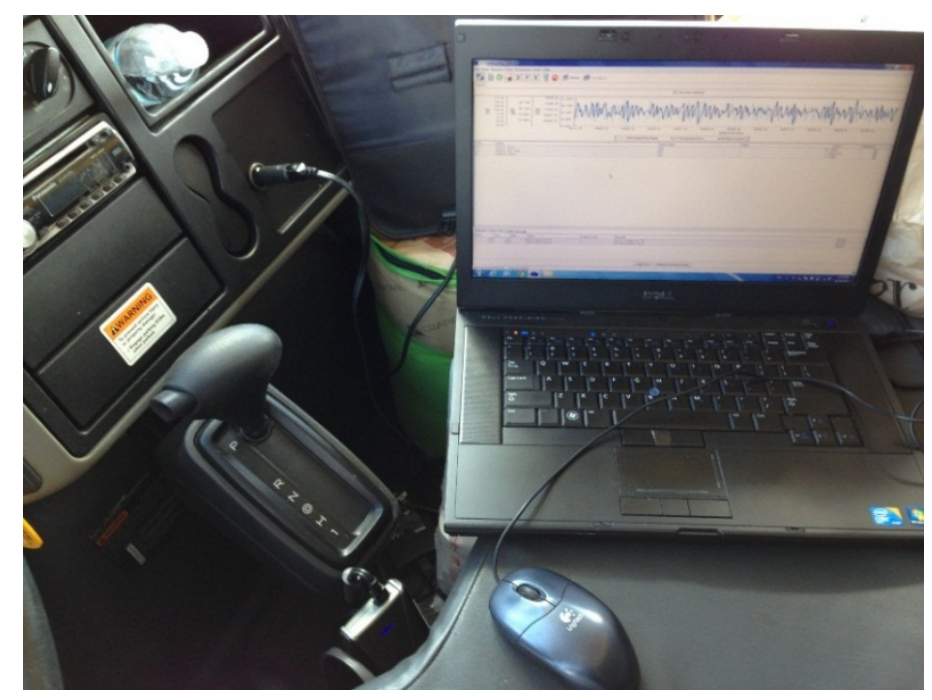

Figure 4.11 Phase II Truck Test Data Recording 


\subsubsection{Data Collection}

Each section was driven two consecutive runs from both traveling directions (northbound/eastbound or southbound/westbound). Two constant speeds were applied for each vehicle type: $93 \mathrm{~km} / \mathrm{h}(58 \mathrm{mph})$ and $112 \mathrm{~km} / \mathrm{h}$ (70mph) for passenger car and $89 \mathrm{~km} / \mathrm{h}(55 \mathrm{mph})$ and $105 \mathrm{~km} / \mathrm{h}(65 \mathrm{mph})$ for truck. The speeds were selected to simulate the lower and higher highway speed conditions, but were suitable for safely driving as well. Experiments were not affected by the traffic flow: no brakes and accelerations were engaged during the data recording sessions. The constant vehicle speeds were assured by the vehicle cruise control function. Data recording was manually operated by data collection personnel: start recording when passing the begin mile marker (BMM) and stop recording at the point of end mile marker (EMM). The experiment was only conducted under dry roadway surface condition. This was intended to exclude the influence of wet surface on the experiment results. All tests were performed at the most outside lane in each traveling direction.

In order to assure a sound test repeatability, the experiment was carefully defined and controlled. Sample data repeatability curves are shown in Figure 4.12. The figure shows the data collected on section CR1 at $93 \mathrm{~km} / \mathrm{h}$. The curves indicate high test repeatability.

In addition, other important pavement/environment information was measured and recorded during the tests. Pavement surface temperatures were measured with an infrared heat gun in ${ }^{\circ} \mathrm{F}$; ambient temperature $\left({ }^{\circ} \mathrm{F}\right)$ and wind speed/direction (mph) were collected using an anemometer. The environmental information is summarized in Table 4.2 and 4.3 . 


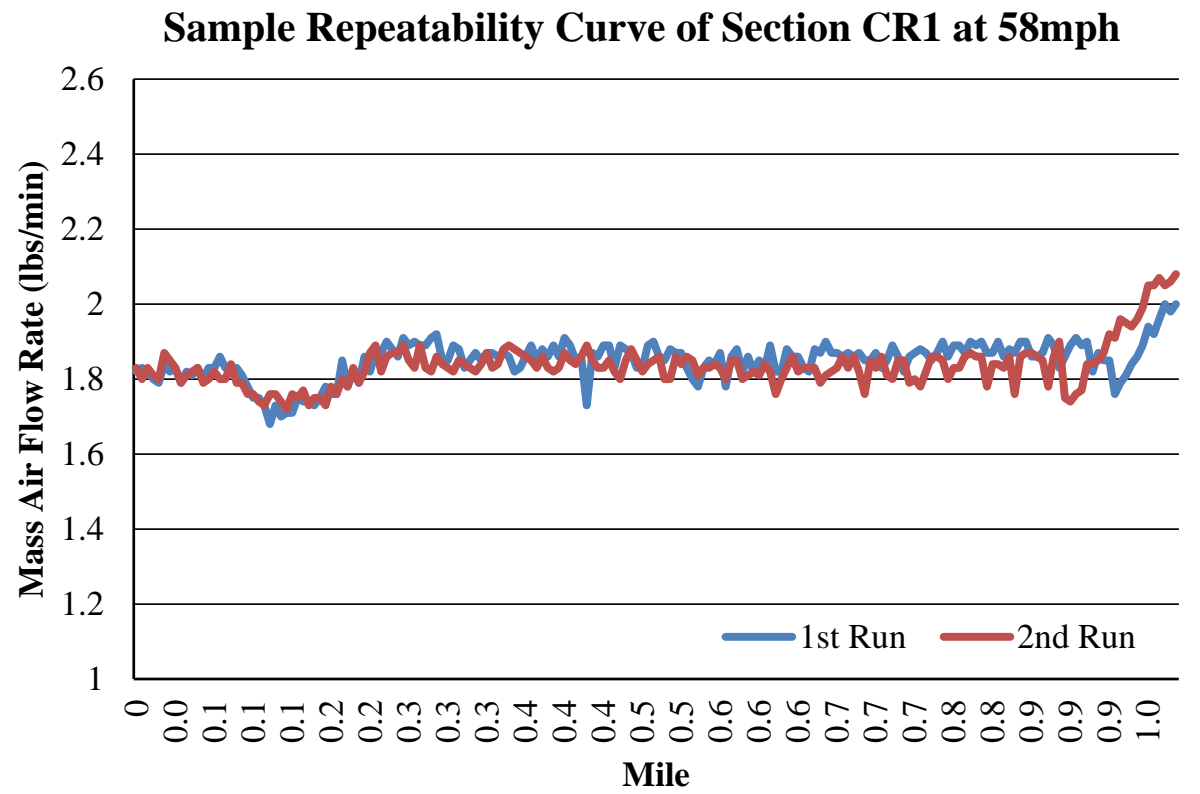

Figure 4.12 Sample Repeatability Curve

\subsubsection{Data Processing}

The instantaneous fuel rates recorded/derived from the field test were used to calculate the fuel consumption on every 0.1 -mile section in liters per $100 \mathrm{~km}$. The IRI data was also available in such scale so they can be used directly. Pavement surface temperatures were calculated on each 0.1-mile section based on the test records. Finally, a number of 260 data (120 for flexible sections and 140 data for rigid sections) were generated for passenger car and 436 data (258 for flexible sections and 178 for rigid sections) were generated for truck. All units were then converted to the metric system and inputted to SPSS for further analysis. Appendix A shows the processed fuel data for 
passenger car and truck at each speed in $\mathrm{L} / 100 \mathrm{~km}$. Appendix B presents the pavement roughness data (IRI) on every 0.1-mile section in $\mathrm{m} / \mathrm{km}$.

Table 4.2 Passenger Car Test Phase II Environmental Condition

\begin{tabular}{|c|c|c|c|c|c|c|c|c|c|c|c|c|c|}
\hline $\begin{array}{c}\text { Passenger } \\
\text { Car }\end{array}$ & CF1 & CF2 & CF3 & CF4 & CF5 & CF6 & CR1 & CR2 & CR3 & CR4 & CR5 & CR6 & CR7 \\
\hline $\begin{array}{c}\text { Testing } \\
\text { Time }\end{array}$ & $3 \mathrm{PM}$ & $4 \mathrm{PM}$ & $6 \mathrm{PM}$ & $4 \mathrm{PM}$ & $12 \mathrm{PM}$ & $1 \mathrm{PM}$ & $10 \mathrm{AM}$ & $11 \mathrm{AM}$ & $11 \mathrm{AM}$ & $12 \mathrm{PM}$ & $1 \mathrm{PM}$ & $2 \mathrm{PM}$ & $4 \mathrm{PM}$ \\
\hline $\begin{array}{c}\text { Wind Speed } \\
\text { And } \\
\text { Direction } \\
\mathbf{( m / s )}^{\mathbf{b}}\end{array}$ & $\mathrm{N}$ & $\mathrm{N}$ & $\mathrm{E}$ & $\mathrm{E}$ & $\mathrm{SSE}$ & $\mathrm{SSE}$ & $\mathrm{N}$ & $\mathrm{NE}$ & $\mathrm{N}$ & $\mathrm{N}$ & $\mathrm{N}$ & $\mathrm{N}$ & $\mathrm{N}$ \\
\hline $\begin{array}{c}\text { Ambient } \\
\text { Temperature } \\
\left.\mathbf{(}^{\circ} \mathbf{C}\right)^{\mathbf{c}}\end{array}$ & 23.3 & 5.3 & 6.2 & 6.2 & 3.1 & 3.1 & 3.2 & 5.8 & 5.3 & 5.3 & 5.2 & 2.2 & 2.1 \\
\hline
\end{tabular}

a: Approximate starting time of each test;

$\mathrm{b} / \mathrm{c}$ : The average value of the data collected during each test.

Table 4.3 Truck Test Phase II Environmental Condition

\begin{tabular}{|c|c|c|c|c|c|c|c|c|c|c|}
\hline Truck & TF1 & TF2 & TF3 & TF4 & TF5 & TR1 & TR2 & TR3 & TR4 & TR5 \\
\hline $\begin{array}{c}\text { Testing } \\
\text { Time }^{\mathbf{a}}\end{array}$ & $8 \mathrm{PM}$ & $9 \mathrm{PM}$ & $6 \mathrm{PM}$ & $7 \mathrm{PM}$ & $9 \mathrm{PM}$ & $1 \mathrm{PM}$ & $2 \mathrm{PM}$ & $8 \mathrm{PM}$ & $9 \mathrm{PM}$ & $10 \mathrm{PM}$ \\
\hline $\begin{array}{c}\text { Wind Speed } \\
\text { and Direction } \\
\left(\mathbf{m} / \mathbf{s} \mathbf{s}^{\mathbf{b}}\right.\end{array}$ & $\mathrm{SE}$ & $\mathrm{SE}$ & $\mathrm{SSE}$ & $\mathrm{SW}$ & $\mathrm{SSW}$ & $\mathrm{E}$ & $\mathrm{E}$ & $\mathrm{SSE}$ & $\mathrm{SE}$ & $\mathrm{W}$ \\
\hline $\begin{array}{c}\text { Ambient } \\
\text { Temperature } \\
\left.\mathbf{(}^{\circ} \mathbf{C}\right)^{\mathbf{c}}\end{array}$ & 27.0 & 28.3 & 28.3 & 27.2 & 28.3 & 33 & 33 & 30 & 27.8 & 31.7 \\
\hline
\end{tabular}

a: Approximate starting time of each test;

$\mathrm{b} / \mathrm{c}$ : The average value of the data collected during each test.

\subsection{STATISTICAL ANALYSIS}

\subsubsection{Statistical Test}

Four sets of raw data were generated from the field trials: 1) passenger car at $89 \mathrm{~km} / \mathrm{h}, 2$ ) passenger car at $105 \mathrm{~km} / \mathrm{h}, 3$ ) truck at $93 \mathrm{~km} / \mathrm{h}$ and 4) truck at $112 \mathrm{~km} / \mathrm{h}$. There are four variables for each set of raw data: pavement type (2 levels: flexible pavement 
and rigid pavement), pavement roughness in IRI (m/km), pavement surface temperature PT $\left({ }^{\circ} \mathrm{C}\right)$ and vehicle fuel consumption (L/100km).

The objective is to 1) examine the effect of pavement type on vehicle fuel consumption at each speed, while statistically control the influence of pavement roughness and pavement temperature; and 2) how much is the impact if the impact is significant. Different statistical tests were examined and compared. The analysis of covariance (ANCOVA) test was found perfectly match the purpose, as indicated from the definition from Wikipedia (cited from (Keppel, 1991)):

"Analysis of Covariance (ANCOVA) evaluates whether population means of a dependent variable are equal across levels of a categorical independent variable often called a treatment, while statistically controlling for the effects of other continuous variables and that are not of primary interest, known as covariates or nuisance variables...”

Intuitively, ANCOVA can be thought as “adjusting” the dependent variable (FC) by group means of the covariates (IRI and PT), or in this study, detecting the differences in fuel consumption between flexible pavement (group) and rigid pavement (group) with adjustment of the effect of non-interested variables IRI and PT. The corresponding variables used in the ANCOVA test were summarized as following:

Dependent Variable: Vehicle Fuel Consumption (FC);

Independent Variable: Pavement Type (flexible pavement group and rigid pavement group);

Covariates: Pavement Roughness (IRI) and/or Pavement Surface Temperature (PT). 


\subsubsection{Statistical Assumptions}

A sound and robust statistical conclusion depends on valid test assumptions. Thus, preliminary checks were conducted to examine the key assumptions of the analysis of covariance (ANCOVA). ANCOVA is an extended test of analysis of variance (ANOVA) test which includes one or more continuous variables that predict the dependent variable. There are five key assumptions of the ANCOVA test: 1 ) linearity of regression, 2) normality, 3) homogeneity of variances, 4) independence of covariates and treatment effect, and 5) homogeneity of regression. The first three assumptions are the basic assumptions that are the same as the AVOVA test. The last two are additional important assumptions for ANCOVA test only, which will be primarily evaluated here.

i. Linearity of Regression: The linearity of regression assumption was mainly examined by visualization. In general, the truck data exhibited better linearity behavior than car data because of the larger data size. Sample linearity plots for truck fuel consumption versus roughness at $89 \mathrm{~km} / \mathrm{h}$ and $105 \mathrm{~km} / \mathrm{h}$ are shown in Figure 4.13 and

Figure 4.14. Generally the vehicle fuel consumption increased with the increase of pavement roughness level regardless traveling speed, which agreed with the findings from past research studies ( (Chatti \& Zaabar, 2012), (Amos, 2006), et al.).

ii. Normality: Residuals were plotted in SPSS and examined by visualization. No obvious violation was found for both passenger car and truck; 


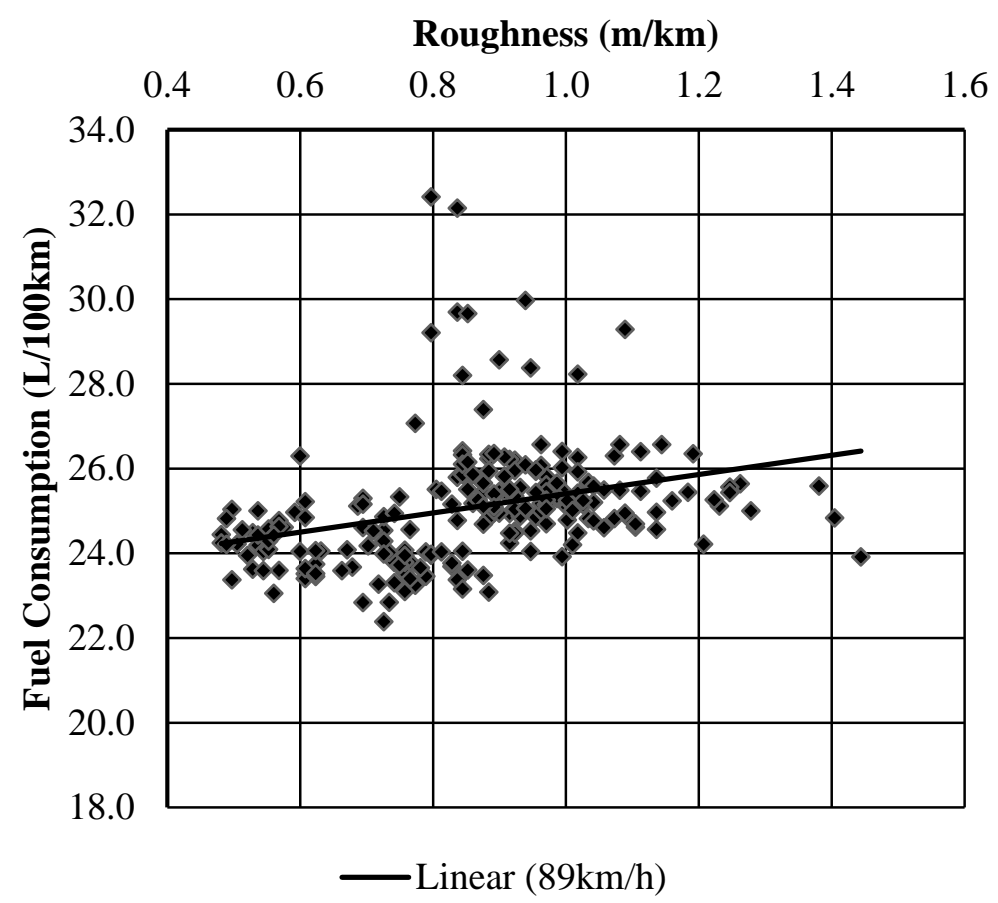

Figure 4.13 Linearity Plot of Truck Test at $89 \mathrm{~km} / \mathrm{h}$

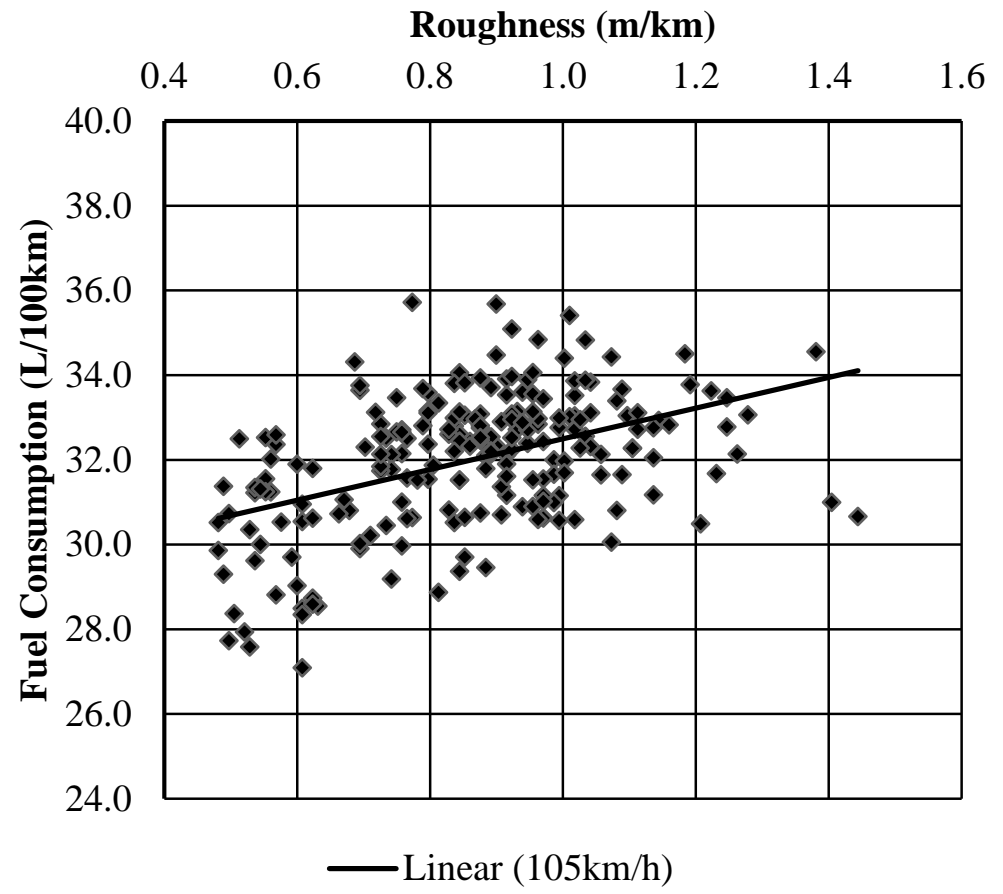

Figure 4.14 Linearity Plot of Truck Test at $105 \mathrm{~km} / \mathrm{h}$ 
iii. Homogeneity of Variances: This assumption tested the equality of error variances. It was tested by Levene’s Test. The null hypothesis of the Levene’s Test was that the error variances were equal across levels of treatment (pavement type). The test result was summarized in Table 4.4. The result indicated that this assumption was only hold for the passenger car data (with p-values larger than 0.05), but not for the truck data (p-values less than 0.05 ). However, given the valid linearity and normality assumptions, no data transformation or nonparametric test was applied for the truck data (the violation of one test assumption only means the losses of some degree of power of test output, but it can still be powerful if the majority of the assumptions hold).

iv. Independence of Covariates and Treatment Effect: This is the first additional assumption of ANCOVA other than the assumption of ANOVA. This assumption holds by the nature of the experimental design: the pavement roughness (IRI) and surface temperature (PT) were independent measured and recorded without dependence of pavement type. Here also explains the reason that pavement texture shall not be included as one of the covariates since texture varies significantly between asphalt and concrete surface.

v. Homogeneity of Regression: The second ANCOVA specified assumption requires the regression relationships be equal (or parallel graphically) among groups of treatment. This can be tested by running a pre-ANCOVA model that includes the interaction terms of the independent variable and each covariate. The assumption holds if the interaction terms are found statistically non-significant. Such methodology was aoolied and based on the results, the truck data only included one covariate, IRI, into further ANCOVA analysis (p-values of PT were all less than 0.05), while the car data had 
both the covariates IRI and PT incorporated. The results of this assumption test were summarized in Table 4.4 .

From the table, the assumption of $93 \mathrm{~km} / \mathrm{h}$ car test for covariate IRI was found violated. But the ANCOVA test was continued since it was not strongly violated (F-value of 5.333 and p-value of 0.023). Two regression plots (fuel consumption versus roughness) were also illustrated in Figure 4.15 and 4.16 for car test at $112 \mathrm{~km} / \mathrm{h}$ and truck test at $89 \mathrm{~km} / \mathrm{h}$. The paralleled regression slops in each plot indicate sound homogeneity of regression assumption.

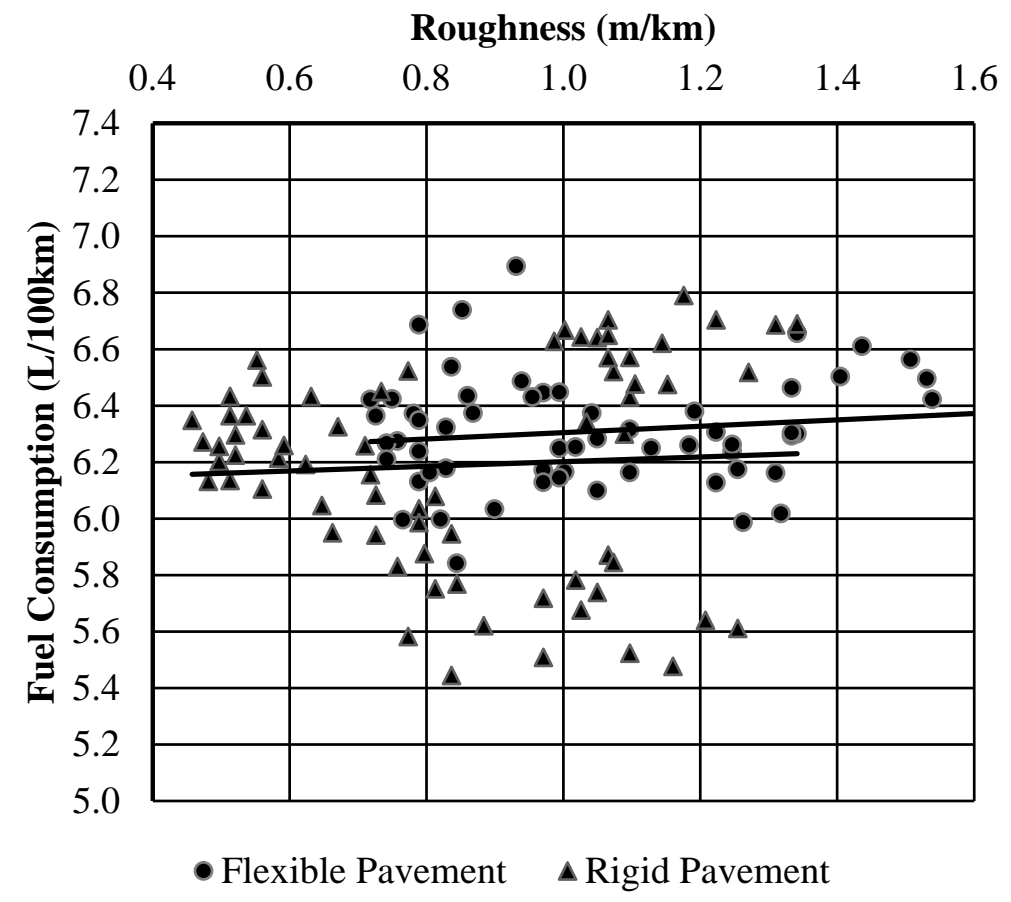

Figure 4.15 Homogeneity of Regression Plot for Car Test at 112km/h 


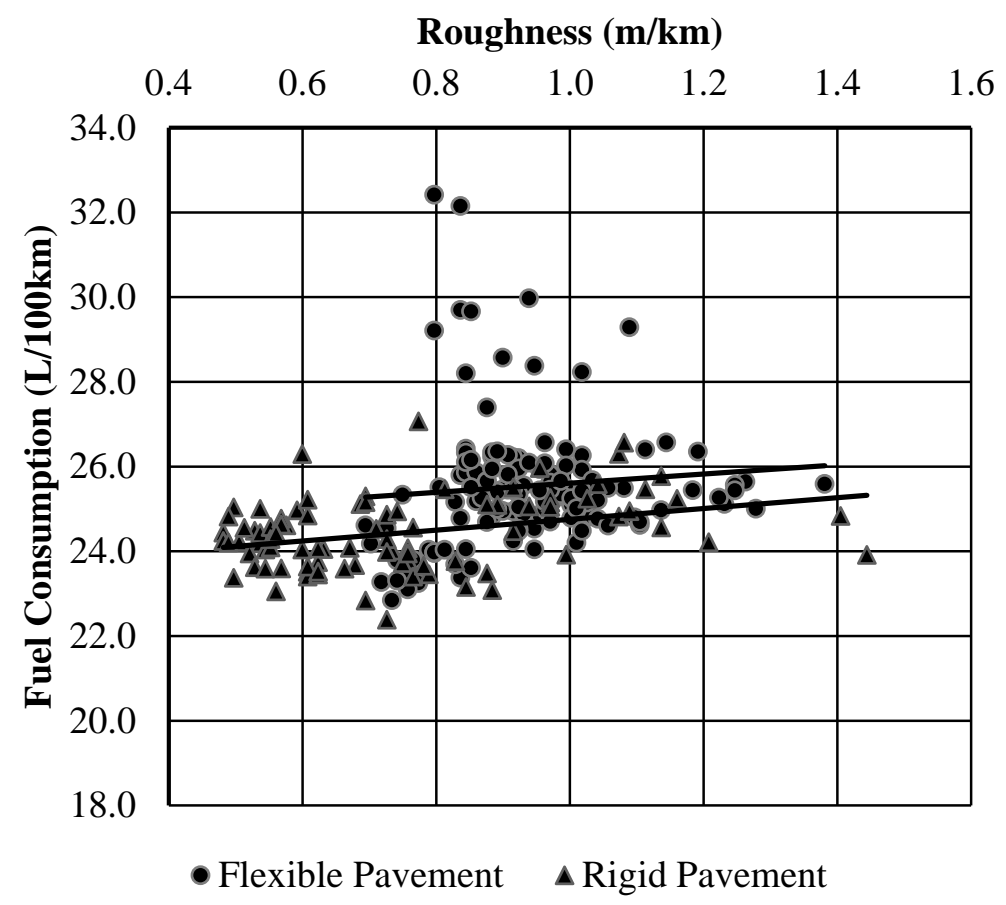

Figure 4.16 Homogeneity of Regression Plot for Truck Test at $89 \mathrm{~km} / \mathrm{h}$

Table 4.4 ANCOVA Test Assumptions

\begin{tabular}{|c|c|c|c|c|c|c|c|c|}
\hline \multirow{2}{*}{ Test } & \multicolumn{4}{|c|}{$\begin{array}{c}\text { Levene's Test for Equality of Error } \\
\text { Variances }\end{array}$} & \multicolumn{4}{|c|}{ Homogeneity of Regression Test } \\
\hline & F-value & df1 & df2 & p-value & Covariates & F-value & df & p-value \\
\hline \multirow{2}{*}{ Car_93km/h } & \multirow{2}{*}{0.024} & \multirow{2}{*}{1} & \multirow{2}{*}{128} & \multirow{2}{*}{0.876} & IRI & 5.333 & 1 & $0.023^{*}$ \\
\hline & & & & & PT & 3.212 & 1 & 0.076 \\
\hline \multirow{2}{*}{ Car_112km/h } & \multirow{2}{*}{0.608} & \multirow{2}{*}{1} & \multirow{2}{*}{128} & \multirow{2}{*}{0.437} & IRI & 0.503 & 1 & 0.480 \\
\hline & & & & & PT & 2.040 & 1 & 0.156 \\
\hline Truck_89km/h & 7.686 & 1 & 216 & $0.006^{*}$ & IRI & 0.027 & 1 & 0.870 \\
\hline Truck_105km/h & 13.381 & 1 & 216 & $0.000 *$ & IRI & 2.895 & 1 & 0.090 \\
\hline
\end{tabular}

* indicates the assumption was violated. 


\subsubsection{Statistical Results}

The ANCOVA test was performed with statistical software SPSS. The results are presented in the following sections.

\subsubsection{Descriptive Statistics}

The descriptive statistics table (Table 4.5) presents the descriptive statistics (mean, standard deviation and the number of data points) of the dependent variable (vehicle fuel consumption) on different levels of independent variable (pavement type). These values do not represent any adjustment made by the covariate(s) in ANCOVA.

Table 4.5 Descriptive Statistics

\begin{tabular}{|c|c|c|c|c|}
\hline Test & Group & Mean & Std. Deviation & Number of Data \\
\hline \multirow{2}{*}{ Car_93km/h } & Flexible Group & 4.869 & 0.175 & 60 \\
\cline { 2 - 5 } & Rigid Group & 4.751 & 0.226 & 70 \\
\hline \multirow{2}{*}{ Car_112km/h } & Flexible Group & 6.310 & 0.197 & 60 \\
\cline { 2 - 5 } & Rigid Group & 6.190 & 0.368 & 70 \\
\hline \multirow{2}{*}{ Truck_89km/h } & Flexible Group & 25.540 & 1.558 & 129 \\
\cline { 2 - 5 } & Rigid Group & 24.433 & 0.861 & 89 \\
\hline \multirow{2}{*}{ Truck_105km/h } & Flexible Group & 32.584 & 1.150 & 129 \\
\cline { 2 - 5 } & Rigid Group & 31.135 & 1.724 & 89 \\
\hline
\end{tabular}

\subsubsection{Tests of Between-Subjects Effect}

The main section of the ANCOVA results are presented in Table 4.6. This table indicates whether the ANCOVA test was statistically significant for each test. More specifically, it explains whether there is an overall statistically significant difference in vehicle fuel consumption between flexible pavement group and rigid pavement group once their mean fuel consumptions were adjusted for IRI and pavement surface temperature. 
Table 4.6 Test of Between-Subjects Effect

\begin{tabular}{|c|c|c|c|c|c|}
\hline Source & Type III Sum of Squares & df & Mean Square & F-value & p-value \\
\hline \multicolumn{6}{|c|}{ Dependent Variable: Car Fuel Consumption at $93 \mathrm{~km} / \mathrm{h}$} \\
\hline Corrected Model & 1.237 & 3 & 0.412 & 11.431 & 0.000 \\
\hline Intercept & 163.171 & 1 & 163.171 & 4523.910 & 0.000 \\
\hline IRI & 0.417 & 1 & 0.417 & 11.571 & 0.001 \\
\hline PT & 0.609 & 1 & 0.609 & 16.880 & 0.000 \\
\hline Group & 0.318 & 1 & 0.318 & 8.816 & $\underline{0.004}$ \\
\hline Error & 4.545 & 126 & 0.036 & & \\
\hline Total & 3007.898 & 130 & & & \\
\hline Corrected Total & 5.782 & 129 & & & \\
\hline \multicolumn{6}{|c|}{ Dependent Variable: Car Fuel Consumption at $112 \mathrm{~km} / \mathrm{h}$} \\
\hline Corrected Model & 2.983 & 3 & 0.994 & 13.735 & 0.000 \\
\hline Intercept & 290.528 & 1 & 290.528 & 4013.278 & 0.000 \\
\hline IRI & 0.577 & 1 & 0.577 & 7.966 & 0.006 \\
\hline PT & 2.441 & 1 & 2.441 & 33.718 & 0.000 \\
\hline Group & 0.517 & 1 & 0.517 & 7.146 & $\underline{0.009}$ \\
\hline Error & 9.121 & 126 & 0.072 & & \\
\hline Total & 5082.357 & 130 & & & \\
\hline Corrected Total & 12.104 & 129 & & & \\
\hline \multicolumn{6}{|c|}{ Dependent Variable: Truck Fuel Consumption at $89 \mathrm{~km} / \mathrm{h}$} \\
\hline Corrected Model & 74.093 & 2 & 37.047 & 21.748 & 0.000 \\
\hline Intercept & 4950.551 & 1 & 4950.551 & 2906.133 & 0.000 \\
\hline IRI & 9.532 & 1 & 9.532 & 5.595 & 0.019 \\
\hline Group & 31.418 & 1 & 31.418 & 18.443 & $\underline{0.000}$ \\
\hline Error & 366.249 & 215 & 1.703 & & \\
\hline Total & 137653.538 & 218 & & & \\
\hline Corrected Total & 440.342 & 217 & & & \\
\hline \multicolumn{6}{|c|}{ Dependent Variable: Truck Fuel Consumption at 105km/h } \\
\hline Corrected Model & 148.631 & 2 & 74.316 & 40.684 & 0.000 \\
\hline Intercept & 7660.473 & 1 & 7660.473 & 4193.697 & 0.000 \\
\hline IRI & 38.090 & 1 & 38.090 & 20.852 & 0.000 \\
\hline Group & 39.967 & 1 & 39.967 & 21.880 & $\underline{0.000}$ \\
\hline Error & 392.733 & 215 & 1.827 & & \\
\hline Total & 223665.217 & 218 & & & \\
\hline Corrected Total & 541.364 & 217 & & & \\
\hline
\end{tabular}


From the table, the p-values of the variable "group" are all (far) less than $\alpha=0.05$, which indicates the differences of the adjusted mean fuel consumption between flexible pavement group and rigid pavement group are statistically significant at 95\% C.L. Results also indicate that IRI and PT also have significant effect on fuel consumption (pvalue all less than 0.05), which agrees with the findings of past studies ( (Chatti \& Zaabar, 2012), (Hultqvist, 2010), (Chupin, et al., 2013)).

\subsubsection{Pairwise Comparisons}

To get a better understanding on how IRI and PT have adjusted the original fuel consumption means and how much were the fuel consumption differences between flexible pavement group and rigid pavement group, Table 4.7 can be consulted. The means (Adjusted Means) in Table 4.7 represent the IRI and/or PT adjusted fuel consumption from their original means in Table 4.5. The differences between the adjusted flexible pavement fuel consumption and rigid pavement fuel consumption were calculated along with their confidence intervals. The percentage differences were calculated as the absolute fuel consumption difference over rigid pavement adjusted fuel consumption.

\subsection{RESULTS DISCUSSION}

\subsubsection{Comparison with Phase I Study}

The statistical results from this study were summarized and compared with the Phase I study, as shown in Table 4.8. Results show that the fuel consumption differences derived from this study are slightly lower than the differences derived from Phase I. But the differences are generally at the same levels: 2 to $2.5 \%$ for passenger car and 3 to $4 \%$ for the truck. Given the fact that the truck weight in Phase I (average weight) is more than 
three times of the truck weight in this phase, a wider range of truck fuel difference is reasonable.

Table 4.7 Pairwise Comparisons

\begin{tabular}{|c|c|c|c|c|c|c|}
\hline \multirow{2}{*}{ Group } & \multirow{2}{*}{$\begin{array}{c}\text { Adjusted } \\
\text { Means } \\
(\text { L/100km) }\end{array}$} & \multirow{2}{*}{$\begin{array}{c}\text { Mean } \\
\text { Difference } \\
\text { (Flexible- } \\
\text { Rigid) }\end{array}$} & \multirow{2}{*}{$\begin{array}{l}\text { Std. } \\
\text { Error }\end{array}$} & \multirow{2}{*}{$\begin{array}{l}\text { Percentage } \\
\text { Difference }\end{array}$} & \multicolumn{2}{|c|}{$\begin{array}{l}\text { 95\% Confidence Interval } \\
\text { for Difference }\end{array}$} \\
\hline & & & & & $\begin{array}{l}\text { Lower } \\
\text { Bound }\end{array}$ & $\begin{array}{l}\text { Upper } \\
\text { Bound }\end{array}$ \\
\hline \multicolumn{7}{|c|}{ Dependent Variable: Car Fuel Consumption at $93 \mathrm{~km} / \mathrm{h}$} \\
\hline Flexible & $4.863^{\mathrm{a}}$ & \multirow{2}{*}{0.107} & \multirow{2}{*}{0.036} & \multirow{2}{*}{$2.25 \%^{\mathrm{c}}$} & 0.036 & 0.179 \\
\hline Rigid & $4.756^{\mathrm{a}}$ & & & & $(0.76 \%)^{c}$ & $(3.76 \%)^{c}$ \\
\hline \multicolumn{7}{|c|}{ Dependent Variable: Car Fuel Consumption at $112 \mathrm{~km} / \mathrm{h}$} \\
\hline Flexible & $6.319^{\mathrm{a}}$ & \multirow{2}{*}{0.137} & \multirow{2}{*}{0.051} & \multirow{2}{*}{$2.22 \%{ }^{\mathrm{c}}$} & 0.036 & 0.238 \\
\hline Rigid & $6.182^{\mathrm{a}}$ & & & & $(0.58 \%)^{\mathrm{c}}$ & $(3.85 \%)^{c}$ \\
\hline \multicolumn{7}{|c|}{ Dependent Variable: Truck Fuel Consumption at $89 \mathrm{~km} / \mathrm{h}$} \\
\hline Flexible & 25.447 & \multirow{2}{*}{0.878} & \multirow{2}{*}{0.204} & \multirow{2}{*}{$3.57 \%^{\mathrm{c}}$} & 0.475 & 1.280 \\
\hline Rigid & 24.569 & & & & $(1.93 \%)^{\mathrm{c}}$ & $(5.21 \%)^{\mathrm{c}}$ \\
\hline \multicolumn{7}{|c|}{ Dependent Variable: Truck Fuel Consumption at $105 \mathrm{~km} / \mathrm{h}$} \\
\hline Flexible & 32.396 & \multirow{2}{*}{0.990} & \multirow{2}{*}{0.212} & \multirow{2}{*}{$3.15 \%{ }^{c}$} & 0.573 & 1.407 \\
\hline Rigid & 31.406 & & & & $(1.82 \%)^{\mathrm{c}}$ & $(4.48 \%)^{\mathrm{c}}$ \\
\hline
\end{tabular}

a: Covariates were evaluated at following values: Car: $\mathrm{IRI}=0.944 \mathrm{~m} / \mathrm{km}, \mathrm{PT}=17^{\circ} \mathrm{C}$, Truck: IRI $=0.860 \mathrm{~m} / \mathrm{km}$;

b: The methodology applied for the pairwise comparisons was Bonferroni approach; and c: Percentage differences were calculated as differences compared to rigid FC.

Moreover, in the higher highway speed tests $(105 \mathrm{~km} / \mathrm{h}$ and $112 \mathrm{~km} / \mathrm{h})$, the fuel differences increased with the increase of vehicle weight (Car of Phase II_1,414kg vs. Car of Phase I_1,700kg vs. Truck of Phase II_10,614kg equal to 2.22\% vs. 2.50\% vs. 3.15\%). The same trend was also found in the lower highway speed tests $(89 \mathrm{~km} / \mathrm{h}$ and 93km/h): (Car of Phase II_1,414kg vs. Truck of Phase II_10,614kg vs. Truck of Phase I_34,709kg equal to $2.25 \%$ vs. $3.57 \%$ vs. $4.04 \%$ ). 
Table 4.8 Comparisons with Phase I Results

\begin{tabular}{|c|c|c|c|c|}
\hline Tests & $\begin{array}{c}\text { Car } \\
\text { Phase II }\end{array}$ & $\begin{array}{c}\text { Truck } \\
\text { Phase II }\end{array}$ & $\begin{array}{c}\text { Car } \\
\text { Phase I }\end{array}$ & $\begin{array}{c}\text { Truck } \\
\text { Phase I }\end{array}$ \\
\hline $\begin{array}{c}\text { Experimental } \\
\text { Design }\end{array}$ & $\begin{array}{l}\text { Parametric } \\
\text { Experiment }\end{array}$ & $\begin{array}{l}\text { Parametric } \\
\text { Experiment }\end{array}$ & $\begin{array}{c}\text { Direct } \\
\text { Comparison }\end{array}$ & $\begin{array}{c}\text { Direct } \\
\text { Comparison }\end{array}$ \\
\hline $\begin{array}{l}\text { Vehicle } \\
\text { Used }\end{array}$ & $\begin{array}{l}2014 \text { Chevy } \\
\text { Cruze }\end{array}$ & $\begin{array}{l}2011 \text { International } \\
4300 \text { Box Truck } \\
\text { (Loaded) }\end{array}$ & $\begin{array}{l}2011 \text { Hyundai } \\
\text { Genesis }\end{array}$ & $\begin{array}{c}2010 \text { Mack Tractor } \\
\text { Truck with Trailer } \\
\text { (Loaded) }\end{array}$ \\
\hline $\begin{array}{c}\text { Axles } \\
\text { Wheels }\end{array}$ & $\begin{array}{c}\text { 2-axles } \\
\text { 4-wheels }\end{array}$ & $\begin{array}{c}\text { 2-axles } \\
\text { 6-wheels }\end{array}$ & $\begin{array}{c}\text { 2-axles } \\
\text { 4-wheels }\end{array}$ & $\begin{array}{c}\text { 5-axles } \\
\text { 18-wheels }\end{array}$ \\
\hline $\begin{array}{c}\text { Vehicle } \\
\text { Weight (kg) }\end{array}$ & 1,414 & 10,614 & 1,700 & $34,709^{a}$ \\
\hline $\begin{array}{c}\text { Statistical } \\
\text { Tests }\end{array}$ & ANCOVA & ANCOVA & Paired-T Test & Paired-T Test \\
\hline $\begin{array}{c}\text { Fuel Savings } \\
\text { at Lower } \\
\text { Highway Speed }\end{array}$ & $\begin{array}{c}2.25 \% \\
(0.76 \%-3.76)\end{array}$ & $\begin{array}{c}3.57 \% \\
(1.93 \%-5.21 \%)\end{array}$ & N/A & $\begin{array}{c}4.04 \% \\
(3.61 \%-4.47 \%)\end{array}$ \\
\hline $\begin{array}{c}\text { Fuel Savings } \\
\text { at Higher } \\
\text { Highway Speed }\end{array}$ & $\begin{array}{c}2.22 \% \\
(0.58 \%-3.85)\end{array}$ & $\begin{array}{c}3.15 \% \\
(1.82 \%-4.48)\end{array}$ & $\begin{array}{c}2.50 \% \\
(1.47 \%-3.34 \%)\end{array}$ & N/A \\
\hline
\end{tabular}

a: averaged truck weight in Phase I study

\subsubsection{Comparison with Other Studies}

Results from the two phases of field studies were also compared with other studies from literatures. A total of ten studies were compared which included two modeling studies: (NPC, 2002), (Pouget, et al., 2012) and eight field trials: (Taylor, 2002), (Taylor \& Petten, 2006), (Chatti \& Zaabar, 2012), (Hultqvist, 2010), (Yoshimoto, et al., 2010), (Sumitsawan, et al., 2009), (Graaff, 1999), (Stubstad, 2009). The differences between flexible pavement and rigid pavement were summarized with no cover of composite pavement or other pavements. Results from nine truck studies and seven car studies were plotted in Figure 4.17 and 4.18. Generally all tests shown either positive or 
zero (non-significant differences) fuel saving on rigid pavement compared to the flexible pavement. The highest fuel saving was found in the passenger car study of Sumitsawan et al. (Sumitsawan, et al., 2009) with more than 8\%. Due to the complexity of each studies, it would be difficult to perform any detailed comparisons among these studies. But the plots can give the readers some general perspectives of the findings of this study among all the literatures.

\subsection{KEY FINDINGS}

The following conclusions can be drawn from the statistical results:

1. Pavement type is, again, proved as a significant factor that affects vehicle fuel consumption for both passenger car and truck, and at both lower and higher highway speeds;

2. The fuel consumption differences between flexible pavement (group) and rigid pavement (group) found in Phase II are $2.25 \%$ and $2.22 \%$ for passenger car at $93 \mathrm{~km} / \mathrm{h}$ and $112 \mathrm{~km} / \mathrm{h}$, and $3.57 \%$ and $3.15 \%$ for truck at $89 \mathrm{~km} / \mathrm{h}$ and $105 \mathrm{~km} / \mathrm{h}$;

3. The effect of pavement roughness and surface temperature on fuel consumption are also found statistically significant.

4. Despite the different experimental design and study methodology compared to Phase I study, both phases exhibits statistically significant fuel savings on rigid pavement (or pavement group) and savings are at same levels.

5. The heavier the vehicle, the larger the fuel consumption differences. 


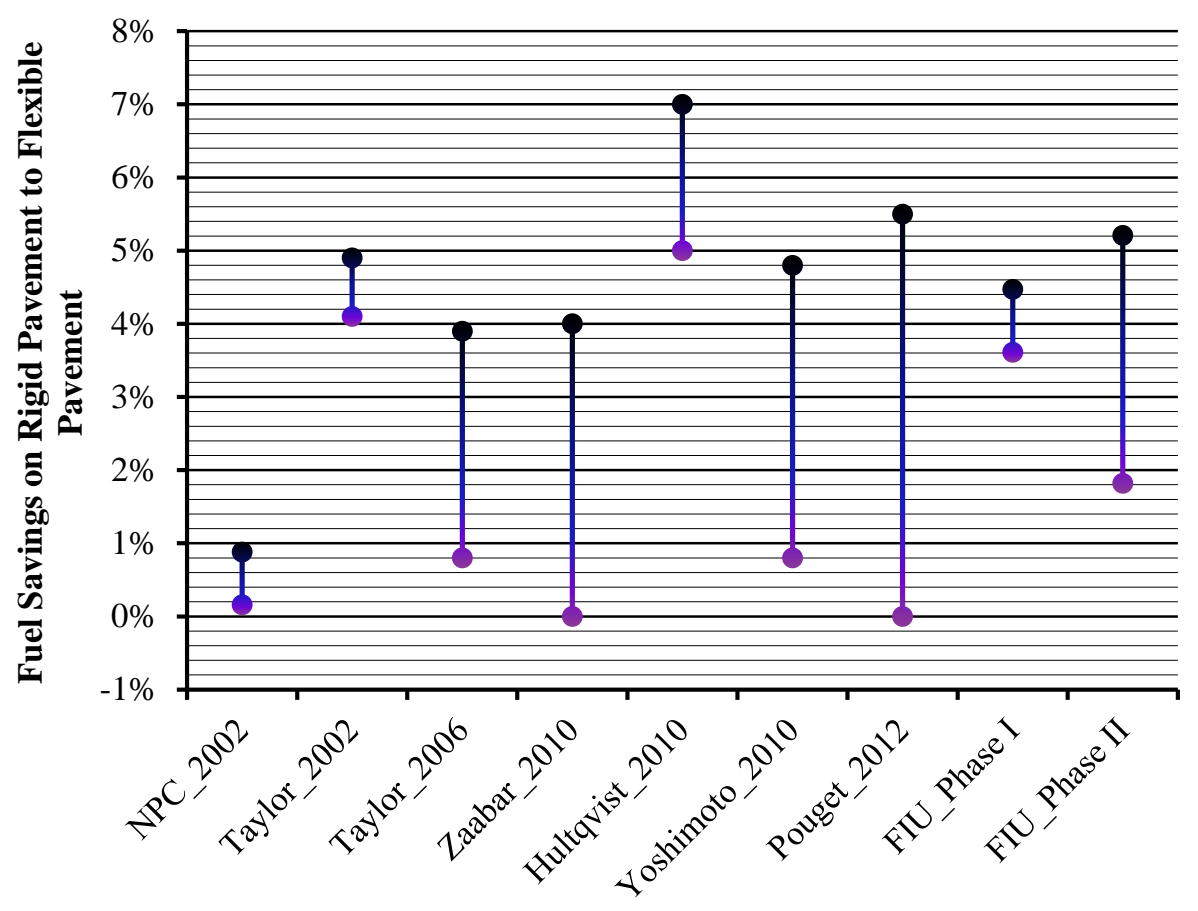

Figure 4.17 Truck Test Results Compared with Other Studies

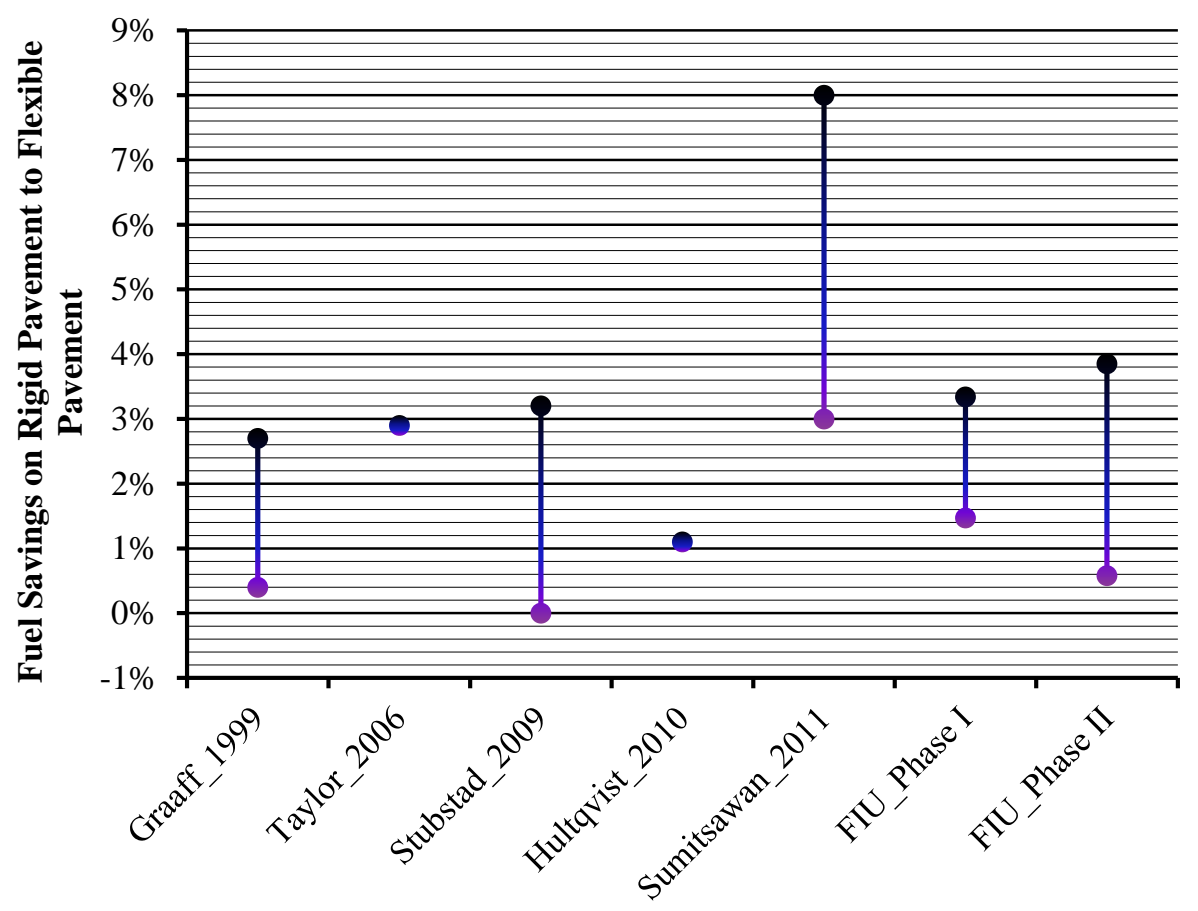

Figure 4.18 Passenger Car Test Results Compared with Other Studies 


\subsection{DISCUSSION AND LIMITATIONS}

Since the effect of pavement roughness and temperature has been excluded in the study, the fuel consumption differences are expected to come from two aspects: pavement type (pavement stiffness) and surface macrotexture. The higher pavement stiffness in rigid pavement leads to lower vehicle fuel consumption by smaller amount of surface deflection compared to the flexible pavement. The viscoelastic behavior of asphalt material is also believed to play a crucial role in the fuel differences. This also explains the positive relationship between vehicle weight and fuel differences since the heavier the vehicle the larger the deflection under the wheels. Another potential cause of the fuel differences comes from the differences in surface texture. The open graded asphalt surface in flexible pavement creates larger degrees of tire-suspension vibrations and thus leads to excess fuel consumption consequently. But the texture effect alone is not able to explain the positive relationship between fuel difference and vehicle weight. Thus it is rational to believe that the effect of pavement type or the combined effects with surface texture cause the fuel savings on rigid pavement relative to the flexible pavement.

Limitations shall be noted as well. First of all, the findings shall be only applied to situations where the pavement and environmental condition are similar to Florida. Generally Florida has a higher annual average temperature than other states in the United States. The pavement structural compositions are also specifically designed for Florida's traffic and soil condition. Thus, any changes of environment or pavement condition can lead to different outcome than this study. Secondly, the exact cause of the fuel difference is not able to be differentiated between pavement type and surface texture. It is unclear how much the difference is due to pavement deflection and how much should be owed to 
surface texture. It is very difficult to distinguish such effect purely by field experiment. Analyses of such nature could be possible with theoretical estimates or computer simulations. Thus, future studies are highly desired to quantify the contributions of each effect. In addition, studies on the non-highway pavement would also be valuable for a comprehensive experimental understanding of the PVI effect on vehicle fuel economy. 


\section{CHAPTER 5}

\section{HDM-IV MODEL CALIBRATION}

\subsection{INTRODUCTION}

The objective of this chapter is to calibrate the HDM-IV fuel consumption model with field data collected in the Phase II field study. The calibrated model is evaluated and validated with different approaches after the model calibration. It is intended to provide a better understanding of the PVI on highway fuel consumption from a mechanistic approach other than field experiments. It also aims at providing a tool to estimate the impact of PVI on the state-wide fuel consumption saving and emission reduction.

\subsection{MODEL DESCRIPTION}

The Highway Development and Management (HDM) Model IV was developed by World Road Association with collaborative international studies since 1995. It has been widely used in consultants, lending agencies and government department for comparative cost evaluations of different roadway construction and maintenance options. Road user effect in HDM-IV describes the total cost of roadway transport. Fuel consumption (cost) comprises one of the most significant components in the road user effects.

The fuel consumption model in HDM-IV was adopted from the mechanistic Australian Road Board Fuel Consumption Model (ARFCOM) which was developed in 1998 (Biggs, 1988). The approach that the ARFCOM models fuel consumption is demonstrated in Chapter 2 "Literature Review". This chapter focuses on the most current HDM-IV fuel consumption model that will be calibrated in this study. 
The HDM-IV fuel consumption model calculates vehicle fuel consumption as proportional to the total power the vehicle required to overcome tractive force, accessories, and internal engine friction (Equation 5.1a/b).

$$
I F C=\max \left(\alpha, \xi \times P_{\text {tot }} \times\left(1+d_{f u e l}\right)\right.
$$

Where IFC is the instantaneous fuel consumption in $\mathrm{mL} / \mathrm{s}$

Ptot is the total power in $\mathrm{kW}$

$\alpha \quad$ is the fuel consumption at idling in $\mathrm{mL} / \mathrm{s}$

dfuel is the excess fuel consumption caused by congestion

The total power is calculated as:

$$
P_{t o t}=\frac{P_{t r}}{e d t}+P_{a c c s}+P_{e n g}
$$

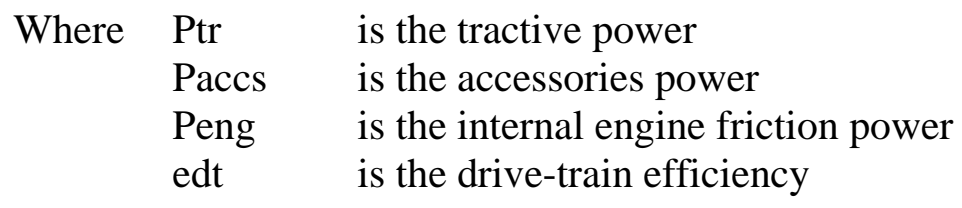

The tractive power Ptr represents the power required to overcome resistances against vehicle motion. It is composed of five resistances: aerodynamic drag resistance, rolling resistance, gradient resistance, curvature resistance, and inertial resistance. The accessories resistance Paccs defines the power required to drive the vehicle accessories such as cooling fan, power steering, air conditioner, alternator etc. Internal engine friction Peng is the level of power consumed to overcome internal friction in the engine itself and is related to engine speed and other engine parameters (Bennett \& Greenwood, 2003a). (Michelin, 2003) generated a relationship between the mechanical energy consumed in a passenger car and vehicle speed (Figure 5.1). Only aerodynamic drag, internal friction 
and rolling resistance are incorporated in the relationship. From the plot, at 113km/h (70mph), around $50 \%$ of the energy consumption comes from aerodynamic drag, $25 \%$ from internal friction, and $25 \%$ from the rolling resistance.

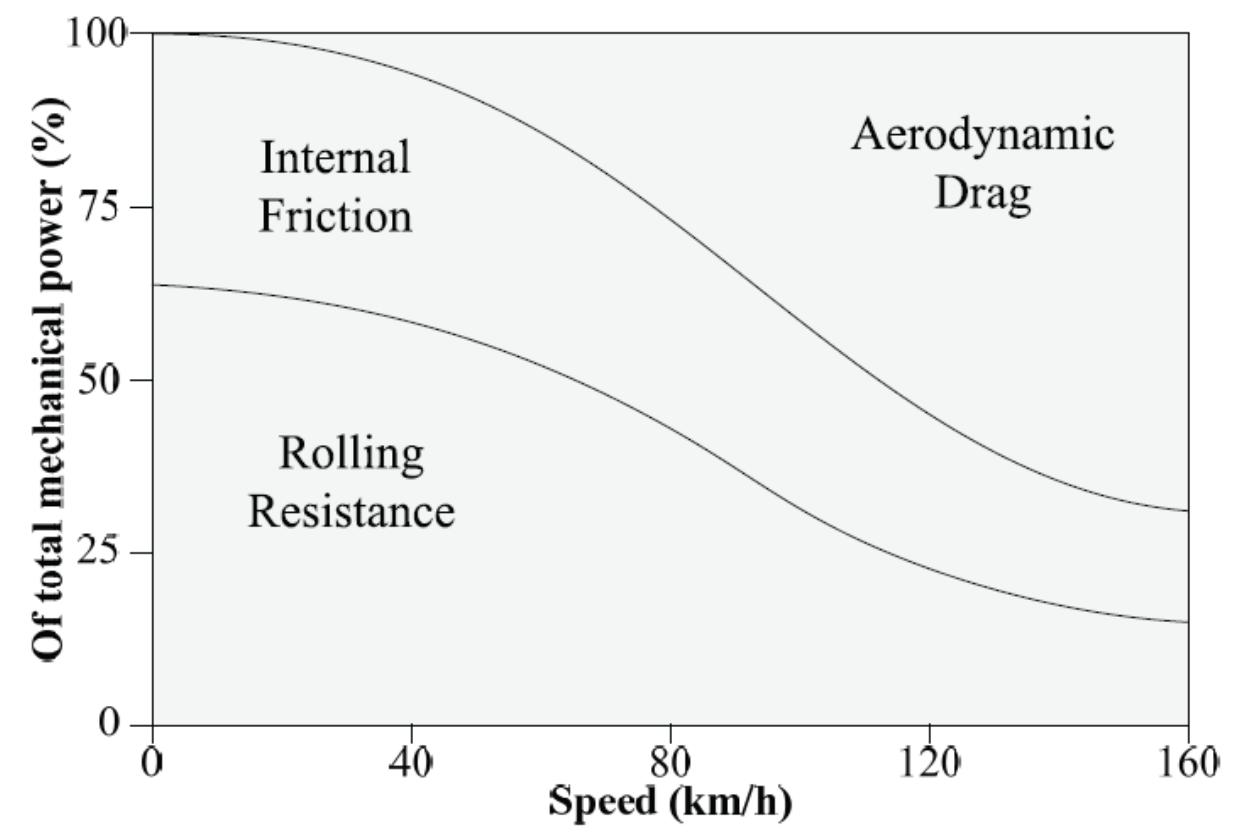

Figure 5.1 Energy Distribution in Passenger Car at Steady Speed (Michelin, 2003)

Precisely, the HDM-IV fuel consumption model is a combined mechanistic and empirical fuel consumption model. The mechanistic part is that it models all driving resistance based on vehicle and driving configurations, while the empirical part is that the model coefficients are determined through various experiments and requires calibration before local application. Table 5.1 shows the detailed model components of HDM-IV fuel consumption model.

Table 5.1 HDM-IV Fuel Consumption Model Components 


\begin{tabular}{|c|c|c|}
\hline Name & Description & Unit \\
\hline Total Power $\left(\mathbf{P}_{\text {tot }}\right)$ & $P_{t o t}=\frac{P_{t r}}{e d t}+P_{a c c s}+P_{e n g}$ & $\mathrm{~kW}$ \\
\hline edt & Drive-train efficiency & \\
\hline $\begin{array}{l}\text { Engine and } \\
\text { Accessories Power } \\
\left(P_{\text {engaccs }}\right)\end{array}$ & $\begin{array}{r}P_{\text {engaccs }}=P_{\text {eng }}+P_{\text {accs }}=\text { Kpea } \times P_{\text {max }} \\
=\left(P_{\text {accs }}+\left(P_{a c c s_{a o}}-P_{a c c s_{a 1}}\right)\right. \\
\left.\times \frac{R P M-R P M I d l e}{R P M 100-\text { RPMIdle }}\right)\end{array}$ & \\
\hline $\mathrm{K}_{\text {pea }}$ & Calibration factor for engine and accessories power & \\
\hline $\mathrm{P}_{\max }$ & Rated engine power & $\mathrm{kW}$ \\
\hline Paccs_a1 & $\begin{array}{l}P_{\text {accs_a1 }}=\frac{-b+\sqrt{b^{2}-4 a c}}{2 a} \\
a=\xi_{b} \times e h p \times K p e a^{2} \times P_{\text {max }} \times \frac{100-\text { PctPeng }}{100} \\
b=\xi_{b} \times \text { Kpea } \times \text { Pmax } \\
c=-\alpha\end{array}$ & \\
\hline$\xi_{b}$ & Base fuel-to-power efficiency (gasoline versus diesel) & $\mathrm{mL} / \mathrm{kW} / \mathrm{s}$ \\
\hline ehp & Proportionate decrease in efficiency at high output power & \\
\hline$\alpha$ & Fuel consumption at idling & $\mathrm{mL} / \mathrm{s}$ \\
\hline Paccs_a0 & $\begin{array}{l}\text { Ratio of engine and accessories drag to rated engine power } \\
\text { when travelling at } 100 \mathrm{~km} / \mathrm{h}\end{array}$ & \\
\hline PctPeng & $\begin{array}{l}\text { Percentage of the engine and accessories power used by the } \\
\text { engine }\end{array}$ & $\%$ \\
\hline Engine Speed (RPM) & $\begin{array}{l}R P M=a 0+a 1 \times S P+a 2 \times S P^{2}+a 3 \times S P^{3} \\
S P=\max (20, v)\end{array}$ & $\mathrm{rev} / \mathrm{min}$ \\
\hline$v$ & Vehicle speed & $\mathrm{m} / \mathrm{s}$ \\
\hline ao to a3 & Engine speed model parameter & \\
\hline RPM100 & Engine speed at $100 \mathrm{~km} / \mathrm{h}$ & $\mathrm{rev} / \mathrm{min}$ \\
\hline RPMIdle & Idle engine speed & $\mathrm{rev} / \mathrm{min}$ \\
\hline Tractive Power $\left(P_{\text {tr }}\right)$ & $P_{t r}=v(F a+F g+F c+F r+F i) / 1000$ & $\mathrm{~kW}$ \\
\hline $\mathrm{Fa}$ & Aerodynamic forces & $\mathrm{N}$ \\
\hline $\mathrm{Fg}$ & Gradient forces & $\mathrm{N}$ \\
\hline $\mathrm{Fc}$ & Curvature forces & $\mathrm{N}$ \\
\hline Fr & Rolling resistance forces & $\mathrm{N}$ \\
\hline
\end{tabular}




\begin{tabular}{|c|c|c|}
\hline $\mathrm{Fi}$ & Inertial forces & $\mathrm{N}$ \\
\hline $\begin{array}{l}\text { Aerodynamic Forces } \\
\left(\mathbf{F}_{\mathbf{a}}\right)\end{array}$ & $F_{a}=0.5 \times \rho \times C D_{\text {mult }} \times C D \times A F \times v^{2}$ & $\mathrm{~N}$ \\
\hline $\mathrm{CD}$ & Drag coefficient & \\
\hline CDmult & CD multiplier & \\
\hline $\mathrm{AF}$ & Front area & $\mathrm{m}^{2}$ \\
\hline$\rho$ & Mass density of the air & $\mathrm{kg} / \mathrm{m}^{3}$ \\
\hline$v$ & Vehicle speed & $\mathrm{m} / \mathrm{s}$ \\
\hline Rolling Resistance $\left(\mathbf{F}_{\mathbf{r}}\right)$ & $\begin{array}{r}F_{r}=C R 2 \times F C L I M \times(b 11 \times N w+C R 1 \\
\left.\times\left(b 12 \times M+b 13 \times v^{2}\right)\right)\end{array}$ & $\mathrm{N}$ \\
\hline CR1 & Rolling resistance tire factor & \\
\hline $\begin{array}{r}\text { Rolling Resistance } \\
\text { Parameters }\end{array}$ & $\begin{aligned} b 11= & 37 \times D w \\
b 12= & \frac{0.067}{D w} \text { old ties } \\
& \frac{0.064}{D w} \text { latest tire } \\
b 13= & 0.012 \times N w / D w^{2}\end{aligned}$ & \\
\hline $\begin{array}{r}\text { Rolling Resistance } \\
\text { Surface Factor (CR2) }\end{array}$ & $\begin{aligned} C R 2=K c r 2 \times & (a 0+a 1 \times T d s p+a 2 \times I R I+a 3 \\
& \times D E F)\end{aligned}$ & \\
\hline Kcr2 & Calibration factor for rolling resistance & \\
\hline a0 to a3 & Rolling resistance model coefficient & \\
\hline Tdsp & Texture depth using sand patch method & $\mathrm{mm}$ \\
\hline IRI & International roughness index & $\mathrm{m} / \mathrm{km}$ \\
\hline DEF & Benkelman beam rebound deflection & $\mathrm{mm}$ \\
\hline FCLIM & $F C L I M=1+0.003 \times P C T D S+0.002 \times P C T D W$ & \\
\hline PCTDS & Percentage driving on snow & \\
\hline PCTDW & Percentage driving on wet surface & \\
\hline Gradient Forces (Fg) & $F_{g}=M \times G R \times g$ & $\mathrm{~N}$ \\
\hline M & Vehicle Weight & $\mathrm{kg}$ \\
\hline GR & Gradient & radians \\
\hline g & Gravity & $\mathrm{m} / \mathrm{s}^{2}$ \\
\hline
\end{tabular}




\begin{tabular}{|r|l|l|}
\hline Curvature Forces (Fc) & $F_{c}=\max \left[0, \frac{\left(\frac{M \times v^{2}}{R}-M \times g \times e\right)^{2}}{N_{w} \times C_{s}} \times 10^{-3}\right]$ & $\mathrm{N}$ \\
\hline $\mathrm{R}$ & Curvature radius & $\mathrm{m}$ \\
\hline Superelevation (e) & $e=\max (0,0.45-0.68 \times \operatorname{Ln}(R))$ & $\mathrm{m} / \mathrm{m}$ \\
\hline $\mathrm{Nw}$ & Number of wheels & \\
\hline Tire Stiffness (Cs) & $C s=K c s \times\left[a 0+a 1 \times \frac{M}{N w}+a 2 \times\left(\frac{M}{N w}\right)^{2}\right]$ & $\mathrm{kN} / \mathrm{rad}$ \\
\hline $\mathrm{Kcs}$ & Calibration Factor & \\
\hline a0 to a2 & Tire stiffness model parameters & $\mathrm{N}$ \\
\hline Inertial forces (Fi) & $F i=M \times\left[a 0+a 1 \times \arctan \left(\frac{a 2}{v^{3}}\right)\right] \times a$ & \\
\hline a0 to a2 & Inertial force model parameters & $\mathrm{m} / \mathrm{s}^{2}$ \\
\hline a & Acceleration & \\
\hline
\end{tabular}

The engine speed parameters (a1, a2, a3, a4) were calibrated by Chatti (Chatti \& Zaabar, 2012) to Michigan’s highway condition. The calibration results, as well as the default model adoptions, were illustrated in Table 5.2 (Bennett \& Greenwood, 2003a).

The rolling resistance term, Fr, describes the characteristics of pavement-vehicle interaction. Pavement roughness and texture are measured as the international roughness index (IRI) and sand patch texture depth (Tdsp). Pavement deflection is denoted by Benkelman Beam Rebound Deflection (DEF), which describes the pavement's structural characteristics and stiffness. Table 5.3 shows the default parameter adoptions in rolling resistance Fr; a1, a2 and a3 are the coefficients that associated with variables of sand patch texture depth (Tdsp), roughness (IRI), and Benkelman Beam Rebound deflection respectively. 
Table 5.2 Parameters Adoption for Engine Speed Model

\begin{tabular}{|c|c|c|c|c|c|c|c|c|}
\hline \multirow{2}{*}{ Vehicle Type } & \multicolumn{4}{|c|}{ Default Adoption } & \multicolumn{4}{c|}{ Chatti \& Zaabar } \\
\cline { 2 - 9 } & $\mathbf{a 1}$ & $\mathbf{a} 2$ & $\mathbf{a 3}$ & $\mathbf{a}$ & $\mathbf{a 1}$ & $\mathbf{a} 2$ & $\mathbf{a 3}$ & $\mathbf{a 4}$ \\
\hline Motorcycle & -162 & 298.86 & -4.6723 & -0.0026 & 720.05 & 0.868 & 0.2006 & -0.0007 \\
\hline Small car & 1910 & -12.311 & 0.2228 & -0.0003 & 720.05 & 0.868 & 0.2006 & -0.0007 \\
\hline Medium car & 1910 & -12.311 & 0.2228 & -0.0003 & 720.05 & 0.868 & 0.2006 & -0.0007 \\
\hline Large car & 1910 & -12.311 & 0.2228 & -0.0003 & 595.73 & 7.311 & -0.2845 & 0.0033 \\
\hline $\begin{array}{c}\text { Light delivery } \\
\text { car }\end{array}$ & 1910 & -12.311 & 0.2228 & -0.0003 & 595.73 & 7.311 & -0.2845 & 0.0033 \\
\hline Light vehicle & 2035 & -20.036 & 0.356 & -0.0009 & 982.37 & 3.6701 & -0.1331 & 0.0019 \\
\hline $\begin{array}{c}\text { Four wheel } \\
\text { drive }\end{array}$ & 2035 & -20.036 & 0.356 & -0.0009 & 550.08 & -3.0722 & 0.3798 & -0.0018 \\
\hline Light truck & 2035 & -20.036 & 0.356 & -0.0009 & 720.05 & 0.868 & 0.2006 & -0.0007 \\
\hline Medium truck & 1926 & -32.352 & 0.7403 & -0.0027 & 550.08 & -3.0722 & 0.3798 & -0.0018 \\
\hline Heavy truck & 1905 & -12.988 & 0.2494 & -0.0004 & 799.6 & -5.3791 & 0.2077 & 0.00006 \\
\hline Articulated & 1900 & -10.178 & 0.1521 & 0.00004 & 799.6 & -5.3791 & 0.2077 & 0.00006 \\
\hline truck & 1910 & -12.311 & 0.2228 & -0.0003 & 799.6 & -5.3791 & 0.2077 & 0.00006 \\
\hline Mini bus & 2035 & -20.036 & 0.356 & -0.0009 & 799.6 & -5.3791 & 0.2077 & 0.00006 \\
\hline Light bus & 1926 & -32.352 & 0.7403 & -0.0027 & 799.6 & -5.3791 & 0.2077 & 0.00006 \\
\hline $\begin{array}{c}\text { Medium bus } \\
\text { Heavy bus }\end{array}$ & 1926 & -32.352 & 0.7403 & -0.0027 & 799.6 & -5.3791 & 0.2077 & 0.00006 \\
\hline Coach & 1926 & -32.352 & 0.7403 & -0.0027 & 799.6 & -5.3791 & 0.2077 & 0.00006 \\
\hline
\end{tabular}

Table 5.3 Default Parameters of CR2 Model in Fr for Flexible and Rigid Pavement

\begin{tabular}{|c|c|c|c|c|c|c|c|c|}
\hline \multirow{2}{*}{$\begin{array}{c}\text { Surface } \\
\text { Type }\end{array}$} & \multicolumn{4}{|c|}{ Less than 2,500kg } & \multicolumn{4}{c|}{ More than 2,500kg } \\
\cline { 2 - 9 } & a0 & a1 & a2 & a3 & a0 & a1 & a2 & a3 \\
\hline Asphalt & 0.5 & 0.02 & 0.1 & 0 & 0.57 & 0.04 & 0.04 & 1.34 \\
\hline Concrete & 0.5 & 0.02 & 0.1 & 0 & 0.57 & 0.04 & 0.04 & 0 \\
\hline
\end{tabular}


However, the Benkelman Beam Rebound Deflection method is barely used and has been replaced by the Falling Weight Deflectometer (FWD) test in most state agencies. The FWD test is designed to impact a load to the pavement surface and measure the surface deformation with the mounted deflection sensors. The maximum deflection under the centre load plate is normally associated with the Benkelman Beam Rebound Deflection with adjustments. This study is intended to substitute the Benkelman Beam Rebound deflection with temperature adjusted FWD centre deflection D0 as the pavement deflection to the model calibration. Figure 5.2 demonstrates the FWD system and deflection basin.

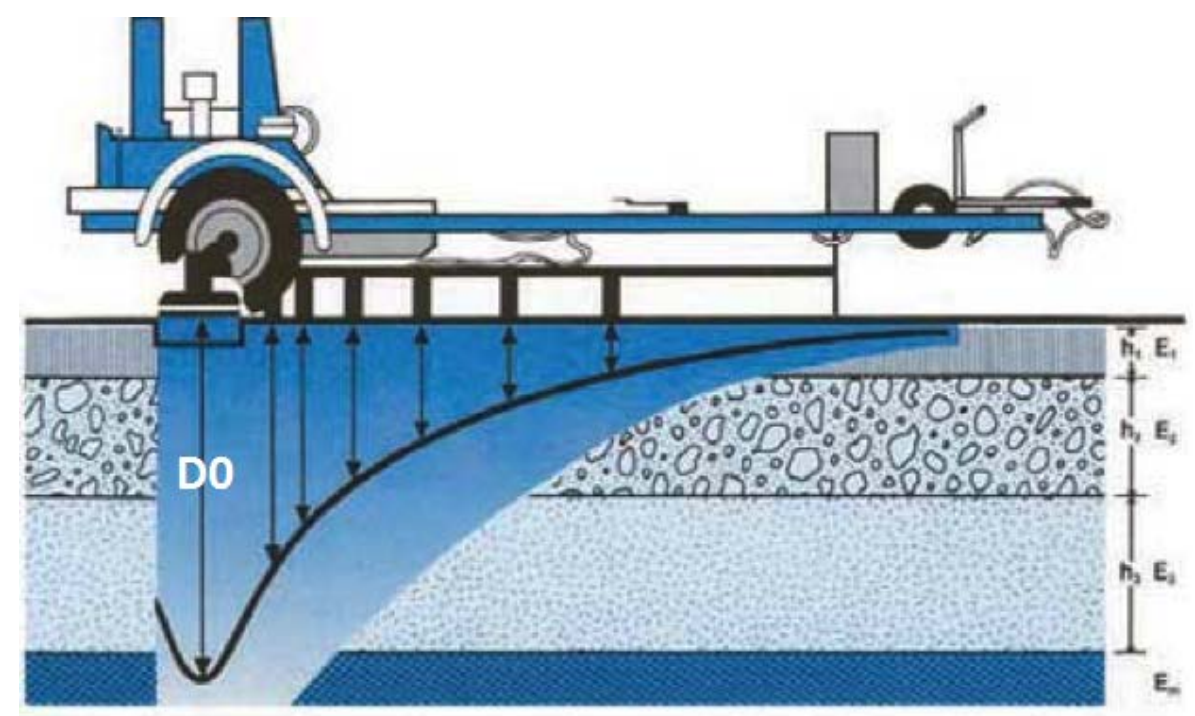

Figure 5.2 FWD System and Deflection Basin

\subsection{MODEL CALIBRATION}

As mentioned in Chapter 4, the instantaneous fuel rates collected from the Phase II field test were used to calculate the fuel consumption on every 0.1-mile roadway section in L/100km. A number of 260 fuel data (120 for flexible sections and 140 data for rigid sections) were generated from passenger car test and 436 fuel data (258 for flexible 
sections and 178 for rigid sections) were generated from the truck test. Appendix A shows the fuel consumption data. The fuel consumptions data were then converted to fuel rates in $\mathrm{mL}$ per second $(\mathrm{mL} / \mathrm{s})$ by multiplying vehicle speed in order to be consistent with the HDM-IV model output.

The FWD data was requested from FDOT Material Office, however, only the data on the flexible pavement sections was available. Since the FWD data on the rigid pavement was not available, assumption has to be made which will be described in the following section. In addition, since the pavement deflection is highly dependent on pavement temperature, adjustments were applied to the FWD centre deflections (D0) based on the FHWA Report 98-085 published in 2000 (Lukanen, et al., 2000). The temperature adjustment factors were calculated based on pavement thickness and ambient temperature (the average pavement temperature recorded during the FWD tests was used to calculate the temperature adjustment factors, to be differentiated with the temperature measured during the fuel consumption test). All D0s were adjusted to a reference pavement temperature of $25^{\circ} \mathrm{C}\left(77^{\circ} \mathrm{F}\right)$. Appendix C demonstrates the resulted D0s for the flexible pavement sections.

In addition, the textures data were converted from mean profile depth (MPD) to sand patch depth Tdsp with Equation 5.2 suggested by HTC (HTC, 1999). Vehicle and engine information were gathered and were directly applied to the model.

$$
T d s p=1.02 \times M P D+0.28
$$

Where Tdsp is the pavement texture depth by sand patch method (mm) MPD is the pavement texture depth in mean profile depth (mm) 


\subsubsection{Calibration Methodology}

This section describes the methodologies applied to the HDM-IV model calibration. There are three levels of calibration efforts based on the available time and resources: basic application, calibration, and adaption. The three levels require low, moderate and major levels of calibration efforts and resources respectively (Bennett \& Greenwood, 2003b). This study focuses on the third level "adaption”, which undertakes controlled experiments to enhance the existing predictive relationship.

\subsubsection{Assumptions and Limitations}

It is important to understand the limitations before further proceeding. The model calibration in this study is limited by the following assumptions:

a). Due the high modulus of elasticity of concrete slab compared to flexible pavement structure layers, the FWD deflections are assumed zero for rigid pavement. Part of the reason is the missing of FWD data on the rigid pavement sections;

b). Field tests in Phase II were conducted in double traveling direction for each section (northbound and southbound). It is assumed that this approach can exclude the influence of wind and roadway gradient on vehicle fuel consumption by averaging the fuel data on both test directions, instead of utilizing data from a single direction;

c). It is assumed that the average pavement data (IRI, texture, D0) on both traveling directions can represent the real characteristics of that centreline roadway section;

d). Two vehicle classes are studied in this chapter: passenger car (2axles/4wheels) and medium duty box truck (2-axles/6-wheels); 
e). The study only focuses on the model calibration on Florida's interstate pavement and traffic condition. All data is collected from Florida's interstate roadways (one exception in passenger car test). The non-interstate/non-highway pavements are not covered;

f). No curvature and gradient effect is considered in the model. The roadway sections selected are on flat terrain and considered as straight roads;

g). Only the steady speed condition is studied. Two levels of highway speeds are evaluated for each vehicle class;

h). Only the dry pavement condition is considered since water has a strong influence on vehicle rolling resistance.

\subsubsection{Identification of Calibration Factors}

There are three default calibration coefficients in HDM-IV fuel consumption model: 1) Kpea which adjusts engine and accessories power, 2) Kcr2 which modifies rolling resistance, and 3) Kcs which adjusts tire stiffness in curvature resistance. Since the curvature effect is excluded, the study only focuses on the first two calibration coefficients Kpea and Kcr2. Beside these two default calibration coefficients, parameters a0, a1, a2, and a3 which comprises the rolling resistance surface factor CR2 are the other calibration emphases of this study. This study is intended to enhance the predictive relationship between CR2 and pavement characteristics (IRI, texture, and D0) with the controlled experimental results from the Phase II study. The equation of rolling resistance surface factor CR2 is rephrased in Equation 5.3. The coefficient a1, a2, and a3 modify pavement texture, roughness, and deflection respectively.

$$
C R 2=K_{c r 2}(a 0+a 1 \times T d s p+a 2 \times I R I+a 3 \times D E F)
$$




\begin{tabular}{|c|c|c|}
\hline Where & $\begin{array}{l}\text { CR2 } \\
\text { Kcr2 } \\
\text { a0 } \\
\text { a1 } \\
\text { a2 } \\
\text { a3 }\end{array}$ & $\begin{array}{l}\text { is the rolling resistance surface factor } \\
\text { is the default calibration coefficient } \\
\text { is the equation constant } \\
\text { is the pavement texture coefficient } \\
\text { is the pavement roughness coefficient } \\
\text { is the pavement deflection coefficient }\end{array}$ \\
\hline
\end{tabular}

The objective is to replace the default pavement deflection DEF by the temperature adjusted FWD centre deflection D0 and calibrate the pavement associated coefficients a0, a1, a2, and a3 with the experiment data. The goal is to evaluate the effect of PVI on fuel consumption with a local calibrated HDM-IV fuel consumption model. To summarize, the factors that are targeted for calibration are: 1) Kpea, 2) Kcr2, and 3) a0, a1, a2, a3.

\subsubsection{Model Calibration}

The model inputs are roughness (IRI), texture (Tdsp), temperature adjusted FWD centre deflection (D0), ambient temperature, and vehicle speed. Other parameters remain constant during the calibration. The parameters measured/adopted in the HDM-IV model are shown in Table 5.4 .

Calibrations were separated for flexible pavement and rigid pavement. Four groups of data sets were applied to the calibration: car test of flexible pavement, car test of rigid pavement, truck test of flexible pavement, and truck test of rigid pavement. Before calibration, 25\% of each data set were randomly selected and held out for validation purposes after the calibration, then the rest of $75 \%$ were used to perform the calibration.

Nonlinear programming optimization technique through MS Excel solver routine was used to perform the calibration. This approach was used to minimize the sum square 
of differences/errors (SSE) between predicted values and measured values. A two-step calibration technique was applied. Firstly, the flexible pavement data and rigid pavement data for the same vehicle class were combined to calibrate coefficients Kpea and Kcr2 until the total SSE reached its minimum value. Second, coefficient a0, a1, a2 and a3 were calibrated in each vehicle-pavement combination until each of their own SEE reached the minimum limit. Four groups of calibration coefficients were generated after the calibration.

Table 5.4. Parameters Adopted in HDM-IV

\begin{tabular}{|c|c|c|c|c|c|}
\hline \multicolumn{2}{|c|}{ Variable } & Description & Car & Truck & Sources $^{\mathrm{a}}$ \\
\hline \multicolumn{2}{|l|}{ Pengacc } & \multicolumn{4}{|l|}{ Engine and Accessories Power (kW) } \\
\hline$\alpha$ & & Fuel consumption at idling $(\mathrm{mL} / \mathrm{s})$ & 0.36 & 0.8 & Observed \\
\hline$\xi_{\mathrm{b}}$ & & Base engine efficiency (mL/kW/s) & 0.067 & 0.059 & Bennett \\
\hline ehp & & $\begin{array}{l}\text { Decrease in engine efficiency at higher } \\
\text { power }\end{array}$ & 0.25 & 0.1 & Bennett \\
\hline Pmax & & Rated engine power (kW) & 103 & 200 & Observed \\
\hline Paccs_ao & & $\begin{array}{l}\text { Ratio of engine/accessory drag to rated } \\
\text { engine power traveling @ 100km/h }\end{array}$ & 0.2 & 0.2 & Bennett \\
\hline Pctpeng & & $\begin{array}{l}\text { Percentage of total engine and accessories } \\
\text { power used by the engine }\end{array}$ & 80 & 80 & Bennett \\
\hline \multirow[t]{4}{*}{ RPM } & $a_{0}$ & Engine speed model parameter & 720.05 & 799.6 & Chatti \\
\hline & $a_{1}$ & Engine speed model parameter & 0.868 & -5.3791 & Chatti \\
\hline & $\mathrm{a}_{2}$ & Engine speed model parameter & 0.2006 & 0.2077 & Chatti \\
\hline & $\mathrm{a}_{3}$ & Engine speed model parameter & -0.0007 & 0.00006 & Chatti \\
\hline RMP_Idle & & Idle engine speed (Rev/min) & 800 & 834 & Observed \\
\hline edt & & Drive train efficiency & 0.9 & 0.86 & Bennett \\
\hline \multicolumn{2}{|l|}{ Ptr } & \multicolumn{4}{|l|}{ Tractive Power (kW) } \\
\hline $\mathrm{CR}_{1}$ & & Rolling resistance tire factor & 1 & 1 & Bennett \\
\hline Dw & & Wheel diameter (m) & 0.62 & 1.07 & Observed \\
\hline $\mathrm{Nw}$ & & Number of wheels & 4 & 6 & Observed \\
\hline $\mathrm{v}$ & & Vehicle speed (m/s) & $25.5 / 31.1$ & $24.6 / 29.1$ & Observed \\
\hline
\end{tabular}




\begin{tabular}{|r|l|c|c|r|}
\hline $\mathrm{M}$ & Vehicle Weight $(\mathrm{kg})$ & 1414 & 10614 & Observed \\
\hline FCLIM & Climatic factor & 1 & 1 & Observed \\
\hline AF & Front area $\left(\mathrm{m}^{2}\right)$ & 2.16 & 6.3 & Observed \\
\hline CD & Drag coefficient & 0.31 & 0.7 & Observed \\
\hline
\end{tabular}

\subsubsection{Calibration Results}

Table 5.5 lists the four groups of coefficient that were generated from the twostep calibration. Calibration results were compared with the default model adoptions from Table 5.3. For passenger car (corresponding to column "less than $2.500 \mathrm{~kg}$ in Table 5.3), coefficient a1 and a2 remained no change before and after model calibration. This indicates good model fitness for the roughness and texture data. Coefficient a3, which modifies pavement deflection, was increased from 0 to a value of 0.09 . This suggests that the refined fuel consumption model discovered the sensitivity of pavement deflection on passenger car fuel consumption. For the truck result, coefficient a1 remained no change, and a2 showed little change (0.04 to 0.03 ) from un-calibrated model to calibrated model. Coefficient a3 was decreased from 1.34 to 0.17 . This indicates pavement deflection exhibited decreased sensitivity in the refined fuel consumption model, but it is still the largest coefficient within the truck CR2 term.

Table 5.5 Calibration Results

\begin{tabular}{|c|c|c|c|c|c|c|c|}
\hline Vehicle & Model & Kpea & Kcr2 & a0 & a1 & a2 & a3 \\
\hline \multirow{2}{*}{ Car } & Flexible Pavement & 0.250 & 1.077 & 0.49 & 0.02 & 0.10 & 0.09 \\
\cline { 2 - 8 } & Rigid Pavement & 0.250 & 1.077 & 0.49 & 0.02 & 0.10 & 0 \\
\hline \multirow{2}{*}{ Truck } & Flexible Pavement & 1.139 & 0.973 & 0.73 & 0.04 & 0.03 & 0.17 \\
\cline { 2 - 8 } & Rigid Pavement & 1.139 & 0.973 & 0.73 & 0.04 & 0.03 & 0 \\
\hline
\end{tabular}




\subsection{MODEL EVALUATION}

The goal of the model calibration is to improve model fitness and reduce the bias of the model predictions to acceptable levels. Different methodologies were applied to evaluate or validate the calibrated results. The following sections describe such efforts.

\subsubsection{Evaluation $I-R^{2}$ and SSE}

Coefficients of determination $\mathrm{R}^{2}$ and adjust $\mathrm{R}^{2}$ were calculated (both before and after calibration) based on sum squared errors (SSE) between the measurement and model prediction. The results are summarized in Table 5.6. The increased $\mathrm{R}^{2}$ and adjusted $\mathrm{R}^{2}$ indicate improved fitness between observed fuel consumption and the prediction model. In addition, the changes of Sum Square of Errors (SSE) before and after model calibration are included in Table 5.6. The decreased SSE also indicates increased model fitness before and after the model calibration.

\subsubsection{Evaluation I - Bias}

Biases were calculated from Equation 5.4 as the mean of measured fuel consumption over the mean of predicted fuel consumption. The calculated biases before and after model calibration are included in Table 5.6. The more close the bias to 1, the less the model bias. From the results, all groups of calibration present decreased bias from un-calibrated model to calibrated model.

$$
\text { Bias }=\frac{\text { Mean of Measurement }}{\text { Mean of Prediction }}
$$

Residuals (errors) were then evaluated graphically in order to see the changes of bias from un-calibrated model to calibrated model. Absolute residuals were plotted for each pavement-vehicle group in Figure 5.3 from plot a to plot d. By fitting a polynomial 
(to the maximum order of 6) to each data pattern, one can visualize if there is a trend in the direction of fitted values. The more clearly the tendency, the larger bias the model possesses. In plot a, b, c and d: the data patterns on top of the chart belong to uncalibrated model, the data patterns at the bottom are respected to the calibrated model. From the plots, all groups of calibration exhibit largely reduced data tendency, which indicate significantly decreased bias from the un-calibrated model to the calibrated model. The conclusions from the residuals plots agree with the results calculated from Equation 5.4.

Table 5.6 Changes of $\mathrm{R}^{2}$ and SSE Before and After Calibration

\begin{tabular}{|c|c|c|c|c|c|c|c|c|}
\hline & \multicolumn{2}{|c|}{ Car at Flexible } & \multicolumn{2}{c|}{ Car at Rigid } & \multicolumn{2}{c|}{ Truck at Flexible } & \multicolumn{2}{c|}{ Truck at Rigid } \\
\cline { 2 - 9 } & 0 & 1 & 0 & 1 & 0 & 1 & 0 & 1 \\
\hline $\mathbf{R}^{\mathbf{2}}$ & $0 \%$ & $96.6 \%$ & $0 \%$ & $92.5 \%$ & $90.6 \%$ & $94.3 \%$ & $83.9 \%$ & $94.3 \%$ \\
\hline Ad. $\mathbf{R}^{\mathbf{2}}$ & $0 \%$ & $96.5 \%$ & $0 \%$ & $92.3 \%$ & $90.5 \%$ & $94.3 \%$ & $83.7 \%$ & $94.2 \%$ \\
\hline SSE & 115.3 & 0.5 & 137.3 & 1.2 & 48.8 & 29.4 & 70.4 & 24.7 \\
\hline Bias & 0.590 & 0.993 & 0.582 & 0.997 & 1.024 & 1.001 & 1.081 & 0.999 \\
\hline
\end{tabular}

Note: 0 represents un-calibrated model;

1 represents calibrated model.

Figure 5.3 Model Residuals Plots 
Fitted Values

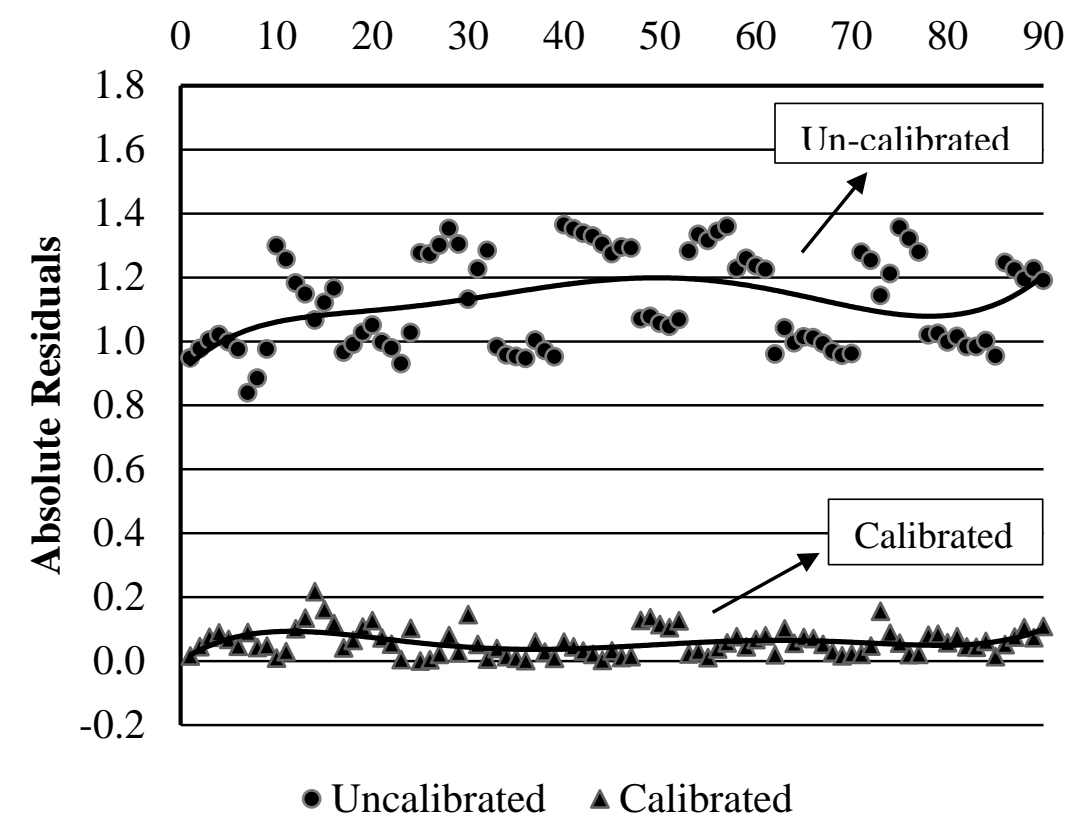

Plot a - Car at Flexible Pavement

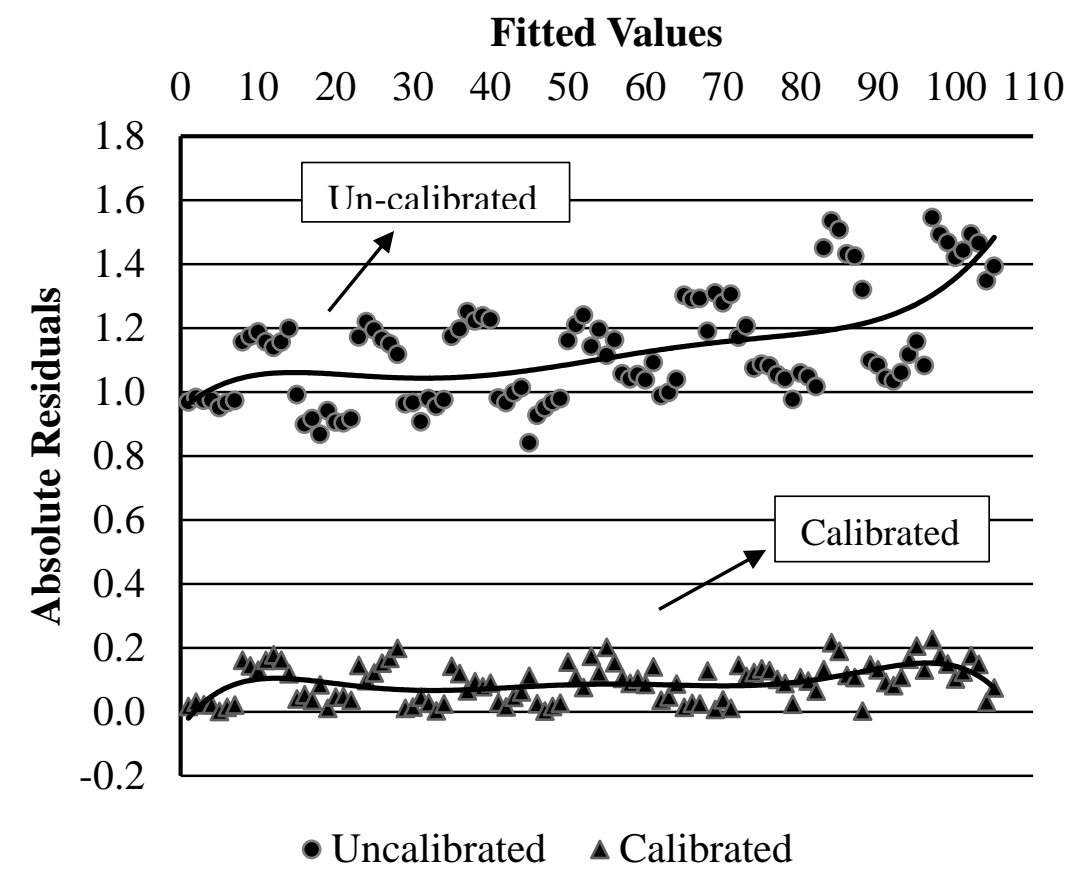

Plot a - Car at Rigid Pavement 
Fitted Values

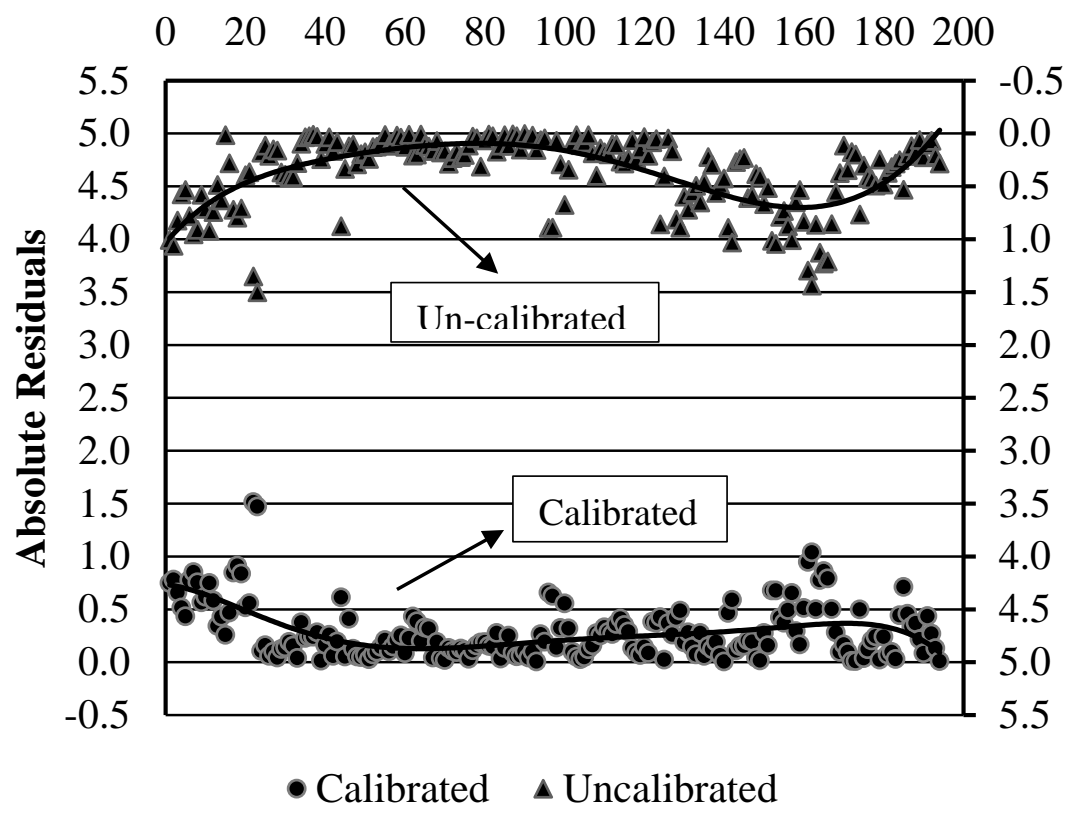

Plot c - Truck at Flexible Pavement

Fitted Values

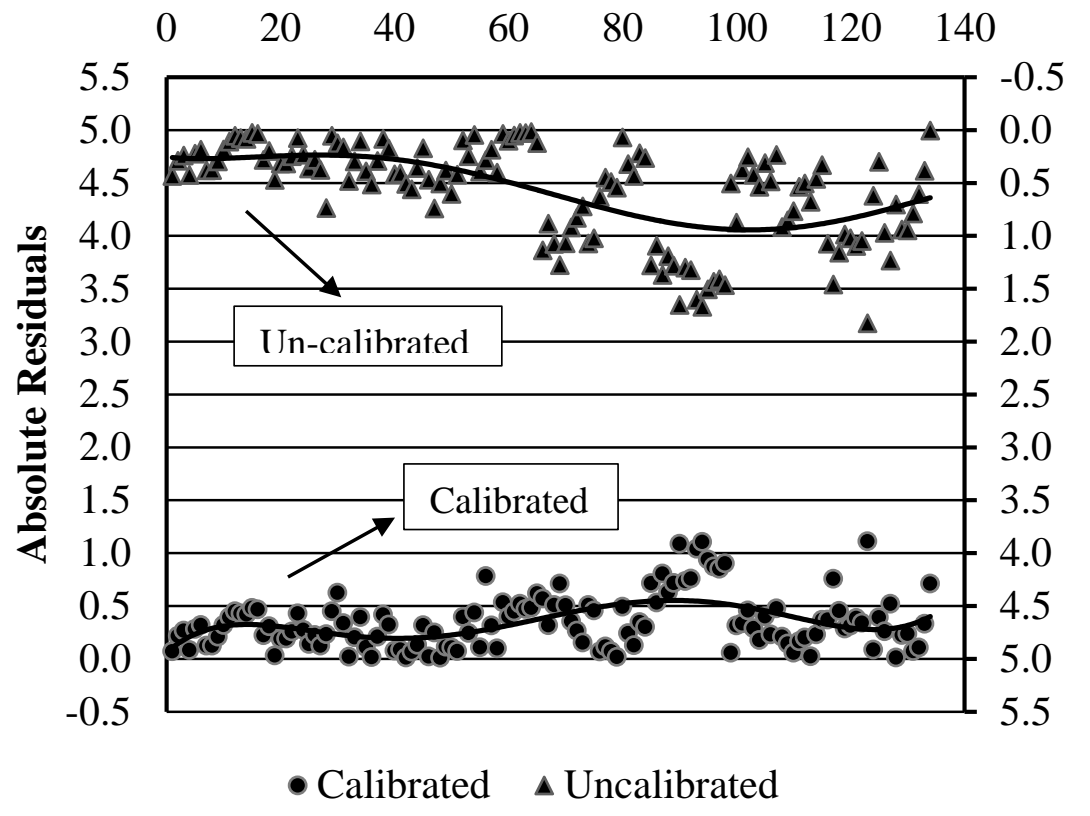

Plot d - Truck at Rigid Pavement 
Figure 5.3 Model Residuals Plots

\subsubsection{Model Validation}

Finally, the calibrated models were evaluated with the 25\% hold-out data (testing data). The advantage of hold-out validation is the application of real data to estimate the true prediction error. For each group, paired t-test was performed between the predicted fuel consumption and real measurement (testing data). The statistical results were summarized in Table 5.7. From the table, all p-values were shown statistically nonsignificant (greater than 0.05), which indicate there is no statistically significant difference between the real measurement and model prediction. Thus, conclusions can be made that the calibrated models were able to predict reality.

Table 5.7 Paired T-Test Results

\begin{tabular}{|c|c|c|c|c|}
\hline & $\begin{array}{c}\text { Car at Flexible } \\
\text { Pavement }\end{array}$ & $\begin{array}{c}\text { Car at Rigid } \\
\text { Pavement }\end{array}$ & $\begin{array}{c}\text { Truck at Flexible } \\
\text { Pavement }\end{array}$ & $\begin{array}{c}\text { Truck at Rigid } \\
\text { Pavement }\end{array}$ \\
\hline $\begin{array}{c}\mathbf{a}_{\mathbf{\mu} 1} \\
\text { (Prediction) }\end{array}$ & 1.652 & 1.631 & 7.763 & 7.517 \\
\hline $\begin{array}{c}\mathbf{b} \mathbf{\mu 2} \\
\text { (Measurement) }\end{array}$ & 1.656 & 1.656 & 7.755 & 7.441 \\
\hline $\mathbf{d f}$ & 29 & 34 & 63 & 43 \\
\hline t-statistic $^{\mathbf{c}}$ & 2.05 & 2.03 & 2.00 & 2.02 \\
\hline p-value $^{\mathbf{c}}$ & 0.78 & 0.23 & 0.85 & 0.24 \\
\hline
\end{tabular}

Note: a: Mean of model predictions;

b: Mean of real measurements;

c: Two-tail t-statistic and p-value. 


\subsection{EFFECT OF PAVEMENT DEFLECTION ON FUEL CONSUMPTION}

The calibrated model was applied to quantify the influence of pavement deflection on vehicle fuel consumption. The pavement deflection here refers to the pavement FWD test centre deflection. Since the results of this study were built upon the assumption of zero pavement deflection for rigid pavement due to its higher stiffness compared to flexible pavement, this section mainly focuses on the effect of deflection on flexible pavement.

In order to solely investigate the deflection-induced fuel effect, fixed values were assigned to non-interested variables. The assigned values were either the average measurements in the field test or are the most common adoptions in Florida's highway network. The following values were assigned to IRI, texture and pavement surface temperature respectively.

1. $\mathrm{IRI}=1 \mathrm{~m} / \mathrm{km}$;

2. Texture $=1.83 \mathrm{~mm}$ (sand patch method $)=1.52 \mathrm{~mm}$ (mean profile depth);

3. Pavement surface temperature $=25^{\circ} \mathrm{C}$, which indicate no temperature adjustment for the FWD centre deflection (D0);

4. Pavement deflection, which represented by $\mathrm{D} 0,=0 \mathrm{~mm}$, and $1 \mathrm{~mm}$.

The objective is to find out how much vehicle fuel consumption can be induced by 1 unit of pavement deflection $(1 \mathrm{~mm})$ relative to the non-deflected $(0 \mathrm{~mm})$ flexible pavement surface. Thus, the fuel consumption changes $(\Delta \mathrm{FC})$ from zero deflection to $1 \mathrm{~mm}$ deflection were calculated at each highway speeds $(1 \mathrm{~km} / \mathrm{h}$ increment) from $72 \mathrm{~km} / \mathrm{h}$ (45mph) to $113 \mathrm{~km} / \mathrm{h}(70 \mathrm{mph})$. Calculations were performed for passenger car and truck separately. The vehicle configurations (passenger car and truck) in Phase II study were 
applied. Appendix D demonstrates the calculation results. Figure 5.4 and 5.5 display the relationship between vehicle speed and $\Delta \mathrm{FC}$ for passenger car and truck respectively.

\section{Passenger Car}

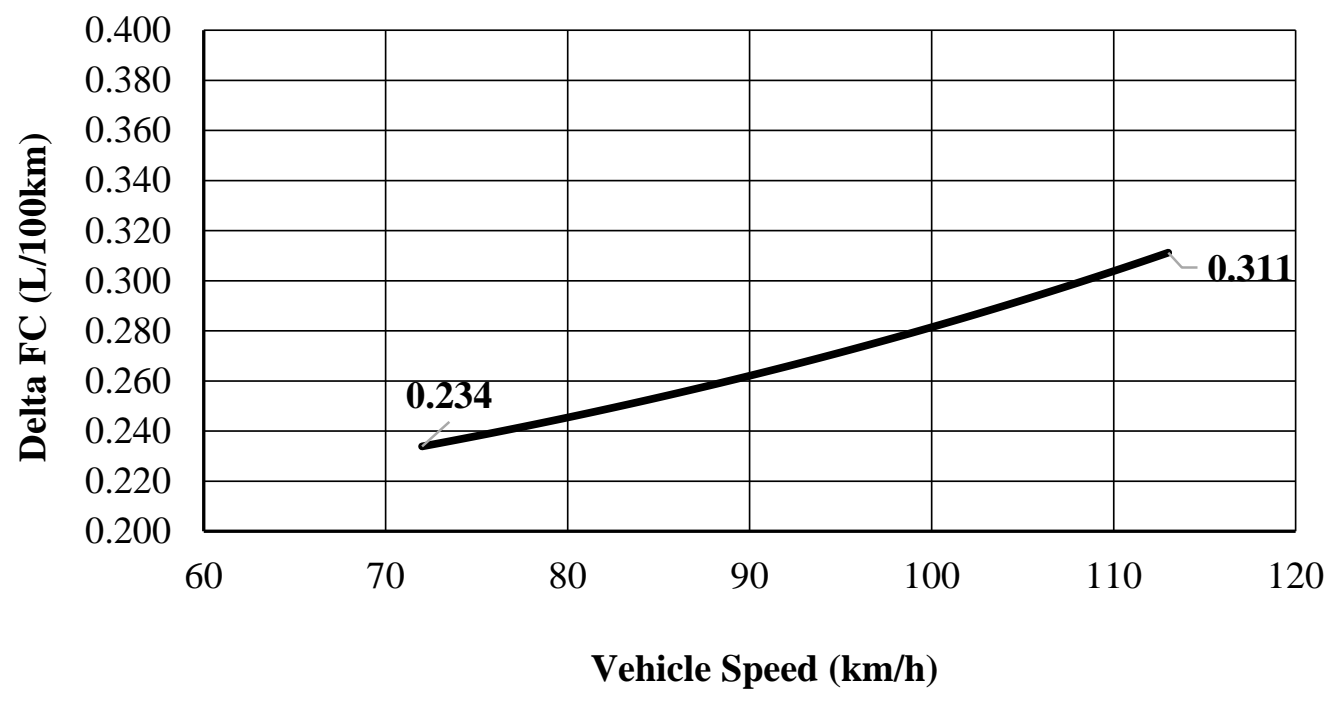

Figure 5.4 Change of Passenger Car FC by 1-unit of Pavement Deflection

\section{Truck}

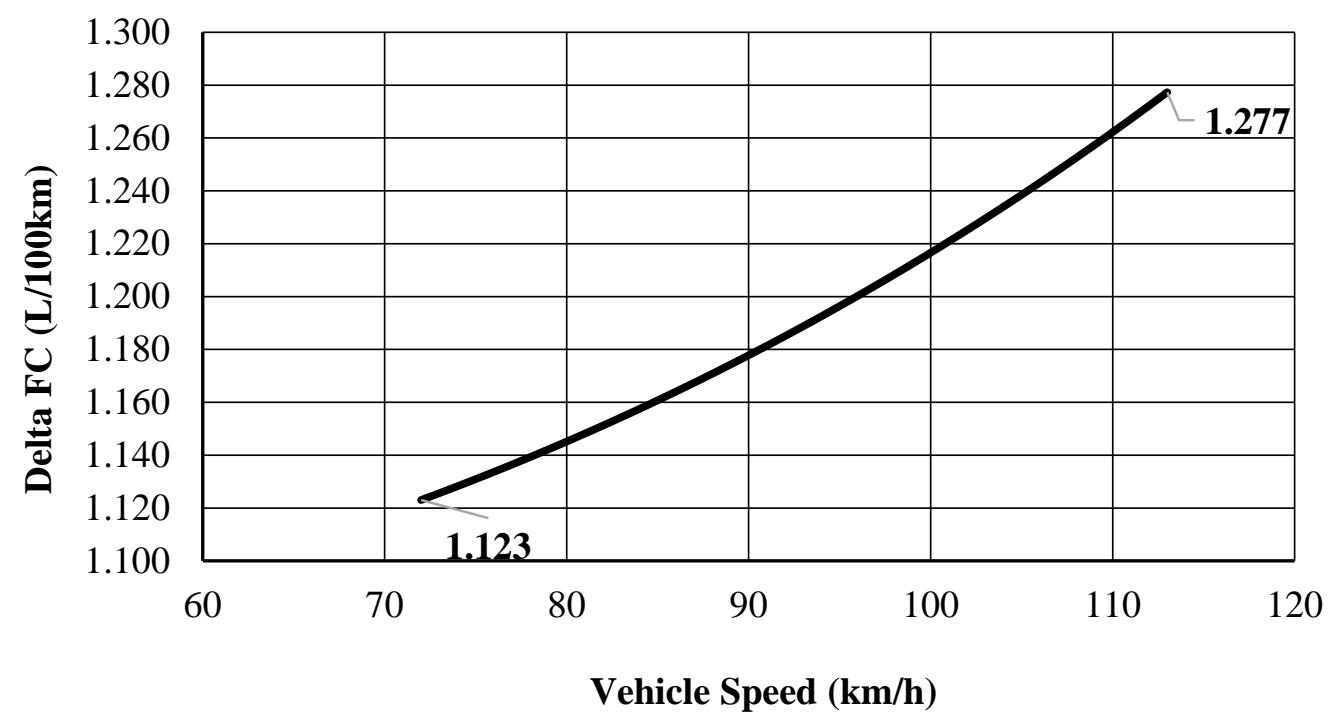


Figure 5.5 Change of Truck FC by 1-unit of Pavement Deflection

From the plots, both passenger car and truck show increased delta fuel consumption with the increase of vehicle speed. In another word, the faster the vehicle travel, the larger the deflection-induced fuel effect. The relationships are very close to linear. Specifically, the delta FC are between 0.234 and $0.311 \mathrm{~L} / 100 \mathrm{~km}$ for passenger car and between 1.123 and $1.277 \mathrm{~L} / 100 \mathrm{~km}$ for the truck.

However, if we plot the percentage change of fuel consumption, $\Delta \mathrm{FC} / \mathrm{FC}_{0}$ deflection, versus vehicle speed, the opposite relationships were resulted as shown in Figure 5.6 and 5.7.

Passenger Car

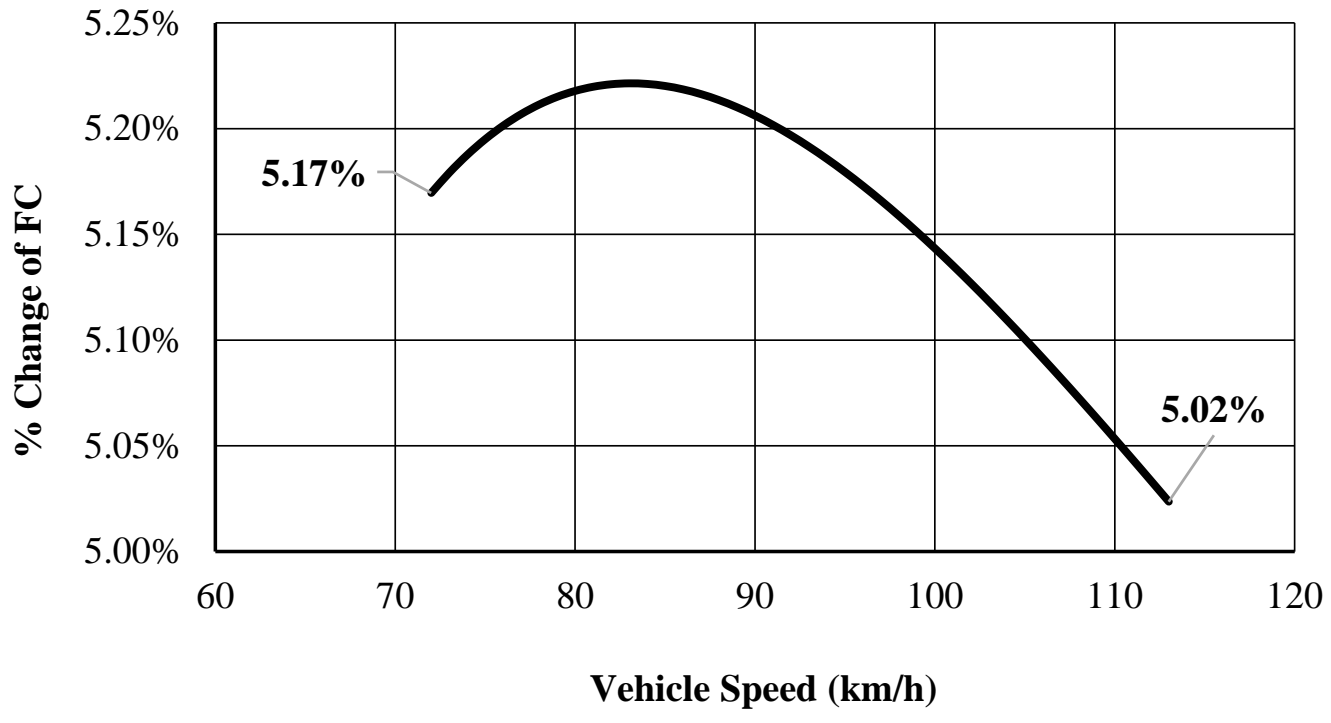

Figure 5.6 Percentage Change of Passenger Car FC by 1-unit of Pavement Deflection 


\section{Truck}

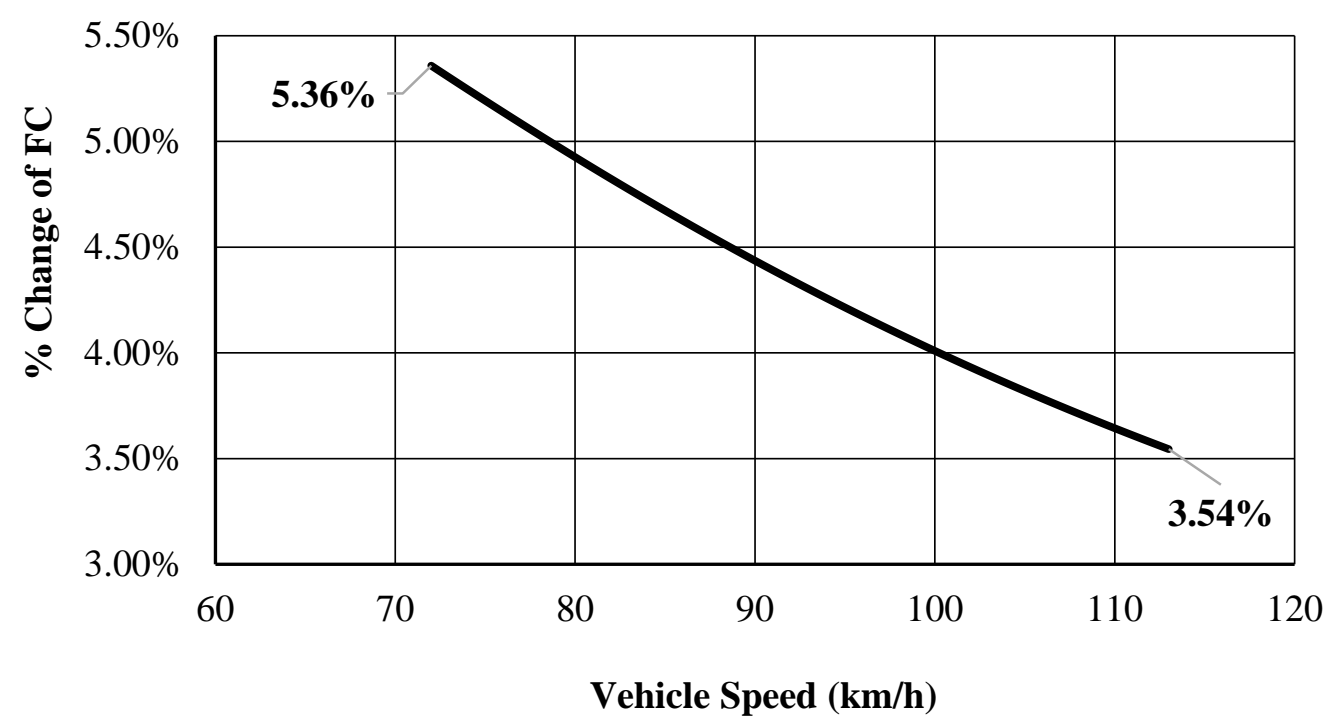

Figure 5.7 Percentage Change of Truck FC by 1-unit of Pavement Deflection

From Figure 5.6, the percentage $\Delta \mathrm{FC}$ was first increased from $5.17 \%$ to a maximum of $5.22 \%$ at $83 \mathrm{~km} / \mathrm{h}$ and then decreased to the lowest of $5.02 \%$. Thus, the highest effect of pavement deflection on fuel consumption was found at the speed of $83 \mathrm{~km} / \mathrm{h}$ (52mph) for the passenger car. For the truck plot, the highest effect was shown at the lowest speed $72 \mathrm{~km} / \mathrm{h}$ (45mph). Also, the range of the truck delta FC was larger than the passenger car delta FC. In summary, both vehicle classes exhibited a more predominant deflection-induced fuel effect at lower highway speed than at higher highway speed.

The findings discovered above can be well explained by the PVI mechanisms. Fewer contact areas between tires and pavement surface were generated for high-speed traveling vehicles compared to low-speed traveling vehicles. The decreased contact area 
leads to less PVI effect on vehicle fuel consumption. This phenomenon is most evident for flexible pavement made on viscoelastic asphaltic material.

\subsection{CONCLUSION}

The emphasis of this chapter is to calibrate the HDM-IV fuel consumption model with data collected from Phase II field test. Defalt model calibration coefficients Kpea and Kcr2 were adjusted along with the pavement related coefficients a0, a1, a2, a3 in rolling resistance surface factor CR2. The coefficient a3, which modifies pavement deflection, was changed from the original value of zero to a non-zero value (0.09) for passenger car on flexible pavement. This indicates a higher vehicle rolling resistance on flexible pavement than rigid pavement with the same levels of surface condition. This also agrees with the empirical findings derived from the two phases of field studies. In addition, coefficients a1 and a2 which modify texture and roughness in HDM-IV, remain little or no change for both passenger car and truck. This suggests good agreement with the default model adoptions. The calibrated models are also evaluated from three aspects: $\mathrm{R}^{2} / \mathrm{SSE}$, bias, and hold-out validations. By results, the final models are proved well calibrated and capable of predicting reality.

The effect of pavement deflection on fuel consumption is investigated with the calibrated HDM-IV fuel consumption model. Results show that one unit of pavement deflection (1mm) can cause an excess fuel consumption compared to a non-deflected flexible pavement surface by 0.234 to $0.311 \mathrm{~L} / 100 \mathrm{~km}$ on passenger car, and by 1.123 to $1.277 \mathrm{~L} / 100 \mathrm{~km}$ on truck. Moreover, the deflection-induced fuel effect is more evident at lower highway speed than higher highway speed for both vehicle classes. 


\section{CHAPTER 6}

\section{NETWORK LEVEL ESTIMATION}

\subsection{INTRODUCTION}

The well calibrated HDM-IV fuel consumption model is implemented to Florida's interstate network to estimate the PVI impact on the annual vehicle fuel consumptions and $\mathrm{CO}_{2}$ emissions. Fuel consumptions and $\mathrm{CO}_{2}$ emissions are estimated based on two scenarios. The first outcome are the total annual fuel consumption and $\mathrm{CO}_{2}$ emission derived from the current flexible pavement and rigid pavement distributions on Florida's interstate roadways: $91.3 \%$ of flexible pavement and $8.7 \%$ of rigid pavement. The second outcome are the total fuel consumptions and $\mathrm{CO}_{2}$ emissions on one extreme circumstance that rigid pavement comprises all the interstate pavement in Florida. The estimations from these two scenarios are compared and findings are presented.

\subsection{INPUT DATA}

The pavement and traffic data of all interstate roadways are collected firstly from the seven legislative districts in Florida. The resulted total annual fuel consumption and $\mathrm{CO}_{2}$ emission are the summation of the estimations from each district. The following sections present the data collected.

\subsubsection{Traffic Data}

Traffic datafiles were obtained from the FDOT Transportation Statistics Office of year 2014. The information extracted from the datafiles include district, roadway identification number, section begin mile post, section end mile post, annual average daily traffic (AADT), and truck annual average daily traffic (Truck AADT). From the database, only the data on interstate roadways were extracted for this study. In addition, 
the passenger car AADT was calculated by subtracting the total AADT by truck AADT. Figure 6.1 and Figure 6.2 displays the passenger car AADT and truck AADT on Florida's interstate roadways.

\subsubsection{Pavement Type}

Pavement type (flexible pavement or rigid pavement) was identified on each section from the database. Results showed an approximately 91.3\% of flexible pavement sections and $8.7 \%$ of rigid pavement sections on Florida's interstate roadways. Composite pavements, which are composed of asphalt surface layer on top of old concrete slabs, were treated as flexible pavement in this study. Figure 6.3 graphically displays the pavement type distribution on Florida's interstate network.

\subsubsection{International Roughness Index (IRI)}

The International Roughness Index (IRI) data was referenced from the 2012 FDOT Flexible Pavement Smoothness Acceptance Report (Holzschunher, et al., 2012). This report is a synthesis of the state-wide project smoothness data from January 2005 to December 2011. It provides the IRI statistics on all flexible pavement roadways in Florida. The statistics of the flexible pavement roadways were applied directly into this study. Such information was not available for the rigid pavement roadways, and the IRI statistics on rigid pavement sections were assumed the same as the flexible pavement sections in each district. This was intended to exclude the influence of roughness on fuel consumption and emission and purely investigate the effect induced by the differences in pavement materials and structural components between flexible pavement and rigid pavement. Table 6.1 summarizes the IRI statistics in each district. 


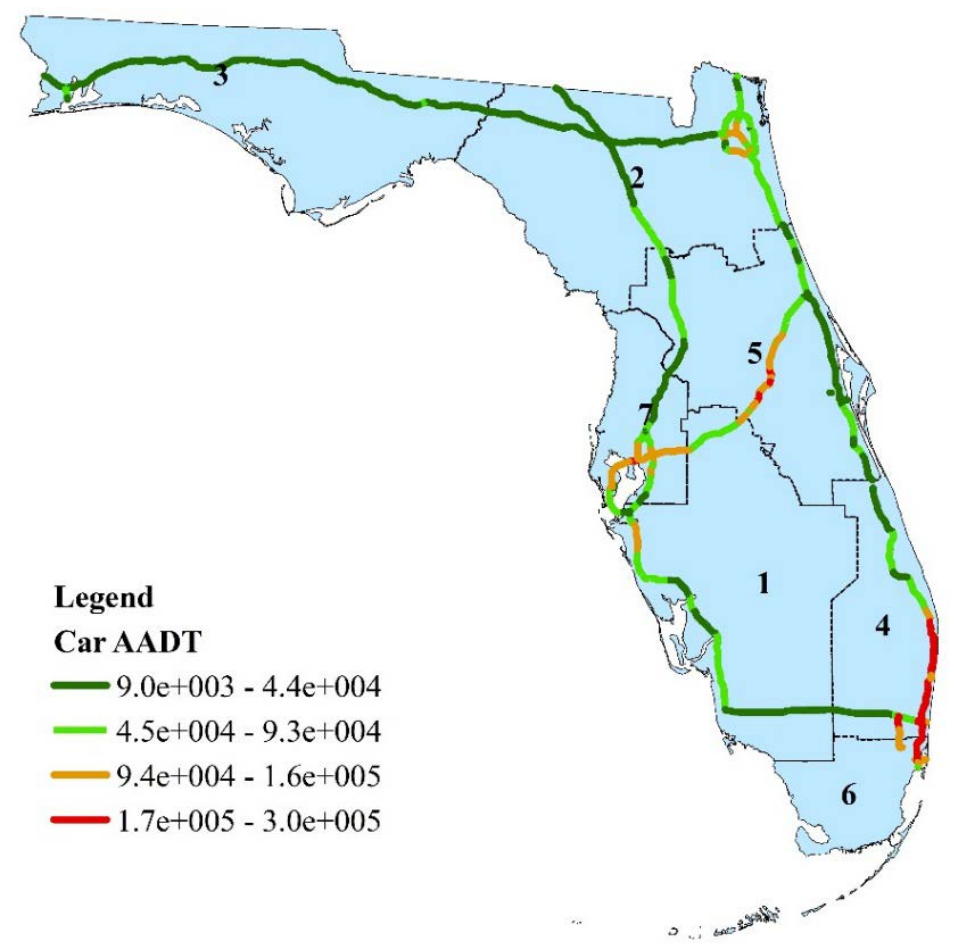

Figure 6.1 2014 Florida Interstate Passenger Car Annual Average Daily Traffic

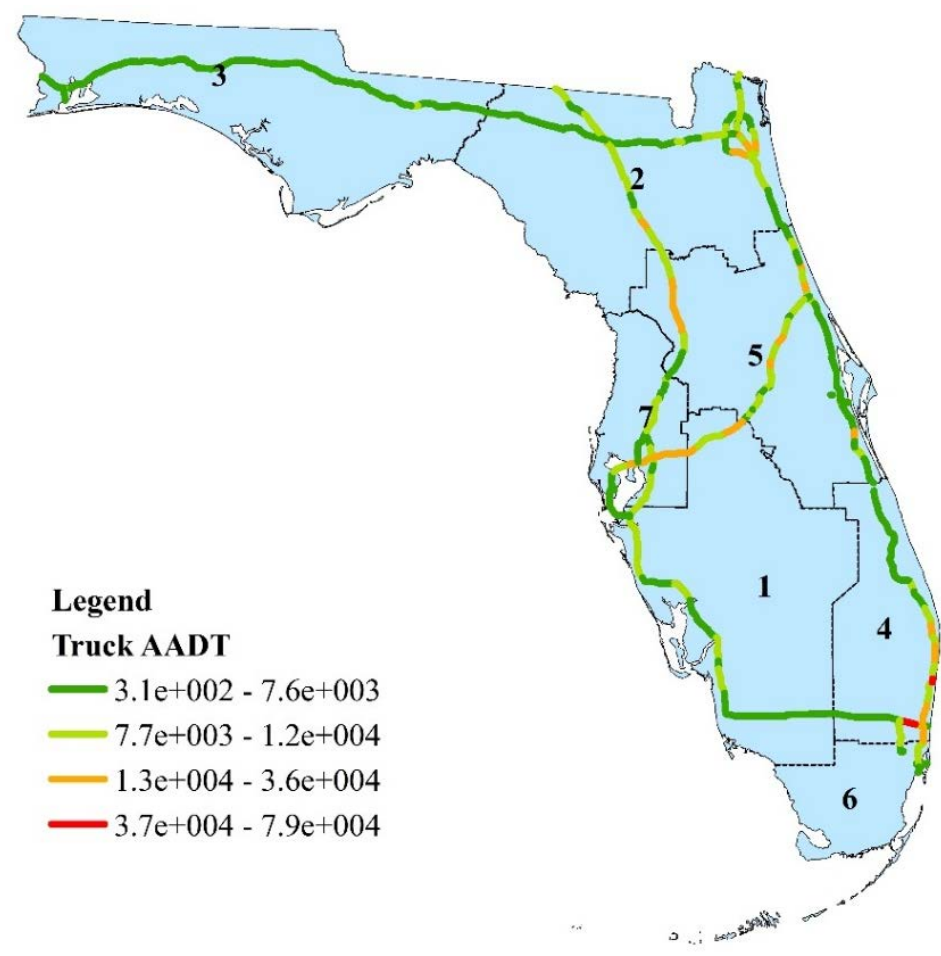

Figure 6.2 2014 Florida Interstate Truck Annual Average Daily Traffic 


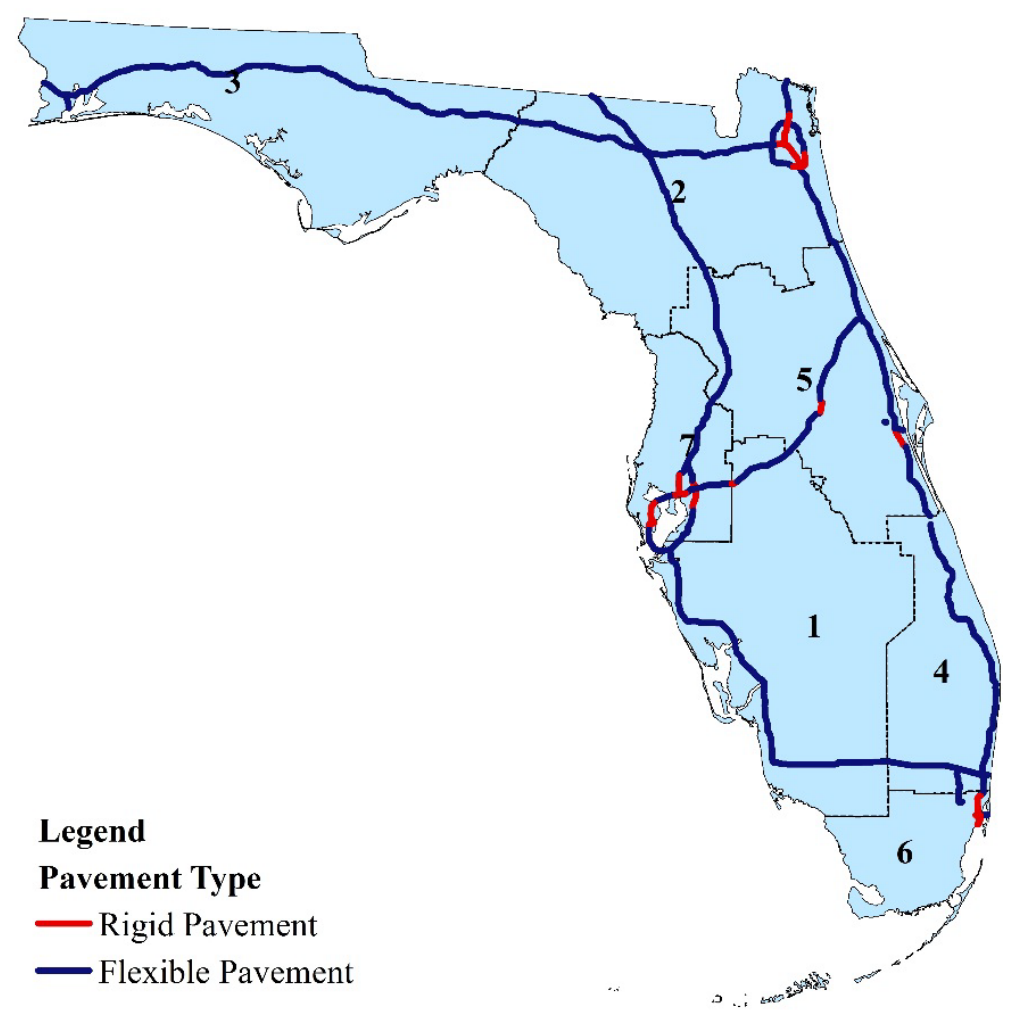

Figure 6.3 Pavement Type on Florida’s Interstate Roadways

Table 6.1 Mean and Standard Deviation of Pavement IRI in in/mile

\begin{tabular}{|c|c|c|c|c|c|c|c|}
\hline $\begin{array}{c}\text { Pavement } \\
\text { Type }\end{array}$ & District 1 & District 2 & District 3 & District 4 & District 5 & District 6 & District 7 \\
\hline Flexible & $\begin{array}{c}46 \\
(9.9)\end{array}$ & $\begin{array}{c}45 \\
(10)\end{array}$ & $\begin{array}{c}40 \\
(7.8)\end{array}$ & $\begin{array}{c}60 \\
(14.6)\end{array}$ & $\begin{array}{c}50 \\
(12.3)\end{array}$ & $\begin{array}{c}60 \\
(11.9)\end{array}$ & $\begin{array}{c}53 \\
(9.6)\end{array}$ \\
\hline Rigid & $\begin{array}{c}46 \\
(9.9)\end{array}$ & $\begin{array}{c}45 \\
(10)\end{array}$ & $\begin{array}{c}40 \\
(7.8)\end{array}$ & $\begin{array}{c}60 \\
(14.6)\end{array}$ & $\begin{array}{c}50 \\
(12.3)\end{array}$ & $\begin{array}{c}60 \\
(11.9)\end{array}$ & $\begin{array}{c}53 \\
\text { (9.6) }\end{array}$ \\
\hline
\end{tabular}

\subsubsection{Falling Weight Deflectometer (FWD) Centre Deflection (D0)}

The FWD test database was requested from the FDOT State Materials Office (SMO). The database contains the FWD test deflection data collected from January 2003 to June 2015. Unlike the IRI data, which is available on every roadway sections, there is 
only certain amount of FWD tests conducted on selected roadway sections every year. But the available data (a total of 39,877) from 2003 to 2015 is large enough to provide a good overall estimation on Florida's interstate highways. However, nearly all the FWD tests were conducted only on the flexible pavement sections. The FWD deflections on rigid pavement were assumed as zero, which is the same as in Chapter 5.

The statistics of the FWD centre deflection (D0) were calculated in each district. No temperature adjustments were performed on the deflection data, but such information is also included in the statistics table (Table 6.2). From the table, the mean pavement surface temperature are all larger (or equal) than $77^{\circ} \mathrm{F}\left(25^{\circ} \mathrm{C}\right)$. The higher the temperature beyond $77^{\circ} \mathrm{F}\left(25^{\circ} \mathrm{C}\right)$, the larger the temperature adjustment coefficient bigger than 1 . Since no temperature adjustment were performed, conservative fuel consumption predictions would be expected from the model. Please note that the deflection data shown in Table 6.2 are in mils (default unit of the FWD test), to be differentiated with the unit used in Chapter $5(\mathrm{~mm})$.

Table 6.2 Mean and Standard Deviation of D0 and Pavement Temperature on Flexible Pavement

\begin{tabular}{|c|c|c|c|c|c|c|c|}
\hline $\begin{array}{c}\text { Pavement } \\
\text { Type }\end{array}$ & District 1 & District 2 & District 3 & District 4 & District 5 & District 6 & District 7 \\
\hline $\begin{array}{c}\text { D0 } \\
\text { (mils) }\end{array}$ & $\begin{array}{c}5.8 \\
(1.9)\end{array}$ & $\begin{array}{c}7.0 \\
(3.5)\end{array}$ & $\begin{array}{c}7.2 \\
(3.5)\end{array}$ & $\begin{array}{c}5.8 \\
(3.2)\end{array}$ & $\begin{array}{c}6.4 \\
(2.1)\end{array}$ & $\begin{array}{c}4.5 \\
(2.5)\end{array}$ & $\begin{array}{c}5.4 \\
(0.9)\end{array}$ \\
\hline $\begin{array}{c}\text { Tem. } \\
\left({ }^{\circ} \mathbf{F}\right)\end{array}$ & $\begin{array}{c}91.3 \\
(15.7)\end{array}$ & $\begin{array}{c}86.4 \\
(18.1)\end{array}$ & $\begin{array}{c}86.6 \\
(22.3)\end{array}$ & $\begin{array}{c}92.9 \\
(18.6)\end{array}$ & $\begin{array}{c}90.6 \\
(20.4)\end{array}$ & $\begin{array}{c}90.2 \\
(16.4)\end{array}$ & $\begin{array}{c}76.7 \\
(21.0)\end{array}$ \\
\hline $\begin{array}{c}\text { Data } \\
\text { Size }\end{array}$ & 7,208 & 12,430 & 4,552 & 6,162 & 5,766 & 852 & 2,907 \\
\hline
\end{tabular}




\subsubsection{Texture (mean profile depth)}

Since FDOT only conducts the texture measurement based on request, there is a very limited texture inventory available. As a result, texture data was not able to be differentiated among seven districts. But the roadway sections tested in the field study are good representatives of Florida's interstate pavements. Therefore, the average texture in mean profile depths (MPD) from the two phases of field studies were adopted for the analysis. This can be a fair estimate since the real data is missing. The resulted average MPD for flexible pavement is $0.060 \mathrm{in}(1.53 \mathrm{~mm})$ and $0.016 \mathrm{in}(0.41 \mathrm{~mm})$ for rigid pavement.

\subsubsection{Representative Vehicles}

Two vehicle classes were applied for the estimation: the passenger car in Phase II field study, and the loaded 18-wheel tractor-trailer in Phase I field study. For the 18wheeler, the average weight of 34,709kg (76,520lbs) measured in Phase I was adopted. Constant highway speed of $113 \mathrm{~km} / \mathrm{h}$ (70mph) was assumed for both vehicle classes.

\subsection{ASSUMPTIONS}

There are a few assumptions and limitations for the estimation. Besides the assumptions and limitations a) and h) in Chapter 5 (section 5.3.1.1), the following assumptions also apply:

a. It is assumed that the average pavement IRI, texture, and deflection data calculated in each district can well represent the real pavement surface and structural condition in that district;

b. Rigid pavement sections are assumed to have the same average IRI with flexible pavement sections in each district. This is intended to exclude the influence of 
roughness on fuel consumption/emission and purely investigate the effect induced by the differences in pavement type (structural and material components and surface texture);

c. It is assumed that the pavement texture adopted is able to reflect the real texture levels on Florida's interstate highways;

d. It is assumed that the calibrated truck model from Chapter 5 is applicable to heavy truck (18-wheels tractor-trailer).

\subsection{ESTIMATION SCENARIOS}

Two scenarios were estimated for the analysis. The difference between the two scenarios is the flexible/rigid pavement distribution in Florida's interstate network. The

first scenario represents the currently flexible/rigid pavement distribution: approximately 1362 centreline miles of flexible pavement (91.3\%) and 130 centreline miles of rigid pavement (8.7\%). Generally the flexible pavement dominates the interstate roadways in Florida. The second scenario represents an extreme circumstance, assuming all interstate roadways in Florida are composed of rigid pavement (1492 centreline miles). The second scenario may not reflect the reality, but it can provide a sound analysis for research purpose. In summary, the two scenarios are:

Scenario 1: Florida's interstate roadways are composed of 1362 centreline miles of flexible pavement and 130 centreline miles of rigid pavement;

Scenario 2: Florida's interstate roadways are composed of 0 centreline mile of flexible pavement and 1492centreline miles of rigid pavement.

\subsection{RESULTS}

The pavement data were applied to the calibrated HDM-IV fuel consumption model to calculate the base fuel rate $(\mathrm{mL} / \mathrm{s})$ in each district on flexible pavement and 
rigid pavement respectively. Calculations were separated for passenger car and heavy truck. Table 6.3 rephrases the equations of rolling resistance surface factors CR2 resulted from Chapter 5.

Table 6.3 Equations for CR2 in Calibrated HDM-IV Model

\begin{tabular}{|c|c|c|}
\hline Vehicle & Model & CR2 Equations \\
\hline \multirow{2}{*}{ Car } & Flexible Pavement & $C R 2 c f=K c r 2(0.49+0.02 T d s p+0.10 I R I+0.09 D 0)$ \\
\cline { 2 - 3 } & Rigid Pavement & $C R 2 c r=K c r 2(0.49+0.02 T d s p+0.10 I R I)$ \\
\hline \multirow{2}{*}{ Truck } & Flexible Pavement & $C R 2 t f=K c r 2(0.73+0.04 T d s p+0.03 I R I+0.17 D 0)$ \\
\cline { 2 - 3 } & Rigid Pavement & $C R 2 t r=K c r 2(0.73+0.04 T d s p+0.03 I R I)$ \\
\hline
\end{tabular}

From the table, regardless vehicle class, flexible pavement exhibits higher rolling resistance (surface factor) than rigid pavement given the same levels of roughness (IRI). The extra rolling resistance comes from the higher texture levels (Tdsp) and pavement deflection (D0) on flexible pavement compared to rigid pavement. The texture difference is largely due to the open graded asphalt materials used in the flexible pavement surface layer (large void coarse aggregates). The pavement deflection is because of the low stiffness of flexible pavement structural layers. As a result, the calculated base fuel rates were higher on flexible pavement than rigid pavement in each district. Table 6.4 summarizes the base fuel rates from the calculations.

\subsubsection{Annual Fuel Consumption}

The resulted base fuel rates were applied to calculate the fuel consumption in each district by multiplying the AADT (times 365) and section length on each roadway section. Calculations were performed separately on passenger car and truck and then 
added up for each scenario. Figure 6.4 displays the annual fuel consumption estimated for passenger car (left) and truck (right) on scenario 1. Figure 6.5 shows the same aspects for scenario 2.

Table 6.4 Base Fuel Consumption

\begin{tabular}{|c|c|c|c|c|c|c|c|c|}
\hline \multirow{2}{*}{$\begin{array}{c}\text { Vehicle/Pavement } \\
\text { Type }\end{array}$} & \multicolumn{7}{|c|}{ Base Fuel Rates in mL/second } \\
\cline { 3 - 9 } \multicolumn{2}{c|}{ Car } & $\begin{array}{c}\text { District } \\
\mathbf{1}\end{array}$ & $\begin{array}{c}\text { District } \\
\mathbf{2}\end{array}$ & $\begin{array}{c}\text { District } \\
\mathbf{3}\end{array}$ & $\begin{array}{c}\text { District } \\
\mathbf{4}\end{array}$ & $\begin{array}{c}\text { District } \\
\mathbf{5}\end{array}$ & $\begin{array}{c}\text { District } \\
\mathbf{6}\end{array}$ & $\begin{array}{c}\text { District } \\
\mathbf{7}\end{array}$ \\
\hline \multirow{2}{*}{ Truck } & Flexible & 1.956 & 1.955 & 1.949 & 1.974 & 1.962 & 1.971 & 1.965 \\
\cline { 2 - 9 } & Rigid & 1.926 & 1.925 & 1.918 & 1.945 & 1.931 & 1.945 & 1.935 \\
\cline { 2 - 9 } & Rigid & 16.625 & 16.622 & 16.605 & 16.671 & 16.638 & 16.671 & 16.648 \\
\hline
\end{tabular}

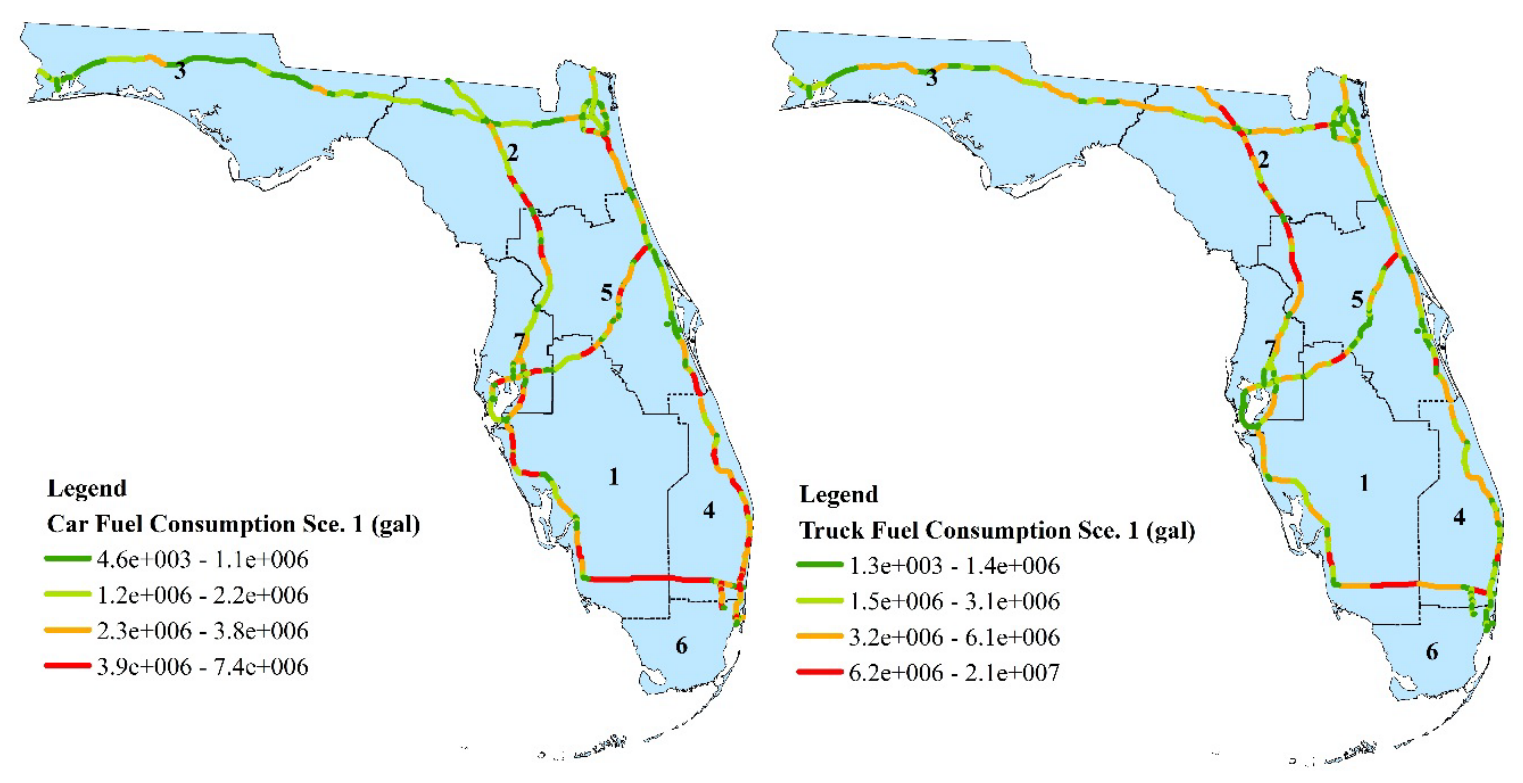

Passenger Car

Truck

Figure 6.4 Annual Fuel Consumption Estimated in Scenario 1 


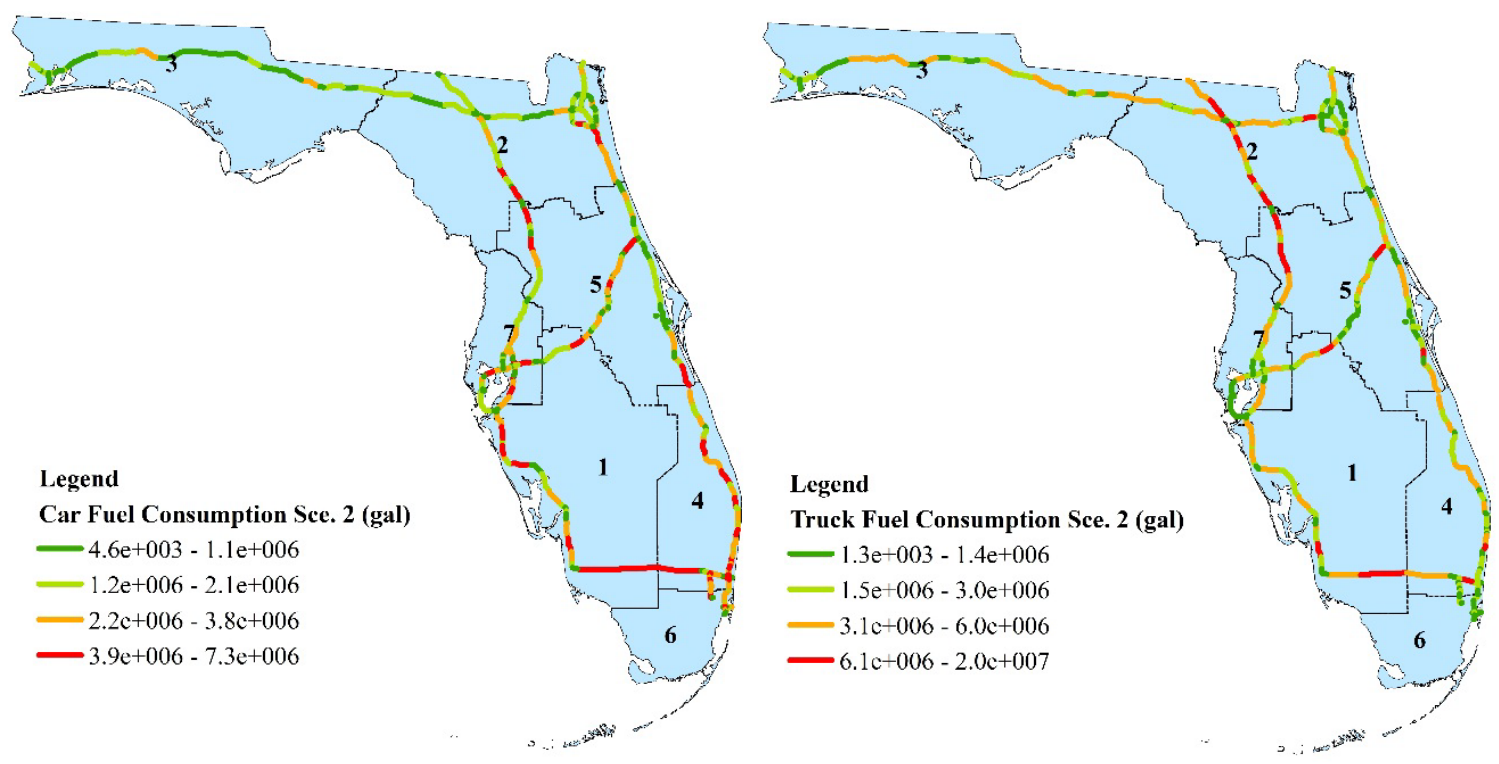

Passenger Car

Truck

Figure 6.5 Annual Fuel Consumption Estimated in Scenario 2

\subsubsection{Annual $\mathrm{CO}_{2}$ Emissions}

The fuel induced $\mathrm{CO}_{2}$ emissions were also derived from the fuel consumptions by multiplying the fuel- $\mathrm{CO}_{2}$ conversion factors. The conversion factor of gasoline fuel is $8.877 \mathrm{~kg} \mathrm{CO} 2$ per gallon of gasoline (Federal Register, n.d.). The conversion factor for diesel fuel is $10.180 \mathrm{CO}_{2}$ per gallon of diesel (CFR 600.113-12, n.d.). Figure 6.6 and 6.7 display the resulted annual vehicle $\mathrm{CO}_{2}$ emission in each estimation scenario. 


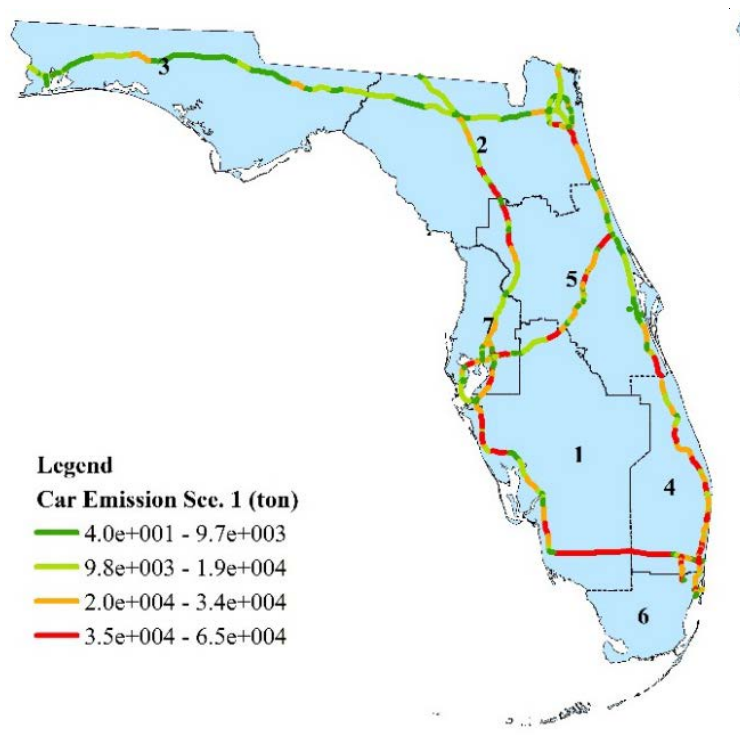

Passenger Car

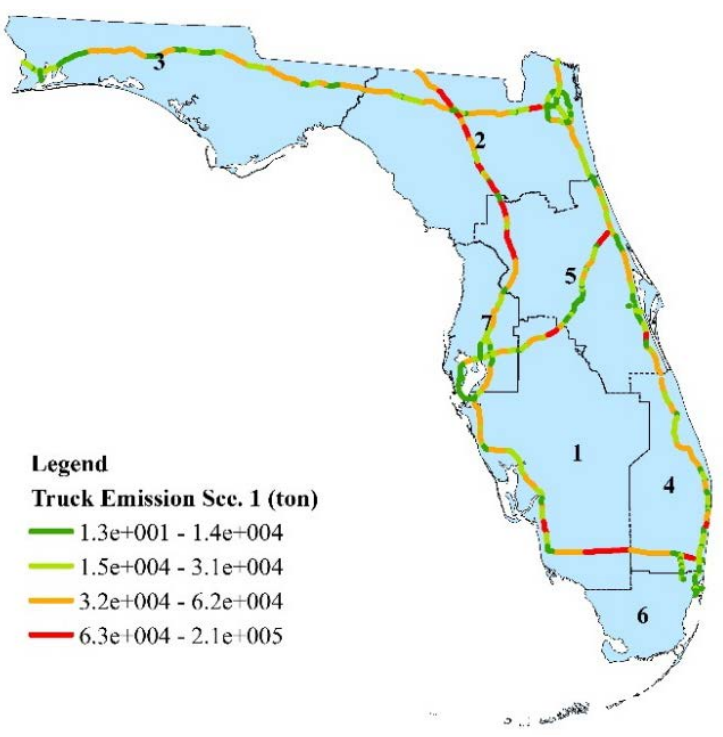

Truck

Figure 6.6 Annual $\mathrm{CO}_{2}$ Emission Estimated in Scenario 1

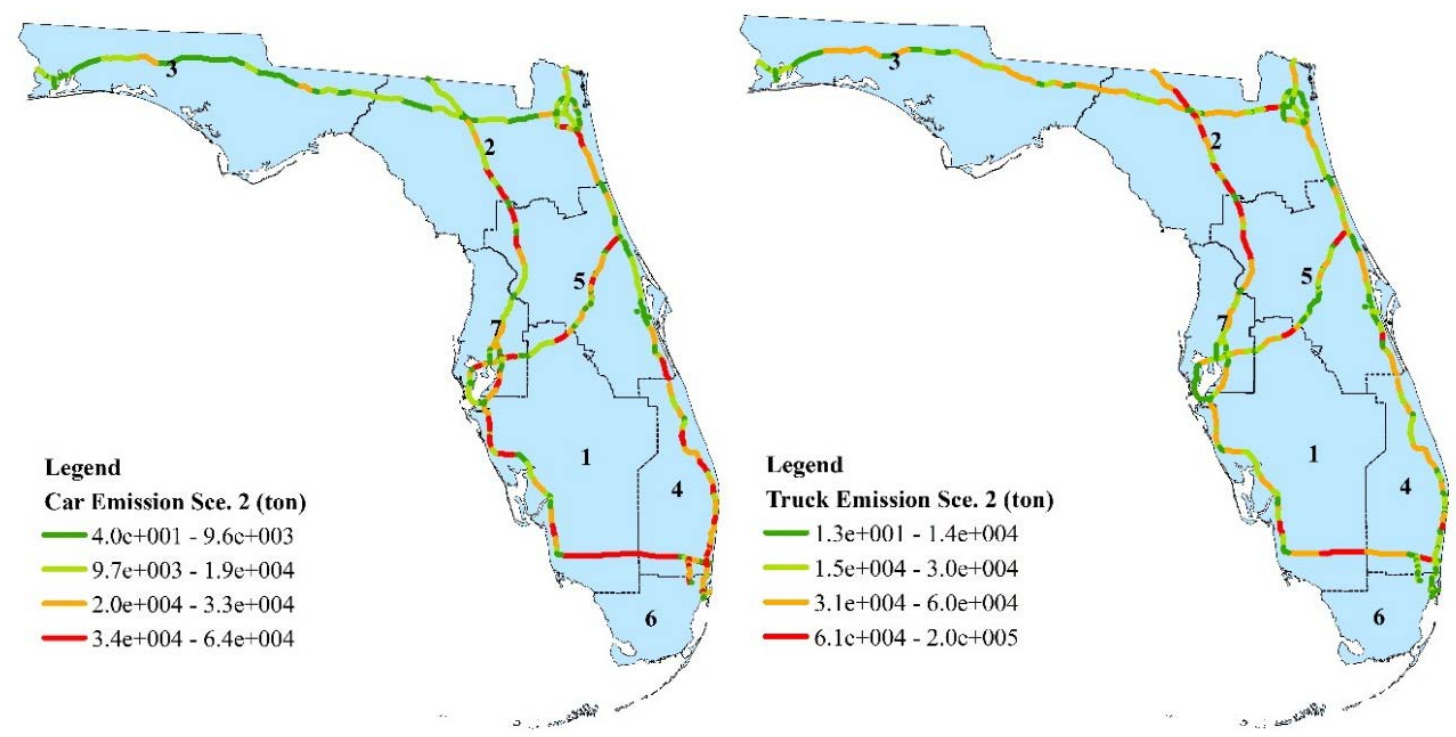

Passenger Car

Truck

Figure 6.7 Total Annual $\mathrm{CO}_{2}$ Emission Estimated in Scenario 2 


\subsubsection{Potential Fuel Savings and Emission Reductions}

The total annual fuel consumptions and $\mathrm{CO}_{2}$ emissions were combined for all the districts and comparisons were performed between the results from scenario 1 and scenario 2. Results show that scenario 2 resulted in a lower total fuel consumption and $\mathrm{CO}_{2}$ emission than scenario 1 . The differences between this two scenarios are the potential fuel savings and emission reductions can be achieved by replacing the existing interstate flexible pavements with the rigid pavements that have the same roughness levels. The potential annual fuel savings and emission reductions are summarized in Table 6.5. Results show that a total of 40 million gallons of fuel savings (combined gasoline and diesel) and 0.39 million metric tons of $\mathrm{CO}_{2}$ emission reduction can be achieved with all interstate flexible pavement be replaced by rigid pavement in Florida. The savings also equal to a total of 0.17 million barrels of oil (EPA, 2015) and 91 million dollars per year. An average fuel price of $\$ 2.30 /$ gal was assumed for the cost estimation (at 08/31/2015-12:15PM). Figure 6.8 and Figure 6.9 graphically display the total annual fuel savings and emission reductions on each roadway section.

Table 6.5 Annual Fuel Savings and Emission Reductions

\begin{tabular}{|c|c|c|c|}
\hline Parameters & Car & Truck & Total \\
\hline Annual Fuel Savings (million gallons) & 11 & 29 & 40 \\
\hline Annual Emission Reductions (million tons) & 0.10 & 0.29 & 0.39 \\
\hline Equivalent Barrels of Oil (million barrels) & 0.04 & 0.13 & 0.17 \\
\hline Equivalent Cost Savings (million \$)* & N/A & N/A & 91 \\
\hline
\end{tabular}

* Estimation based on an average fuel price of \$2.30/gal in Florida (08/31/2015$12: 15 \mathrm{PM})$ 


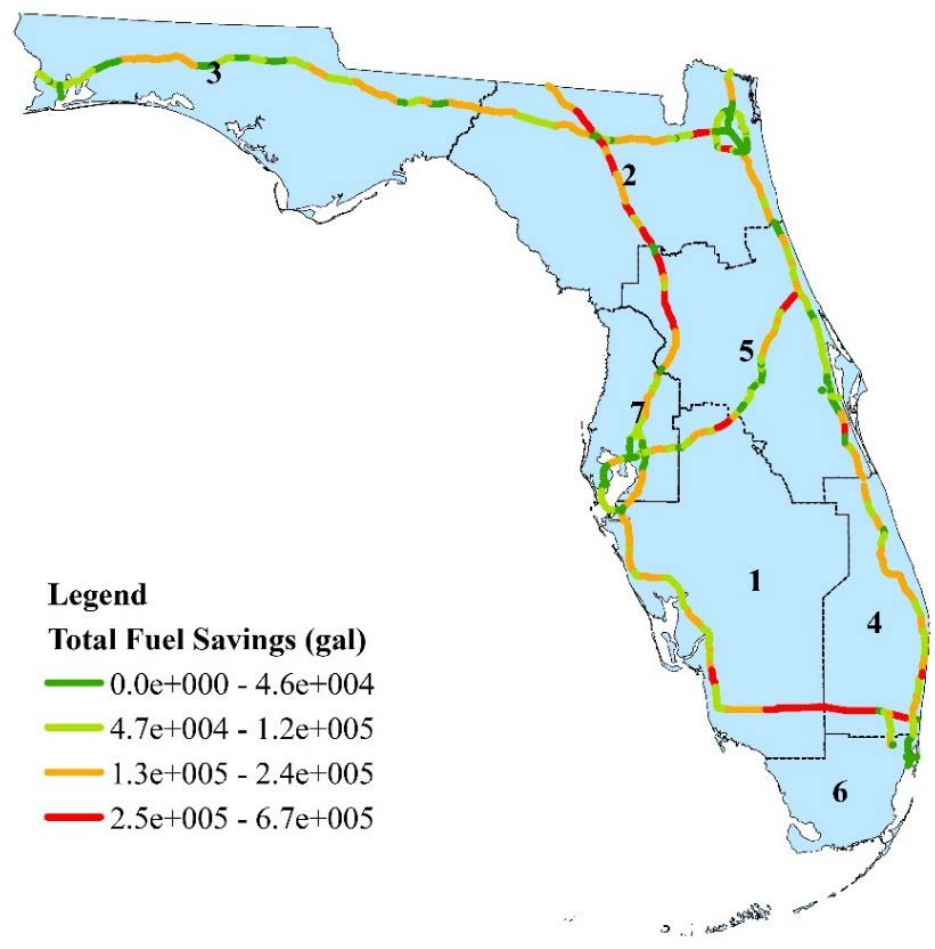

Figure 6.8 Total Annual Fuel Savings (Combined Car and Truck)

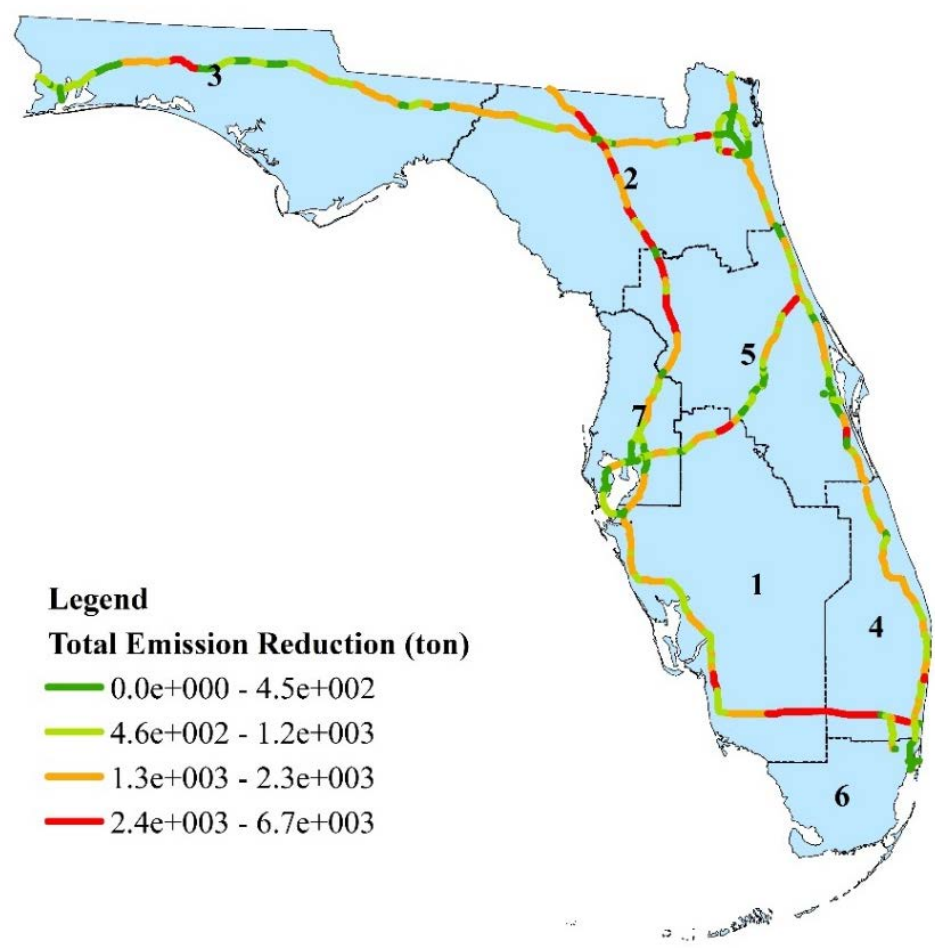


Figure 6.9 Total Annual Emission Reductions (Combined Car and Truck)

If a linear change was assumed between the outcomes (fuel consumption and $\mathrm{CO}_{2}$ emission) from scenario 1 and scenario 2, Chart (Figure) 6.10 can be generated. It displays the fuel savings and emission reductions with every $10 \%$ of interstate flexible pavement being replaced by rigid pavement in Florida.

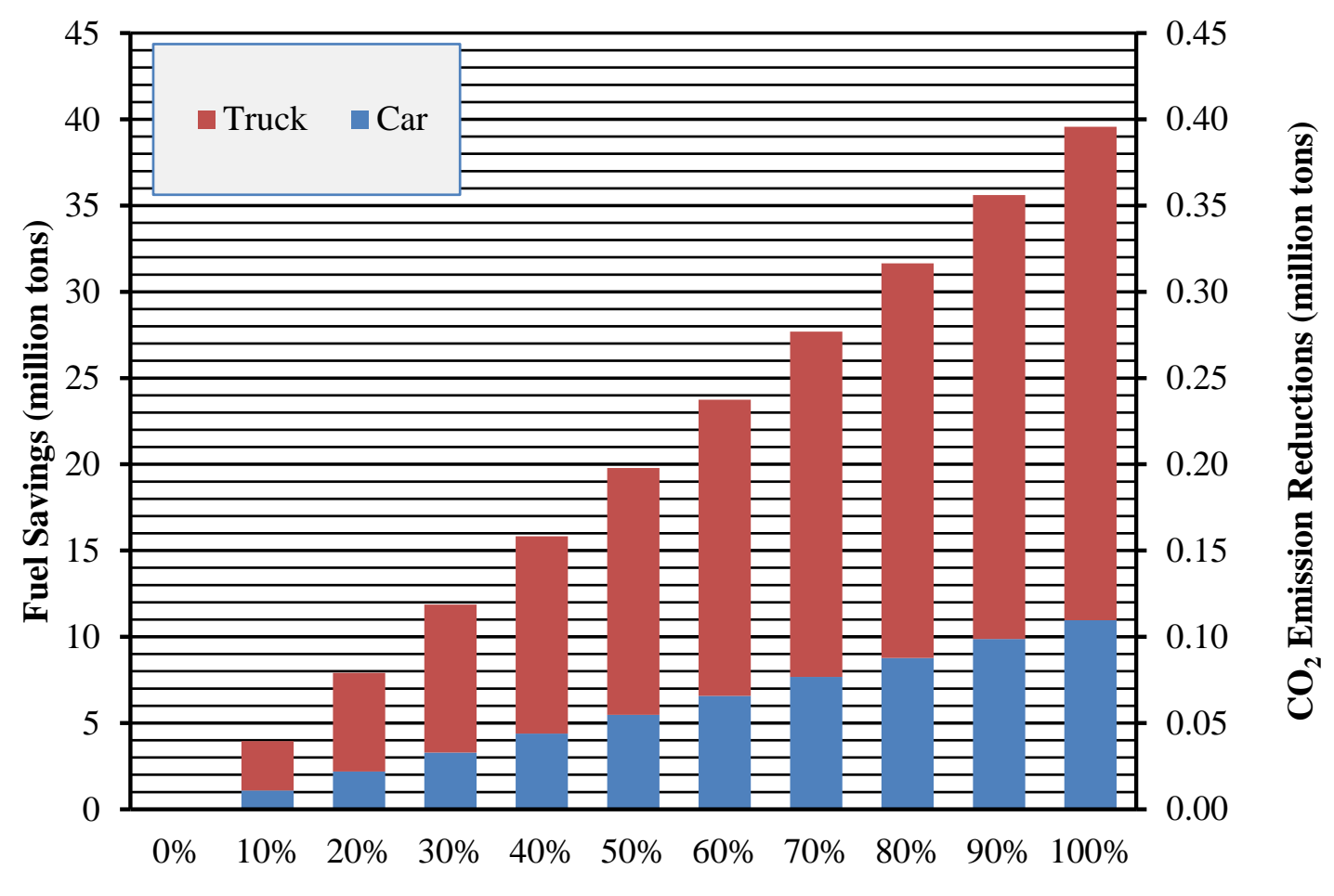

\section{Percentage of Flexible Pavement Replaced by Rigid Pavement on Florida's Interstate Highways}

Figure 6.10 Potential Fuel Savings and Emission Reductions

If a 1-mile scale is further considered, savings of 29 thousand gallons of fuel, 258 tons of $\mathrm{CO}_{2}$ emission, and 67 thousand dollars will be expected with every 1-mile of interstate flexible pavement replaced by rigid pavement. Table 6.6 summarizes these results. 
Table 6.6 Fuel Savings and Emission Reductions of 1-mile Scale

\begin{tabular}{|c|c|c|c|}
\hline \multicolumn{4}{|c|}{ Potential Savings/Reductions with Every 1-mile of Flexible Pavement Replaced by Rigid } \\
Pavement on Florida's Interstate Roadways
\end{tabular}

\subsection{CONCLUSION AND DISCUSSION}

The emphasis of this chapter is to estimate the total annual interstate fuel consumption and $\mathrm{CO}_{2}$ emission with the well-calibrated HDM-IV fuel consumption model. Two scenarios were investigated with variation in the percentage of flexible pavement and rigid pavement that comprise Florida’s interstate roadways. The state-wide pavement and traffic information were collected first. The annual interstate fuel consumptions and $\mathrm{CO} 2$ emissions were estimated separately for passenger car and heavy truck, but results were combined to draw the final conclusion. By comparing the results between scenario 1 and scenario 2, conclusions were made as:

1) An approximately of 40 million gallons of fuel (combined gasoline and diesel) can be saved annually for the road users with all Florida's interstate flexible pavement replaced by rigid pavement with the same levels of roughness;

2) The annual savings also equal to 0.39 million tons of $\mathrm{CO}_{2}$ emission, 0.17 million barrels of oil and 91 million dollars;

3) If a linear change in fuel consumption and emission is assumed from scenario 1 to scenario 2, each 1-mile of flexible-rigid conversion can result in savings of 29 thousand gallons of fuel, 258 tons of $\mathrm{CO}_{2}$ emission, and 67 thousand dollars yearly. 
Commercial Carrier Corporation indicated that for every 0.10 mpg savings over the entire fleet for one year, the company can realize an additional $\$ 240,000$ to its bottom line. These findings indicate that if the company could move its goods over rigid pavements similar to the sections used in this study, Commercial Carrier Corporation could have a substantial increase on their profits. These funds could be used to upgrade its fleet, hire new employees and build larger infrastructure, all of which have a lasting positive impact in the Florida economy.

From an environmental perspective, the reduction on the GHG emission is as astonishing as the economic impact to the traveling public. This is especially critical in urban areas such as Miami, Orlando, Tampa and Jacksonville where large numbers of vehicles operate in highly congested areas on a daily basis.

As a recommendation, utilizing rigid pavements in express and premium lanes could contribute to increased usage as the cost of the toll may be somewhat offset by the savings in fuel consumption, depending on the toll charged at the time of use. At any rate, the fuel savings could have a substantial positive impact on fuel costs and greenhouse gas emissions. Both factors could be used on life cycle cost analyses in pavement type selections.

The study performed in this chapter is intended to provide an overall understanding on how pavement-vehicle interaction affects the road user fuel expenses and greenhouse gas emissions on Florida's interstate network. The objective is to help engineers and researchers better recognize the role of pavement in goals of fuel economy improvement and GHG emission reduction. It is desired that the findings can be useful 
references for policymakers and stakeholders for roadway maintenance and rehabilitation decision makings. 


\section{CHAPTER 7}

\section{SUMMARY, CONCLUSIONS AND FUTURE WORK}

\subsection{SUMMARY}

This dissertation investigated the impact of pavement-vehicle interaction (PVI) on vehicle highway fuel consumption and emission. There are three aspects of pavementvehicle interaction (PVI): pavement roughness, pavement texture, and pavement deflection. This study mainly focused on the effect induced by the differences between the highway flexible pavement and rigid pavement in Florida. The differences between flexible pavement and rigid pavement are reflected primarily by pavement texture and pavement deflection under the load. This study was aiming at investigating how these differences have an impact on a single vehicle's fuel efficiency as well as the total fuel and emission impact on the state network.

Two phases of field experimental studies were carried out at first. The Phase I field study conducted direct comparison investigations on two pairs of equal-distance flexible-rigid pavement sections in Florida. Fuel consumptions were measured with passenger car and 18-wheel tractor trailer at constant speed. Paired t-test was applied to the collected data and findings were generated. The second phase of field study involved a more comprehensive and detailed experimental design and setup. Pavement roughness and surface temperature were considered into the experimental design. Two vehicle classes at two levels of highway speeds were studied. The purpose is to independently investigate the impact on vehicle fuel efficiency with control of possible confounding variables as pavement roughness and surface temperature. Analysis of Covariance (ANCOVA) test was applied to the data and results were analyzed and discussed. 
The third part of the dissertation involved the calibration work of the HDM-IV fuel consumption model. Model coefficients were adjusted with fuel data collected from Phase II field study. The calibrated model was evaluated and validated with different methodologies. Furthermore, the impact of pavement deflection on vehicle fuel consumption was quantified with the well-calibrated model. This part of dissertation is intended to study the effect of PVI on vehicle fuel consumption from a mechanistic approach.

The final part of the work applied the calibrated HDM-IV model to estimate the total annual fuel consumptions and $\mathrm{CO}_{2}$ emissions on Florida's interstate network. It is intended to evaluate the potential fuel savings and emission reductions that can be achieved by optimizing the pavement type distributions on Florida's interstate pavements. The total annual fuel consumption and $\mathrm{CO}_{2}$ emissions were estimated on two scenarios. The first scenario represented the current Florida's interstate pavement distribution: 91.3\% flexible pavement and 8.7\% rigid pavement. The second scenario simulated one extreme circumstance: rigid pavement comprises all Florida's interstate pavements. The outcomes from the two scenarios were compared and findings were summarized.

\subsection{CONCLUSIONS.}

The following conclusions were summarized from the results of each main chapter. 


\subsubsection{Phase I Field Study}

a. The direct fuel comparison study on the first test site showed a $2.24 \%$ fuel saving on rigid pavement compared to the paired flexible pavement for passenger car and 4.04\% for 18-wheel tractor-trailer;

b. The direct fuel comparison study on the second test site resulted in a $2.76 \%$ fuel saving on rigid pavement compared to its paired flexible pavement for the same passenger car in the first test site;

c. The fuel savings were all statistically significant at a 95\% confidence level (C.L.).

d. Combine the results from both test sites, the average fuel saving on rigid pavement for passenger car was $2.50 \%$ and the average fuel saving on tractortrailer was 4.04\%;

e. By calculating the $95 \%$ confidence interval (C.I.) for the percentage fuel savings, there was a $95 \%$ possibility that the intervals of $1.47 \%$ to $3.34 \%$ and $3.61 \%$ to 4.47\% contained the true fuel savings on passenger car and tractor-trailer with the test condition specified.

\subsubsection{Phase II Field Study}

a. With a more detailed and comprehensive field experiment, pavement type was again proved as a significant factor that affect vehicle highway fuel consumption. The effect was found statistically significant for both passenger car and mediumduty truck, and at both lower and higher highway speed;

b. For passenger car, the fuel consumption differences between flexible pavement (group) and rigid pavement (group) after excluding the effect of pavement roughness and/or surface temperature were found as $2.25 \%$ at speed of $93 \mathrm{~km} / \mathrm{h}$, 
and $2.22 \%$ at $112 \mathrm{~km} / \mathrm{h}$, all with lower fuel consumptions on rigid pavement (group);

c. The fuel differences found for the medium-duty truck were $3.57 \%$ at speed of $89 \mathrm{~km} / \mathrm{h}$ and $3.15 \%$ at $105 \mathrm{~km} / \mathrm{h}$, also with lower fuel consumptions on rigid pavement (group);

d. The differences found in b and c were statistically significant at 95\% C.L.;

e. Effect of pavement roughness and surface temperature on vehicle fuel consumption were also found statistically significant;

f. Despite the different experimental design and study methodology compared to Phase I study, both phases exhibited statistically significant fuel savings on rigid pavement (or pavement group) and the savings were at the same level;

g. The heavier the vehicle, the larger the fuel consumption difference between flexible pavement and rigid pavement.

\subsubsection{HDM-IV Model Calibration}

a. The calibrated HDM-IV fuel consumption model showed decreased model bias and increased model fitness to real measurements. The calibrated model was also shown be able to predict the reality;

b. In the calibrated HDM-IV model for passenger car, the coefficient that modifies pavement deflection (a3) was adjusted from zero to a non-zero value (0.09) from non-calibrated model to the calibrated model. This indicated a higher model rolling resistance output (fuel consumption consequently) on flexible pavement compared to the rigid pavement with same levels of surface roughness. These findings agrees with the empirical findings discovered from the two phases of 
field studies. In addition, model coefficients a1 and a2, which modifies pavement texture and roughness, remained little or no changes before and after the model calibration. This suggested sound agreement with the default model adoptions;

c. With the calibrated HDM-IV fuel consumption model, the effect of pavement deflection on fuel consumption was quantified. Results showed that every one unit of flexible pavement deflection in $\mathrm{mm}$ can lead to an increase of fuel consumption by 0.234 to $0.311 \mathrm{~L} / 100 \mathrm{~km}$ compared to an ideally non-deflected pavement surface for passenger car. The effect on the medium-duty truck is from 1.123 to $1.277 \mathrm{~L} / 100 \mathrm{~km}$. The findings were on basis of constant vehicle speed at 113km/h (70mph);

d. The deflection-induced fuel effect was more evident at lower highway speed than higher highway speed for both passenger car and truck.

\subsubsection{Network Level Estimation}

a. The calibrated HDM-IV model was applied to estimate the total annual fuel consumption and $\mathrm{CO}_{2}$ emission on Florida's interstate network based on two scenarios. Results revealed that an approximately of 40 million gallons of fuel (combined gasoline and diesel) can be saved annually for the road users if all interstate flexible pavement in Florida were replaced by rigid pavement with the same levels of roughness; The savings were also equivalent to 0.39 million tons of $\mathrm{CO}_{2}$ emission, 0.17 million barrels of oil and 91 million dollars per year;

b. If a linear change in fuel consumption and emission was assumed from scenario 1 to scenario 2, each 1-mile of conversion from flexible pavement to rigid pavement 
would result in savings of 29 thousand gallons of fuel, 258 tons of $\mathrm{CO}_{2}$ emission, and 67 thousand dollars yearly.

c. The practical findings that were discovered suggested a non-negligible effect of pavement-vehicle interaction (PVI) in the sustainability development of transportation infrastructures.

\subsection{FUTURE WORK}

The findings derived from both experimental and mechanistic approach have demonstrated the importance of pavement-vehicle interaction (PVI) in the green transportation initials. However, there are still some areas that can be beneficial from future's research:

a. It is desired to perform similar investigations on non-interstate or non-highway sections and in/outside the state of Florida. More pavement varieties are desired such as dense graded asphalt pavement, stone matrix asphalt pavement, joint reinforced concrete pavement, and so forth. Different environmental conditions shall also be addressed especially under low temperature environment;

b. Different vehicle classes other than passenger car and truck would be greatly helpful to this research efforts. Vehicle fuel consumptions during acceleration/deceleration and congestions are also worth to investigate. Roadway grade and curvature are another two characteristics that are preferred to be considered in future study;

c. Life-cycle cost analysis (LCCA) and life-cycle assessments (LCA) can also be studied under pavement's life-time framework. The impact of PVI throughout the whole phases of pavement life-cycle can be very beneficial on basis of the 
findings of this study. Combined it can draw more practical conclusions and provide more accurate decision guidance for researchers and engineers. 


\section{REFERENCES}

AASHTO, 1993. AASHTO Guide for Design of Pavement Structures, Washington, D.C.: American Association of State Highway and Transportation Officials.

Amos, D., 2006. Pavement Smoothness and Fuel Efficiency: An Analysis of the Economic Dimensions of the Missour Smooth Road Initiative, Jefferson City, MO: Missouri Department of Transportation.

Arbarian, M. \& Ulm, F., 2012. Model Based Pavement-Vehicle Interaction Simulation for Life Cycle Assessment of Pavements, s.l.: Massachusetts Institute of Technology, Concrete Sustainability Hub.

Benbow, E., Iaquinta, J., Lodge, R. \& Wright, A., 2007. Investigation of the Effects of Pavement Stiffness on Fuel Consumption, U.K.: Transport Research Laboratory.

Bennett, C. \& Greenwood, I., 2003a. Volume 7: Modeling Road User and Environmental Effects in HDM-4, Version 3.0, International Study of Highway Development and Management Tools (ISOHDM), s.l.: World Road Association (PIARC).

Bennett, C. \& Greenwood, I., 2003b. Volume 5: HDM-4 Calibration Reference Manual. International Study of Highway Development and Management Tools (ISOHDM), s.l.: World Road Association (PIARC).

Bester, C., 1981. Fuel Consumption of Highway Traffic, s.l.: Ph.D. Thesis, University of Pretoria.

Bester, C., 1984. Effect of Pavement Type and Condition on the Fuel Consumption of Vehicles. Washington, D.C., Transportation Research Record, pp. 28-32.

Biggs, D., 1988. ARFCOM - Models For Estimating Light to Heavy Vehicle , Nunawading, Australia: Research Report ARR 152, Australian Road Research Board.

Bowyer, D., Akcelik, R. \& Biggs, D., 1985. Guide to Fuel Consumption Analyses for Urban Traffic Management, Nunawading, Australia: Special Report No. 32, Australian Road Research Board .

Cenek, P., 1994. Rolling Resistance Characteristics of New Zealand Road Surfaces. In: B. Kulakowski, ed. Vehicle-Road Interaction. Philadelphia, PA: American Society for Testing and Materials, pp. 248-262.

CFR 600.113-12, n.d. Fuel Economy, CO2, Emissions, and Carbon-Related Exhaust Emission Calculations for FTP, HFET, USO6, SCO3 and Cold Temperature FTP tests. s.l.:s.n. 
Chatti, K. \& Zaabar, I., 2012. NCHRP Report 720: Estimating the Effects of Pavement Condition on Vehicle Operating Costs , Washington, D.C.: Transportation Research Boar of the National Academies.

Chupin, O., Piau, J. \& Chabot, A., 2013. Evaluation of the Structure-Induced Rolling Resistance (SRR) for Pavements including Viscoelastic Material Layers. Materials and Structures, 46(4), pp. 683-696.

De Weille, J., 1966. Quantification of Road User Savings. Washington D.C., World Bank Occasional Papers No.2.

Delanne, Y., 1994. The Influence of Pavement Evenness and Macrotexture on Fuel Consumption. In: B. Kulakowski, ed. Vehicle-Road Interaction. Philadelphia, PA: American Society for Testing and Materials, pp. 240-247.

Deraad, L., 1978. The Influencen of Road Surface Texture on Tire Rolling Resistance, Troy, MI: Society of Automotive Engineers.

Descornet, G., 1990. Road-Surface Influence on Tire Rolling Resistance. In: W. Meyer \& J. Reichert, eds. Surface Characteristics of Roadways: International Research and Technologies. Philadelphia, PA: American Society for Testing and Materials, pp. 401415.

Du Plessis, H., Visser, A. \& Curtayne, P., 1990. Fuel Consumption of Vehicles as Affected by Road-Surface Characteristics. In: W. Meyer \& J. Reichert, eds. Surface Characteristics of Roadways: International Research and Technologies. Philadelphia, PA: American Society for Testing and Materials, pp. 480-496.

EPA, 2015. Inventory of U.S. Greenhouse Gas Emissions and Sinks: 1990-2013, Washington, D.C.: U.S. Environmental Protection Agency.

Federal Register, n.d. Light-Duty Vehicle Greenhouse Gas Emission Standards and Corporate Average Fuel Economy Standards: Final Rule. s.l.:s.n.

Gee, K., 2005. Technical Advisory: Surface Texture for Asphalt and Concrete Pavements, Washington, D.C.: Federal Highway Administration, U.S. Department of Transportation.

Graaff, D., 1999. Rolweerstand van ZOAB-een pilotstudie (Dutch Report: Rolling Resistance of Porous Asphalt - A Pilot Study), Vught, Netherlands: Report No. M+P.MVM.97.2.1.

Greenwood , I. \& Bennett , C., 2003. HDM-4 Fuel Consumption Modelling, s.l.: World Road Association .

Heffernan, M., 2006. NCAT Fuel Economy Research Overview, Auburn, AL: Master of Science Thesis, Auburn University. 
Holzschunher, C., Scott, S., Whitaker, J. \& Kroodsma, K., 2012. Flexible Pavement Smoothness Acceptance Report, International Roughness Index Edition, Gainesville, Florida: Report FL/DOT/SMO/12-550, State Materials Office (SMO), Florida Department of Transportation (FDOT).

HTC, 1999. Calibration of HDM Speed Prediction Model to Thailand, Auckland: HTC Infrastructure Management Ltd..

Hultqvist, B., 2010. Measurements of Fuel Consumption on an Asphalt Pavement and a Concrete Pavement in Sweden. Seville, Spain, 11th International Symposium on Concrete Roads.

ISO 13473-2, 2002. Characterization of pavement texture by use of surface profiles, s.l.: S.n.

Kane, A., 1990. Technical Advisory: Open Graded Friction Courses, Washington, D.C.: Federal Highway Administration, U.S. Department of Transportation.

Keppel, G., 1991. Design and Analysis: A Research's Handbook. 3rd edition ed. s.l.:Englewood Cliffs: Prentice-Hall, Inc..

Laganier, R. \& Lucas, J., 1990. The Influence of Pavement Evenness and Macrotexture on Fuel Consumption. In: W. Meyer \& J. Reichert, eds. Surface Characteristics of Roadwasys: International Research and Technologies. Philadelphia, PA: Ameircan Society for Testing and Materials, pp. 454-459.

Lengrenn, C. \& Faldner, L., 2010. Fuel Cost Consideration Regarding Truck Rolling Resistance on Different Pavement in Sweden. Seville, Spain, 11th International Symposium on Concrete Roads.

Lenz, R., 2011. Pavement Design Guide, s.l.: TxDOT Department of Transportation.

Lightner, B., 2004. AVR-Based Fuel Consumption Gauge. Circuit Cellar: The Magezine for Computer Application.

Louhghalam, A., Akbarian, M. \& Ulm, F., 2014. Scaling Relationship of DissipationInduced Pavement-Vehicle Interactions. Transportation Research Record: Journal of the Transportation Research Board, Issue 2457, pp. 95-104.

Lukanen, E. \& Stubstad, R., 2010. Numerical Simulation of the Influence of Pavement Stiffness on Energy Dissipation. Nottingham, UK, Computing in Civil and Building Engineering, Proceedings of the International Conference.

Lukanen, E., Stubstad, R. \& Briggs, R., 2000. Temperature Predictions and Adjustment Factors for Asphalt Pavement, Washington, D.C.: Report FHWA-RD-98-085, Federal Highway Administration. 
Lu, X., 1985. Effects of Road Roughness on Vehicular Rolling Resistance. In: T. Gillespie \& M. Sayers, eds. Measuring Road Roughness and its Effects on User Cost and Comfort. Philadelphia: American Society for Testing and Materials, pp. 143-161.

Michelin, 2003. The Tyre - Rolling Resistance and Fuel Savings. Clermont-Ferrand, France: Michelin, Société de Technologie.

NPC, 2002. VEROAD Calculation: Maximum Energy Dissipation when Driving on Asphalt Pavement versus Driving on Rigid Cement Concrete, Utrecht, Netherlands: Netherlands Pavement Consultants.

Pouget, S., Sauzeat, H. \& Olard, F., 2012. Viscous Energy Dissipation in Asphalt 19 Pavement Structures and Implication for Vehicle Fuel Consumption. Journal of Materials in Civil Engineering, 24(5), pp. 568-576.

Rasmussen, R., 2013. CENEWS: Pavement Texture Fundamentals. [Online] Available at: http://cenews.com/article/9399/pavement-texture-fundamentals [Accessed 0809 2015].

Sandberg, U., 1990. Road Macro-and Megatexture Influence on Fuel Consumption. In: W. Meyer \& J. Reichert, eds. Surface Characteristics of Roadways: International Research and Technologies. Philadelphia, PA: American Society for Testing and Materials, pp. 460-479.

Sandberg, U., 2011. Rolling Resistance - Basic Information and State-of-the-Art on Measurement Methods, Copenhagen, Denmark: Danish Road Directorate.

Soliman, A., 2006. Effect of Road Roughness on the Vehicle Ride Comfort and Rolling Resistance, Troy, MI: Society of Automotive Engineers.

Stubstad, R., 2009. Fuel Efficiency Study of Concrete Pavements. Oakland, California, 2009 California Pavement Preservation Conference.

Sumitsawan, P., Romanoschi, S. \& Ardekani, S., 2009. Effect of Pavement Type on Fuel Consumption and Emissions. Ames, Iowa, Proceedings of the 2009 Mid-Continent Transportation Research Symposium.

Taylor, G., 2002. Additional Analysis of the Effect of Pavement Structure on Truck Fuel Consumption, Ottawa, Canada: Cement Association of Canada.

Taylor, G. \& Petten, J., 2006. Effects of Pavement Structure on Vehicle Fuel Consumption - Phase III, Ontario, Canada: Cement Association of Canada.

The White House, 2011. Driving Efficiency: Cutting Costs for Families at the Pump and Slashing Dependence on Oil, Washington, D.C.: The White House, Office of Press Secretary. 
The White House, 2012. Obama Administration Finalizes Historic 54.5 MPG Fuel Efficiency Standards. Available at: https://www.whitehouse.gov/the-press-office/2012/08/28/obamaadministration-finalizes-historic-545-mpg-fuel-efficiency-standard

The White House, 2014. Improving the Fuel Efficiency of American Trucks - Bolstering Energy Security, Cutting Carbon Pollution, Saving Money and Supporting Manufacturing Innovation, Washington, D.C.: The White House, Office of Press Secretary.

Velinsky, S. \& White, R., 1979. Increased Vehicle Energy Dissipation Due to Changes in Road Roughness with Emphasis on Rolling Losses, Troy, MI: Society of Automotive Engineers.

Walter, J. \& Conant, F., 1974. Energy Losses in Tires. Tire Science and Technology, 2(4), pp. 235-260.

Yoshimoto, T., Kazato, T. \& Hayakawa, I., 2010. Effect of Pavement Type on Rolling Resistance and fuel Consumption of Heavy-duty Vehicles. Seville, Spain, 11th International Symposium on Concrete Roads.

Zaniewski, J. et al., 1982. Vehicle Operating Costs. Fuel Consumption, and Pavement Type and Condition Factors, Washington, D.C.: Federal Highway Administration. 


\section{APPENDIX A PHASE II FIELD TEST FUEL DATA}

Table A1 Passenger Car Test at 93km/h on Flexible Pavement (L/100km)

\begin{tabular}{|c|c|c|c|c|c|c|}
\hline Section(mile) & CF1 & CF2 & CF3 & CF4 & CF5 & CF6 \\
\hline $\mathbf{0 - 0 . 1}$ & 5.03 & 4.94 & 5.05 & 4.81 & 4.98 & 4.67 \\
\hline $\mathbf{0 . 1 - 0 . 2}$ & 4.86 & 4.89 & 5.09 & 4.77 & 5.02 & 4.70 \\
\hline $\mathbf{0 . 2 - 0 . 3}$ & 4.76 & 4.80 & 5.12 & 4.73 & 4.72 & 4.65 \\
\hline $\mathbf{0 . 3 - 0 . 4}$ & 4.73 & 4.70 & 5.09 & 4.65 & 4.83 & 4.83 \\
\hline $\mathbf{0 . 4 - 0 . 5}$ & 4.80 & 4.60 & 5.11 & 4.59 & 4.74 & 4.81 \\
\hline $\mathbf{0 . 5 - 0 . 6}$ & 4.86 & 4.79 & 5.01 & 4.69 & 4.78 & 4.89 \\
\hline $\mathbf{0 . 6 - 0 . 7}$ & 5.14 & 4.87 & 5.12 & 4.72 & 4.81 & 4.86 \\
\hline $\mathbf{0 . 7 - 0 . 8}$ & 5.46 & 4.81 & 4.93 & 4.70 & 4.90 & 4.84 \\
\hline $\mathbf{0 . 8 - 0 . 9}$ & 5.27 & 5.04 & 5.04 & 4.65 & 4.93 & 4.80 \\
\hline $\mathbf{0 . 9 - 1 . 0}$ & 4.89 & 4.68 & 5.10 & 4.64 & 4.89 & 4.98 \\
\hline
\end{tabular}


Table A2 Passenger Car Test at 93km/h on Rigid Pavement (L/100km)

\begin{tabular}{|c|c|c|c|c|c|c|c|}
\hline Section(mile) & CR1 & CR2 & CR3 & CR4 & CR5 & CR6 & CR7 \\
\hline $\mathbf{0 - 0 . 1}$ & 5.09 & 4.77 & 4.74 & 4.73 & 4.45 & 4.57 & 4.52 \\
\hline $\mathbf{0 . 1 - 0 . 2}$ & 5.00 & 4.83 & 4.78 & 4.74 & 4.47 & 4.61 & 4.59 \\
\hline $\mathbf{0 . 2 - 0 . 3}$ & 5.05 & 5.05 & 4.75 & 4.71 & 4.61 & 4.56 & 4.70 \\
\hline $\mathbf{0 . 3 - 0 . 4}$ & 5.02 & 5.05 & 4.97 & 4.51 & 4.58 & 4.64 & 4.74 \\
\hline $\mathbf{0 . 4 - 0 . 5}$ & 4.96 & 5.16 & 4.88 & 4.87 & 4.44 & 4.65 & 4.62 \\
\hline $\mathbf{0 . 5 - 0 . 6}$ & 5.04 & 5.19 & 4.72 & 5.16 & 4.64 & 4.63 & 4.31 \\
\hline $\mathbf{0 . 6 - 0 . 7}$ & 4.99 & 4.99 & 4.75 & 4.96 & 4.67 & 4.74 & 4.17 \\
\hline $\mathbf{0 . 7 - 0 . 8}$ & 4.94 & 5.09 & 4.74 & 4.91 & 4.54 & 4.55 & 4.48 \\
\hline $\mathbf{0 . 8 - 0 . 9}$ & 4.85 & 5.11 & 4.72 & 4.65 & 4.45 & 4.62 & 4.50 \\
\hline $\mathbf{0 . 9 - 1 . 0}$ & 4.95 & 5.02 & 4.67 & 4.68 & 4.48 & 4.80 & 4.47 \\
\hline
\end{tabular}


Table A3 Passenger Car Test at $112 \mathrm{~km} / \mathrm{h}$ on Flexible Pavement $(\mathrm{L} / 100 \mathrm{~km})$

\begin{tabular}{|c|c|c|c|c|c|c|}
\hline Section(mile) & CF1 & CF2 & CF3 & CF4 & CF5 & CF6 \\
\hline $\mathbf{0 - 0 . 1}$ & 6.27 & 6.18 & 6.38 & 6.37 & 6.17 & 6.26 \\
\hline $\mathbf{0 . 1 - 0 . 2}$ & 6.42 & 6.24 & 6.10 & 6.13 & 6.30 & 6.31 \\
\hline $\mathbf{0 . 2 - 0 . 3}$ & 6.27 & 6.00 & 6.13 & 6.25 & 6.49 & 6.26 \\
\hline $\mathbf{0 . 3 - 0 . 4}$ & 6.13 & 5.84 & 6.17 & 6.14 & 6.66 & 6.29 \\
\hline $\mathbf{0 . 4 - 0 . 5}$ & 6.21 & 6.00 & 6.17 & 6.03 & 6.46 & 6.56 \\
\hline $\mathbf{0 . 5 - 0 . 6}$ & 6.36 & 6.69 & 6.25 & 6.45 & 5.99 & 6.61 \\
\hline $\mathbf{0 . 6 - 0 . 7}$ & 6.54 & 6.32 & 6.37 & 6.43 & 6.02 & 6.30 \\
\hline $\mathbf{0 . 7 - 0 . 8}$ & 6.89 & 6.37 & 6.32 & 6.45 & 6.24 & 6.44 \\
\hline $\mathbf{0 . 8 - 0 . 9}$ & 6.74 & 6.35 & 6.28 & 6.43 & 6.16 & 6.42 \\
\hline $\mathbf{0 . 9 - 1 . 0}$ & 6.42 & 6.16 & 6.16 & 6.49 & 6.25 & 6.50 \\
\hline
\end{tabular}


Table A4 Passenger Car Test at $112 \mathrm{~km} / \mathrm{h}$ on Rigid Pavement (L/100km)

\begin{tabular}{|c|c|c|c|c|c|c|c|}
\hline Section(mile) & CR1 & CR2 & CR3 & CR4 & CR5 & CR6 & CR7 \\
\hline $\mathbf{0 - 0 . 1}$ & 6.79 & 6.57 & 6.10 & 6.32 & 5.94 & 5.72 & 5.48 \\
\hline $\mathbf{0 . 1 - 0 . 2}$ & 6.69 & 6.62 & 6.13 & 6.36 & 6.05 & 5.87 & 5.64 \\
\hline $\mathbf{0 . 2 - 0 . 3}$ & 6.70 & 6.43 & 6.27 & 6.26 & 6.08 & 5.61 & 5.68 \\
\hline $\mathbf{0 . 3 - 0 . 4}$ & 6.69 & 6.48 & 6.35 & 6.21 & 6.45 & 5.52 & 5.84 \\
\hline $\mathbf{0 . 4 - 0 . 5}$ & 6.57 & 6.30 & 6.33 & 6.43 & 5.88 & 5.78 & 5.74 \\
\hline $\mathbf{0 . 5 - 0 . 6}$ & 6.64 & 6.34 & 6.13 & 6.36 & 5.95 & 5.75 & 5.51 \\
\hline $\mathbf{0 . 6 - 0 . 7}$ & 6.70 & 6.48 & 6.22 & 6.26 & 6.03 & 5.44 & 5.58 \\
\hline $\mathbf{0 . 7 - 0 . 8}$ & 6.67 & 6.65 & 6.19 & 6.50 & 6.52 & 5.62 & 5.99 \\
\hline $\mathbf{0 . 8 - 0 . 9}$ & 6.52 & 6.52 & 6.20 & 6.56 & 6.16 & 5.95 & 5.83 \\
\hline $\mathbf{0 . 9 - 1 . 0}$ & 6.64 & 6.63 & 6.30 & 6.43 & 6.26 & 6.08 & 5.77 \\
\hline
\end{tabular}


Table A5 Truck Test at $89 \mathrm{~km} / \mathrm{h}$ on Flexible Pavement (L/100km)

\begin{tabular}{|c|c|c|c|c|c|}
\hline Section(mile) & TF1 & TF2 & TF3 & TF4 & TF5 \\
\hline $0-0.1$ & 23.37 & 27.39 & 25.45 & 25.59 & 26.20 \\
\hline 0.1-0.2 & 23.25 & 28.20 & 25.44 & 25.44 & 25.86 \\
\hline $0.2-0.3$ & 23.54 & 29.69 & 25.29 & 25.26 & 26.32 \\
\hline $0.3-0.4$ & 23.96 & 29.97 & 25.33 & 25.00 & 26.23 \\
\hline 0.4-0.5 & 23.69 & 29.66 & 25.09 & 25.43 & 26.10 \\
\hline $0.5-0.6$ & 23.60 & 28.37 & 25.49 & 25.20 & 26.22 \\
\hline $0.6-0.7$ & 23.80 & 28.57 & 25.50 & 24.94 & 26.34 \\
\hline $0.7-0.8$ & 24.18 & 29.21 & 25.35 & 24.79 & 26.27 \\
\hline $0.8-0.9$ & 24.03 & 32.42 & 25.64 & 25.46 & 26.15 \\
\hline $0.9-1.0$ & 24.54 & 32.15 & 26.26 & 24.88 & 25.66 \\
\hline $1.0-1.1$ & 23.10 & & 26.35 & 24.04 & 25.34 \\
\hline $1.1-1.2$ & 22.84 & & 26.57 & 24.24 & 25.95 \\
\hline $1.2-1.3$ & 23.27 & & 26.40 & 25.01 & 25.18 \\
\hline $1.3-1.4$ & 23.97 & & 25.92 & 24.95 & 26.57 \\
\hline $1.4-1.5$ & 23.78 & & 24.85 & 24.48 & 26.35 \\
\hline $1.5-1.6$ & 23.30 & & 24.20 & 24.52 & 25.40 \\
\hline $1.6-1.7$ & 23.98 & & 24.82 & 25.65 & 25.04 \\
\hline $1.7-1.8$ & 24.53 & & 24.77 & 24.48 & 25.16 \\
\hline $1.8-1.9$ & 24.96 & & 24.80 & 25.00 & 25.18 \\
\hline $1.9-2.0$ & 24.61 & & 24.62 & 25.68 & 24.69 \\
\hline $2.0-2.1$ & & & 25.81 & & 25.65 \\
\hline 2.1-2.2 & & & 25.11 & & 25.26 \\
\hline $2.2-2.3$ & & & 24.69 & & 24.05 \\
\hline $2.3-2.4$ & & & 25.56 & & 24.77 \\
\hline 2.4-2.5 & & & 25.15 & & 25.46 \\
\hline $2.5-2.6$ & & & 24.83 & & 25.62 \\
\hline 2.6-2.7 & & & 24.97 & & 26.09 \\
\hline $2.7-2.8$ & & & 28.23 & & 25.42 \\
\hline $2.8-2.9$ & & & 29.29 & & 25.45 \\
\hline $2.9-3.0$ & & & 25.94 & & 25.51 \\
\hline 3.0-3.1 & & & 24.03 & & 26.02 \\
\hline 3.1-3.2 & & & 25.25 & & 25.65 \\
\hline $3.2-3.3$ & & & 26.42 & & 25.44 \\
\hline $3.3-3.4$ & & & 25.96 & & 25.81 \\
\hline 3.4-3.5 & & & 26.40 & & 25.94 \\
\hline $3.5-3.6$ & & & 25.55 & & 26.08 \\
\hline 3.6-3.7 & & & 25.51 & & 24.70 \\
\hline $3.7-3.8$ & & & 25.50 & & 24.60 \\
\hline 3.8-3.9 & & & 25.79 & & 25.00 \\
\hline $3.9-4.0$ & & & 25.86 & & \\
\hline
\end{tabular}


Table A6 Truck Test at $89 \mathrm{~km} / \mathrm{h}$ on Rigid Pavement (L/100km)

\begin{tabular}{|c|c|c|c|c|c|}
\hline Section(mile) & TR1 & TR2 & TR3 & TR4 & TR5 \\
\hline $0-0.1$ & 25.04 & 22.84 & 25.47 & 27.07 & 25.15 \\
\hline $0.1-0.2$ & 24.44 & 24.02 & 26.30 & 24.48 & 25.26 \\
\hline $0.2-0.3$ & 24.24 & 25.30 & 26.56 & 23.16 & 25.10 \\
\hline $0.3-0.4$ & 25.00 & 24.56 & 25.24 & 23.92 & 25.51 \\
\hline $0.4-0.5$ & 24.61 & 23.79 & 25.59 & 25.11 & 25.78 \\
\hline $0.5-0.6$ & 24.19 & 24.94 & 25.06 & 25.12 & 24.82 \\
\hline $0.6-0.7$ & 24.04 & 25.46 & 25.97 & 23.46 & 25.05 \\
\hline $0.7-0.8$ & 24.97 & 24.53 & 25.24 & 22.39 & 24.95 \\
\hline $0.8-0.9$ & 24.82 & 23.68 & 23.92 & 24.29 & 24.84 \\
\hline $0.9-1.0$ & 24.84 & 24.07 & 24.57 & 25.16 & 24.22 \\
\hline $1.0-1.1$ & 24.49 & & & 23.72 & \\
\hline 1.1-1.2 & 24.04 & & & 23.40 & \\
\hline $1.2-1.3$ & 24.22 & & & 23.95 & \\
\hline $1.3-1.4$ & 24.05 & & & 23.77 & \\
\hline $1.4-1.5$ & 23.75 & & & 23.48 & \\
\hline $1.5-1.6$ & 23.52 & & & 23.98 & \\
\hline $1.6-1.7$ & 23.40 & & & 23.66 & \\
\hline $1.7-1.8$ & 23.95 & & & 24.08 & \\
\hline $1.8-1.9$ & 23.59 & & & 23.59 & \\
\hline $1.9-2.0$ & 23.64 & & & 23.08 & \\
\hline $2.0-2.1$ & 23.63 & & & & \\
\hline 2.1-2.2 & 23.37 & & & & \\
\hline $2.2-2.3$ & 23.06 & & & & \\
\hline 2.3-2.4 & 23.45 & & & & \\
\hline $2.4-2.5$ & 24.43 & & & & \\
\hline $2.5-2.6$ & 24.09 & & & & \\
\hline 2.6-2.7 & 25.22 & & & & \\
\hline $2.7-2.8$ & 24.57 & & & & \\
\hline 2.8-2.9 & 24.56 & & & & \\
\hline 2.9-3.0 & 24.29 & & & & \\
\hline $3.0-3.1$ & 23.59 & & & & \\
\hline 3.1-3.2 & 24.21 & & & & \\
\hline $3.2-3.3$ & 24.77 & & & & \\
\hline $3.3-3.4$ & 24.63 & & & & \\
\hline 3.4-3.5 & 24.43 & & & & \\
\hline $3.5-3.6$ & 24.06 & & & & \\
\hline 3.6-3.7 & 24.86 & & & & \\
\hline $3.7-3.8$ & 26.30 & & & & \\
\hline $3.8-3.9$ & 23.52 & & & & \\
\hline
\end{tabular}


Table A7 Truck Test at $105 \mathrm{~km} / \mathrm{h}$ on Flexible Pavement (L/100km)

\begin{tabular}{|c|c|c|c|c|c|}
\hline Section(mile) & TF1 & TF2 & TF3 & TF4 & TF5 \\
\hline $\mathbf{0 - 0 . 1}$ & 30.52 & 33.93 & 30.70 & 34.55 & 33.08 \\
\hline $\mathbf{0 . 1 - 0 . 2}$ & 30.64 & 34.05 & 30.75 & 34.50 & 32.43 \\
\hline $\mathbf{0 . 2 - 0 . 3}$ & 32.15 & 33.80 & 32.00 & 33.63 & 31.52 \\
\hline $\mathbf{0 . 3 - 0 . 4}$ & 31.54 & 33.60 & 33.46 & 33.06 & 32.08 \\
\hline $\mathbf{0 . 4 - 0 . 5}$ & 30.82 & 33.05 & 31.97 & 33.46 & 32.44 \\
\hline $\mathbf{0 . 5 - 0 . 6}$ & 30.64 & 32.39 & 30.80 & 33.84 & 32.11 \\
\hline $\mathbf{0 . 6 - 0 . 7}$ & 31.57 & 32.34 & 31.16 & 33.54 & 32.10 \\
\hline $\mathbf{0 . 7 - 0 . 8}$ & 32.30 & 32.37 & 31.66 & 34.40 & 32.90 \\
\hline $\mathbf{0 . 8 - 0 . 9}$ & 32.80 & 33.11 & 32.14 & 34.48 & 33.82 \\
\hline $\mathbf{0 . 9 - 1 . 0}$ & 32.85 & 32.80 & 33.52 & 33.14 & 33.08 \\
\hline $\mathbf{1 . 0 - 1 . 1}$ & 32.71 & & 33.77 & 32.71 & 32.25 \\
\hline $\mathbf{1 . 1 - 1 . 2}$ & 32.51 & & 32.93 & 33.91 & 32.52 \\
\hline $\mathbf{1 . 2 - 1 . 3}$ & 33.12 & & 32.72 & 35.41 & 32.84 \\
\hline $\mathbf{1 . 3 - 1 . 4}$ & 33.16 & & 33.04 & 35.68 & 32.97 \\
\hline $\mathbf{1 . 4 - 1 . 5}$ & 32.12 & & 33.56 & 33.86 & 32.54 \\
\hline $\mathbf{1 . 5 - 1 . 6}$ & 31.77 & & 33.02 & 33.97 & 32.21 \\
\hline $\mathbf{1 . 6 - 1 . 7}$ & 33.58 & & 32.56 & 34.83 & 32.95 \\
\hline $\mathbf{1 . 7 - 1 . 8}$ & 33.89 & & 32.31 & 35.09 & 32.60 \\
\hline $\mathbf{1 . 8 - 1 . 9}$ & 33.71 & & 33.04 & 34.84 & 32.33 \\
\hline $\mathbf{1 . 9}-2.0$ & 33.64 & & 32.28 & 33.88 & 32.46 \\
\hline $\mathbf{2 . 0 - 2 . 1}$ & & & 31.55 & & 32.75 \\
\hline $\mathbf{2 . 1 - 2 . 2}$ & & & 31.68 & & 32.97 \\
\hline $\mathbf{2 . 2 - 2 . 3}$ & & & 32.27 & & 33.13 \\
\hline $\mathbf{2 . 3 - 2 . 4}$ & & & 32.78 & & 32.20 \\
\hline $\mathbf{2 . 4 - 2 . 5}$ & & & 32.28 & & 31.17 \\
\hline $\mathbf{2 . 5 - 2 . 6}$ & & & 32.35 & & 30.64 \\
\hline $\mathbf{2 . 6 - 2 . 7}$ & & & 32.05 & & 30.89 \\
\hline $\mathbf{2 . 7 - 2 . 8}$ & & & 32.72 & & 30.59 \\
\hline $\mathbf{2 . 8 - 2 . 9}$ & & & 33.67 & & 30.63 \\
\hline $\mathbf{2 . 9 - 3 . 0}$ & & & 34.06 & & 29.70 \\
\hline $\mathbf{3 . 0 - 3 . 1}$ & & & 33.34 & & 30.57 \\
\hline $\mathbf{3 . 1 - 3 . 2}$ & & & 31.70 & & 30.99 \\
\hline $\mathbf{3 . 2 - 3 . 3}$ & & & 31.52 & & 30.90 \\
\hline $\mathbf{3 . 3 - 3 . 4}$ & & & 31.53 & & 31.37 \\
\hline $\mathbf{3 . 4 - 3 . 5}$ & & & 32.76 & & 31.80 \\
\hline $\mathbf{3 . 5 - 3 . 6}$ & & & 32.72 & & 30.59 \\
\hline $\mathbf{3 . 6 - 3 . 7}$ & & & 31.87 & & 31.16 \\
\hline $\mathbf{3 . 7 - 3 . 8}$ & & & 32.13 & & 31.65 \\
\hline $\mathbf{3 . 8 - 3 . 9}$ & & & 32.99 & & 32.14 \\
\hline $\mathbf{3 . 9 - 4 . 0}$ & & & 32.61 & & \\
\hline & & & & \\
\hline
\end{tabular}


Table A8 Truck Test at 105km/h on Rigid Pavement (L/100km)

\begin{tabular}{|c|c|c|c|c|c|}
\hline Section(mile) & TR1 & TR2 & TR3 & TR4 & TR5 \\
\hline $0-0.1$ & 30.73 & 29.91 & 33.11 & 35.72 & 33.44 \\
\hline 0.1-0.2 & 29.86 & 30.45 & 34.43 & 31.61 & 32.43 \\
\hline $0.2-0.3$ & 30.52 & 30.02 & 33.39 & 29.37 & 32.19 \\
\hline 0.3-0.4 & 31.23 & 30.61 & 32.83 & 30.66 & 31.90 \\
\hline 0.4-0.5 & 30.53 & 31.00 & 33.11 & 32.81 & 31.17 \\
\hline 0.5-0.6 & 29.62 & 29.19 & 32.88 & 34.31 & 30.06 \\
\hline 0.6-0.7 & 30.00 & 28.87 & 33.14 & 33.68 & 31.02 \\
\hline $0.7-0.8$ & 29.70 & 30.22 & 32.95 & 31.84 & 31.65 \\
\hline $0.8-0.9$ & 29.30 & 30.81 & 32.99 & 32.55 & 31.00 \\
\hline $0.9-1.0$ & 30.54 & 29.97 & 32.76 & 33.76 & 30.49 \\
\hline $1.0-1.1$ & 30.35 & & & 32.66 & \\
\hline 1.1-1.2 & 29.03 & & & 32.51 & \\
\hline $1.2-1.3$ & 28.37 & & & 32.65 & \\
\hline $1.3-1.4$ & 28.55 & & & 32.72 & \\
\hline $1.4-1.5$ & 28.73 & & & 32.53 & \\
\hline $1.5-1.6$ & 28.49 & & & 32.13 & \\
\hline $1.6-1.7$ & 27.09 & & & 31.52 & \\
\hline $1.7-1.8$ & 27.94 & & & 31.06 & \\
\hline $1.8-1.9$ & 28.81 & & & 30.73 & \\
\hline $1.9-2.0$ & 28.35 & & & 29.46 & \\
\hline $2.0-2.1$ & 27.58 & & & & \\
\hline 2.1-2.2 & 27.73 & & & & \\
\hline $2.2-2.3$ & 31.24 & & & & \\
\hline $2.3-2.4$ & 30.63 & & & & \\
\hline $2.4-2.5$ & 31.35 & & & & \\
\hline $2.5-2.6$ & 31.55 & & & & \\
\hline 2.6-2.7 & 30.95 & & & & \\
\hline $2.7-2.8$ & 31.25 & & & & \\
\hline $2.8-2.9$ & 32.50 & & & & \\
\hline 2.9-3.0 & 32.53 & & & & \\
\hline 3.0-3.1 & 31.31 & & & & \\
\hline 3.1-3.2 & 31.38 & & & & \\
\hline $3.2-3.3$ & 32.36 & & & & \\
\hline $3.3-3.4$ & 32.59 & & & & \\
\hline 3.4-3.5 & 32.02 & & & & \\
\hline 3.5-3.6 & 31.80 & & & & \\
\hline 3.6-3.7 & 31.74 & & & & \\
\hline $3.7-3.8$ & 31.90 & & & & \\
\hline 3.8-3.9 & 28.59 & & & & \\
\hline
\end{tabular}




\section{APPENDIX B PHASE II SECTION ROUGHNESS DATA}

Table B1 IRI of Flexible Pavement of Passenger Car Test $(\mathrm{m} / \mathrm{km})$

\begin{tabular}{|c|c|c|c|c|c|c|}
\hline Section(mile) & CF1 & CF2 & CF3 & CF4 & CF5 & CF6 \\
\hline $\mathbf{0 - 0 . 1}$ & 0.76 & 0.83 & 1.19 & 0.87 & 1.25 & 1.18 \\
\hline $\mathbf{0 . 1 - 0 . 2}$ & 0.75 & 0.79 & 1.05 & 0.97 & 1.34 & 1.22 \\
\hline $\mathbf{0 . 2 - 0 . 3}$ & 0.74 & 0.77 & 1.22 & 1.02 & 1.53 & 1.25 \\
\hline $\mathbf{0 . 3 - 0 . 4}$ & 0.79 & 0.84 & 1.00 & 0.99 & 1.34 & 1.33 \\
\hline $\mathbf{0 . 4 - 0 . 5}$ & 0.74 & 0.82 & 0.97 & 0.90 & 1.33 & 1.51 \\
\hline $\mathbf{0 . 5 - 0 . 6}$ & 0.73 & 0.79 & 0.99 & 0.97 & 1.26 & 1.44 \\
\hline $\mathbf{0 . 6 - 0 . 7}$ & 0.84 & 0.83 & 1.04 & 0.95 & 1.32 & 1.33 \\
\hline $\mathbf{0 . 7 - 0 . 8}$ & 0.93 & 0.78 & 1.10 & 0.99 & 1.25 & 1.60 \\
\hline $\mathbf{0 . 8 - 0 . 9}$ & 0.85 & 0.79 & 1.05 & 0.86 & 1.31 & 1.54 \\
\hline $\mathbf{0 . 9 - 1 . 0}$ & 0.72 & 0.80 & 1.10 & 0.94 & 1.13 & 1.40 \\
\hline
\end{tabular}


Table B2 IRI of Rigid Pavement of Passenger Car Test (m/km)

\begin{tabular}{|c|c|c|c|c|c|c|c|}
\hline Section(mile) & CR1 & CR2 & CR3 & CR4 & CR5 & CR6 & CR7 \\
\hline $\mathbf{0 - 0 . 1}$ & 1.18 & 1.07 & 0.56 & 0.56 & 0.73 & 0.97 & 1.16 \\
\hline $\mathbf{0 . 1 - 0 . 2}$ & 1.34 & 1.14 & 0.48 & 0.51 & 0.65 & 1.07 & 1.21 \\
\hline $\mathbf{0 . 2 - 0 . 3}$ & 1.22 & 1.10 & 0.47 & 0.50 & 0.73 & 1.25 & 1.03 \\
\hline $\mathbf{0 . 3 - 0 . 4}$ & 1.31 & 1.15 & 0.46 & 0.58 & 0.73 & 1.10 & 1.07 \\
\hline $\mathbf{0 . 4 - 0 . 5}$ & 1.10 & 1.09 & 0.67 & 0.63 & 0.80 & 1.02 & 1.05 \\
\hline $\mathbf{0 . 5 - 0 . 6}$ & 1.05 & 1.03 & 0.51 & 0.54 & 0.66 & 0.81 & 0.97 \\
\hline $\mathbf{0 . 6 - 0 . 7}$ & 1.07 & 1.10 & 0.52 & 0.59 & 0.79 & 0.84 & 0.77 \\
\hline $\mathbf{0 . 7 - 0 . 8}$ & 1.00 & 1.07 & 0.62 & 0.56 & 0.77 & 0.88 & 0.79 \\
\hline $\mathbf{0 . 8 - 0 . 9}$ & 1.07 & 1.27 & 0.50 & 0.55 & 0.72 & 0.84 & 0.76 \\
\hline $\mathbf{0 . 9 - 1 . 0}$ & 1.03 & 0.99 & 0.52 & 0.51 & 0.71 & 0.81 & 0.84 \\
\hline
\end{tabular}


Table B3 IRI of Flexible Pavement of Truck Test (m/km)

\begin{tabular}{|c|c|c|c|c|c|}
\hline Section(mile) & TF1 & TF2 & TF3 & TF4 & TF5 \\
\hline $0-0.1$ & 0.84 & 0.88 & 0.91 & 1.38 & 0.92 \\
\hline $0.1-0.2$ & 0.77 & 0.84 & 0.88 & 1.18 & 0.86 \\
\hline $0.2-0.3$ & 0.76 & 0.84 & 0.99 & 1.22 & 0.84 \\
\hline $0.3-0.4$ & 0.80 & 0.94 & 0.75 & 1.28 & 0.88 \\
\hline $0.4-0.5$ & 0.83 & 0.85 & 1.00 & 1.25 & 0.84 \\
\hline $0.5-0.6$ & 0.85 & 0.95 & 1.08 & 1.04 & 0.92 \\
\hline $0.6-0.7$ & 0.77 & 0.90 & 0.99 & 0.92 & 0.88 \\
\hline $0.7-0.8$ & 0.70 & 0.80 & 0.99 & 1.00 & 0.91 \\
\hline $0.8-0.9$ & 0.79 & 0.80 & 1.26 & 0.90 & 0.85 \\
\hline $0.9-1.0$ & 0.73 & 0.84 & 1.02 & 0.93 & 0.88 \\
\hline $1.0-1.1$ & 0.76 & & 1.19 & 0.95 & 0.92 \\
\hline $1.1-1.2$ & 0.73 & & 1.14 & 0.92 & 0.92 \\
\hline $1.2-1.3$ & 0.72 & & 1.11 & 1.01 & 0.96 \\
\hline $1.3-1.4$ & 0.80 & & 1.02 & 0.90 & 0.96 \\
\hline $1.4-1.5$ & 0.74 & & 0.95 & 1.02 & 0.89 \\
\hline $1.5-1.6$ & 0.74 & & 1.01 & 0.92 & 0.89 \\
\hline $1.6-1.7$ & 0.80 & & 1.03 & 1.03 & 0.92 \\
\hline $1.7-1.8$ & 0.95 & & 1.04 & 0.92 & 0.83 \\
\hline $1.8-1.9$ & 0.89 & & 1.10 & 0.96 & 0.86 \\
\hline $1.9-2.0$ & 0.69 & & 1.10 & 1.03 & 0.88 \\
\hline 2.0-2.1 & & & 0.97 & & 0.88 \\
\hline 2.1-2.2 & & & 1.23 & & 0.87 \\
\hline $2.2-2.3$ & & & 1.10 & & 0.84 \\
\hline $2.3-2.4$ & & & 1.25 & & 0.84 \\
\hline $2.4-2.5$ & & & 1.03 & & 0.92 \\
\hline $2.5-2.6$ & & & 0.88 & & 0.97 \\
\hline $2.6-2.7$ & & & 1.14 & & 0.94 \\
\hline $2.7-2.8$ & & & 1.02 & & 1.02 \\
\hline $2.8-2.9$ & & & 1.09 & & 0.97 \\
\hline $2.9-3.0$ & & & 0.95 & & 0.85 \\
\hline 3.0-3.1 & & & 0.81 & & 0.99 \\
\hline 3.1-3.2 & & & 1.00 & & 0.99 \\
\hline $3.2-3.3$ & & & 0.84 & & 0.95 \\
\hline $3.3-3.4$ & & & 0.95 & & 0.91 \\
\hline 3.4-3.5 & & & 0.99 & & 0.88 \\
\hline $3.5-3.6$ & & & 0.93 & & 0.96 \\
\hline 3.6-3.7 & & & 0.80 & & 0.97 \\
\hline $3.7-3.8$ & & & 1.06 & & 1.06 \\
\hline 3.8-3.9 & & & 0.84 & & 0.89 \\
\hline 3.9-4.0 & & & 0.84 & & \\
\hline
\end{tabular}


Table B4 IRI of Rigid Pavement of Truck Test (m/km)

\begin{tabular}{|c|c|c|c|c|c|}
\hline Section(mile) & TR1 & TR2 & TR3 & TR4 & TR5 \\
\hline $0-0.1$ & 0.50 & 0.69 & 1.11 & 0.77 & 0.97 \\
\hline $0.1-0.2$ & 0.48 & 0.73 & 1.07 & 0.92 & 0.97 \\
\hline $0.2-0.3$ & 0.48 & 0.69 & 1.08 & 0.84 & 0.89 \\
\hline 0.3-0.4 & 0.54 & 0.77 & 1.16 & 1.44 & 0.92 \\
\hline 0.4-0.5 & 0.58 & 0.76 & 1.04 & 0.88 & 1.14 \\
\hline $0.5-0.6$ & 0.54 & 0.74 & 0.94 & 0.69 & 1.07 \\
\hline $0.6-0.7$ & 0.54 & 0.81 & 0.95 & 0.79 & 0.97 \\
\hline $0.7-0.8$ & 0.59 & 0.71 & 1.03 & 0.73 & 1.09 \\
\hline $0.8-0.9$ & 0.49 & 0.68 & 0.99 & 0.73 & 1.40 \\
\hline $0.9-1.0$ & 0.61 & 0.76 & 1.14 & 0.69 & 1.21 \\
\hline $1.0-1.1$ & 0.53 & & & 0.75 & \\
\hline $1.1-1.2$ & 0.60 & & & 0.77 & \\
\hline $1.2-1.3$ & 0.51 & & & 0.76 & \\
\hline $1.3-1.4$ & 0.63 & & & 0.83 & \\
\hline $1.4-1.5$ & 0.62 & & & 0.88 & \\
\hline $1.5-1.6$ & 0.61 & & & 0.73 & \\
\hline $1.6-1.7$ & 0.61 & & & 0.78 & \\
\hline $1.7-1.8$ & 0.52 & & & 0.67 & \\
\hline $1.8-1.9$ & 0.57 & & & 0.66 & \\
\hline $1.9-2.0$ & 0.61 & & & 0.88 & \\
\hline $2.0-2.1$ & 0.53 & & & & \\
\hline $2.1-2.2$ & 0.50 & & & & \\
\hline $2.2-2.3$ & 0.56 & & & & \\
\hline $2.3-2.4$ & 0.62 & & & & \\
\hline $2.4-2.5$ & 0.54 & & & & \\
\hline $2.5-2.6$ & 0.55 & & & & \\
\hline $2.6-2.7$ & 0.61 & & & & \\
\hline $2.7-2.8$ & 0.55 & & & & \\
\hline 2.8-2.9 & 0.51 & & & & \\
\hline $2.9-3.0$ & 0.55 & & & & \\
\hline $3.0-3.1$ & 0.54 & & & & \\
\hline 3.1-3.2 & 0.49 & & & & \\
\hline $3.2-3.3$ & 0.57 & & & & \\
\hline 3.3-3.4 & 0.57 & & & & \\
\hline 3.4-3.5 & 0.56 & & & & \\
\hline $3.5-3.6$ & 0.62 & & & & \\
\hline 3.6-3.7 & 0.73 & & & & \\
\hline 3.7-3.8 & 0.60 & & & & \\
\hline 3.8-3.9 & 0.62 & & & & \\
\hline
\end{tabular}




\section{APPENDIX C PHASE II FLEXIBLE PAVEMENT FWD DEFELECTION DATA}

Table C1 Passenger Car Test Adjusted FWD Centre Deflection D0 (mm)

\begin{tabular}{|c|c|c|c|c|c|c|}
\hline Section(mile) & CF1 & CF2 & CF3 & CF4 & CF5 & CF6 \\
\hline $\mathbf{0 - 0 . 1}$ & 0.286 & 0.398 & 0.124 & 0.134 & 0.160 & 0.175 \\
\hline $\mathbf{0 . 1 - 0 . 2}$ & 0.284 & 0.390 & 0.128 & 0.147 & 0.145 & 0.176 \\
\hline $\mathbf{0 . 2 - 0 . 3}$ & 0.323 & 0.368 & 0.116 & 0.141 & 0.146 & 0.159 \\
\hline $\mathbf{0 . 3 - 0 . 4}$ & 0.272 & 0.444 & 0.119 & 0.129 & 0.162 & 0.158 \\
\hline $\mathbf{0 . 4 - 0 . 5}$ & 0.296 & 0.391 & 0.107 & 0.152 & 0.165 & 0.179 \\
\hline $\mathbf{0 . 5 - 0 . 6}$ & 0.328 & 0.390 & 0.109 & 0.139 & 0.163 & 0.167 \\
\hline $\mathbf{0 . 6 - 0 . 7}$ & 0.334 & 0.376 & 0.113 & 0.138 & 0.149 & 0.171 \\
\hline $\mathbf{0 . 7 - 0 . 8}$ & 0.327 & 0.376 & 0.120 & 0.123 & 0.150 & 0.163 \\
\hline $\mathbf{0 . 8 - 0 . 9}$ & 0.342 & 0.381 & 0.122 & 0.135 & 0.165 & 0.164 \\
\hline $\mathbf{0 . 9 - 1 . 0}$ & 0.334 & 0.390 & 0.126 & 0.142 & 0.170 & 0.160 \\
\hline
\end{tabular}


Table C2 Truck Test Adjusted FWD Centre Deflection D0 (mm)

\begin{tabular}{|c|c|c|c|c|c|}
\hline Section(mile) & TF1 & TF2 & TF3 & TF4 & TF5 \\
\hline $0-0.1$ & 0.372 & 0.379 & 0.097 & 0.141 & 0.172 \\
\hline $0.1-0.2$ & 0.385 & 0.337 & 0.113 & 0.132 & 0.172 \\
\hline $0.2-0.3$ & 0.254 & 0.306 & 0.102 & 0.132 & 0.171 \\
\hline $0.3-0.4$ & 0.269 & 0.300 & 0.111 & 0.131 & 0.183 \\
\hline $0.4-0.5$ & 0.327 & 0.307 & 0.110 & 0.133 & 0.183 \\
\hline $0.5-0.6$ & 0.323 & 0.304 & 0.114 & 0.127 & 0.207 \\
\hline $0.6-0.7$ & 0.290 & 0.338 & 0.111 & 0.133 & 0.198 \\
\hline $0.7-0.8$ & 0.275 & 0.313 & 0.122 & 0.139 & 0.199 \\
\hline $0.8-0.9$ & 0.269 & 0.325 & 0.140 & 0.142 & 0.176 \\
\hline $0.9-1.0$ & 0.295 & 0.231 & 0.124 & 0.139 & 0.173 \\
\hline $1.0-1.1$ & 0.248 & & 0.118 & 0.135 & 0.176 \\
\hline $1.1-1.2$ & 0.297 & & 0.134 & 0.153 & 0.163 \\
\hline $1.2-1.3$ & 0.323 & & 0.116 & 0.141 & 0.189 \\
\hline $1.3-1.4$ & 0.252 & & 0.125 & 0.123 & 0.182 \\
\hline $1.4-1.5$ & 0.293 & & 0.107 & 0.136 & 0.161 \\
\hline $1.5-1.6$ & 0.331 & & 0.106 & 0.150 & 0.193 \\
\hline $1.6-1.7$ & 0.324 & & 0.114 & 0.141 & 0.184 \\
\hline $1.7-1.8$ & 0.338 & & 0.112 & 0.134 & 0.176 \\
\hline $1.8-1.9$ & 0.314 & & 0.130 & 0.115 & 0.161 \\
\hline $1.9-2.0$ & 0.347 & & 0.120 & 0.138 & 0.194 \\
\hline 2.0-2.1 & & & 0.131 & & 0.173 \\
\hline $2.1-2.2$ & & & 0.112 & & 0.187 \\
\hline $2.2-2.3$ & & & 0.098 & & 0.184 \\
\hline $2.3-2.4$ & & & 0.130 & & 0.180 \\
\hline $2.4-2.5$ & & & 0.114 & & 0.204 \\
\hline 2.5-2.6 & & & 0.117 & & 0.205 \\
\hline $2.6-2.7$ & & & 0.107 & & 0.201 \\
\hline $2.7-2.8$ & & & 0.113 & & 0.195 \\
\hline $2.8-2.9$ & & & 0.110 & & 0.210 \\
\hline $2.9-3.0$ & & & 0.105 & & 0.211 \\
\hline 3.0-3.1 & & & 0.105 & & 0.184 \\
\hline $3.1-3.2$ & & & 0.129 & & 0.194 \\
\hline $3.2-3.3$ & & & 0.126 & & 0.206 \\
\hline $3.3-3.4$ & & & 0.127 & & 0.171 \\
\hline 3.4-3.5 & & & 0.119 & & 0.158 \\
\hline $3.5-3.6$ & & & 0.125 & & 0.150 \\
\hline 3.6-3.7 & & & 0.114 & & 0.146 \\
\hline $3.7-3.8$ & & & 0.123 & & 0.143 \\
\hline 3.8-3.9 & & & 0.126 & & 0.172 \\
\hline 3.9-4.0 & & & 0.140 & & \\
\hline
\end{tabular}




\section{DEFLECTION}

Table D1 Passenger Car FC at Each Speed (zero Deflection and 1mm Deflection)

\begin{tabular}{|c|c|c|c|}
\hline Speed $(\mathrm{km} / \mathrm{h})$ & FC at $0 \mathrm{~mm}(\mathrm{~L} / 100 \mathrm{~km})$ & FC at $1 \mathrm{~mm}(\mathrm{~L} / 100 \mathrm{~km})$ & $\Delta F C(\mathrm{~L} / 100 \mathrm{~km})$ \\
\hline 72 & 4.525 & 4.759 & 0.234 \\
\hline 73 & 4.543 & 4.778 & 0.235 \\
\hline 74 & 4.562 & 4.798 & 0.237 \\
\hline 75 & 4.582 & 4.820 & 0.238 \\
\hline 76 & 4.604 & 4.844 & 0.239 \\
\hline 77 & 4.627 & 4.868 & 0.241 \\
\hline 78 & 4.652 & 4.894 & 0.242 \\
\hline 79 & 4.677 & 4.921 & 0.244 \\
\hline 80 & 4.704 & 4.949 & 0.245 \\
\hline 81 & 4.732 & 4.979 & 0.247 \\
\hline 82 & 4.761 & 5.009 & 0.249 \\
\hline 83 & 4.791 & 5.041 & 0.250 \\
\hline 84 & 4.823 & 5.074 & 0.252 \\
\hline 85 & 4.855 & 5.109 & 0.253 \\
\hline 86 & 4.889 & 5.144 & 0.255 \\
\hline 87 & 4.924 & 5.180 & 0.257 \\
\hline 88 & 4.959 & 5.218 & 0.259 \\
\hline 89 & 4.996 & 5.257 & 0.260 \\
\hline 90 & 5.034 & 5.297 & 0.262 \\
\hline 91 & 5.074 & 5.337 & 0.264 \\
\hline 92 & 5.114 & 5.379 & 0.266 \\
\hline 93 & 5.155 & 5.423 & 0.268 \\
\hline 94 & 5.197 & 5.467 & 0.270 \\
\hline 95 & 5.241 & 5.512 & 0.271 \\
\hline 96 & 5.285 & 5.558 & 0.273 \\
\hline 97 & 5.330 & 5.606 & 0.275 \\
\hline 98 & 5.377 & 5.654 & 0.277 \\
\hline 99 & 5.424 & 5.704 & 0.279 \\
\hline 100 & 5.473 & 5.754 & 0.281 \\
\hline 101 & 5.522 & 5.806 & 0.284 \\
\hline 102 & 5.573 & 5.858 & 0.286 \\
\hline 103 & 5.624 & 5.912 & 0.288 \\
\hline 104 & 5.677 & 5.967 & 0.290 \\
\hline 105 & 5.730 & 6.023 & 0.292 \\
\hline 106 & 5.785 & 6.080 & 0.295 \\
\hline 107 & 5.841 & 6.137 & 0.297 \\
\hline 108 & 5.897 & 6.196 & 0.299 \\
\hline
\end{tabular}




\begin{tabular}{|l|l|l|l|}
\hline 109 & 5.955 & 6.256 & 0.301 \\
\hline 110 & 6.014 & 6.317 & 0.304 \\
\hline 111 & 6.073 & 6.379 & 0.306 \\
\hline 112 & 6.134 & 6.443 & 0.309 \\
\hline 113 & 6.196 & 6.507 & 0.311 \\
\hline
\end{tabular}

Table D2 Truck FC at Each Speed (zero Deflection and 1mm Deflection)

\begin{tabular}{|c|c|c|c|}
\hline Speed (km/h) & FC at $0 \mathrm{~mm}(\mathrm{~L} / 100 \mathrm{~km})$ & FC at $1 \mathrm{~mm}(\mathrm{~L} / 100 \mathrm{~km})$ & $\Delta F C(\mathrm{~L} / 100 \mathrm{~km})$ \\
\hline 72 & 20.960 & 22.083 & 1.123 \\
\hline 73 & 21.228 & 22.354 & 1.126 \\
\hline 74 & 21.502 & 22.630 & 1.128 \\
\hline 75 & 21.781 & 22.912 & 1.131 \\
\hline 76 & 22.065 & 23.198 & 1.134 \\
\hline 77 & 22.353 & 23.490 & 1.136 \\
\hline 78 & 22.647 & 23.786 & 1.139 \\
\hline 79 & 22.946 & 24.088 & 1.142 \\
\hline 80 & 23.249 & 24.394 & 1.145 \\
\hline 81 & 23.558 & 24.706 & 1.148 \\
\hline 82 & 23.871 & 25.022 & 1.151 \\
\hline 83 & 24.189 & 25.344 & 1.154 \\
\hline 84 & 24.512 & 25.670 & 1.158 \\
\hline 85 & 24.840 & 26.001 & 1.161 \\
\hline 86 & 25.173 & 26.337 & 1.164 \\
\hline 87 & 25.511 & 26.678 & 1.167 \\
\hline 88 & 25.853 & 27.024 & 1.171 \\
\hline 89 & 26.201 & 27.375 & 1.174 \\
\hline 90 & 26.553 & 27.731 & 1.178 \\
\hline 91 & 26.910 & 28.092 & 1.181 \\
\hline 92 & 27.272 & 28.457 & 1.185 \\
\hline 93 & 27.639 & 28.828 & 1.189 \\
\hline 94 & 28.011 & 29.203 & 1.193 \\
\hline 95 & 28.388 & 29.584 & 1.196 \\
\hline 96 & 28.769 & 29.970 & 1.200 \\
\hline 97 & 29.156 & 30.360 & 1.204 \\
\hline 98 & 29.548 & 30.756 & 1.208 \\
\hline 99 & 29.944 & 31.157 & 1.212 \\
\hline 100 & 30.346 & 31.563 & 1.217 \\
\hline 101 & 30.753 & 31.974 & 1.221 \\
\hline 102 & 31.165 & 32.390 & 1.225 \\
\hline 103 & 31.581 & 32.811 & 1.230 \\
\hline
\end{tabular}




\begin{tabular}{|l|l|l|l|}
\hline 104 & 32.003 & 33.237 & 1.234 \\
\hline 105 & 32.430 & 33.669 & 1.239 \\
\hline 106 & 32.863 & 34.106 & 1.243 \\
\hline 107 & 33.300 & 34.548 & 1.248 \\
\hline 108 & 33.743 & 34.995 & 1.253 \\
\hline 109 & 34.191 & 35.448 & 1.257 \\
\hline 110 & 34.644 & 35.906 & 1.262 \\
\hline 111 & 35.103 & 36.370 & 1.267 \\
\hline 112 & 35.567 & 36.839 & 1.272 \\
\hline 113 & 36.036 & 37.313 & 1.277 \\
\hline
\end{tabular}




\section{VITA}

XIN JIAO

Born, China

2007-2011

B.A., Civil Engineering

China Agricultural University

Beijing, China

Dec. 2012

M.S., Civil Engineering

Florida International University

Miami, Florida, U.S.

2011-2015

Doctoral Candidate

Florida International University

Miami, Florida, U.S.

\section{PUBLICATIONS AND PRESENTATIONS}

Jiao, X., and Bienvenu, M., “The Influence of Pavement-Vehicle Interaction on Highway Fuel Consumption by Field Measurement”, accepted by TRANSPORT: Special Issue on Impact of Vehicle Movement on Exploitation Parameters of Roads and Runways (IVMEPRR), July 2015.

Jiao, X., and Bienvenu, M., "Field Measurement and Calibration of HDM-4 Fuel Consumption Model on Interstate Highway in Florida”, International Journal of Transportation Science and Technology: Special Issue on Sustainable Transportation Technology and Policy, Volume 4, Issue 1-2015, page 29-46, 2015.

Jiao, X., Bienvenu, M., "Impact of Pavement-Vehicle Interaction on Fuel Consumption by Field Measurement in Florida - Phase II”, 2015 International Concrete Sustainability Conference, Miami, FL, May 2015. 
Bienvenu, M., and Jiao, X. "Calibration of HDM-4 Fuel Consumption Model to Field Measurement on I-95 in Florida”, 2015 Airfield and Highway Pavement Conference, ASCE, Miami FL, Nov. 2014.

Bienvenu, M., and Jiao, X. "Measurement of Fuel Consumption on Rigid and Flexible Pavements along I-95 in Florida”, $12^{\text {th }}$ International Symposium on Concrete Road, Prague, Czech Republic, Sep. 2014.

Bienvenu, M., and Jiao, X. "Comparison of Fuel Consumption on Rigid Versus Flexible Pavement in Florida”, 2014 International Concrete Sustainability Conference, Boston, MA, May 2014.

Jiao, X. “Calibration of HDM-4 Fuel Consumption Model to Field Measurement on I-95 in Florida”, 2015 Airfield and Highway Pavement Conference, ASCE, Miami FL, June 2015.

Jiao, X., and Bienvenu, M. "Impact of Pavement-Vehicle Interaction on Highway Fuel Consumption by Measurement in Florida”, 2015 International Concrete Sustainability Conference, Miami, FL, May 2015.

Bienvenu, M., and Jiao, X. "Pavement Vehicle Interaction: Comparison of Fuel Consumption on Rigid versus Flexible Pavement on I-95 and I-75 in Florida”, 2014 International Concrete Sustainability Conference, Boston, MA, May 2014.

Bienvenu, M., and Jiao, X. "Comparison of Fuel Consumption on Rigid versus Flexible Pavements along I-95 in Florida”, 2014 Transportation Research Board (TRB) 93rd Annual Meeting, Washington, D.C., Jan. 2014. 